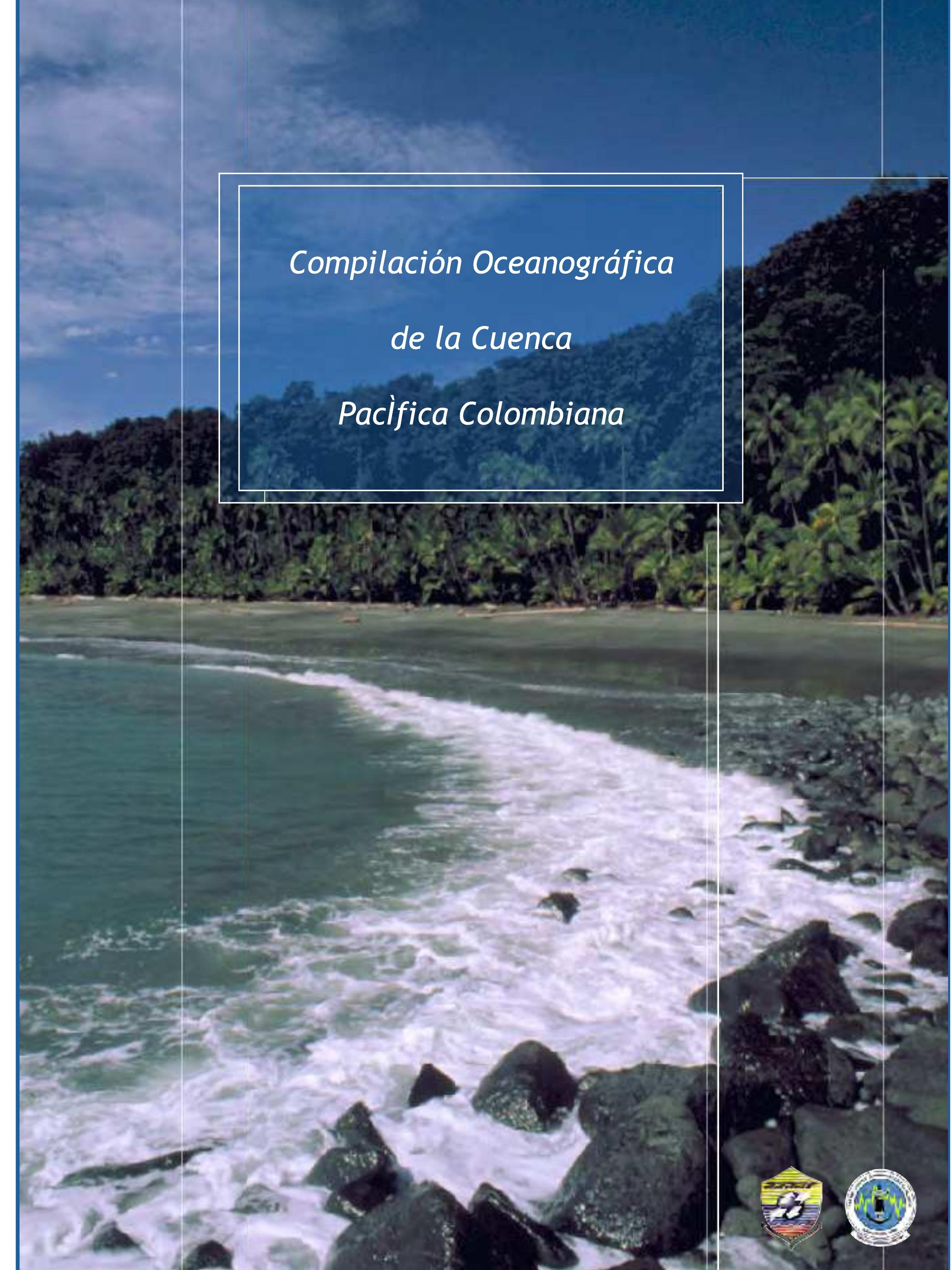


Compilación Oceanográfica

de la Cuenca

Pacífica Colombiana
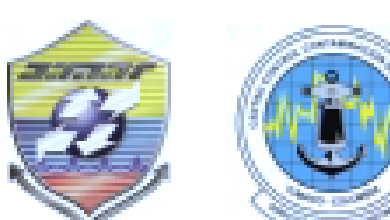


\section{COMPILACIÓN OCEANOGRÁFICA DE LA CUENCA PACÍFICA COLOMBIANA}

\section{Director General Marítimo}

Contralmirante Carlos Humberto Pineda Gallo

Centro Control Contaminación del Pacífico, CCCP

Director

Capitán de Fragata Carlos Enrique Tejada Vélez

MSc en Ciencias y Tecnologías para la Gestión de la Costa

\section{Consejo Editorial}

Capitán de Fragata Carlos Enrique Tejada Vélez, MSc en Ciencias y Tecnologías para la Gestión de la Costa Teniente de Navío Erick Bermy Guayana Labrador, Oceanógrafo Físico

Angélica María Castrillón Gálvez, Comunicadora Social

\section{Textos}

Andrea Devis Morales, Oceanóloga

Ingrid García Hansen, Bióloga Marina

Igor Málikov, MSc en Ingeniería Oceanológica

Nancy Liliana Villegas Bolaños, Oceanóloga

\section{Revisores Externos}

Affonso da Silveira Mascarenhas Jr., PhD en Oceanografía Física

Emel Enrique Vega Rodríguez, MSc en Ciencias Meteorológicas

\section{Colaboradores}

Suboficial Jefe Jair García Robles, Tecnólogo en Oceanografía Física

Suboficial Segundo Fabián Molina Urueta, Tecnólogo en Oceanografía Física

Suboficial Tercero Yuber Paul Cantor, Tecnólogo en Oceanografía Física

Suboficial Tercero Oscar Javier Fajardo Espinosa, Técnico en Oceanografía Física

Edición:

Imágenes de la Naturaleza

Dirección editorial: Diego Miguel Garcés G.

(c) Fotografías: Diego Miguel Garcés G.

Coordinación: Patricia Salazar S.

Diagramación: Diego Mauricio Cano E.

(c) Centro Control Contaminación del Pacífico, CCCP, 2002

ISBN: 958-33-3869-9

Ninguna parte de este libro puede ser reproducida, almacenada en sistema recuperable o transmitida en ninguna forma 0 por ningún medio electrónico, mecánico, fotocopia, grabación u otros, sin el permiso escrito de los editores. 


\section{Tabla de contenido}

$\begin{array}{ll}\text { PRÓLOGO } & 1\end{array}$

\begin{tabular}{l|l} 
INTRODUCCIÓN & 2
\end{tabular}

$\begin{array}{ll}\text { CAPÍTULO I - Particularidades Geográficas de la Cuenca Pacífica Colombiana } & 7\end{array}$

CAPÍTULO II - Meteorología General de la Cuenca Pacífica Colombiana

2.1 Vientos 11

2.1.1 Variabilidad intranual del campo de vientos 12

2.2 Precipitación 14

$\begin{array}{lll}2.3 & \text { Temperatura del aire } & 15\end{array}$

2.4 Humedad 15

$\begin{array}{lll}2.5 & \text { Cobertura del cielo, techo y visibilidad } & 16\end{array}$

2.6 Delimitación de las zonas climáticas 16

2.6.1 Clima en la Zona Norte 17

$\begin{array}{ll}\text { 2.6.2 Clima en la Zona Centro } & 17\end{array}$

2.6.3 Clima en la Zona Sur 18

CAPÍTULO III - Investigación Oceanográfica en la Cuenca Pacífica Colombiana 21

3.1 Información obtenida en cruceros oceanográficos desde 1970 hasta 1996 en la CPC 21

3.2 Descripción con datos promedios de la temperatura y salinidad de la superficie del mar 21

3.3 Descripción de perfiles verticales de temperatura y salinidad promedio anuales 29

3.3.1 Descripción de la distribución vertical de temperatura promedio anual 29

3.3.2 Descripción de la distribución vertical de salinidad promedio anual 34

3.4 Estudio sobre las Zonas Homogéneas 41

3.5 Estudio de la variación del contenido de calor de la capa activa 42

$\begin{array}{lll}3.6 & \text { Las surgencias } & 45\end{array}$

CAPITULO IV - Búsqueda de la Relación de las Condiciones Oceanográficas de la Cuenca Pacífica Colombiana con el Ciclo Enos

4.1 Condiciones Normales 56

4.1.1 Características Físicas

4.1.2 Características Químicas $\quad 59$

4.1.3 Características Biológicas $\quad 62$

4.1.4 Análisis General Condición Normal 64

4.2 Condiciones en Presencia de El Niño 65

4.2.1 Características Físicas 66

4.2.2 Características Químicas $\quad 69$

4.2.3 Características Biológicas $\quad 71$ 
4.2.4 Análisis General Condición Niño

4.3 Condiciones en Presencia de La Niña

4.3.1 Características Físicas

4.3.2 Características Químicas

4.3.3 Características Biológicas

4.3.4 Análisis General Condición Niña

83

4.4 Análisis General de las condiciones oceanográficas de la Cuenca Pacífica Colombiana 


\section{Tabla de contenido de Figuras y Tablas}

Figura 1.1 $\quad$ Cuenca Pacífica Colombiana y delimitación de su zona costera

Figura 2.1 Valores medios de velocidad del viento en la zona costera del Pacífico

Figura 2.2 Campo de presión atmosférica en mbar y dirección del viento predominante durante los meses de enero-abril. La línea azul indica la posición de la ZCIT

Figura 2.3 Campo de presión atmosférica en mbar y dirección del viento predominante durante los meses de mayo-agosto. La línea azul indica la posición de la ZCIT

Figura 2.4 Campo de presión atmosférica en mbar y dirección del viento predominante durante los meses de septiembre-diciembre. La línea azul indica la posición de la ZCIT

Figura 2.5 Media anual de precipitación en la zona costera del Pacífico colombiano

Figura 2.6

Figura 2.7

Figura 2.8

Figura 2.9

Figura 2.10

Figura 3.1

Figura 3.2 Promedio de número de días con precipitación en la zona costera del Pacífico colombiano Temperatura del aire media anual en estaciones costeras del Pacífico colombiano Valores medios mensuales de humedad relativa en la zona costera del Pacífico colombiano Techo y visibilidad. Buenaventura, Colombia Delimitación de zonas climáticas en el Pacífico colombiano Grilla de estaciones de cruceros oceanográficos realizados por el CCCP y transeptos seleccionados para estudio de perfiles de temperatura y salinidad Temperatura $\left({ }^{\circ} \mathrm{C}\right)$ y salinidad superficial del mar en febrero

Figura 3.3 Temperatura $\left({ }^{\circ} \mathrm{C}\right)$ y salinidad superficial del mar en marzo

Figura 3.4

Figura 3.5 Temperatura $\left({ }^{\circ} \mathrm{C}\right)$ y salinidad superficial del mar en abril

Figura 3.6 Temperatura $\left({ }^{\circ} \mathrm{C}\right)$ y salinidad superficial del mar en mayo

Figura 3.7 Temperatura $\left({ }^{\circ} \mathrm{C}\right)$ y salinidad superficial del mar en junio

Figura 3.8 Temperatura $\left({ }^{\circ} \mathrm{C}\right)$ y salinidad superficial del mar en agosto

Figura 3.9 Temperatura $\left({ }^{\circ} \mathrm{C}\right)$ y salinidad superficial del mar en septiembre

Figura 3.10

Figura 3.11

Figura 3.12

Figura 3.13

Figura 3.14

Figura 3.15

Figura 3.16

Figura 3.17

Figura 3.18

Figura 3.19

Figura 3.20

Figura 3.21.

Figura 3.22

Figura 3.23

Figura 3.24 Temperatura $\left({ }^{\circ} \mathrm{C}\right)$ y salinidad superficial del mar en octubre

Temperatura $\left({ }^{\circ} \mathrm{C}\right)$ y salinidad superficial del mar en noviembre Temperatura $\left({ }^{\circ} \mathrm{C}\right)$ y salinidad superficial del mar en diciembre

Variación vertical de la temperatura $\left({ }^{\circ} \mathrm{C}\right.$ ) promedio en el transepto $2^{\circ} \mathrm{N}$, marzo Variación vertical de la temperatura $\left({ }^{\circ} \mathrm{C}\right.$ ) promedio en el transepto $2^{\circ} \mathrm{N}$, junio Variación vertical de la temperatura $\left({ }^{\circ} \mathrm{C}\right.$ ) promedio en el transepto $2^{\circ} \mathrm{N}$, septiembre Variación vertical de la temperatura $\left({ }^{\circ} \mathrm{C}\right.$ ) promedio en el transepto $2^{\circ} \mathrm{N}$, diciembre Variación vertical de la temperatura $\left({ }^{\circ} \mathrm{C}\right.$ ) promedio en el transepto $3^{\circ} \mathrm{N}$, marzo Variación vertical de la temperatura $\left({ }^{\circ} \mathrm{C}\right.$ ) promedio en el transepto $3^{\circ} \mathrm{N}$, junio Variación vertical de la temperatura $\left({ }^{\circ} \mathrm{C}\right.$ ) promedio en el transepto $3^{\circ} \mathrm{N}$, septiembre Variación vertical de la temperatura $\left({ }^{\circ} \mathrm{C}\right.$ ) promedio en el transepto $3^{\circ} \mathrm{N}$, diciembre Variación vertical de la temperatura $\left({ }^{\circ} \mathrm{C}\right.$ ) promedio en el transepto $4^{\circ} \mathrm{N}$, marzo Variación vertical de la temperatura $\left({ }^{\circ} \mathrm{C}\right.$ ) promedio en el transepto $4^{\circ} \mathrm{N}$, junio Variación vertical de la temperatura $\left({ }^{\circ} \mathrm{C}\right.$ ) promedio en el transepto $4^{\circ} \mathrm{N}$, septiembre Variación vertical de la temperatura $\left({ }^{\circ} \mathrm{C}\right.$ ) promedio en el transepto $4^{\circ} \mathrm{N}$, diciembre Variación vertical de la temperatura $\left({ }^{\circ} \mathrm{C}\right)$ promedio en el transepto $5^{\circ} \mathrm{N}$, marzo

Figura 3.25 Variación vertical de la temperatura $\left({ }^{\circ} \mathrm{C}\right)$ promedio en el transepto $5^{\circ} \mathrm{N}$, junio 
Figura 3.26 Variación vertical de la temperatura $\left({ }^{\circ} \mathrm{C}\right.$ ) promedio en el transepto $5^{\circ} \mathrm{N}$, septiembre

Figura 3.27 Variación vertical de la temperatura $\left({ }^{\circ} \mathrm{C}\right)$ promedio en el transepto $5^{\circ} \mathrm{N}$, diciembre Variación vertical de la salinidad promedio en el transepto $2^{\circ} \mathrm{N}$, marzo Variación vertical de la salinidad promedio en el transepto $2^{\circ} \mathrm{N}$, junio Variación vertical de la salinidad promedio en el transepto $2^{\circ} \mathrm{N}$, septiembre Variación vertical de la salinidad promedio en el transepto $2^{\circ} \mathrm{N}$, diciembre Variación vertical de la salinidad promedio en el transepto $3^{\circ} \mathrm{N}$, marzo Variación vertical de la salinidad promedio en el transepto $3^{\circ} \mathrm{N}$, junio Variación vertical de la salinidad promedio en el transepto $3^{\circ} \mathrm{N}$, septiembre Variación vertical de la salinidad promedio en el transepto $3^{\circ} \mathrm{N}$, diciembre Variación vertical de la salinidad promedio en el transepto $4^{\circ} \mathrm{N}$, marzo Variación vertical de la salinidad promedio en el transepto $4^{\circ} \mathrm{N}$, junio Variación vertical de la salinidad promedio en el transepto $4^{\circ} \mathrm{N}$, septiembre Variación vertical de la salinidad promedio en el transepto $4^{\circ} \mathrm{N}$, diciembre Variación vertical de la salinidad promedio en el transepto $5^{\circ} \mathrm{N}$, marzo Variación vertical de la salinidad promedio en el transepto $5^{\circ} \mathrm{N}$, junio Variación vertical de la salinidad promedio en el transepto $5^{\circ} \mathrm{N}$, septiembre Variación vertical de la salinidad promedio en el transepto $5^{\circ} \mathrm{N}$, diciembre Distribución de las zonas homogéneas en la CPC Oscilaciones anuales cantidad de calor y flujo. Zona I CPC Oscilaciones anuales cantidad de calor y flujo. Zona II CPC Oscilaciones anuales cantidad de calor y flujo. Zona II CPC Oscilaciones anuales cantidad de calor y flujo. Zona III CPC Oscilaciones anuales cantidad de calor y flujo. Zona IV CPC Oscilaciones anuales cantidad de calor y flujo. Zona V CPC Oscilaciones anuales cantidad de calor y flujo. Zona VI CPC Oscilaciones anuales cantidad de calor y flujo. Zona VII CPC Distribución global de las surgencias Zonas de surgencia capa de 0 - $10 \mathrm{~m}$. Febrero-mayo, CPC Zonas de surgencia capa de 0 - $10 \mathrm{~m}$. Junio-octubre, CPC Zonas de surgencia capa de 0-10 m. Noviembre-diciembre, CPC Centros de diferencia de presión en el océano Pacífico Estabilidad de las aguas en el océano Pacífico Ecuatorial Condiciones normales en las aguas del Pacífico Ecuatorial Fenómeno La Niña o condiciones frías en las aguas del Pacífico Ecuatorial Fenómeno El Niño o condiciones cálidas en las aguas del Pacífico Ecuatorial Grilla de muestreo, Crucero Pacífico XXXII Erfen XXX - Mayo de 2000 Distribución de temperatura horizontal y vertical por capas, mayo de 2000 Distribución de temperatura por transeptos latitudinales, mayo de 2000. Distribución de salinidad horizontal y vertical por capas, mayo de 2000. Distribución vertical de salinidad por transeptos latitudinales, mayo de 2000.

Figura 4.11 Distribución horizontal y vertical de Oxígeno Disuelto (mg/l) por capas, mayo de 2000. 
Figura 4.12

Figura 4.13

Figura 4.14

Figura 4.15

Figura 4.16

Figura 4.17

Figura 4.18

Figura 4.19

Figura 4.20

Figura 4.21

Figura 4.22

Figura 4.23

Figura 4.24

Figura 4.25

Figura 4.26

Figura 4.27

Figura 4.28

Figura 4.29

Figura 4.30

Figura 4.31

Figura 4.32

Figura 4.33

Figura 4.34

Figura 4.35

Figura 4.36

Figura 4.37

Figura 4.38

Figura 4.39

Figura 4.40

Figura 4.41

Figura 4.42

Figura 4.43

Figura 4.44

Figura 4.45

Figura 4.46

Tabla 1

Tabla 3.1

Tabla 4.1

Distribución horizontal y vertical del Amonio (NH4 $\mu \mathrm{g}$-at/l) por capas, mayo de 2000 Distribución horizontal y vertical del Nitrato (NO3 $\mu \mathrm{g}$-at/l) por capas, mayo de 2000 Distribución horizontal y vertical del Fosfato (po4 $\mu \mathrm{g}$-at/l) por capas, mayo de 2000 Distribución horizontal y vertical del Silicato (SiO3 $\mu \mathrm{g}$-at/l) por capas, mayo de 2000 Distribución horizontal y vertical de Clorofila "a" ( $\left.\mathrm{mg} / \mathrm{m}^{3}\right)$ por capas, mayo de 2000 Distribución horizontal y vertical de abundancia de Diatomeas (cel/l) por capas, mayo de 2000 Distribución horizontal y vertical de abundancia de Dinoflagelados (cel/l) por capas, mayo de 2000 Grilla de muestreo Crucero PACÍFICO XXIX ERFEN XXVII - Mayo de 1998 Distribución de temperatura horizontal y vertical por capas, mayo de 1998 Distribución de temperatura por transeptos latitudinales, mayo de 1998 Distribución de salinidad horizontal y vertical por capas, mayo de 1998 Distribución vertical de salinidad por transeptos latitudinales, mayo de 1998 Distribución horizontal y vertical de OD (mg/l) por capas, mayo de 1998 Distribución horizontal y vertical de Amonio (nh4 $\mu$ g-at/l) por capas, mayo de 1998 Distribución horizontal y vertical de Nitrato (no3 $\mu \mathrm{g}$-at/l) por capas, mayo de 1998 Distribución horizontal y vertical de Fosfato (po4 $\mu \mathrm{g}$-at/l) por capas, mayo de 1998 Distribución horizontal y vertical de Silicato (sio3 $\mu \mathrm{g}$-at/l) por capas, mayo de 1998 Distribución horizontal y vertical de Clorofila "a" $\left(\mathrm{mg} / \mathrm{m}^{3}\right)$ por capas, mayo de 1998 Distribución horizontal y vertical de abundancia de diatomeas (cel/l) por capas, mayo de 1998 Distribución horizontal y vertical de abundancia de dinoflagelados (cel/l) por capas, mayo de 1998 Grilla de muestreo, Crucero PACÍFICO XXXI ERFEN XXIX - Mayo de 1999 Distribución de temperatura horizontal y vertical por capas, mayo de 1999 Distribución de temperatura por transeptos latitudinales, mayo de 1999 Distribución de salinidad horizontal y vertical por capas, mayo de 1999 Distribución vertical de salinidad por transeptos latitudinales, mayo de 1999 Distribución horizontal y vertical de OD (mg/l) por capas, mayo de 1999 Distribución horizontal y vertical de amonio (nh4 $\mu \mathrm{g}$-at/l) por capas, mayo de 1999 Distribución horizontal y vertical de nitrato (n03 $\mu \mathrm{g}$-at/l) por capas, mayo de 1999 Distribución horizontal y vertical de fosfato (p04 $\mu \mathrm{g}$-at/l) por capas, mayo de 1999 Distribución horizontal y vertical de silicato (si03 $\mu \mathrm{g}$-at/l) por capas, mayo de 1999 Distribución horizontal y vertical de Clorofila "a" ( $\left.\mathrm{mg} / \mathrm{m}^{3}\right)$ por capas, mayo de 1999 Distribución horizontal y vertical de abundancia de Diatomeas (cel/ $\mathrm{ml}$ ) por capas, mayo de 1999 Distribución horizontal y vertical de abundancia de Dinoflagelados (cel/l) por capas, mayo de 1999 Anomalía de temperatura superficial (TSM) para 1998, 1999 y 2000 Anomalía de salinidad superficial (SSM) para 1998, 1999 y 2000 Resumen de los cruceros oceanográficos realizados en la CPC Valores promedio de las corrientes verticales $\left(\times 10^{-5} \mathrm{~cm} / \mathrm{s}\right)$ en capas de $0-100 \mathrm{~m}$ Cuenca del Pacífico colombiano. 


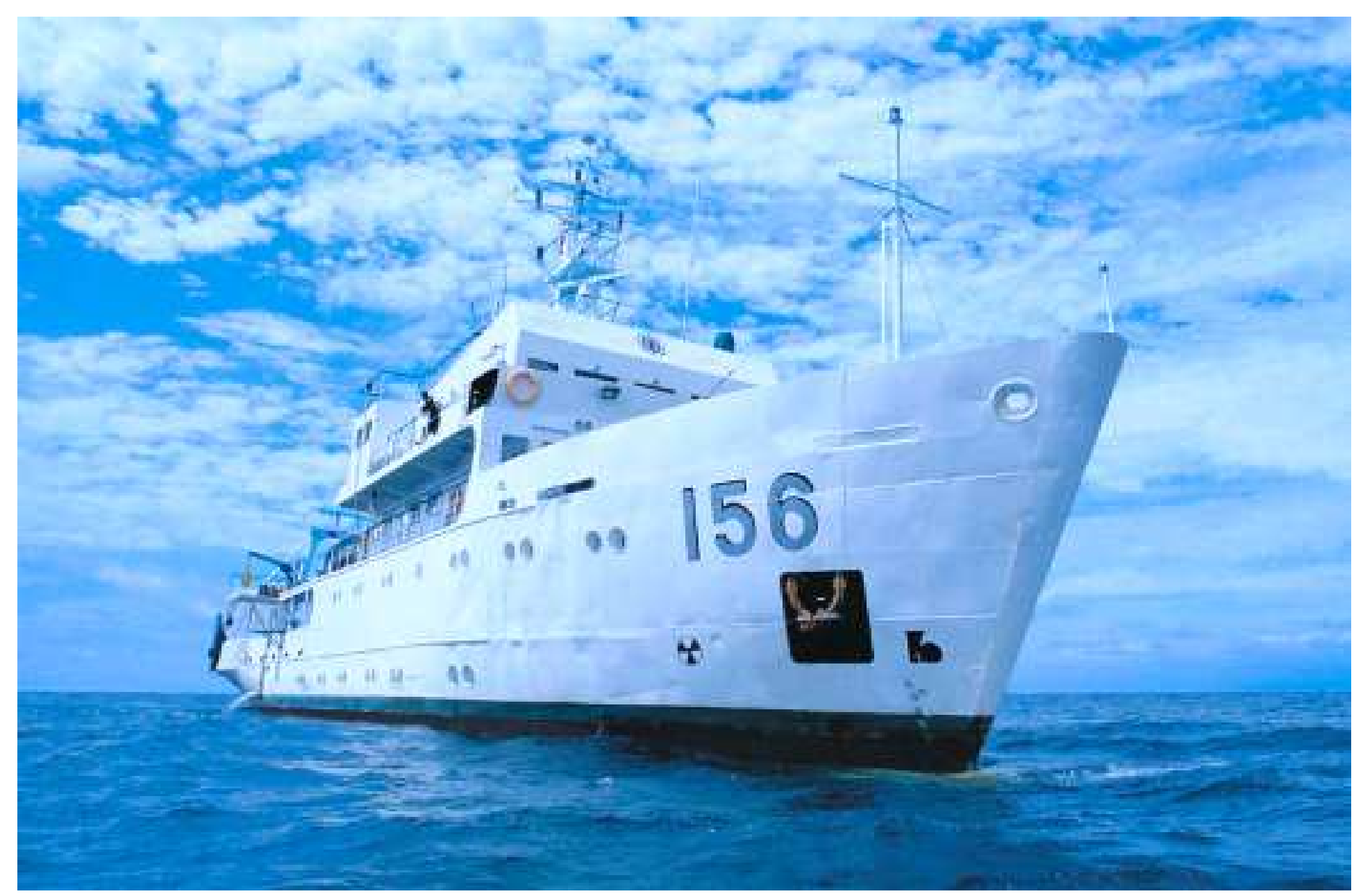

ARC Malpelo, barco oceanográfico abordo del cual se realizan algunos de los cruceros de investigación del Centro Control de la Contaminación del Pacífico, CCCP. 


\section{PRÓLOGO}

Dieciocho años de vehemente labor en beneficio del mar y sus costas le han otorgado al Centro Control Contaminación del Pacífico, CCCP, la trayectoria y la estructura que le permiten encauzar el cumplimiento de su misión hacia la investigación científica marina en las áreas marítimas jurisdiccionales de la Nación sobre el océano Pacífico.

Como significativo avance del cumplimiento de su función esencial el CCCP, bajo la orientación de la Dirección General Marítima, DIMAR, da a conocer una completa y actualizada publicación sobre oceanografía del océano Pacífico, denominada: Compilación Oceanográfica de la Cuenca Pacífica Colombiana. Ambiciosa en sus albores, pero estricta en sus investigaciones, ésta presenta análisis y resultados arrojados por los estudios desarrollados en el programa de Oceanografía Operacional del CCCP.

Es esta la primera vez que el CCCP desarrolla una publicación bajo estas características, realizada en un lenguaje dúctil y dirigida a un público amplio; lo cual se constituyó en un reto asumido con el interés de llegar a niveles y ámbitos que por las especificidades del tema se consideraban inaccesibles. De esta manera DIMAR alcanza su propósito de contribuir a la difusión del conocimiento, desarrollo y conservación de los recursos marinos.

La presente publicación no podía contar con un título más apropiado; en ella convergen estudios, investigaciones y análisis de las condiciones físicas del océano Pacífico; los fenómenos oceanográficos propios del trópico, y el análisis de 30 años de cruceros oceanográficos que han sido recopilados y estudiados por un consolidado grupo de investigadores en la sede del CCCP, ubicada en San Andrés de Tumaco desde su fundación.

Por sus cualidades, este libro constituye un valioso documento que oficiará como herramienta de apoyo para difundir el conocimiento científico; sensibilizar a los lectores sobre la importancia de conservar y manejar sosteniblemente los ecosistemas marinocosteros; dar a conocer los potenciales elementos contaminantes y las características oceanográficas de la zona, que permitan el desarrollo de acciones oportunas para conservar el medio ambiente marino y sus recursos, observando los lineamientos de la Armada Nacional y la Dirección General Marítima.

Porque el mar y todos los elementos que lo integran hacen parte del patrimonio natural de la Nación; éste constituye un extenso y casi inagotable tema de estudio para el CCCP, que proyecta con una visión de mediano plazo el desarrollo del atlas de la Cuenca Pacífica Colombiana, con el ánimo de dar continuidad a este esfuerzo de divulgación que hasta ahora empieza. 


\section{INTRODUCCIÓN}

Los primeros esfuerzos colombianos por entender el comportamiento de las diferentes variables oceanográficas de la Cuenca Pacifica Colombiana, CPC, se remontan al año 1965, cuando a bordo del ARC Bocas de Ceniza se desarrollaron cuatro cruceros oceanográficos denominados ACENTO; programados y llevados a cabo por la Comisión Interamericana del Atún Tropical, CIAT, en el área del Panamá Bight, con los cuales se pretendía estudiar la variabilidad estacional y cíclica en la circulación y distribución de las propiedades físicas, químicas y biológicas en nuestras aguas jurisdiccionales.

Posteriormente y a partir de 1967 se desarrollaron los cruceros EASTROPAC, patrocinados también por la CIAT, como un esfuerzo cooperativo hacia el entendimiento de la oceanografía en el Pacífico Este Tropical (adaptado de CCO 25 Años).

A partir de 1970 la Armada Nacional de Colombia empezó a llevar a cabo sus propios cruceros oceanográficos sobre aguas jurisdiccionales, tanto en el Caribe como en el Pacífico. Estos cruceros fueron ejecutados, inicialmente, con personal científico del Centro de Investigaciones Oceanográficas e Hidrográficas, $\mathrm{ClOH}$, hasta 1994, cuando esa responsabilidad fue transferida al Centro Control Contaminación del Pacífico, CCCP.

El CCCP es un centro de investigaciones en el área de Oceanografía, perteneciente a la DIMAR, creado en 1984 mediante el Decreto Ley 2324. Inicialmente su accionar se concentró en temas relativos a la contaminación marina, ya que fue un siniestro marítimo el que le dio origen (hundimiento del petrolero Saint Peter, en aguas ecuatorianas, muy cerca de la frontera con Colombia), pues se puso en evidencia la necesidad de crear un instituto que manejara el tema.

Poco a poco la labor científica del CCCP se fue ampliando hasta serle asignada la ejecución de tres programas de investigación en el área de la CPC incluidas sus costas, siendo estos:

- Protección del Medio Marino (Contaminación Marina)

- Zona Costera (Modelado Integral y Riesgos Ambientales Marinos)

- Oceanografía Operacional (Fenómeno de El Niño)
Entre paréntesis se resaltan las áreas en las cuales se ha concentrado el quéhacer científico del centro de investigaciones, y es precisamente sobre el último que el presente libro concentrará su atención.

El CCCP adelantó su primer crucero oceanográfico en 1996 y a la fecha ha realizado trece, completándose así 36 cruceros sobre la CPC (23 de ellos ejecutados por el $\mathrm{ClOH}$ ), en un lapso de 32 años. Durante estos cruceros se colecta la mayor cantidad de información posible en cada una de las estaciones oceanográficas; tomando datos de parámetros físicos, químicos y biológicos del océano, los cuales se complementan con observaciones de las condiciones meteorológicas reinantes.

Como se aprecia en la tabla anexa, la ejecución de dichos cruceros no ha sido regularmente espaciada en el tiempo; ejecutándose a partir de la fecha en que pasó la responsabilidad al CCCP dos cruceros anuales, uno por cada semestre.

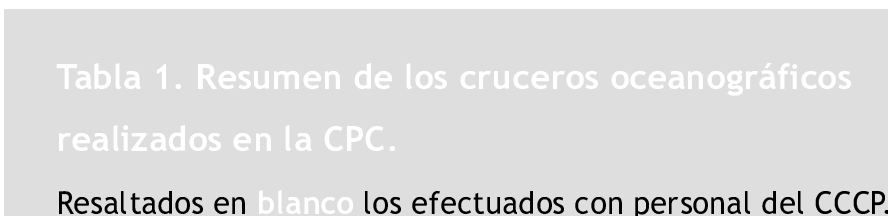

Resaltados en blanco los efectuados con personal del CCCP.

El esfuerzo por regularizar los cruceros y aumentar su número en el año ha permitido elevar considerablemente la cantidad de datos disponibles, aunque todavía no se llega a contar con una serie de tiempo suficientemente larga para presentar la climatología de las variables oceanográficas de la región. Esta falencia es particularmente visible en los meses de enero y julio, en los que hasta la fecha no se cuenta con algún crucero oceanográfico.

Paralelo al incremento de los datos, se ha pasado de la mera descripción de los parámetros medidos durante los cruceros a analizar y entender el comportamiento de las aguas presentes en la CPC. Es así como se han determinado zonas homogéneas; se han hecho estimaciones del contenido calórico; se han presentado esquemas de la circulación oceánica, y se han realizado estudios de la capa activa del 
océano y de los movimientos verticales de las masas de agua (surgencias).

Igualmente, se modificó la grilla de monitoreo, ampliándola a zonas más abiertas del océano Pacífico; se densificaron las estaciones en las áreas costeras y se incorporaron a los cruceros experimentos con mediciones de más de 24 horas en puntos específicos de la CPC, con miras a determinar la variabilidad de los parámetros oceanográficos a lo largo del día.

De otro lado y en aras de alcanzar una visión más amplia e integral de lo que ocurre en las aguas del Pacífico Sudeste, el CCCP ha participado en cruceros oceanográficos desarrollados conjuntamente con otros países de la Cuenca Pacífica (Chile, Perú y Ecuador). Estos se han ejecutado bajo la coordinación de la Comisión Permanente del Pacífico Sur, del país sobre el océano Pacífico está enfocado a conocer su comportamiento en las denominadas condiciones normales, además de aquellas variaciones o anomalías que se presentan cuando en nuestras aguas se manifiesta el conocido Fenómeno de El Niño o el de La Niña, más conocido como evento ENOS. Dicho evento indica la presencia de anomalías positivas o negativas de la temperatura del agua de mar y la variación de otros parámetros físicos, químicos y biológicos, que a su vez, indican variaciones de los procesos de interacción océanoatmósfera y variaciones en el comportamiento de la atmósfera sobre las aguas del océano y sobre el continente. Estas manifestaciones generan, en consecuencia, modificaciones en los regímenes de lluvia del país y aumento del nivel medio del mar, entre otras; ocasionando importantes impactos sobre las actividades económicas del país, basta mencionar a

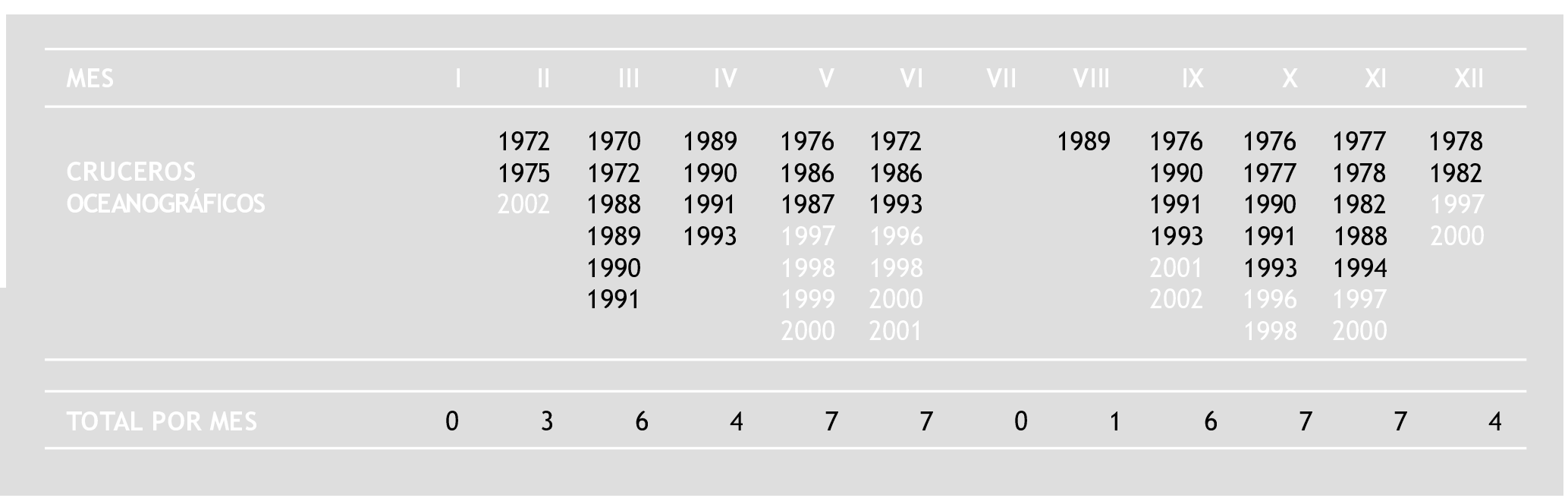

CPPS, con el nombre de Cruceros Regionales en los cuales se obtienen mediciones simultáneas de diferentes parámetros oceanográficos a lo largo del Pacífico Sudeste, al mismo tiempo y por espacio de un mes. De éstos, se han realizado cinco cruceros desde 1998.

Los resultados obtenidos en las investigaciones adelantadas por el CCCP durante los cruceros han quedado registrados en dieciséis artículos publicados en ocho boletines científicos y cuatro artículos más pendientes por publicar, trece informes de cruceros y varios reportes internos; los cuales por su naturaleza diversa no facilitan la revisión del estado del conocimiento sobre nuestras aguas jurisdiccionales, y por tanto fueron el móvil de gestación de esta publicación.

Es de anotar que el estudio de las características oceanográficas y meteorológicas de las aguas jurisdiccionales manera de ejemplo: la producción agrícola, la estabilidad del nivel de los embalses para la producción de energía eléctrica y la pesca. Dichos impactos no son necesariamente negativos, ya que en presencia de La Niña llegan a nuestras aguas especies que bajo condiciones normales se encuentran en aguas ecuatorianas o peruanas.

Con miras a cumplir con tan importante tarea, el CCCP ha conformado un grupo de investigación en esta temática, compuesto principalmente por oceanógrafos, oceanólogos, biólogos marinos y meteorólogos que abordan de manera integral los fenómenos a estudiar. Para su consolidación se ha contado con el apoyo de miembros del Instituto Hidrometeorológico de Rusia, de la Universidad Autónoma de Baja California de México y del Programa de Postgrado en Meteorología de la Universidad Nacional de Colombia; organizaciones con las cuales se están 
formulando convenios que permitirán afianzar los vínculos hasta ahora alcanzados a nivel individual.

Con el concurso de los antes mencionados se ha formulado un Plan de Investigaciones para los próximos diez años, el cual ha sido articulado con las nueve estrategias que conforman el Plan de Acción con el que se dará cumplimiento al Programa Nacional para el Estudio del Fenómeno de El Niño; documento realizado bajo el Comité Técnico Nacional de la Comisión Colombiana del Océano, CCO, que trata el tema y que cuenta con la participación de entidades como el Instituto Hidrología, Meteorología y Estudios Ambientales, Ideam; el Instituto Nacional de Pesca, Inpa; el Instituto de Investigaciones Marinas y Costeras José Benito Vives De Andréis, Invemar, y la Dirección General Marítima, Dimar, de la cual hace parte el Centro.

El mencionado programa consta de cuatro componentes, a saber: oceanográfico, meteorológico, biológico pesquero y socioeconómico. El CCCP tiene la responsabilidad, a nivel nacional, del componente oceanográfico.

Todos los elementos antes mencionados definen el contenido de la presente publicación, cuyo objetivo es compilar toda la información que hasta el momento ha colectado el CCCP dentro de su Programa de Oceanografía; divulgando a la comunidad científica y a los interesados en el tema no sólo la información disponible, sino el estado del arte del conocimiento oceanográfico sobre nuestra Cuenca Pacífica Colombiana.

Esta compilación consta de cinco capítulos. En el primero de ellos describe las generalidades de la CPC, así como algunas de sus particularidades. El segundo capítulo analiza la información meteorológica. El tercero recopila la información obtenida en los cruceros oceanográficos realizados desde 1970, también incluye algunos de los principales trabajos realizados recientemente relacionados con temas como la dinámica general de la Cuenca, las zonas homogéneas, la capa activa del océano y el fenómeno de surgencia, además de una amplia descripción del comportamiento de la temperatura y la salinidad. El cuarto capítulo muestra la búsqueda de la relación entre los datos oceanográficos de la CPC y el Fenómeno ENOS (El Niño, Oscilación del Sur). Finalmente, el capítulo quinto presenta el Plan Científico del Programa de Investigación sobre Oceanografía Operacional que adelantará el CCCP para el lapso 2001 2010, el cual muestra hacia dónde se dirigirán los esfuerzos por mejorar el conocimiento científico de nuestro mar Pacífico.

DIRECTOR CENTRO CONTROL CONTAMINACIÓN DEL PACIFICO

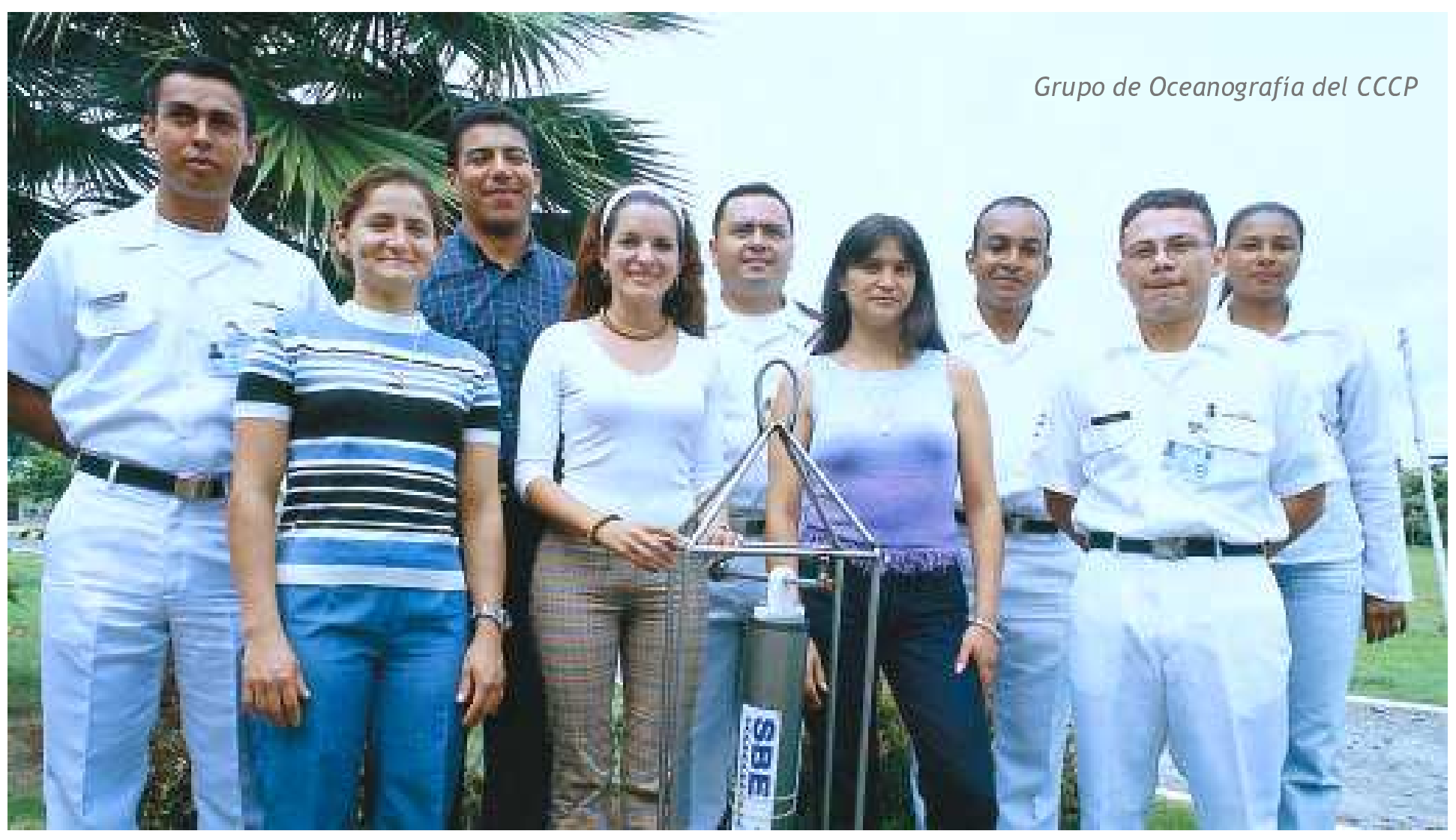



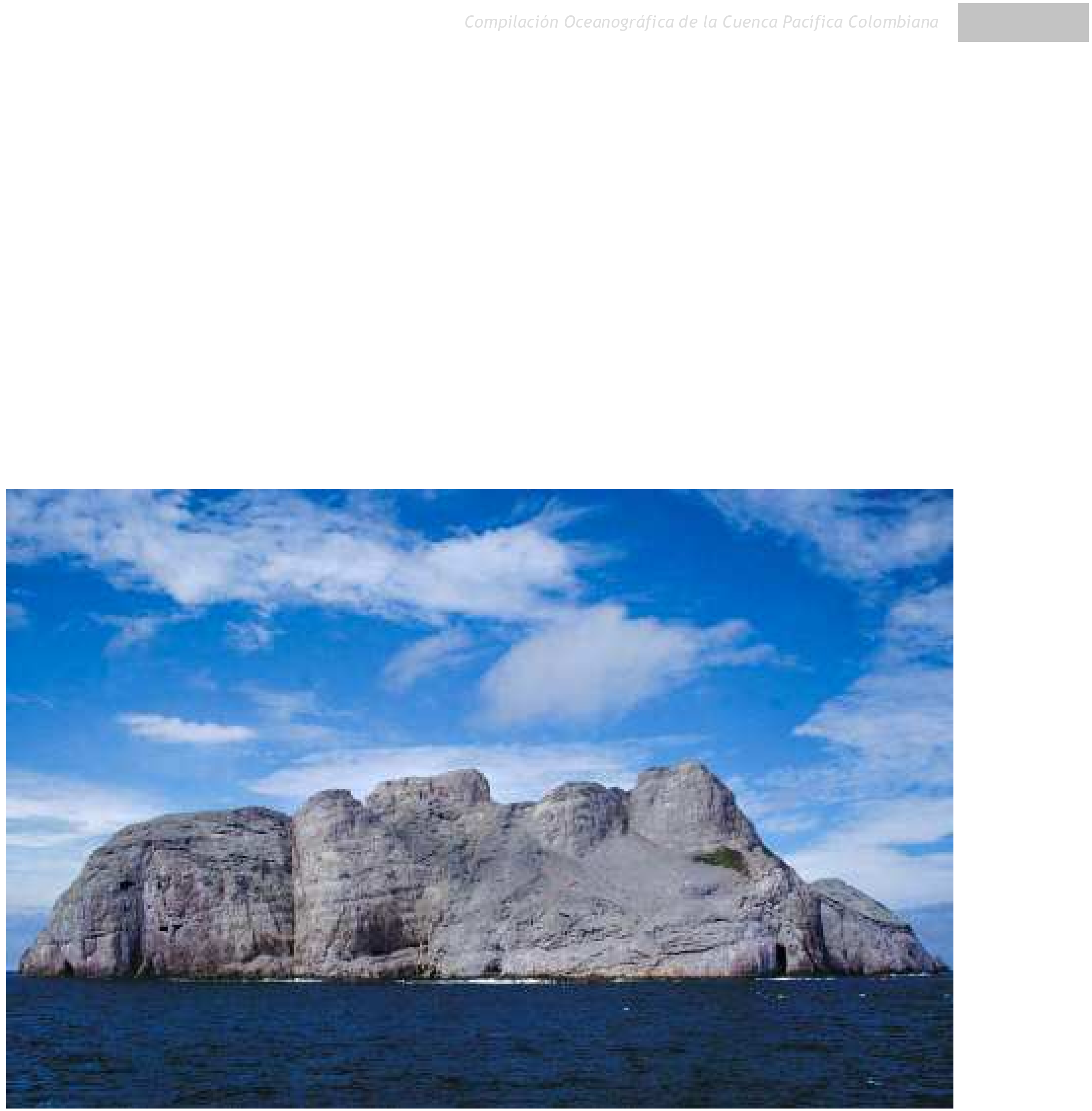

Malpelo, cúspide de una drosal submarina que se levanta desde los fondos abisales, dista 270 millas naúticas del litoral. 


\section{CAPÍTULO I - Particularidades Geográficas de la Cuenca Pacífica Colombiana}

Situada en el extremo occidental del país, la Cuenca Pacífica Colombiana (Fig. 1.1), CPC, se ubica geográficamente entre los paralelos $01^{\circ} 30^{\prime}$ hasta los $07^{\circ} 10^{\prime}$ de latitud Norte y entre los $77^{\circ} 40^{\prime}$ y $82^{\circ} 00^{\prime}$ de longitud Oeste.

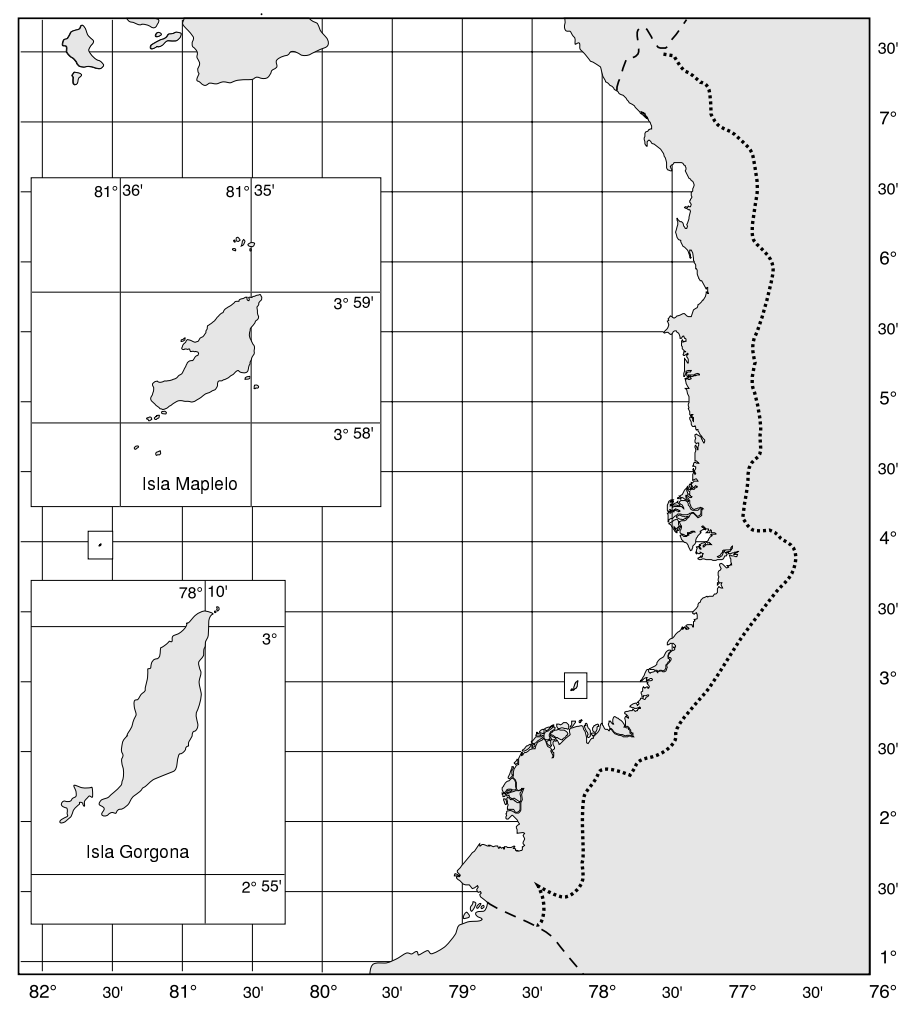

Figura 1.1 - Cuenca Pacífica Colombiana y delimitación de su zona costera.

De acuerdo con esta localización son sus límites geográficos las aguas del Golfo de Panamá, al Norte; el litoral occidental de Colombia, integrado por los departamentos de Chocó, Valle del Cauca, Cauca y Nariño, al Este; las aguas de la costa ecuatoriana y la cordillera submarina de Carnegie $(1350 \mathrm{~km}$ longitud, $300 \mathrm{~km}$ de ancho), al Sur; el océano Pacífico, las aguas territoriales de la República de Panamá (30 km) y la cordillera de Cocos (aproximadamente 200 km de ancho, 1000 km de longitud) al Oeste (Trojer, H., 1958, Graefe et al., 1997 y Gutscher et al., 1999).

Las dos cordilleras submarinas que enmarcan sus límites se unen en la plataforma de Galápagos, constituyendo uno de los 20 puntos calientes del planeta y elevándose desde más de 3700 metros hasta 1000 metros de profundidad, impidiendo procesos de intercambio de aguas profundas. Por esto se dice que la CPC tiene forma de piscina cerrada por fronteras líquidas y sólidas (Hey, 1977; Lonsdale y Klitgord, 1978 y Meschede et al., 1998).

La CPC se localiza en el margen occidental de la placa continental de Sudamérica (aproximadamente 200-300 km de espesor), que choca con la placa oceánica de Nazca (aproximadamente $50 \mathrm{~km}$ de espesor), la cual se hunde ocasionando en la fosa Peruana-Chilena una zona de subducción de 200-300 km, a una velocidad media de $6 \mathrm{~cm} /$ año, que se extiende a lo largo de las costas occidentales del continente suramericano. Dentro de esta región se encuentra la zona de fractura de Panamá, que presenta un centro litosférico en expansión con dos dorsales asísmicas: Malpelo y Coiba, con relieves poco marcados y el graben de Yaquina que es una dorsal de expansión reciente. Este último es una falla joven, formada por la tensión producida por la subducción de la placa bajo el continente. Estos centros de expansión, los puntos calientes de las islas Galápagos y la separación entre las placas de Cocos y Nazca determinan una gran actividad tectónica en los fondos marinos del Pacífico colombiano (Gansser, 1950 y Scientific American, 1976).

Las características geomorfológicas más importantes de la CPC son:

- La isla de Gorgona, ubicada sobre los $2^{\circ} 55^{\prime}$ y $3^{\circ} 00^{\prime}$ de latitud Norte y 78 $09^{\prime}$ y $78^{\circ} 14^{\prime}$ de longitud Oeste, es una isla de origen volcánico, distante $30 \mathrm{~km}$ de la costa más cercana; localizada a mitad de camino entre un océano de profundidades abisales de aguas transparentes y la contrastante zona costera, construída por planos aluviales que reciben considerables cantidades de agua dulce y sedimentos aportados por ríos caudalosos e innumerables quebradas (Barrios y López, 2001).

- La isla de Malpelo, también de formación volcánica, se encuentra a $3^{\circ} 51^{\prime}$ de latitud Norte y $81^{\circ} 35^{\prime}$ de longitud Oeste. Ubicada a 270 millas náuticas al Oeste de Buenaventura, es la única prolongación emergida del relieve oceánico submarino (la dorsal de Malpelo), que se eleva bruscamente desde fondos abisales (Palacios, 1999).

El oleaje oceánico predominante en la CPC, al igual que el viento y la corriente, provienen del Suroeste. Se trata de 
trenes de olas de amplio período y escasas alturas procedentes del océano abierto, que incrementan su altura sobre fondos someros y se refractan perdiendo su energía y cambiando la dirección. Por ser una región de alta actividad tectónica es muy probable la ocurrencia de tsunamis o maremotos (Wiches Chaux y Velásquez, 1993).

La región costera de la CPC tiene aproximadamente 80000 $\mathrm{km}^{2}$ de superficie, siendo sus límites geográficos: la hoya del río Juradó, al Norte $\left(7^{\circ} 28^{\prime} \mathrm{N}\right)$; el río Guaitará, afluente del río Patía, al Sur $\left(0^{\circ} 14^{\prime} \mathrm{N}\right)$; el nacimiento del río San Juan, al Este $\left(75^{\circ} 51^{\prime} \mathrm{W}\right)$, y la desembocadura del río Mira en Cabo Manglares, al Oeste $\left(79^{\circ} 02^{\prime} \mathrm{W}\right)$.

Esta delimitación de zona costera se encuentra incluida dentro de la franja conocida como la ensenada de Panamá (Panamá Bight), la cual se extiende por las costas de Panamá, Colombia y Ecuador hasta la longitud $81^{\circ} \mathrm{W}$ (Wooster, 1959). La oceanografía y climatología de esta región se conoc hace relativamente poco tiempo, gracias a algunas expediciones internacionales que produjeron los informes de Forsbergh (1969) y Wyrtky (1965); y más recientemente por los informes de los cruceros oceanográficos de la Armada Nacional de Colombia ( ARC San Andrés, ARC Providencia y ARC Malpelo), los cuales han presentado datos oceanográficos y meteorológicos de zonas alejadas a la costa y de regiones costeras, publicados por el CCCP. 


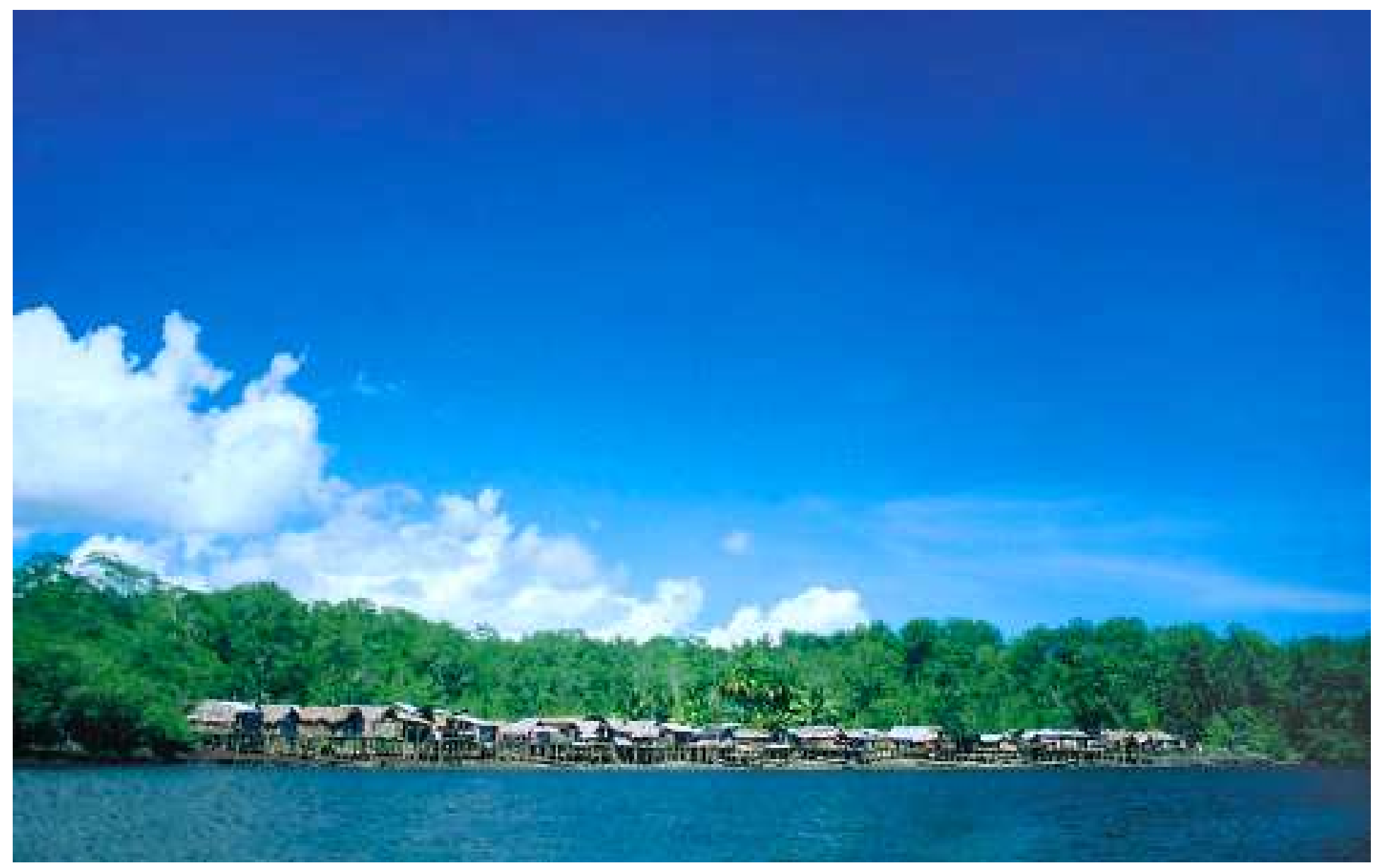

Al sur de Cabo Corrientes, la costa pacífica colombiana es una sucesión de depósitos aluviales sobre los que se desarrollan bosques de manglar de gran productivad natural. 


\section{CAPÍTULO II - Meteorología General de la Cuenca Pacífica Colombiana}

Para la elaboración de un análisis general del comportamiento de los principales parámetros meteorológicos de la CPC se utilizó como base la información de 135 estaciones distribuidas en el Pacífico colombiano, con series de 30 años de información en promedio, recolectadas por el Ideam.

Del total de las estaciones meteorológicas consultadas se descartaron 20, por encontrarse instaladas en el flanco occidental de las estribaciones de la cordillera, con alturas considerables que distorsionaban el estudio de la zona costera (para las zonas Norte y Centro). Adicionalmente, el Ideam proporcionó la actualización de las principales estaciones referenciadas, siendo complementadas con series cortas de estaciones navales.

De acuerdo con la información obtenida podría decirse que el régimen climático del área se encuentra bajo la influencia de los desplazamientos Sur-Norte Sur sobre la franja Ecuatorial de la denominada Zona de Convergencia Intertropical, ZCIT; la cual regula, en asocio con los sistemas pluviogenéticos regionales, la climatología de la región. También ejercen influencia fenómenos de escala local como los procesos convectivos e intercambios continente-océanocontinente (brisas de mar).

Durante determinadas épocas del año otros fenómenos de mayor escala ejercen influencia sobre las condiciones medias, como la presencia de la depresión tropical en la bahía de Panamá y la incursión de aire polar (frente frío) sobre el Caribe colombiano, que afecta principalmente la dirección y velocidad de los vientos en la Zona Norte del Pacífico, aunque normalmente esta influencia no supera las 48 horas de duración.

El movimiento de la ZCIT en dirección Sur-Norte-Sur (Fig. 2.2 - 2.4) resulta de los desplazamientos de las altas subtropicales respecto a la línea del Ecuador y su amplitud latitudinal media es de, aproximadamente, $4^{\circ}$ en el área del Pacífico colombiano, calculada con base en los núcleos nubosos asociados a ésta que inciden sobre el área costera.

Sobre la región costera del Pacífico colombiano no se distinguen las épocas secas de las húmedas. El clima en general se caracteriza como tropical lluvioso Isotermal, según la clasificación del modelo climático de Koeppen; lo que sugiere la presencia de precipitaciones durante todo el año y diferencias menores a $5^{\circ} \mathrm{C}$ entre el mes más cálido y el mes más frío (Eslava,1994).

\subsection{VIENTOS}

Los vientos en esta región del planeta se originan a partir de los gradientes de presión, generados por los desplazamientos de las altas subtropicales y por los gradientes térmicos producidos tanto por la corriente fría de Humboldt como por el calentamiento solar diurno.

En la parte oriental del océano Pacífico se encuentra la frontera entre las aguas frías, provenientes del sur, y las cálidas aguas ecuatoriales. Esta frontera se marca severamente y tiene carácter de frente oceánico. Su formación ocurre como resultado de la influencia de los vientos del Sur (Bubnov, 1990).

En la costa Pacífica colombiana los vientos Alisios del Sureste se recurvan y se convierten en vientos Ecuatoriales del Oeste (Alisios del Oeste). Estos vientos, de componente oeste, se presentan al sur de la ZCIT cerca de $1^{\circ} \mathrm{N}$. Los vientos más intensos del Oeste coinciden con la posición más septentrional de la ZCIT.

De igual forma, los vientos Alisios del Noreste se recurvan al norte de la ZCIT, adquiriendo un nuevo componente noroeste, y en consecuencia se forman las líneas de convergencia cerca de la costa. Dichas líneas permanecen costa afuera hasta cerca del amanecer y en la medida que la brisa terrestre se debilita, se mueven costa adentro siguiendo el flujo de gradiente.

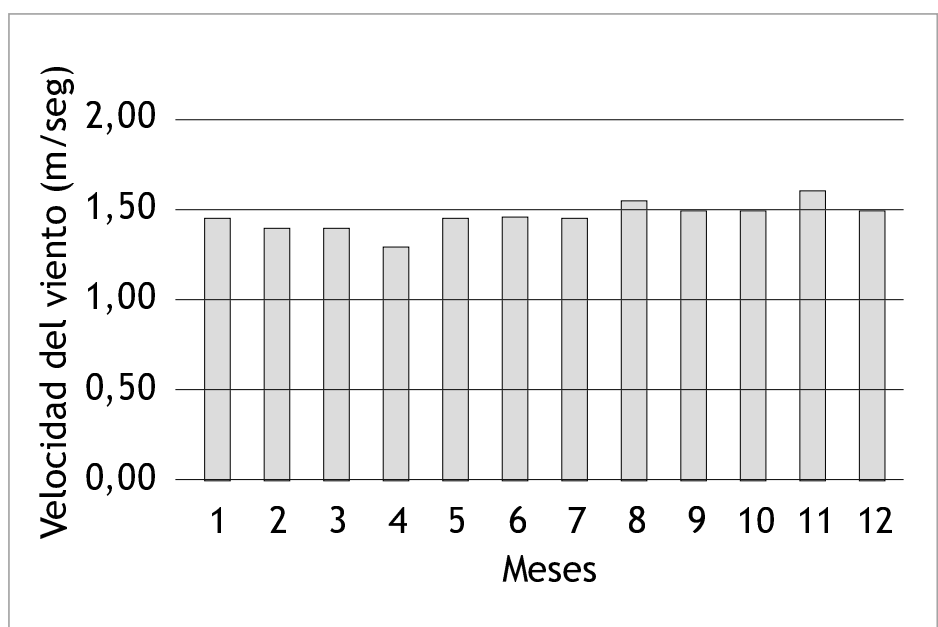

Figura 2.1. Valores medios de velocidad del viento en la zona costera del Pacífico. 
No existe un patrón bien definido del comportamiento de la velocidad del viento en la zona costera del Pacífico colombiano, debido a que los valores medios mensuales son bajos. El valor medio anual para toda la región apenas alcanza los $1,5 \mathrm{~m} / \mathrm{seg}$ (aproximadamente tres nudos). No obstante, es evidente que el comportamiento diario de este parámetro se ajusta a la variación que presentan las zonas tropicales, que se caracteriza por presentar los mínimos en la mañana y los máximos después del medio día.

La Figura 2.1 muestra los valores medios de velocidad del viento en el área, destacando un comportamiento cuasiuniforme durante el año, con un pico máximo en noviembre y un mínimo en abril. Este último coincide con el inicio del primer período de lluvias y el pico máximo se presenta junto con la culminación del segundo período de lluvias. Así mismo, en noviembre la ZCIT se encuentra al norte del área, lo que facilita el flujo libre del viento sobre la costa y su valor máximo durante el año. Caso contrario ocurre en abril cuando la ZCIT se sitúa sobre el centro del área, lo que podría minimizar la acción del viento y provocar valores moderados.

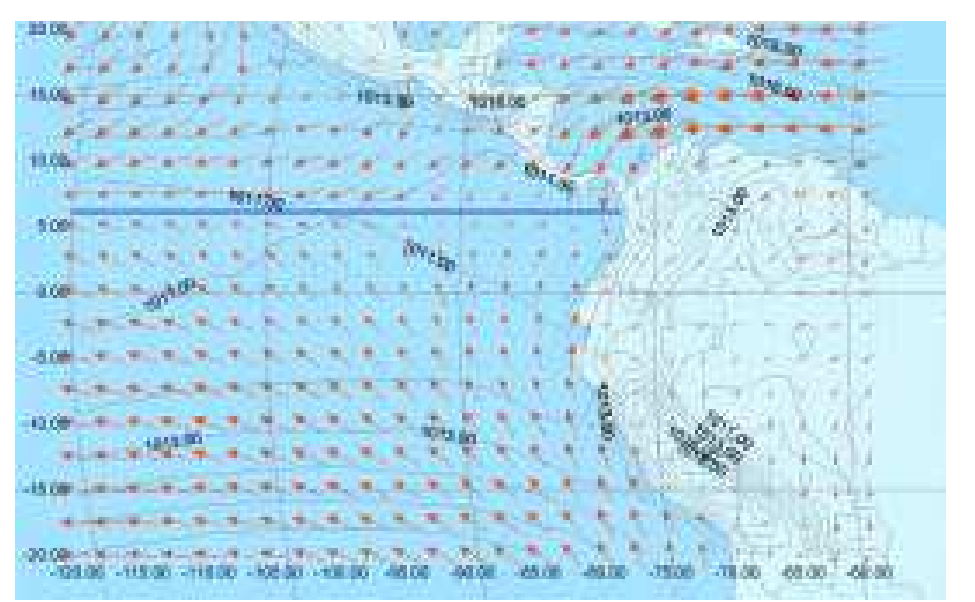

a) Enero

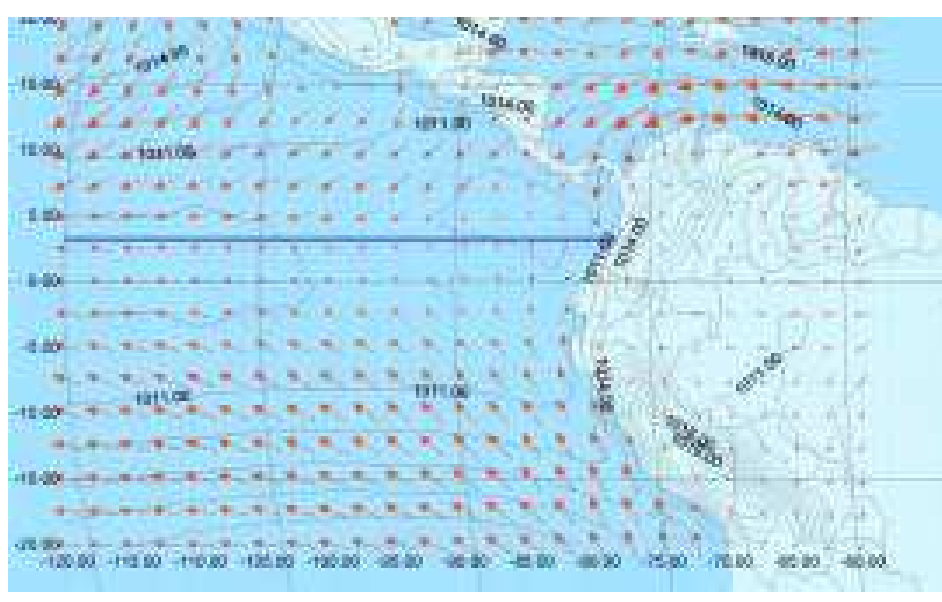

c) Marzo
En general se puede decir que sobre el Pacífico colombiano desde junio hasta noviembre predominan los vientos Alisios del Sureste. Luego, desde noviembre hasta enero se produce un cambio, cuando los Alisios del Sureste se debilitan y los Alisios del Noreste se intensifican. Entre enero y abril actúan los Alisios del Noreste, pero en este período en la Zona Sur del Pacífico colombiano se aprecia la influencia de los Alisios del Sureste. Desde abril hasta junio, nuevamente, se observa el cambio de comportamiento de los Alisios sobre el Pacífico colombiano.

\subsubsection{Variabilidad intranual del campo de vientos}

La variabilidad de las condiciones del viento en las latitudes bajas del hemisferio norte en el océano Pacífico está conectada con la migración de la ZCIT (Fig. 2.2-2.4).

A continuación se observa cómo cambia la distribución del viento sobre el Pacífico colombiano a través del año según los desplazamientos de la ZCIT, de acuerdo con la información

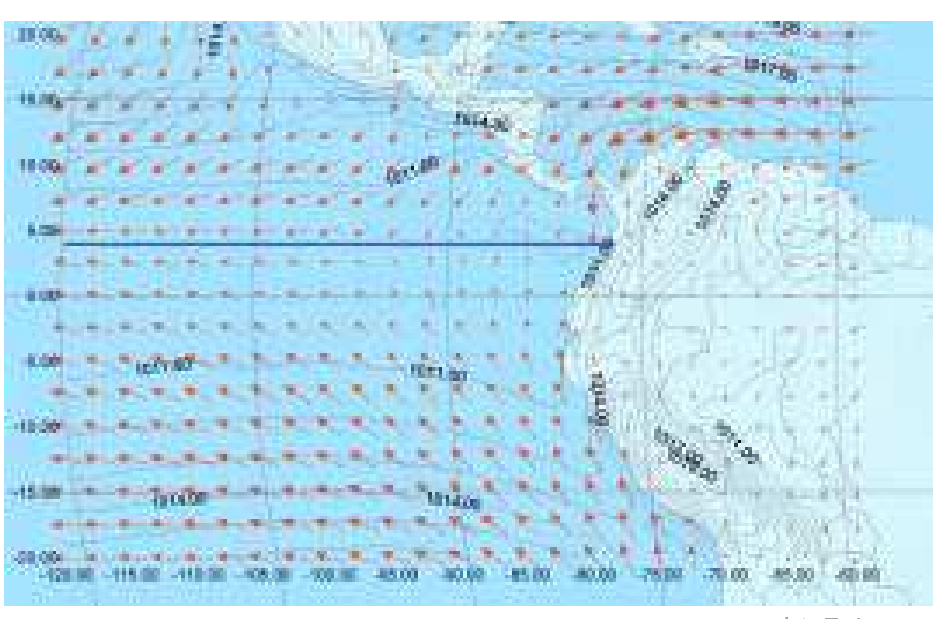

b) Febrero

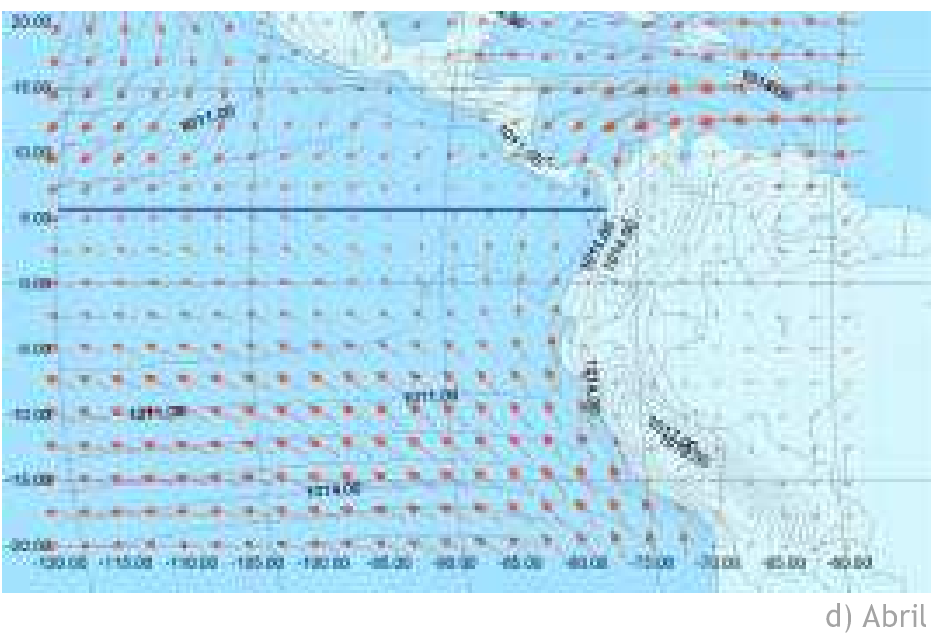

d) Abril

Figura 2.2 - Campo de presión atmosférica en mbar y dirección del viento predominante durante los meses de enero-abril. La línea azul indica la posición de la ZCIT 
contenida en el CD de la National Oceanic and Atmospheric Administration, NOAA, se obtuvieron características de presión atmosférica, dirección y velocidad del viento. Esta información corresponde a todo el globo terráqueo distribuida en una malla de $2.5^{\circ}$. Las características del viento fueron estimadas por medio del modelo numérico del Centro Meteorológico Europeo.

En enero (Fig. 2.2.a.) en la parte Norte del Pacífico colombiano se aprecia que los vientos Alisios del Noreste se localizan hasta las zonas próximas a la ZCIT. Por debajo de la ZCIT, en las regiones aledañas a la línea de costa, se observan aún vientos del Noreste con menor intensidad que en el Norte. En el Sur predomina el viento Suroeste, un poco más intenso que en la parte central.

En febrero (Fig. 2.2.b.) el territorio del Pacífico colombiano es dividido en dos partes por acción de la ZCIT. Al Norte se posicionan los vientos Alisios del Noreste, más intensos en comparación con enero; y al Sur de la ZCIT se localizan los vientos del Sur, transformándose en vientos del Suroeste en

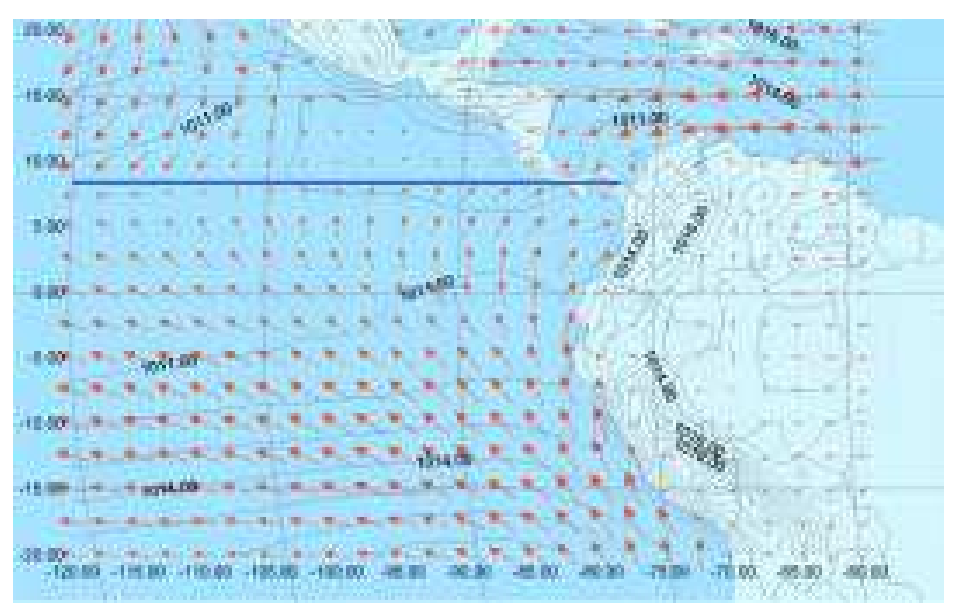

a) Mayo

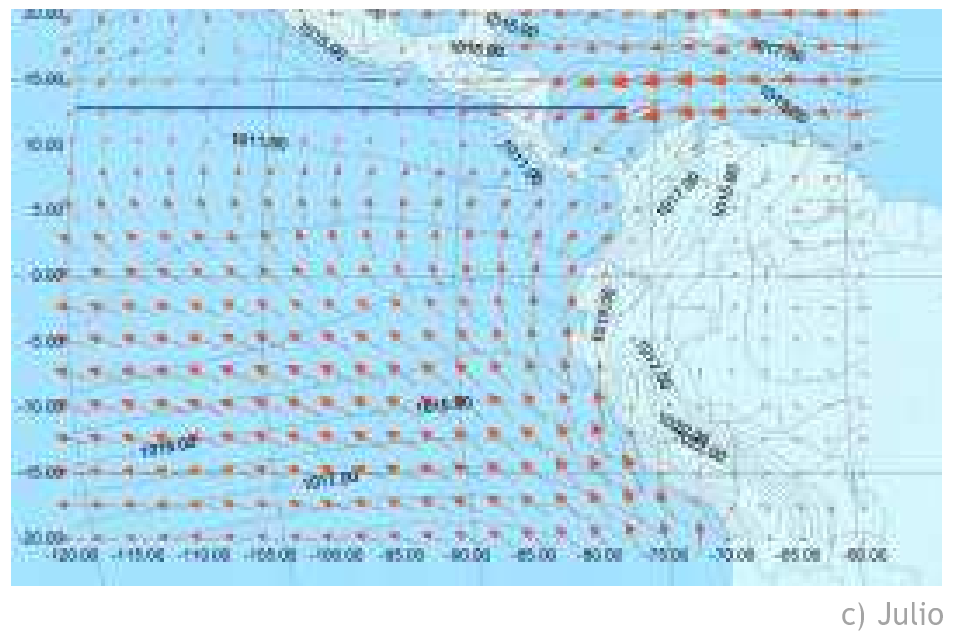

Figura 2.3. - Campo de presión atmosférica en mbar y dirección del viento predominante durante los meses de mayo-agosto. La línea azul indica la posición de la ZCIT

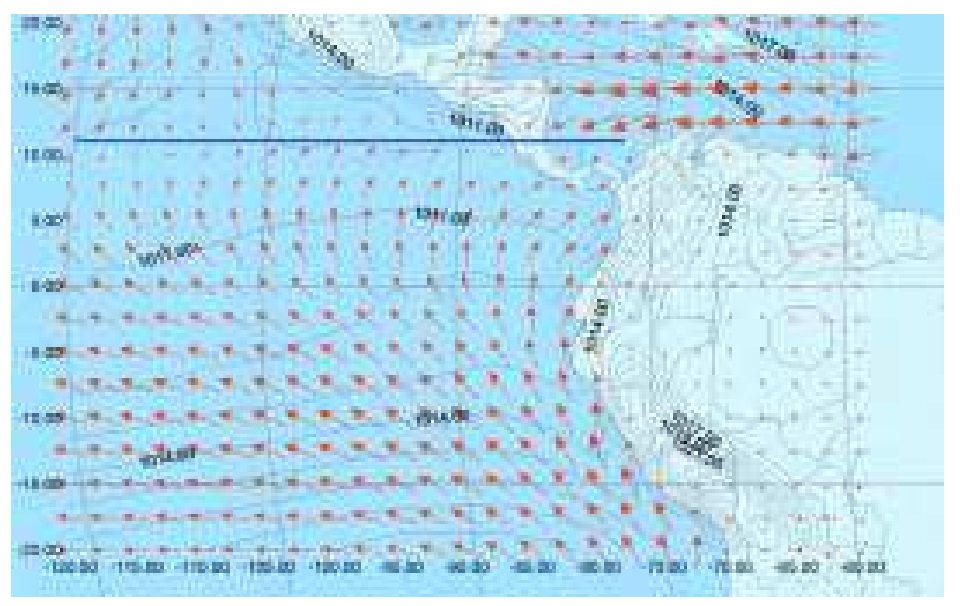

b) Junio

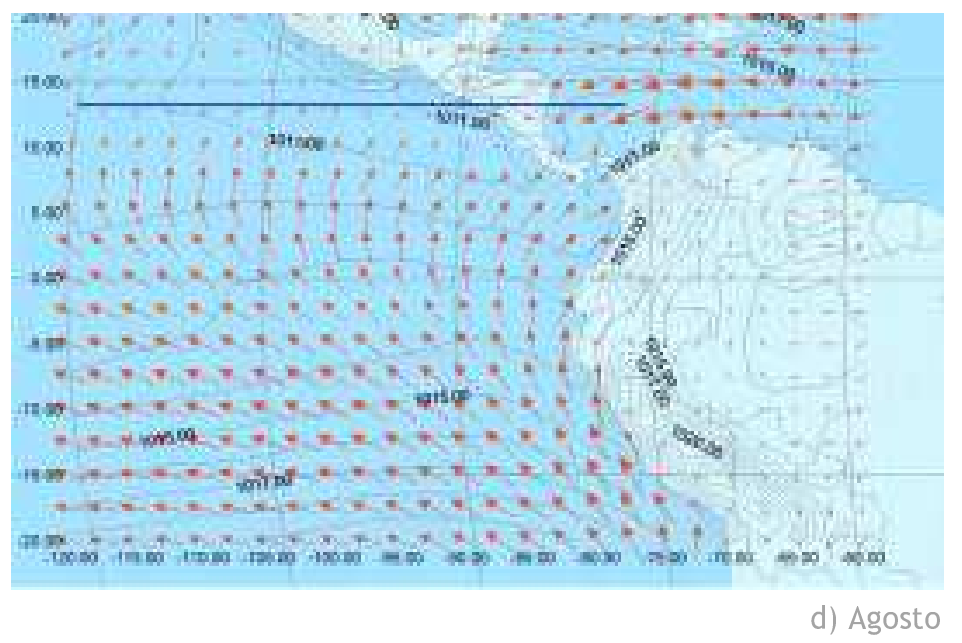

d) Agosto

las regiones aledañas a la costa, con intensidades menores que en enero.

En marzo (Fig. 2.2.c.) la ZCIT llega hasta la frontera sur del Pacífico colombiano. Al Norte de ésta se observan vientos con componentes norte y noreste, con moderadas intensidades (más débiles que en el mes anterior). Al Sur de la ZCIT se aprecian vientos procedentes del sur y del suroeste.

En abril (Fig. 2.2.d.) la ZCIT se desplaza hacia el Norte situándose en el centro de la Zona Norte del Pacífico colombiano, donde el viento posee un componente Norte, el cual penetra un poco más abajo de la ZCIT en la costa colombiana. Al Sur de la ZCIT predominan los vientos del Sur y Suroeste, con aumento de su velocidad en relación a marzo.

En mayo (Fig. 2.3.a.) la ZCIT pasa a lo largo del istmo de Panamá, por tal razón el territorio del Pacífico colombiano es influenciado por los vientos Alisios del Sureste. Los vientos que se observan son del Sur y Suroeste; estos giran cerca de Panamá y toman la dirección Noroeste.

En junio (Fig. 2.3.b.) la ZCIT se sitúa al Norte y los vientos$$
\text { . }
$$ 


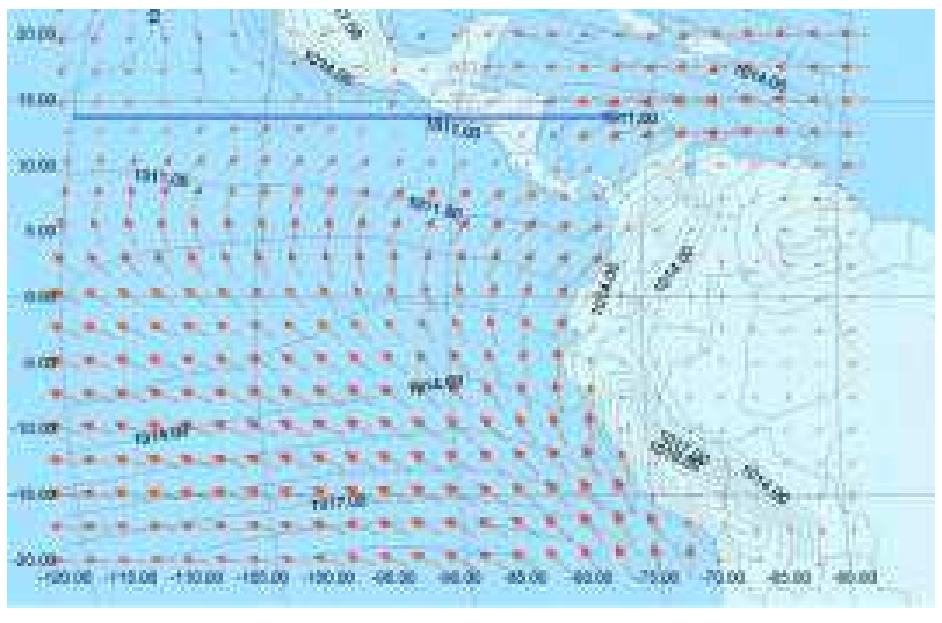

a) Septiembre

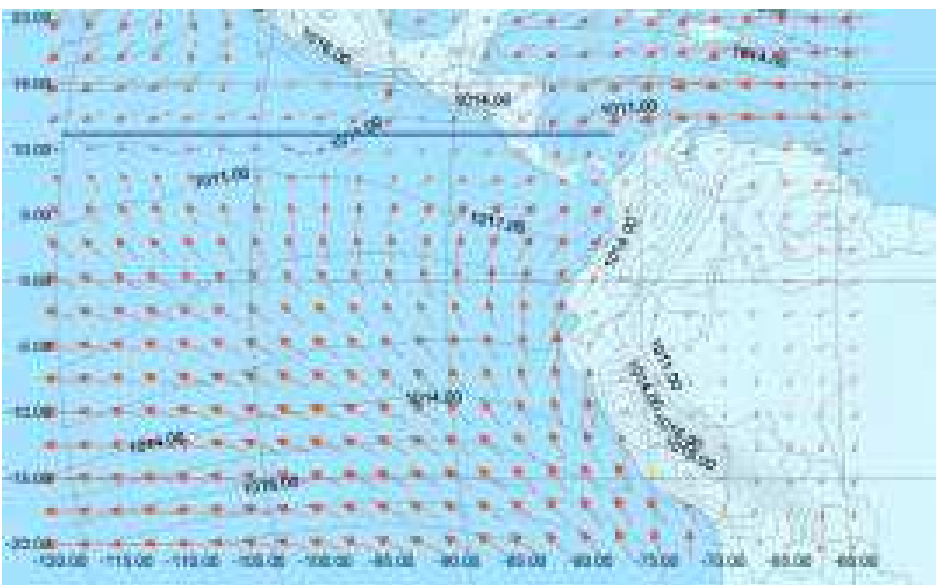

c) Noviembre

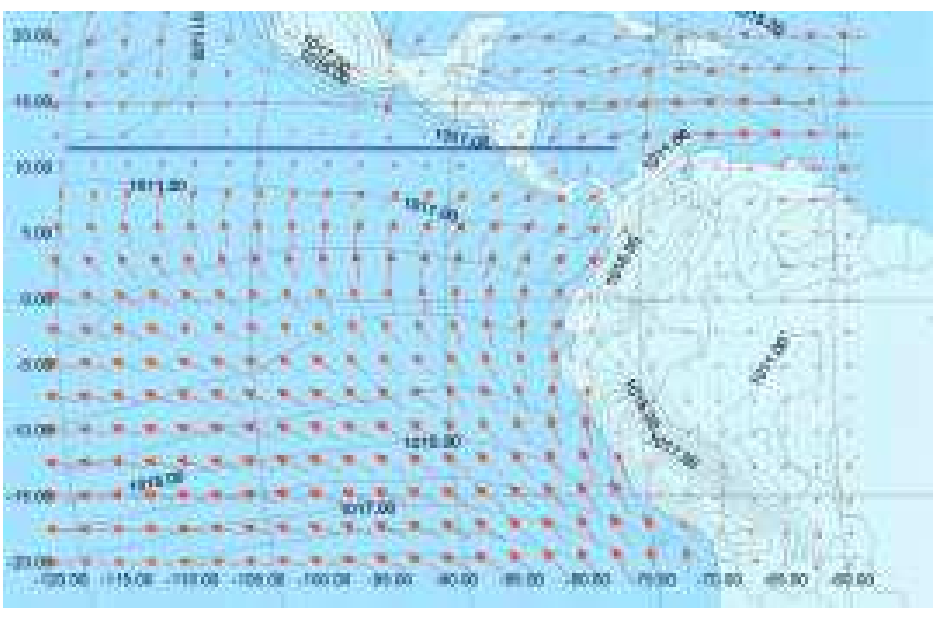

b) Octubre

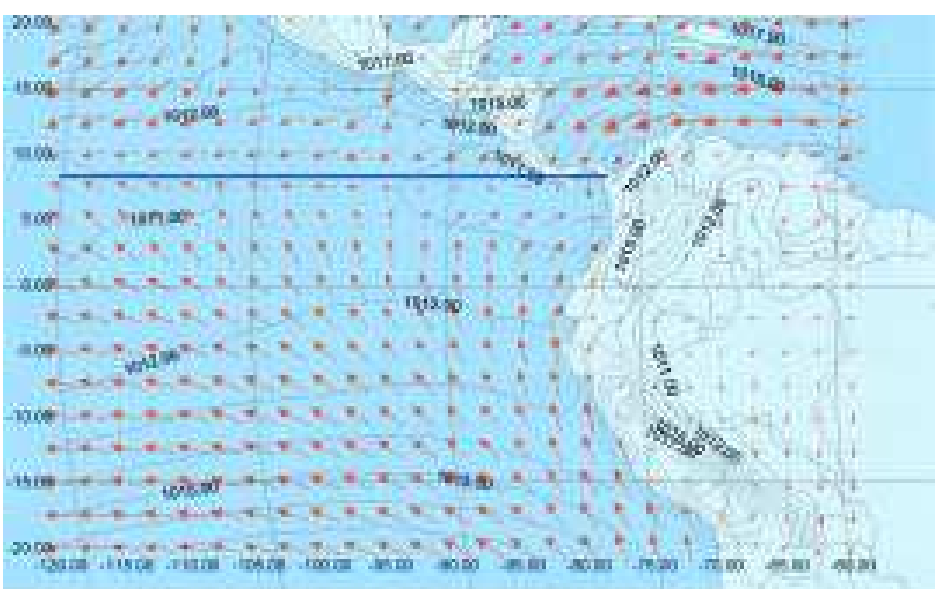

d) Diciembre

Figura 2.4 - Campo de presión atmosférica en mbar y dirección del viento predominante durante los meses de septiembre-diciembre. La línea azul indica la posición de la ZCIT.

sobre el Pacífico colombiano tienen componente suroeste. Cerca de Panamá el viento sopla del Oeste. La velocidad del viento se intensifica logrando magnitudes superiores a las registradas durante mayo.

Desde julio hasta octubre (Fig. 2.3.c., 2.3.d., 2.4.a., 2.4.b) la distribución del viento presenta características similares, con pleno predominio de los vientos del Suroeste sobre toda la CPC; logrando sus máximos de intensidad durante el mes de agosto con valores hasta de $4 \mathrm{~m} / \mathrm{seg}$.

En noviembre (Fig. 2.4.c.), cuando la ZCIT comienza a descender y y se aproxima al Pacífico colombiano, la intensidad de los vientos disminuye y cerca de Panamá aparecen vientos del Oeste.

Durante el mes de diciembre (Fig. 2.4.d.) la ZCIT, nuevamente, se sitúa paralelamente por encima del istmo de Panamá y ya en el Norte del Pacífico colombiano comienzan a fluir vientos del Norte y Noroeste. En las zonas Centro y Sur fluyen vientos del Suroeste.

\subsection{PRECIPITACIÓN}

En la CPC ocurren fuertes lluvias durante todo el año. El acumulado promedio de precipitación para toda la zona costera del Pacífico colombiano recibe $17.057 \mathrm{~mm} /$ año. El comportamiento de la curva media anual de precipitación para la Zona Norte (Fig. 2.5.) presenta un régimen de carácter bimodal-multimodal con excepción de las zonas Centro y Sur que presentan regímenes de carácter monomodal.

Para la Zona Norte durante el primer trimestre del año se registran los menores valores de precipitación anual; un segundo período de transición comprende los meses de julio y agosto, donde los valores se reducen mínimamente. Los mayores valores de precipitación para esta zona se registran durante octubre alcanzando valores hasta de $570 \mathrm{~mm} / \mathrm{mes}$ en promedio. 


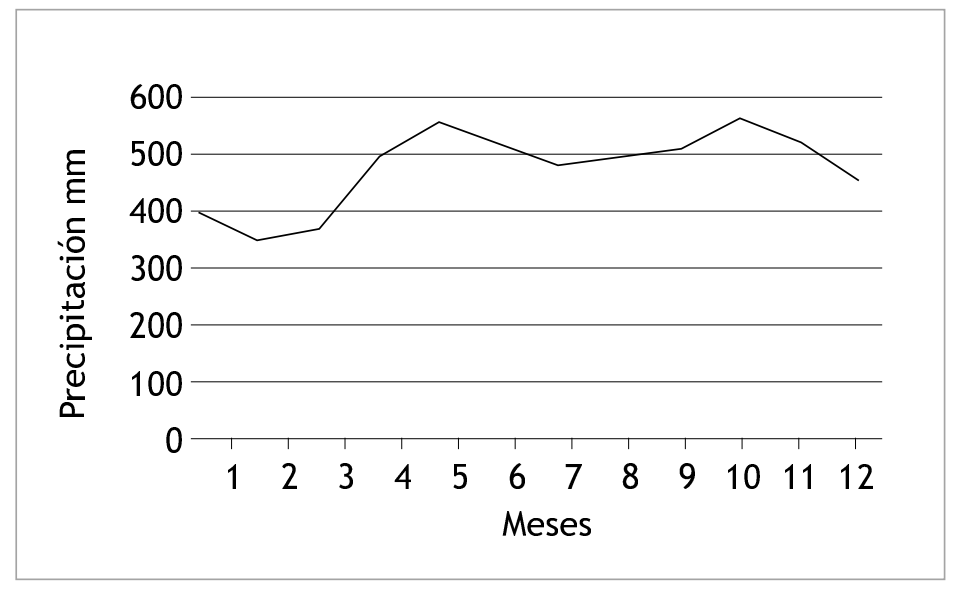

Figura 2.5 - Media anual de precipitación en la zona costera del Pacífico colombiano.

El valor promedio de número de días con precipitación durante el año es de 259, reafirmando el concepto de alta pluviosidad para toda el área.

La Figura 2.6 indica los promedios de número de días con registros de precipitación en toda la zona costera del Pacífico colombiano. El mes con menor cantidad de días lluviosos es febrero, no obstante presenta 17 días con precipitaciones que dejan en promedio 339 milímetros de agua, la cual resulta ser una cifra significativa.

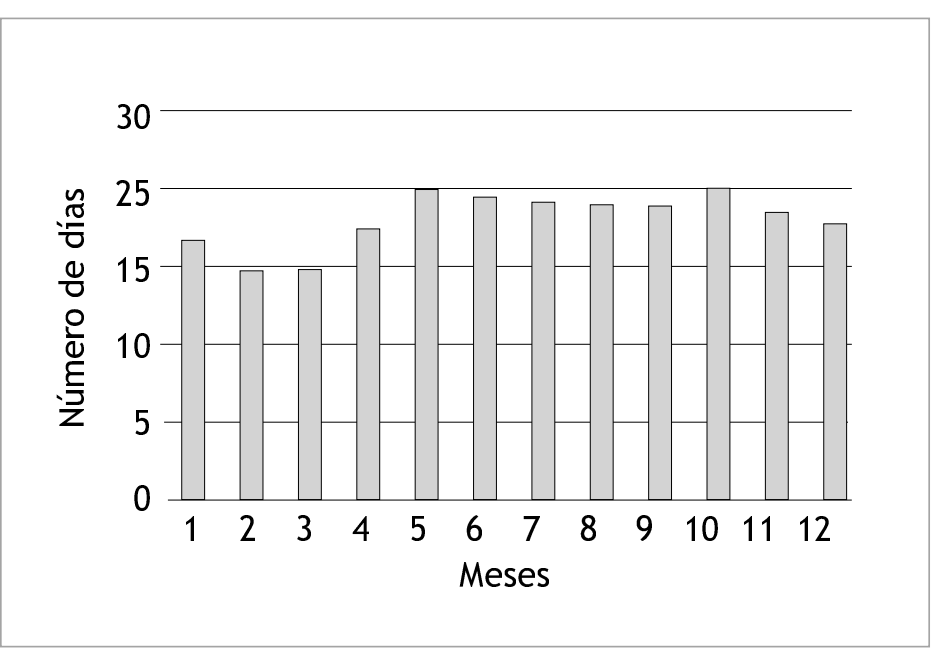

Figura 2.6 - Promedio de número de días con precipitación en la zona costera del Pacífico colombiano.

La zona Sur presenta un régimen de precipitación monomodal, alcanzando los máximos valores durante los meses de marzo y abril con 500 y 400 mm/mes de agua lluvia.

\subsection{TEMPERATURA DEL AIRE}

La temperatura del aire para toda el área costera tiene un valor medio de $25.6^{\circ} \mathrm{C}$. La gráfica de valores medios de temperatura para la zona costera del Pacífico (Fig. 2.7) muestra un comportamiento monomodal con valores máximos en abril (inicio del período de lluvias) y mínimos durante octubre y noviembre. Los rangos de temperaturas van desde las mínimas de 23 a $24^{\circ} \mathrm{C}$, hasta las máximas desde 27 a $28^{\circ} \mathrm{C}$.

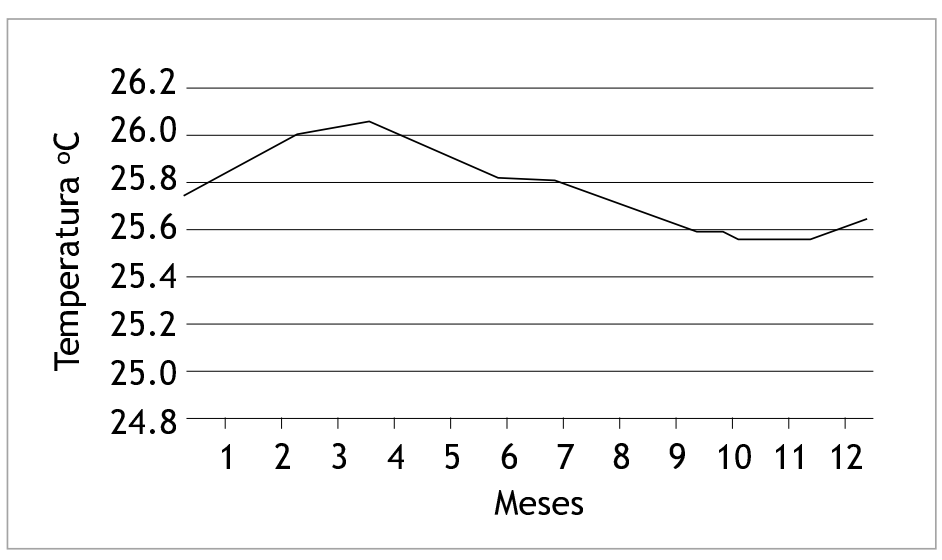

Figura 2.7 - Temperatura del aire media anual en estaciones costeras del Pacífico colombiano.

\subsection{HUMEDAD}

Es evidente que el excesivo aire cálido y húmedo tropical, reinante en toda el área, favorece la rápida formación de abundante nubosidad, de la cual se desprenden los altos valores de precipitación registrados. Se establece una media anual de humedad relativa para esta área de $89 \%$.

La Figura 2.8 muestra valores medios mensuales de humedad relativa en toda el área, donde se destaca el valor mínimo de este parámetro en marzo (excepto para la zona Sur), conocido por ser el mes que marca el final de la llamada "época seca" o de menores valores de precipitación; y unos picos máximos en los meses de junio, octubre y diciembre, producto de constantes lluvias características de todos estos meses.

Para la zona Sur ocurre todo lo contrario, los meses más húmedos son marzo y abril, en tanto que los meses con menores valores de humedad son agosto y septiembre. 


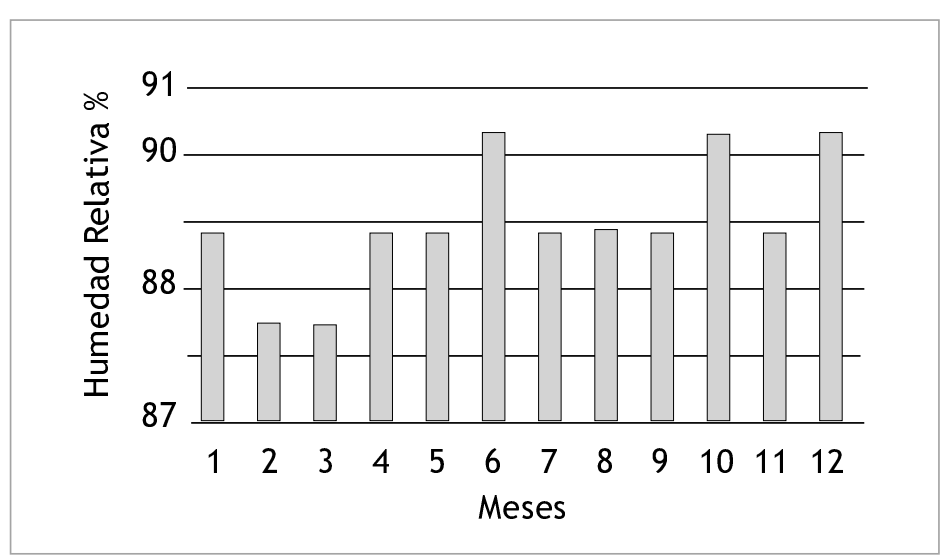

Figura 2.8.- Valores medios mensuales de humedad relativa en la zona costera del Pacífico colombiano.

\subsection{COBERTURA DEL CIELO, TECHO Y VISIBILIDAD}

Durante la desaparición de los vientos Alisios grandes cúmulos y cumulonimbus incrementan su intensidad y área de cobertura. Esto puede ocurrir a cualquier hora; no obstante, el horario prevaleciente para el desarrollo y formación de estas nubes son las horas de la tarde hasta el amanecer.

No se exhiben valores medios de nubosidad para la zona costera del Pacífico colombiano debido a que estos valores muestran una constante durante la mayor parte del año que se caracteriza por presentar coberturas de nubosidad entre $6 / 8$ y $8 / 8$, permitiendo determinar que los cielos permanecen entre semicubiertos y cubiertos.

La curva de techo para el área de Buenaventura es típica para toda la zona costera y evidencia los menores valores de nubosidad entre las 07:00 y 10:00 horas, para posteriormente incrementarse alcanzando sus máximos en horas de la madrugada. La curva de visibilidad tipifica la mayor parte del área de esta región, mostrando los mayores porcentajes de visibilidad en las horas que coinciden con la menor presencia de nubes (Fig. 2.9).

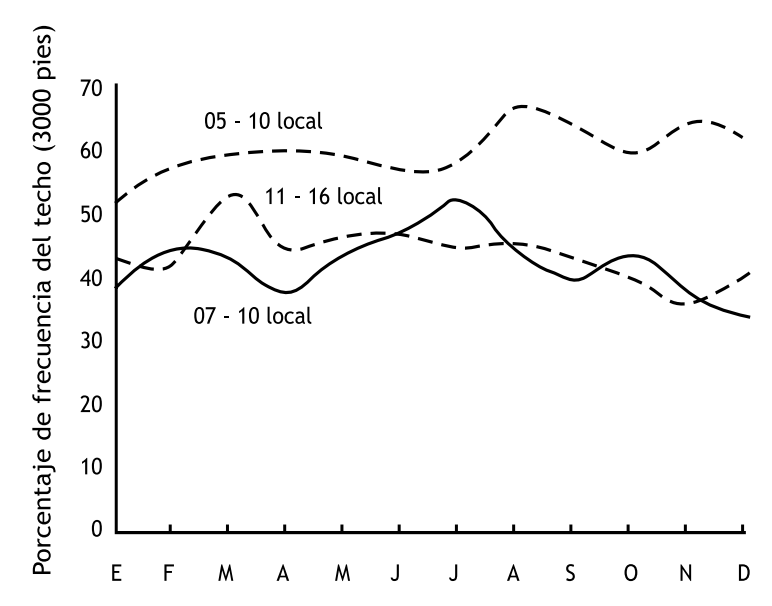

Figura 2. 9 - Techo y visibilidad. Buenaventura, Colombia.

\subsection{DELIMITACIÓN DE LAS ZONAS CLIMÁTICAS}

A continuación se presenta la delimitación de cada una de las zonas climáticas en las que se podria dividir la costa Pacífica colombiana, de acuerdo con sus características meteorológicas (Fig. 2.10):

- Zona Norte: comprendida desde punta Ardita hasta Pizarro (aproximadamente entre las latitudes $07^{\circ} 08^{\prime}$ y 045' Norte).

Zona Centro: comprendida desde Pizarro hasta punta El Coco Gorgona (aproximadamente entre latitudes $04^{\circ} 57^{\prime}$ y $03^{\circ} 00^{\prime}$ Norte).

- Zona Sur: área comprendida desde punta El Coco Gorgona hasta Cabo Manglares (aproximadamente entre latitudes $03^{\circ} 00^{\prime}$ y $01^{\circ} 36^{\prime}$ Norte).

La Figura 2.10 señala la distribución de las áreas delimitadas; ésta incluye la zonificación para el área marítima que es referida en los boletines de pronóstico diario que emite la Central de Pronósticos del Pacífico del CCCP.

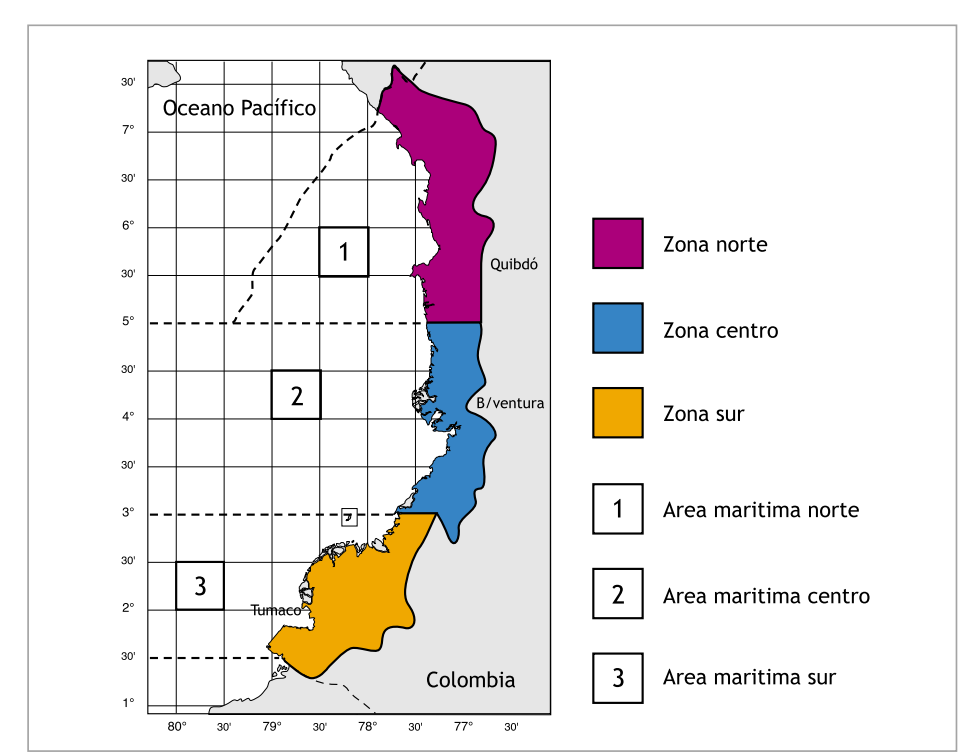

Figura 2.10 - Delimitación de zonas climáticas en el Pacífico colombiano.

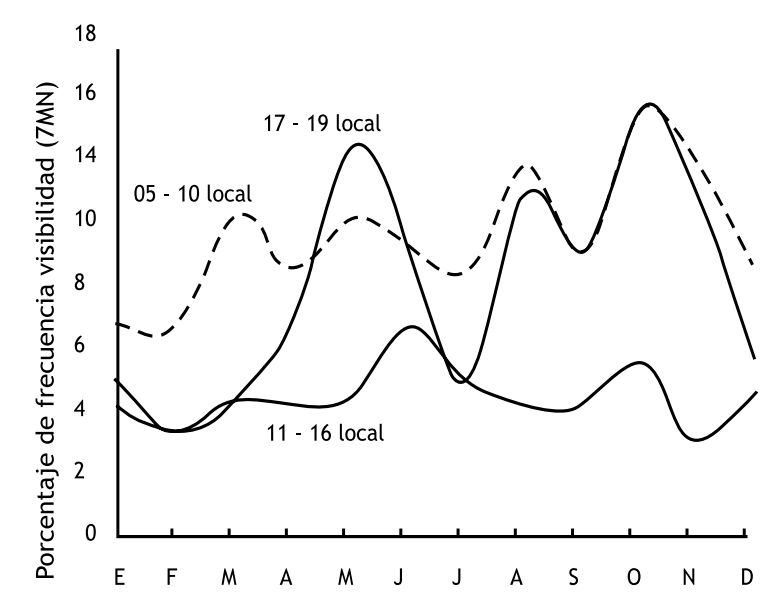




\subsubsection{Clima en la Zona Norte}

Esta zona presenta los índices más altos de precipitación durante el año. El valor anual alcanza los $6452 \mathrm{~mm}$. Esto se debe a que abarca en su totalidad el departamento del Chocó y a su proximidad con la región selvática del Darién en Centroamérica, áreas de reconocido aporte a la liberación de calor latente y su consecuente abastecimiento hídrico.

Dentro de esta zona se encuentra uno de los puntos más lluviosos del globo, teniendo en cuenta un valor anual de $12717 m m$ en Lloró (Chocó). Durante cierta época del año es notable la influencia de la baja presión anclada de Panamá o del Darién, la cual registra una continua presencia de núcleos convectivos y sus consecuentes lluvias fuertes, en algunas ocasiones acompañadas de fuertes vientos (vendavales).

La precipitación en esta zona es intensa durante todo el año, presenta sus valores más altos entre los meses de mayo y agosto; lo cual coincide con la presencia de la ZCIT en esta región del Pacífico. Los mínimos valores se registran durante el primer trimestre de año; época en la cual la ZCIT se encuentra al Sur. Durante los otros meses se presentan valores intermedios entre los menores y los mayores.

\subsubsection{Clima en la Zona Centro}

El clima de esta zona es predominantemente cálido, muy húmedo, con altas temperaturas y precipitaciones durante la mayor parte del año. En zonas de ascenso cerca de la cordillera Occidental, el enfriamiento de las masas de aire provoca la condensación y, por consiguiente, la formación de nubosidad y de precipitaciones. Esto también determina que en las laderas altas, por la reducción de la insolación debido a la alta nubosidad producida por la convección diurna, disminuyan las temperaturas máximas; mientras que en la llanura costera, el aumento del contenido de vapor de agua, disminuye la liberación radiación nocturna y, por consiguiente, disminuye la taza de enfriamiento.

La reducción de las condiciones de radiación se refleja en una oscilación muy pequeña de la temperatura alrededor de las medias anuales de 25 a $27^{\circ} \mathrm{C}$ al nivel del mar, con un ligero aumento en los valles del río San Juan de 26 a $28^{\circ} \mathrm{C}$.
Esta diferencia se debe a un leve aumento de la insolación, que hace más calientes los valles que otras localidades de la misma altura (Prahl et al., 1990).

En cuanto a la distribución horaria de las precipitaciones, se puede presentar una acumulación de las lluvias hacia las horas de la tarde, la cual se debe principalmente al efecto de la circulación local diurna y enfriamiento nocturno. También se puede presentar la circulación contraria, cuando el aire frío de las montañas fluye hacia los valles y planicies, provocando precipitaciones durante las horas de noche. Según la localización del área puede predominar uno u otro sistema de circulación (Prahl et al., 1990). Las precipitaciones se incrementan, además por el fenómeno local de descarga de la humedad que entra del mar al chocar con las estribaciones de la cordillera cerca de la costa (efecto de barrera).

El desplazamiento de la banda nubosa del cinturón que genera la ZCIT determina una variación de las precipitaciones en la zona Norte-Central y meridional de la CPC. Así, la zona Norte-Central, que se encuentra hacia el norte y sur de la vertiente hidrográfica del río San Juan, se caracteriza por contar con dos períodos de precipitaciones. Durante los meses de abril a noviembre se presenta una temporada de lluvias abundantes, en el cual se recibe aproximadamente el 70\% de la precipitación anual. La otra temporada es menos lluviosa y corresponde a la época comprendida entre diciembre y marzo (cuando el cinturón nuboso se ha desplazado hacia el Sur). En esta zona se registran precipitaciones que fluctúan alrededor de los $8000 \mathrm{~mm} /$ año, lo que determina que sea la hoya hidrográfica con mayor precipitación para todo el territorio colombiano.

Las abundantes precipitaciones se deben principalmente a que las masas de nubes que se forman a poca altura sobre el mar, saturadas de humedad, son arrastradas por los fuertes vientos del occidente hacia el interior y al encontrarse con la cordillera Occidental se detienen, se enfrían sobre las estribaciones de ésta y se condensan, precipitando abundantes lluvias.

De acuerdo con los registros de precipitación de las estaciones meteorológicas en el área de Buenaventura, se observa que el primer trimestre del año es el de menor precipitación, incrementándose hasta mayo; en junio se mantiene para incrementarse gradualmente, ente los meses de julio y octubre. 
Finalmente, se presenta una disminución gradual en noviembre y diciembre.

La evaporación presenta un promedio que oscila entre 711.9 y $1028 \mathrm{~mm} /$ año, valores muy inferiores a la precipitación, en razón del alto grado de humedad relativa de la zona.

La baja salinidad del mar presentada cerca de la costa, originada por el alto volumen de agua dulce que descargan los ríos en el litoral, la evaporación de los manglares y selvas de la costa, y el estancamiento de las masas de nubes arrastradas por los vientos marítimos por la presencia de la cordillera Occidental, causa principalmente el sostenimiento permanente de una alta humedad atmosférica a lo largo del año.

La temperatura del aire, está relacionada con la fluctuación cenital del sol durante el año, ésta es escasa, lo que impide variaciones estacionales anuales de temperatura. Sin embargo, en la región se presenta un clima tropical de ciclos térmicos diurnos.

En general, la radiación solar que llega a la atmósfera se dispersa, absorbida o reflejada por las nubes y las formas del relieve. Las nubes de la región reflejan al ambiente gran cantidad de radiación solar incidente, ésta depende básicamente del tipo de nubes y de su albedo. El albedo y la absorción de las nubes varía considerablemente con el espesor y el contenido de humedad.

Según los registros, el valor medio anual de nubosidad oscila entre 6 y 7/8 durante todo el año, lo cual permite concluir que la zona permanece cubierta o semicubierta de nubes.

\subsubsection{Clima en la Zona Sur}

La zona sur del Pacífico colombiano presenta durante el año un sistema de comportamiento definido en sus dos semestres; donde es más regular el primero en relación al comportamiento de los parámetros meteorológicos, presentando variaciones durante el segundo semestre.

El aspecto de lluvias es de tipo monomodal, considerándose el invierno durante el primer semestre y acentuándose en el segundo trimestre, siendo la época de verano el segundo semestre con un promedio histórico anual de $2300 \mathrm{~mm}$.

El comportamiento de la temperatura ambiente fue analizado, presentando durante la época húmeda temperaturas superiores o iguales a $25.8^{\circ} \mathrm{C}$, siendo abril el mes que tiende a presentar un mayor valor en el rango de la temperatura con promedios que oscilan entre $26.1^{\circ} \mathrm{C}$ y $26.3^{\circ} \mathrm{C}$, condicionado en sus características por el desplazamiento hacia el norte de la ZCIT en la región Pacífica durante esta época. Posteriormente, entre julio y diciembre (época seca) la temperatura disminuye y se estabiliza por debajo de los $25.7^{\circ} \mathrm{C}$, ajustándose el comportamiento de la temperatura a manifestaciones monomodales, con un período caliente de febrero a junio y otro relativamente frío de julio a enero.

Las temperaturas durante el día y la noche, y entre las épocas semisecas y húmedas, tienen muy poca variación debido a que la zona se encuentra muy cerca al mar, lo cual proporciona condiciones favorables para el desarrollo de la agricultura (promedio medio anual $25.7^{\circ} \mathrm{C}$, con fluctuaciones extremas entre 23 y $30^{\circ} \mathrm{C}$ ).

La humedad relativa es más regular en el primer semestre, arrojando valores promedio de $86 \%$ los cuales son muy constantes, para posteriormente mostrar oscilaciones durante el segundo semestre con valores promedio entre $85 \%$ y $87 \%$. En término general este parámetro presenta índices altos en la región porque en esta zona se caracteriza la permanencia de aires fríos.

Frecuentemente, en la Zona Sur al final de la mañana se establece un viento que sopla del mar, alcanza su intensidad máxima al comienzo de la tarde, después disminuye progresivamente y cesa en la noche. La intensidad de esta brisa es mayor cuando el día es cálido, pero puede ser menor cuando el día está nublado.

En síntesis, la CPC presenta características especiales dentro del océano Pacífico por estar ubicada dentro de la región de bajas presiones atmosféricas conocida como Concavidad Ecuatorial, en la cual convergen los vientos Alisios de cada hemisferio para formar la ZCIT. El choque de masas de aire ascendente con diferencias térmicas y gradientes de humedad genera la formación de una banda nubosa por procesos de convección, lo que ocasiona que el clima se caracterice por sus vientos variables y débiles (zona de calmas ecuatoriales) y por su alta pluviosidad (Trojer, 1958).

Las variaciones en las precipitaciones dependen del desplazamiento de la banda nubosa de la ZCIT (Prahl et al., 1990). La temperatura del aire en la zona costera varía muy poco anualmente, entre 25 y $27^{\circ} \mathrm{C}$, pero existe una marcada diferencia entre la temperatura diurna y nocturna de aproximadamente $12^{\circ} \mathrm{C}$. 


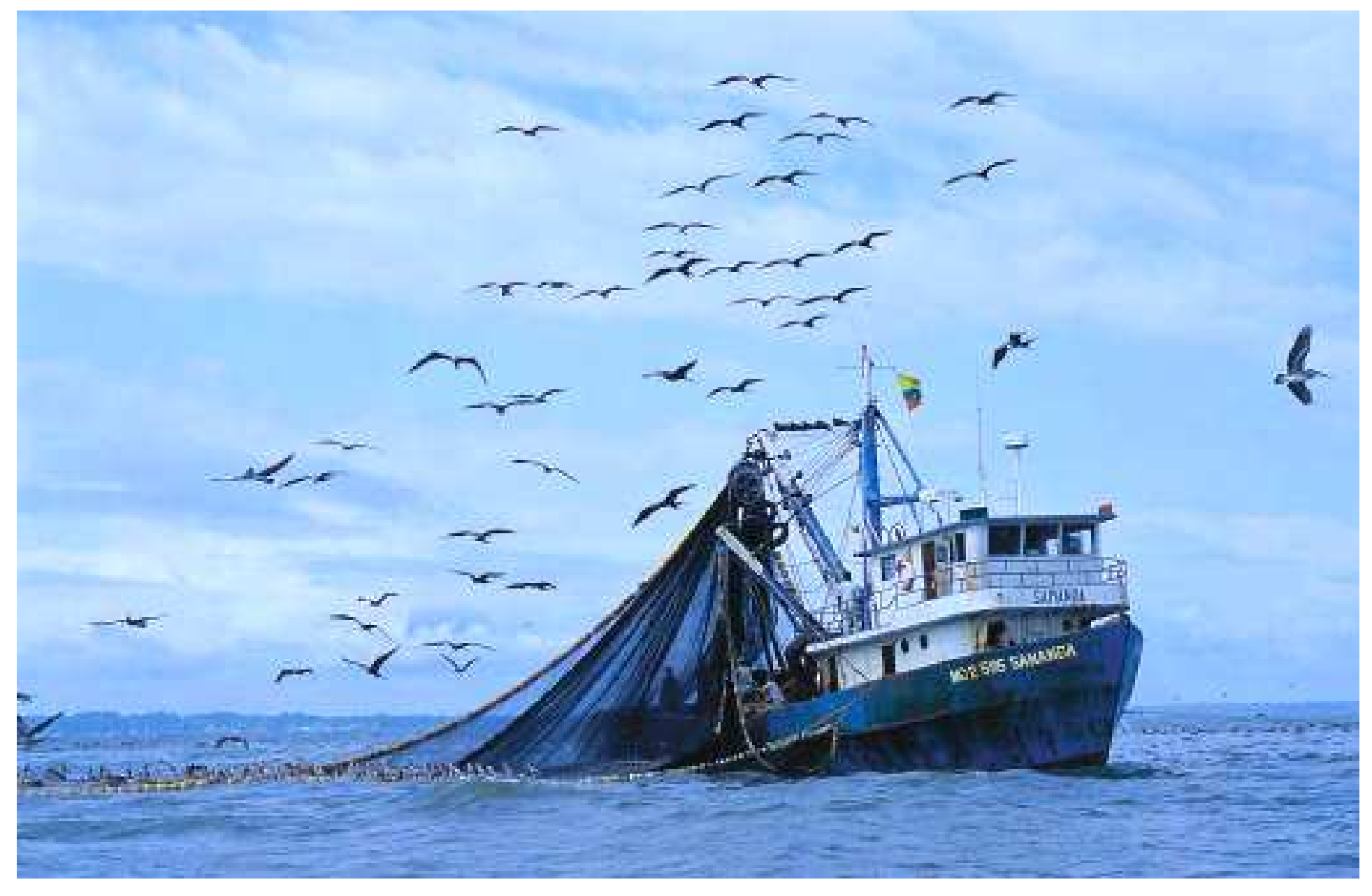

La predicción de las anomalías tiene gran importancia para las pesquerías en aguas del Pacífico colombiano 


\section{CAPÍTULO III - Investigación Oceanográfica en la Cuenca Pacífica Colombiana}

\subsection{INFORMACIÓN OBTENIDA EN CRUCEROS OCEANOGRÁFICOS DESDE 1970 HASTA 1996 EN LA CPC}

La Armada Nacional ha realizado exploraciones oceanográficas en la CPC desde 1970 hasta el presente. Durante este período se han tomado muestras y se ha medido con instrumentos oceanográficos la salinidad y temperatura del agua; así como también parámetros químicos y biológicos, además de meteorológicos, los cuales intervienen en el intercambio océano-atmósfera. En general, la información utilizada en este capítulo corresponde a promedios mensuales simulados por una regresión polinomial de quinto grado de toda la información que se tenía hasta el momento, sin diferenciar épocas del ciclo El Niño Oscilación Sur, ENOS, a causa de la poca información inicial.

Los resultados que aquí se presentan pueden ser tomados como una primera aproximación de un promedio histórico o de la oscilación climática de los parámetros físicos de la CPC. Los meses de enero y julio carecen de información inicial, por lo cual no se registran observaciones de los mismos.

Para el desarrollo del presente capítulo se utilizaron los datos mensuales de temperatura y salinidad de la CPC tomados del trabajo de Málikov y Camacho (1998), Método de Aproximación para Determinar Cambios Entreanuales Aplicado a Parámetros de Temperatura y Salinidad del Pacífico Colombiano, 1998; los cuales fueron obtenidos en los cruceros oceanográficos realizados por la Armada Nacional de Colombia desde 1970 hasta 1996.

Fue necesario realizar un análisis objetivo de la información aplicando análisis visuales para su interpolación a profundidades estándar $(0,10,20,25,30,50,75,100,150,200,300,400$, $500)$, utilizando una modificación de la interpolación lineal del Método de Reiniger y Ross -1968 (Boyer, y Levitus, 1994). Después de unificar verticalmente las estaciones de trabajo, se procedió a efectuar la interpolación de los datos hacia una grilla de trabajo que se empezó a utilizar en 1982 (Fig. 3.1). Esta grilla se caracteriza porque las distancias establecidas entre cada estación son iguales tanto en latitud como longitud (30 millas); lo que por su cercanía permite realizar una interpolación en forma horizontal, en la cual se tuvo que hacer un análisis objetivo para el cálculo de los valores medios de los puntos de la grilla, teniendo en cuenta el movimiento dinámico de las aguas (Villegas, 1997a).

Debido a la poca información obtenida de algunas estaciones dentro del período de observación 1970-1996, fue indispensable realizar la restauración de datos ausentes utilizando una regresión polinomial de quinto grado, la cual describe las oscilaciones del año a través de los datos iniciales para regiones ecuatoriales $\left(10^{\circ} \mathrm{S}\right.$ a $\left.10^{\circ} \mathrm{N}\right)$ (Málikov, 1998).

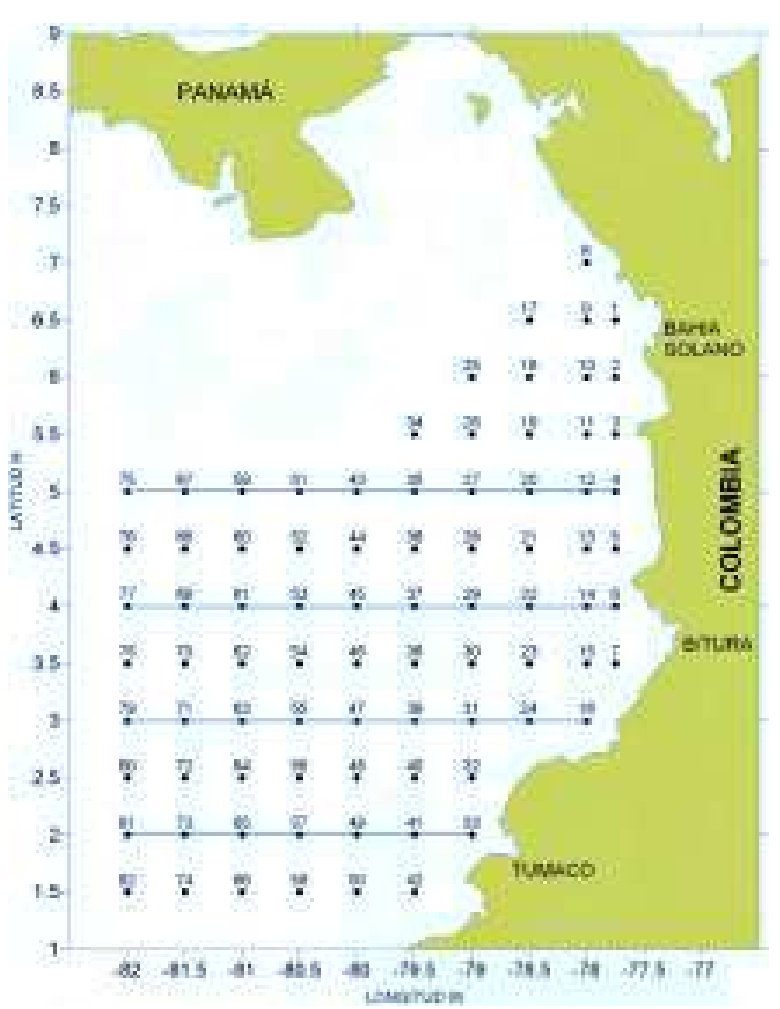

Figura 3.1. - Grilla de estaciones de cruceros oceanográficos realizados por el CCCP y transeptos seleccionados para estudio de perfiles de temperatura y salinidad (líneas azules).

3.2. DESCRIPCIÓN CON DATOS PROMEDIOS DE LA TEMPERATURA Y SALINIDAD DE LA SUPERFICIE DEL MAR

El cambio de distribución de la temperatura y la salinidad en la CPC durante un año refleja las peculiaridades generales de los procesos que existen en esta región.

La temperatura del agua en la capa superficial es la más alta debido a que el flujo de calor proviene de la atmósfera, especialmente en esta región localizada en la Zona Ecuatorial, 
por lo tanto en el área de estudio el flujo de calor es máximo. Las pequeñas amplitudes estacionales de la capa superficial de la región no sobrepasan los 2 ó $3^{\circ} \mathrm{C}$ (Doronin, 1986).

Los intercambios de calor, salinidad y cantidad de movimiento ocurren únicamente en la capa superficial, que presenta un espesor máximo de 200 metros. Los factores generales que ocasionan la formación de los regímenes hidrodinámicos y termohalinos son la radiación solar, la distribución del viento, la precipitación, la intensidad de los aportes fluviales en las desembocaduras de los ríos y las variaciones de las corrientes de Humbolt y la contracorriente Ecuatorial, CCE. (Bubnov, 1990)

Es por esto que la circulación oceánica en superficie está estrechamente relacionada con la circulación atmosférica. En la CPC predominan vientos planetarios, determinados por el desplazamiento de la ZCIT, los cuales presentan masas de agua superficiales con características similares.

Estas masas de agua en el Pacífico colombiano forman parte del sistema anticiclónico de corrientes del Pacífico Oriental, cuyos principales componentes en el hemisferio norte son las corrientes de California y Ecuatorial Septentrional; y en en el hemisferio sur, las corrientes de Perú, Humboldt y Surecuatorial. Las principales corrientes superficiales que afectan la CPC son:

- La corriente Ecuatorial del Norte, alimentada por el agua del Pacífico Oriental Tropical y la corriente de California, se desplazan hacia el oeste a nivel de los $12^{\circ} \mathrm{N}$.

- La contracorriente Ecuatorial del Norte, CCE, que se manifiesta con mayor intensidad de mayo a diciembre, proviene del Pacífico Central $140^{\circ} \mathrm{W}$ y se desplaza entre los 4 y $11^{\circ} \mathrm{N}$ hacia las aguas tropicales del Pacífico Oriental. Al Este de los $90^{\circ} \mathrm{W}$ la CCE se bifurca, parte se vuelve hacia el norte y noreste, donde se integra al sistema de circulación de Costa Rica y Panamá; y parte toma rumbo sur y oeste entrando en el sistema de la corriente Ecuatorial del Sur (Wyrtki, 1965). Durante febrero hasta abril, esta corriente disminuye temporalmente, los vientos Alisios del Noreste se intensifican, permitiendo la entrada de aguas tropicales a la CPC.

- La corriente de Humboldt, conocida también como la corriente del Perú, caracterizada por sus aguas frías, se presenta para la época de verano, comprendida de mayo a noviembre. Esta marca el inicio del cambio de estación fría, ya que cuando sus aguas llegan a las costas de Ecuador y Colombia se produce una disminución en la Temperatura Superficial del Mar y del aire. Esta corriente fluye de sur a norte, proveniente de los 40 a $45^{\circ}$ latitud sur.

Debido a que la corriente del Humboldt se caracteriza por sus aguas frías es muy favorable para la pesca, ya que es rica en nutrientes. Esta corriente es más intensa entre julio y septiembre; posteriormente, se debilita en forma gradual hasta desaparecer por completo para el mes de diciembre, época en la que aparece la llamada corriente El Niño, con características totalmente contrarias a las de la corriente de Humboldt (Wyrtki, 1965).

Frente a las costas colombianas, en el área de Gorgona, el patrón general está dominado por un remolino ciclónico de forma elíptica. Su rama con dirección norte, a lo largo de la costa es la corriente de Colombia. Su rama con dirección sur abandona el golfo de Panamá en una dirección hacia el sur y el suroeste, desarrollándose con mayor fuerza de diciembre a abril. Durante este período, la mayor parte del agua que abandona el golfo de Panamá, donde ocurre un fuerte afloramiento, toma rumbo oeste y se une a la circulación anticiclónica centrada cerca de los $5^{\circ} \mathrm{N}$ y $88^{\circ} \mathrm{W}$.

Durante el resto del año, el remolino frente a Colombia se desarrolla más débilmente (Wyrtki, 1963). La corriente de Colombia arrastra aguas de baja salinidad hacia el norte y a lo largo de la costa colombiana, permitiendo la entrada de aguas oceánicas con temperaturas más bajas, provenientes del frente ecuatorial de transición (Stevenson et al., 1970).

La primera pauta típica del sistema de circulación superficial se manifiesta de agosto a diciembre, cuando la CCE está desarrollándose totalmente y la corriente Ecuatorial del Sur es muy fuerte, especialmente al norte del Ecuador. Esta situación es la más estable y la que más perdura durante el año y se da cuando la ZCIT se encuentra a los $10^{\circ} \mathrm{N}$.

La segunda pauta típica se da de febrero a abril, cuando la ZCIT se encuentra cerca de los $3^{\circ} \mathrm{N}$. Se desarrollan dos remolinos frente a Centroamérica, uno ciclónico alrededor del domo de Costa Rica y el otro anticiclónico, alrededor de los $5^{\circ} \mathrm{Ny}$ los $88^{\circ} \mathrm{W}$. La corriente Surecuatorial es más débil y las corrientes al Este se manifiestan, ocasionalmente, cerca del Ecuador. La corriente del Perú es también, relativamente, más débil. 
La tercera pauta típica de la circulación se desarrolla de mayo a julio, cuando la CCE se forma de nuevo, debido a que la ZCIT se encuentra cerca de los $10^{\circ} \mathrm{N}$. La CCE fluye hacia el norte, penetrando en la corriente costera de Costa Rica que durante este período corre a lo largo de América Central hasta Cabo Corrientes, en Colombia. De julio a agosto, la corriente Ecuatorial del Norte es alimentada por las aguas del Pacífico Oriental Tropical (Wyrtki, 1965).

Los cambios en la pauta de la circulación están, claramente, relacionados con las variaciones en la intensidad y localización del sistema principal de los vientos. Desde enero hasta marzo predomina el viento del Norte, lo cual corresponde a la máxima posición sur de la ZCIT. De junio a octubre hay debilitamiento de los vientos Alisios del Noreste y en septiembre su área de influencia y su fuerza son mínimas. En el período de junio a noviembre los vientos Alisios del Sureste predominan en la CPC (Málikov, 1998).

Es por esto que durante el año en las capas superficiales se observan dos máximos y dos mínimos de temperatura. Desde la región costera hacia el sector central de la CPC los dos máximos son casi iguales y se observan en junio y diciembre. Los mínimos de temperatura se observan de febrero a marzo y de septiembre a octubre (Málikov, 1998). La diferencia de las capas superficiales de la región oceánica de la CPC con respecto a otras regiones radica en que el máximo de temperatura observado de diciembre a enero es superior al de febrero a marzo, a excepción de la zona costera del sur.

En cuanto a la salinidad se observa de manera generalizada una gran diferencia entre aguas costeras de bajas salinidades y aguas de regiones oceánicas con salinidades más altas. El cambio de salinidad en la capa superficial del mar en la zona costera del Pacífico Colombiano está influenciada por las precipitaciones y por el cambio de intensidad de los aportes de las desembocaduras de los ríos, cuya mezcla con el agua de mar se observa en la capa $0-10 \mathrm{~m}$ donde las oscilaciones son iguales (Málikov, 1998). La distribución de precipitación y de la intensidad del aporte de los ríos, igualmente, está asociada con los cambios de la ZCIT (Tchansev y Cabrera, 1998).

Un máximo significativo de salinidad se presenta en febrero marzo (Fig. 3.2 - 3.3) y un mínimo en diciembre (Fig. 3.11), con los cuales se observan otros máximo y mínimo pero menos representativos (Málikov, 1998).
Las aguas superficiales costeras tienden a hacerse menos salinas de abril hasta noviembre (Fig. 3.4 - 3.10), aumentando su extensión superficial; de diciembre a febrero (Fig. 3.11 y 3.2) son de áreas más pequeñas y con salinidades más altas. Estas salinidades bajas concuerdan con lo establecido anteriormente sobre los meses más lluviosos del año (abril, mayo, junio, septiembre, octubre y noviembre) (Fig. 2.4).

Las aguas dulces se distribuyen en la superficie desde la costa hacia el mar, las de mayor salinidad llegan desde el mar hacia la costa y en un lugar de encuentro se mezclan (Abuziarov, 1988). En la región de mezcla, las aguas conforman una estructura de salinidad más conservativa que en otros lugares, esta estructura tiene iguales oscilaciones en la capa 0-20 metros. En esta región la salinidad tiene un máximo en marzo abril y un mínimo en octubre (Málikov, 1998).

En la región oceánica el comportamiento varía de febrero a marzo, cuando las salinidades aumentan hasta su valor máximo (Fig. 3.2-3.3); de abril a junio disminuyen (Fig. 3.43.6); de agosto a septiembre (Fig. 3.7-3.8) aumentan su valor y de octubre a diciembre (Fig. 3.9-3.11) disminuyen nuevamente siendo noviembre el mes que presenta las salinidades más bajas (Málikov, 1998).

En general, la región Ecuatorial presenta máximos de salinidad en marzo y mínimos en diciembre (Bubnov, 1990 y Doronin, 1986). Esto se aprecia en la capa superficial del Pacífico colombiano.

\section{Febrero}

La temperatura promedio en febrero presenta condiciones homogéneas $\left(26.7^{\circ} \mathrm{C}\right.$ para la costa y $26.9^{\circ} \mathrm{C}$ para aguas oceánicas), alteradas por pequeños núcleos de altas temperaturas alrededor de $\operatorname{los} 28^{\circ} \mathrm{C}$ en algunos puntos de la costa y la región central (Figura 3.2). También se observa en el límite oeste del área de estudio, sobre el meridiano $82^{\circ} \mathrm{W}$, entre latitudes 3 y $5^{\circ} \mathrm{N}$, condiciones cálidas que no alcanzan a llegar a los $81^{\circ} 30^{\prime} \mathrm{W}$.

La salinidad promedio en febrero muestra las condiciones de la costa con valores bajos, plenamente diferenciados del área oceánica de la CPC, (Fig. 3.2). Los valores costeros se hallan por debajo de las 30 y se localizan desde los $3^{\circ} \mathrm{N}$ hasta 

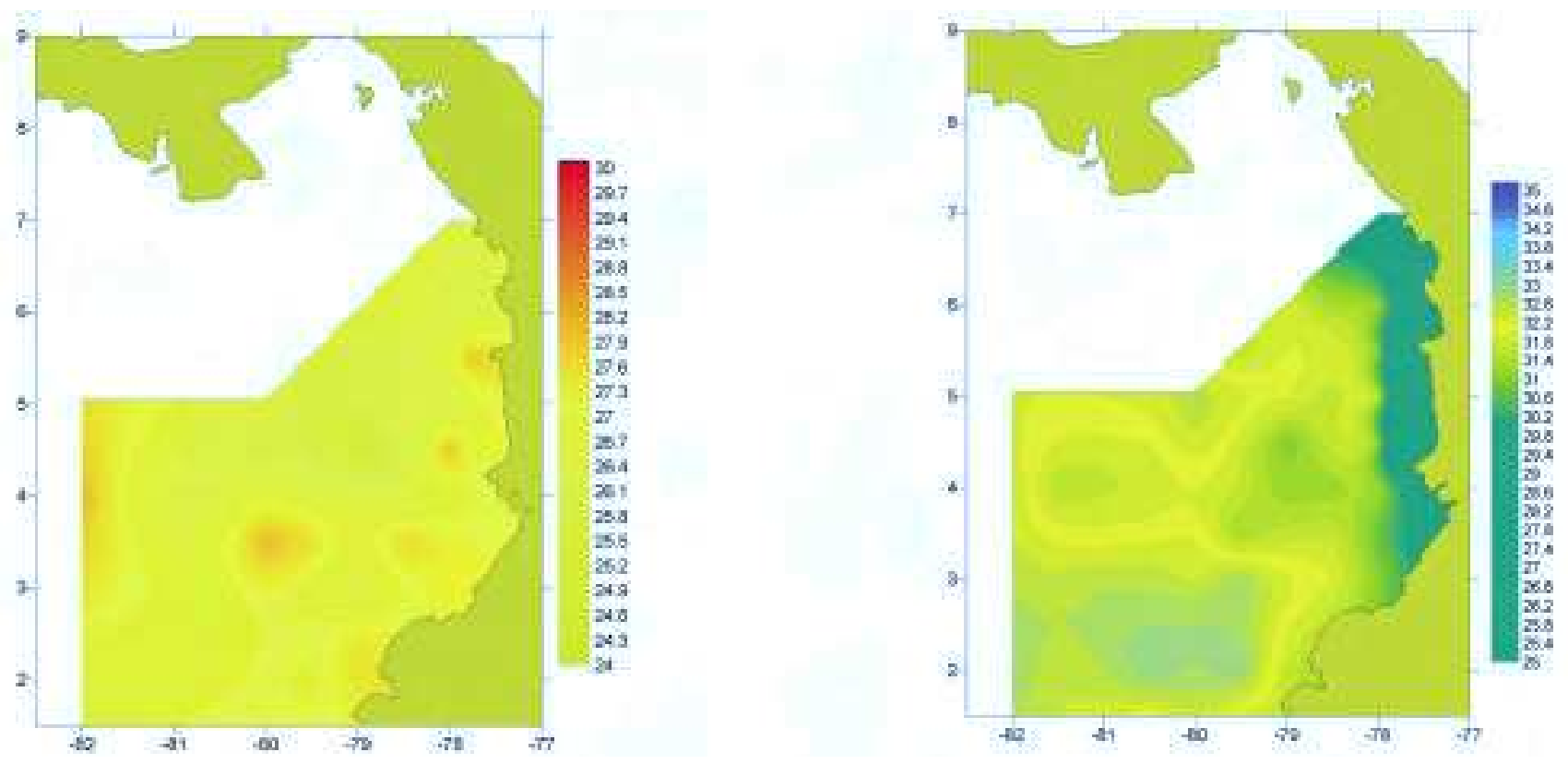

Figura 3.2. - Temperatura $\left({ }^{\circ} \mathrm{C}\right)$ y salinidad superficial del mar en febrero

el límite norte del área de estudio. Las condiciones en el sector sur oceánico de la costa se presentan con valores que superan las 32, con un máximo de 33. Se observa una franja de salinidad constante de 32, que cruza la región oceánica de sur a noreste hasta los $3^{\circ} \mathrm{N}$, después se aleja de la costa con dirección oeste haciendo un giro y regresándose hacia la zona costera a $\operatorname{los} 5^{\circ} \mathrm{N}$. Alrededor de esta franja los valores de salinidad son un poco menores

Teniendo en cuenta que febrero es el mes menos lluvioso de todo el año, se puede observar que las salinidades son en general altas para la CPC y que la franja costera de bajas salinidades es reducida.

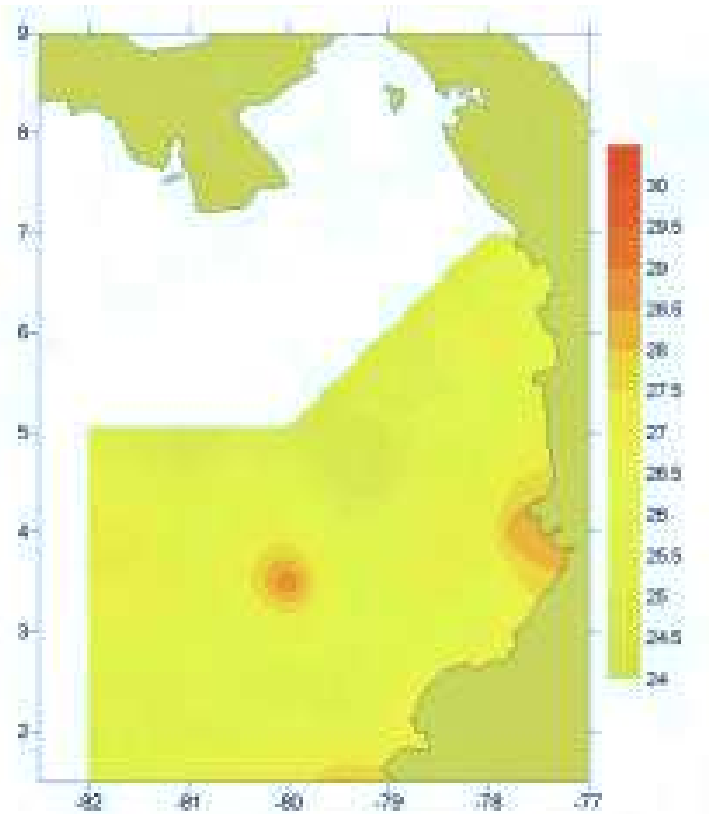

\section{Marzo}

La temperatura promedio de marzo se caracteriza por presentar en forma generalizada valores bajos, $26.2^{\circ} \mathrm{C}$ para la costa y $26^{\circ} \mathrm{C}$ para la sección oceánica, excepto en un pequeño sector con aguas cálidas cercanas a la costa frente a la bahía de Buenaventura (Fig. 3.3) con temperaturas de $27.9^{\circ} \mathrm{C}$.

En cuanto a la salinidad, en este mes se registran promedios altos sobre los sectores oceánicos de la cuenca de 33.6 y condiciones de salinidades más bajas en la zona costera, partiendo de los 4 hacia los $7^{\circ} \mathrm{N}$ (Fig. 3.3) con un promedio de 32.2. Los valores máximos de 34.4 se dan en tres áreas

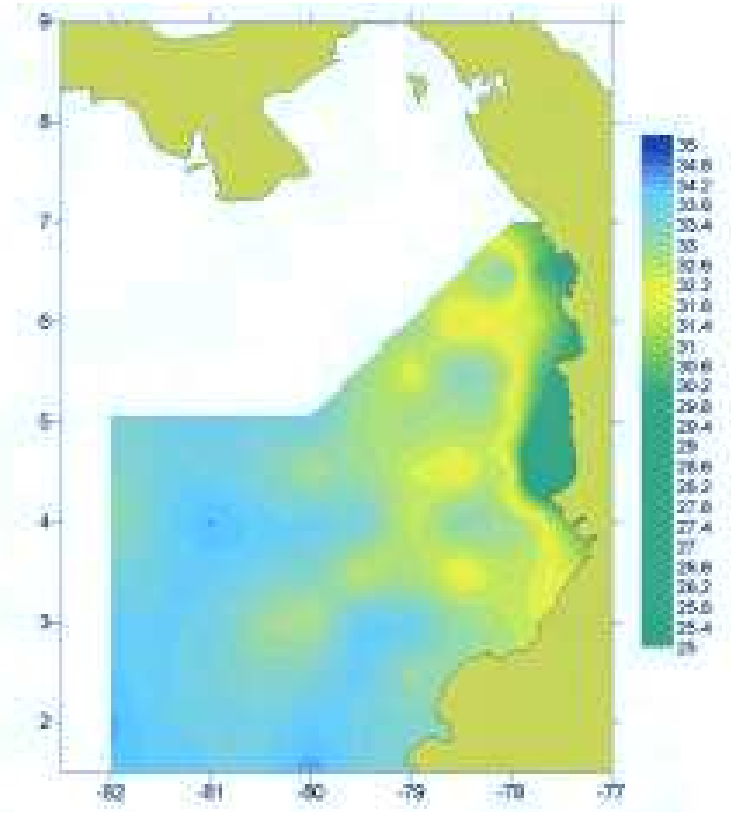

Figura 3.3. - Temperatura $\left({ }^{\circ} \mathrm{C}\right)$ y salinidad superficial del mar en marzo. 

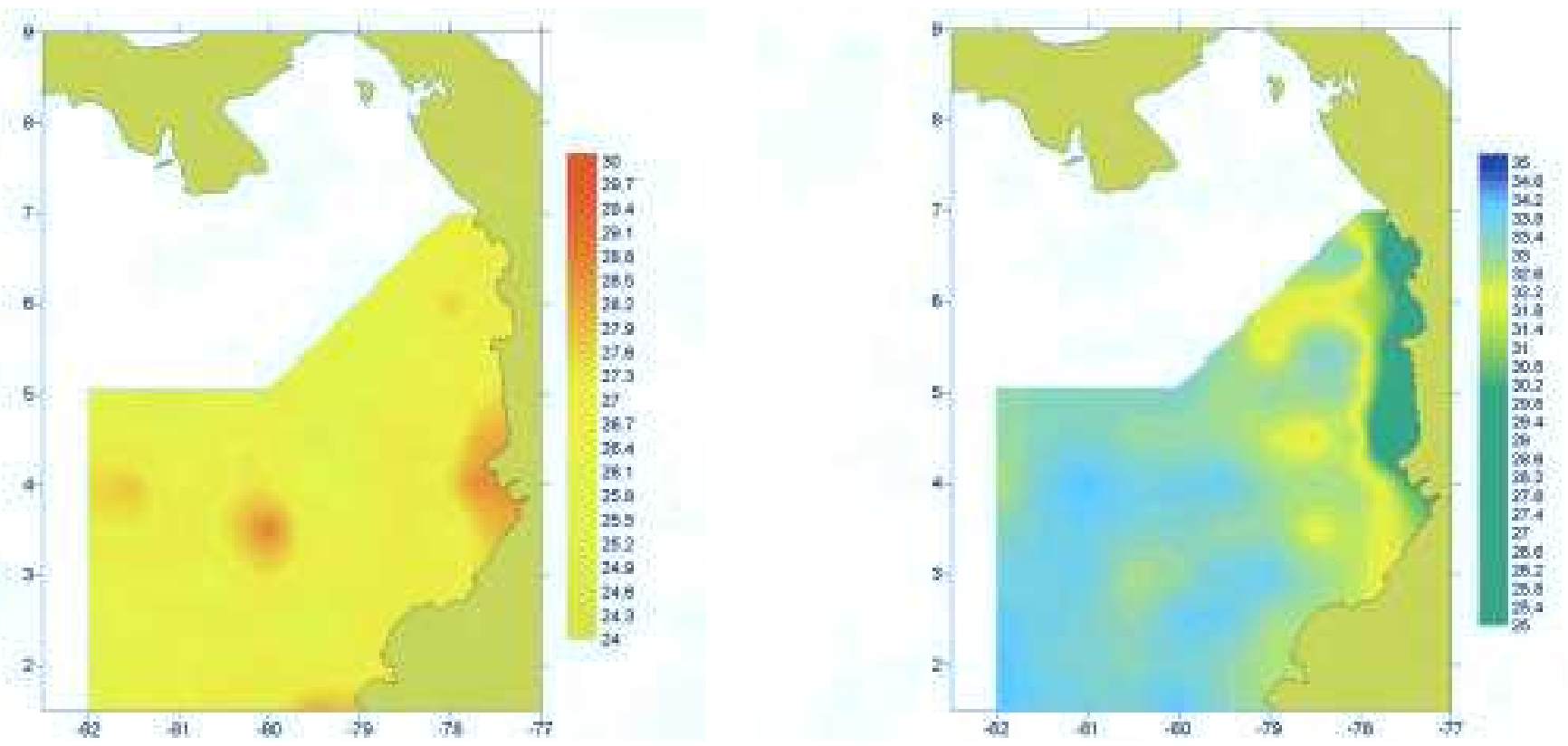

Figura 3.4. - Temperatura $\left({ }^{\circ} \mathrm{C}\right)$ y salinidad superficial del mar en abril

pequeñas definidas en la región oceánica. Se observan valores intermedios entre las dos zonas, que las separan y en donde se da la mezcla de las aguas costeras y oceánicas.

Abril

Las condiciones de temperatura para abril son alteradas por núcleos de aguas cálidas ubicados, indistintamente, sobre la CPC (Fig. 3.4), con valores entre los 28 y $29^{\circ} \mathrm{C}$. La temperatura promedio de la región oceánica es de $26.6^{\circ} \mathrm{C}$ y para la costa de $26.8^{\circ} \mathrm{C}$, presentándose en la bahía de Buenaventura uno de los núcleos cálidos más grandes.
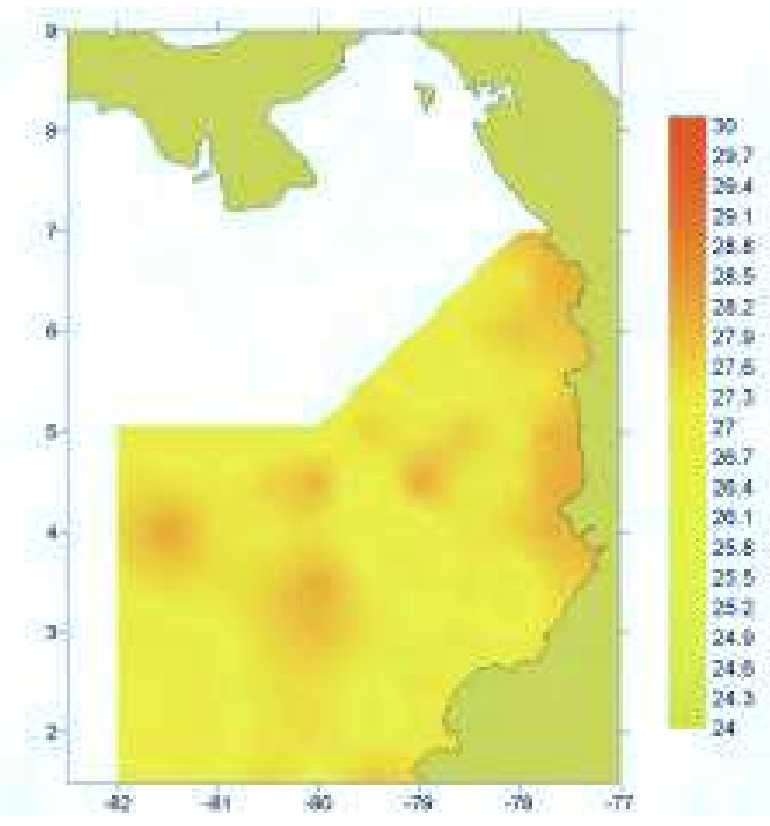

Al igual que en los meses anteriores, en abril se presentan condiciones de salinidades bajas en la zona costera que se diferencian de manera marcada con las altas del sector oceánico (Fig. 3.4). Las bajas salinidades de la costa presenta valores por debajo de 27 entre los 4 y $7^{\circ} \mathrm{N}$ (promedio 32). En el sector oceánico se presenta un promedio de 33.5.

\section{Mayo}

Las condiciones de la temperatura para mayo en la CPC (Fig. 3.5) son poco definidas por las regiones costera y

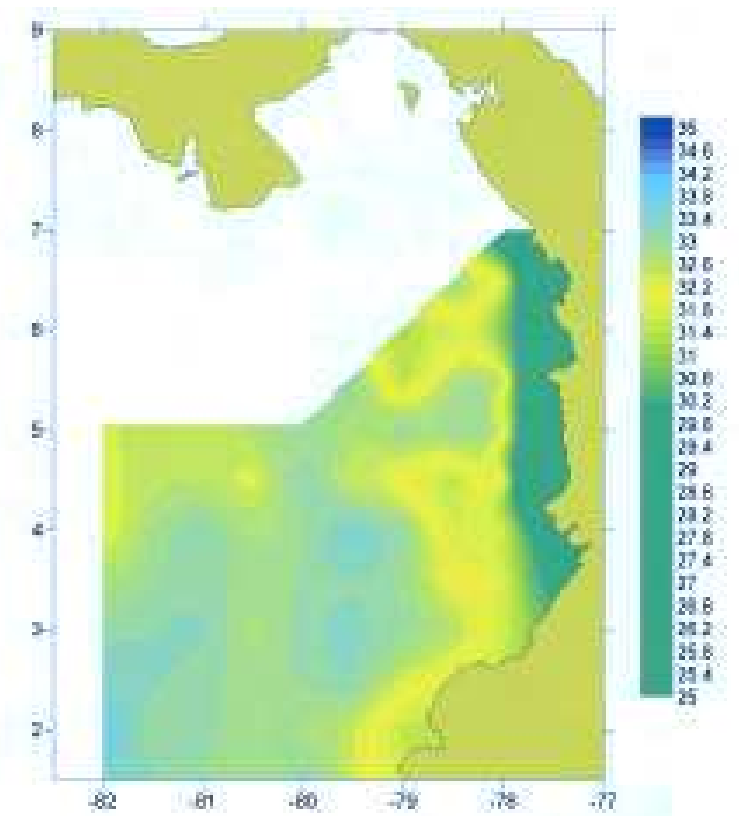

Figura 3.5. - Temperatura $\left({ }^{\circ} \mathrm{C}\right)$ y salinidad superficial del mar en mayo 


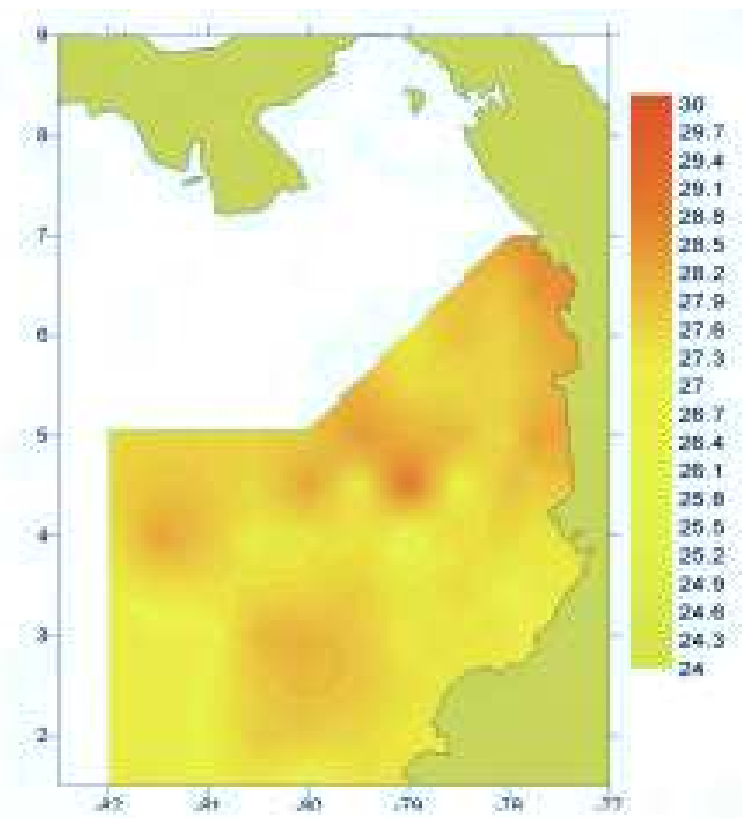

Figura 3.6. - Temperatura $\left({ }^{\circ} \mathrm{C}\right)$ y salinidad superficial del mar en junio

oceánica. Se presentan temperaturas con promedios superiores a los tres meses anteriores $27.4^{\circ} \mathrm{C}$ para la costa y $27.2^{\circ} \mathrm{C}$ para las aguas oceánicas.

La salinidad promedio de mayo presenta los valores más bajos en la costa (promedio de 31.4 ) y un poco más altos en el sector oceánico (promedio 32.9) (Fig. 3.5). Se observa una franja de salinidad constante a 32 que separa las dos zonas y corre a lo largo de la CPC desde los $1^{\circ} 30^{\prime} \mathrm{N}$ hasta los $6^{\circ} \mathrm{N}$ y entre los 78 y los $79^{\circ} \mathrm{W}$. A diferencia de los meses anteriores la región costera está toda cubierta por salinidades bajas.

Junio

La temperatura en junio presenta valores menores al sur de la CPC; sobre el centro se combinan las temperaturas bajas con las altas y hacia el norte predominan las temperaturas altas (Fig. 3.6). El rango de valores que cubre toda la cuenca se ubica entre los 26 y $29^{\circ} \mathrm{C}$, con temperaturas promedio de $27.5^{\circ} \mathrm{C}$.

En este mes se observa que la salinidad presenta las condiciones propias de la costa con bajos valores de salinidad y un poco más elevados en el sector oceánico (Fig. 3.6). La costa cuenta con valores promedio de 30.6, mientras que el sector oceánico alcanza un promedio de 32.5. Se puede identificar una franja de salinidad constante de 32, que separa la sección costera de la oceánica, pero a diferencia de abril y mayo, ésta se propaga más hacia el océano.

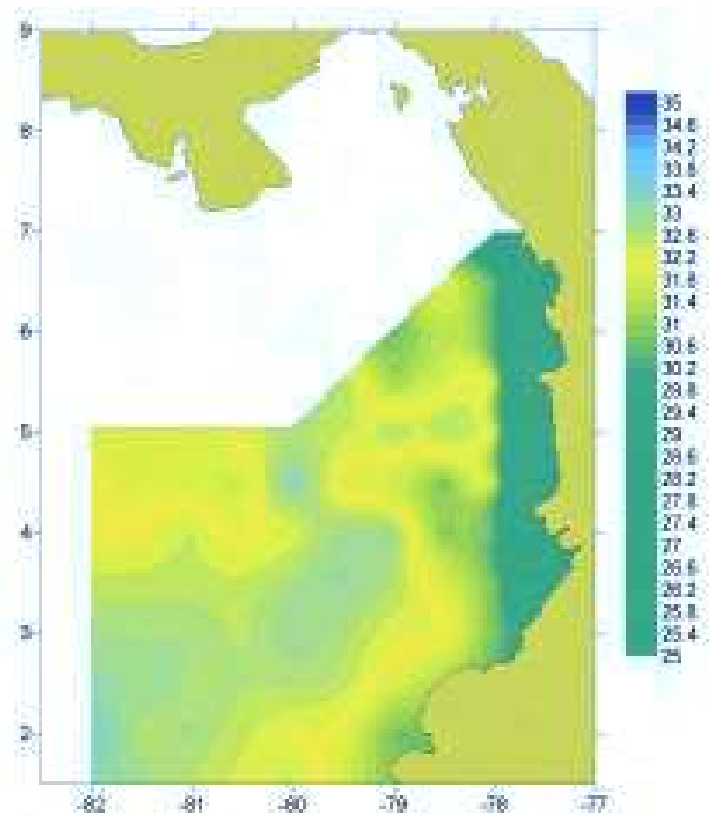

Agosto

En este mes la temperatura desciende en forma generalizada para la CPC quedando solamente pequeñas áreas con temperaturas superiores a $27.5^{\circ} \mathrm{C}$ ubicadas en la región norte y central (Fig. 3.7). Los valores de TSM de la cuenca se ubican entre 26 y $28^{\circ} \mathrm{C}$. El promedio de temperatura para la zona costera es de $27.3^{\circ} \mathrm{C}$, mientras que en el océano fue similar a febrero con valores de $26.9^{\circ} \mathrm{C}$

La salinidad muestra en este mes las condiciones propias de la costa con áreas de bajas salinidades, las cuales van ensanchándose, paulatinamente, hacia la región central (Fig. 3.7). Los valores promedio en la costa son de 30 y en el sector oceánico de 32.5. Se puede observar la isohalina de 32 que corre a lo largo de la CPC, de manera similar al mes de febrero.

\section{Septiembre}

Las condiciones promedio de temperatura para septiembre muestran que el agua de la CPC adelanta un proceso de enfriamiento a medida que finaliza el año (Fig. 3.8). El promedio para la costa es de $27^{\circ} \mathrm{C}$ y en el sector oceánico de $26.5^{\circ} \mathrm{C}$. Los valores máximos se dan en la parte norte de la cuenca entre 5 y $7^{\circ}$ de latitud Norte.

Las salinidades en septiembre dividen notablemente el sector costero del oceánico con una isohalina que atraviesa la cuenca en 

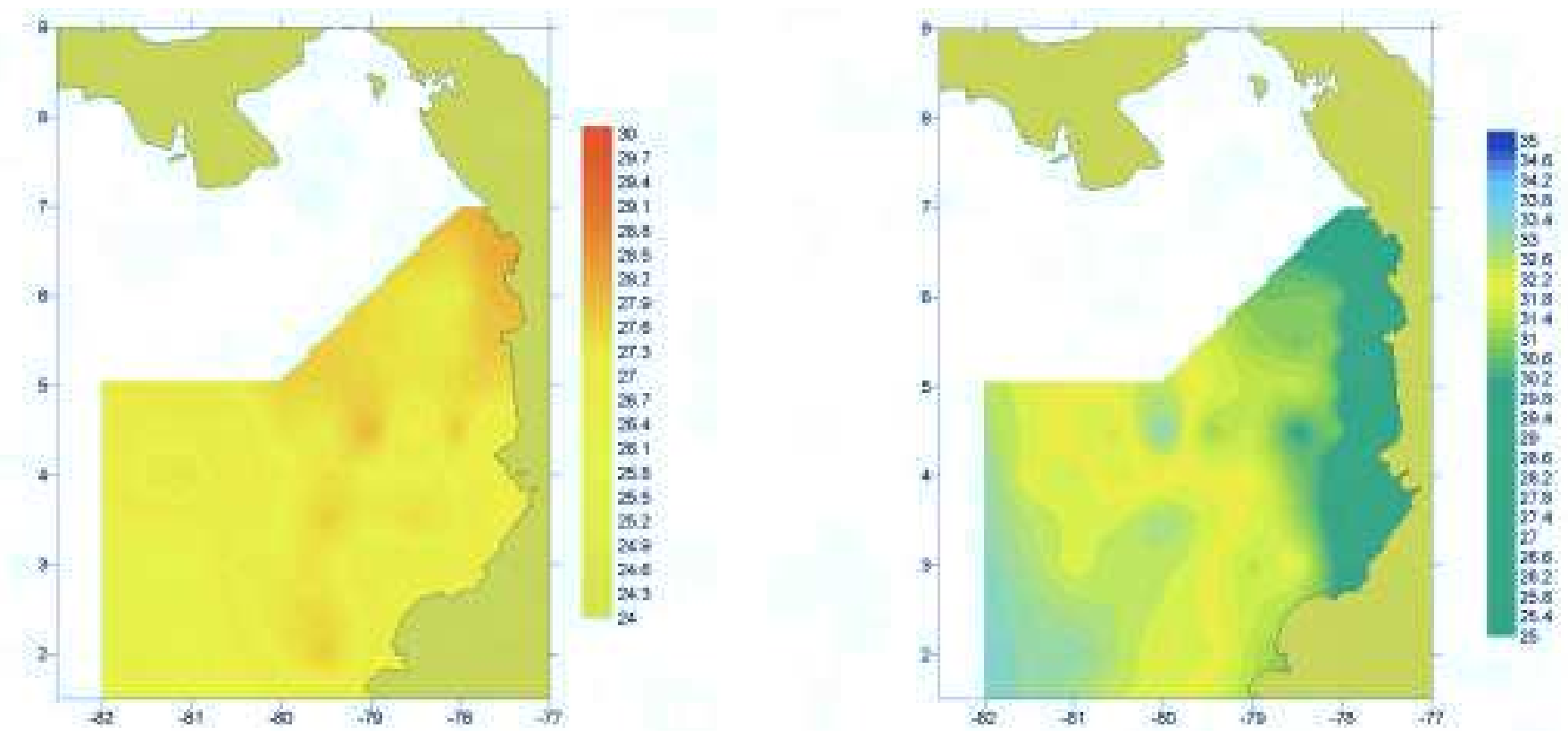

Figura 3.7. - Temperatura $\left({ }^{\circ} \mathrm{C}\right)$ y salinidad superficial del mar en agosto

sentido longitudinal entre los meridianos $79^{\circ}$ y $80^{\circ} \mathrm{W}$ (Fig. 3.8). Hacia el sector costero los valores descienden por debajo de 31, llegando en el sector oceánico a alcanzar registros de 33.6.

\section{Octubre}

Las condiciones en octubre (Fig. 3.9) muestran una continuación en el descenso de la temperatura en comparación con el mes anterior; presentándose pocas áreas cálidas que se ubican hacia el extremo norte de la zona costera y una pequeña región central entre $\operatorname{los} 79^{\circ}$ y $80^{\circ} \mathrm{W}$. Los promedios de temperatura son de $27^{\circ} \mathrm{C}$ para la costa y de $26.4^{\circ} \mathrm{C}$ para las aguas oceánicas.
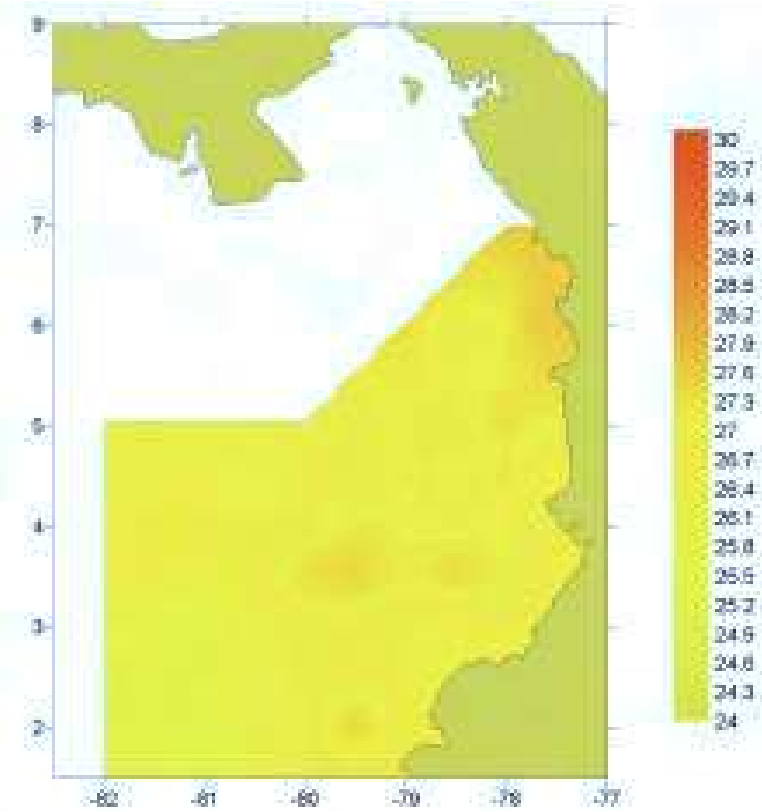

La salinidad presenta en este mes diferencias similares a las encontradas en meses anteriores entre la costa y el sec tor oceánico (Fig. 3.9). Se observa la isohalina de 32 dividiendo los sectores de la cuenca en dos, costero y oceánico; y a partir de ésta, los valores descienden hacia la costa (promedio de 29.7) y aumentan hacia el océano (promedio de 32.5 ).

\section{Noviembre}

La temperatura en este mes presenta condiciones similares al anterior, con un área mayor en la que se presentan

Figura 3.8. - Temperatura $\left({ }^{\circ} \mathrm{C}\right)$ y salinidad superficial del mar en septiembre

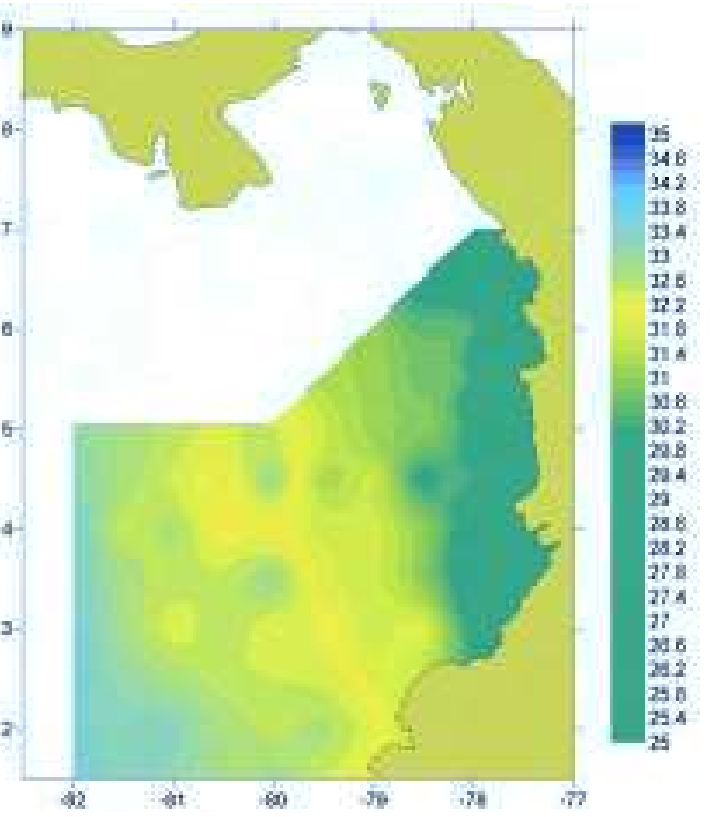



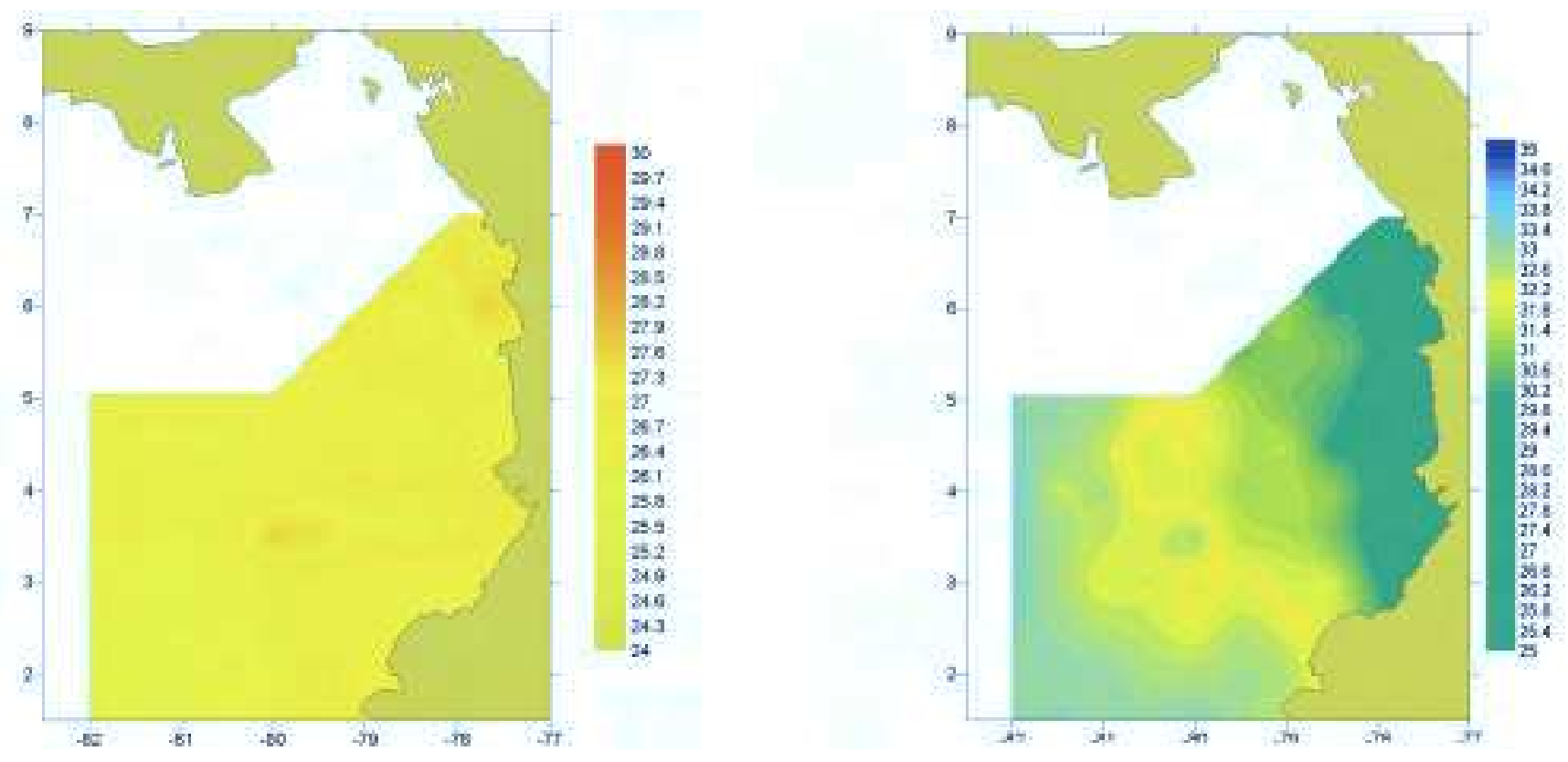

Figura 3.9. - Temperatura $\left({ }^{\circ} \mathrm{C}\right)$ y salinidad superficial del mar en octubre

temperaturas entre 27.5 y $28^{\circ} \mathrm{C}$ (Fig. 3.10). La temperatura promedio para la costa es de $27.3^{\circ} \mathrm{C}$ y para el sector costero de $26.9^{\circ} \mathrm{C}$, evidenciándose un leve calentamiento de la CPC.

Las condiciones costeras de bajas salinidades abarcan un sector más extenso que en los meses anteriores, desplazando las condiciones del sector oceánico más hacia el Oeste (Fig. 3.10). La isohalina de 32.2 se aleja un poco más de la costa, permitiendo que se ubiquen valores menores a los presentados en meses anteriores sobre el sector oceánico.

\section{Diciembre}

En diciembre la temperatura alcanza registros superiores a los promedios que se presentaron en los tres meses anteriores, siendo este comportamiento generalizado para toda la cuenca, registrando valores promedio de $27.7^{\circ} \mathrm{C}$ (Fig. 3.11).

En cuanto a salinidad, en este mes se presentan, al igual que en el mes anterior, bajas salinidades propias de la costa extendiéndose sobre un área oceánica más amplia hacia los $80^{\circ} \mathrm{W}$ (Fig. 3.11). Los valores no superan las 30 en la costa y las 31.6 en la región oceánica, siendo los valores más bajos para este sector.

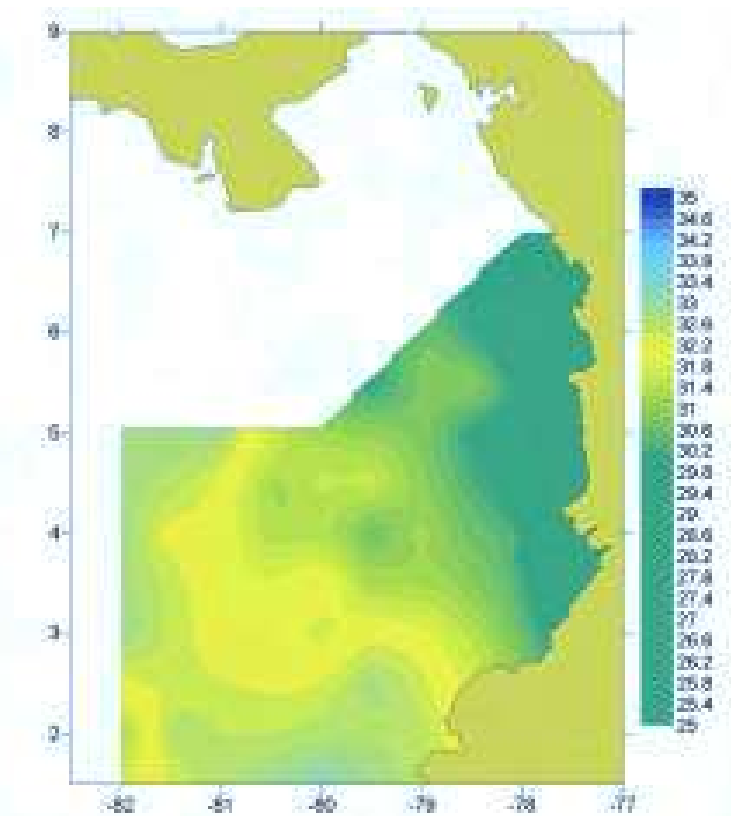

Figura 3.10. - Temperatura $\left({ }^{\circ} \mathrm{C}\right)$ y salinidad superficial del mar en noviembre 

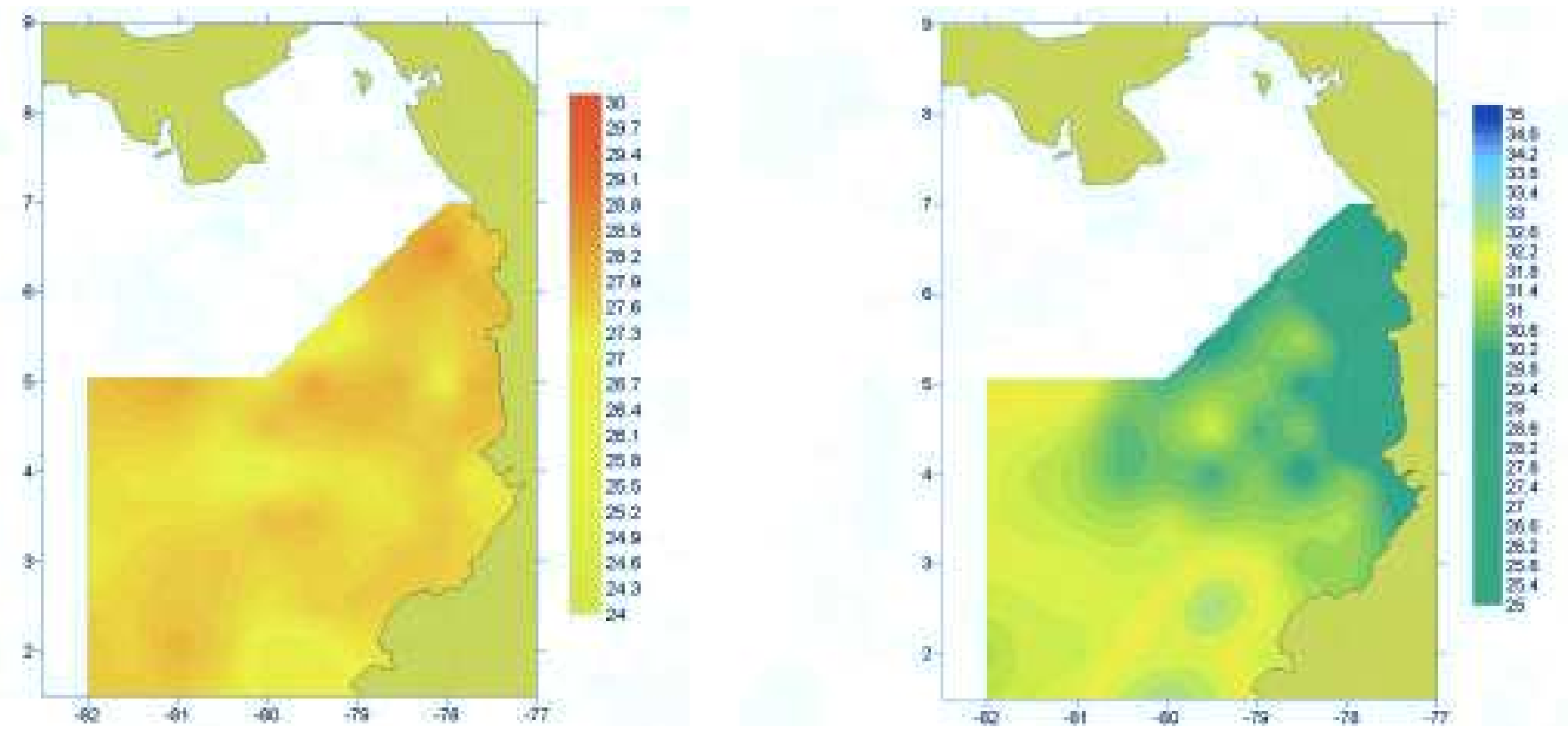

Figura 3.11. - Temperatura $\left({ }^{\circ} \mathrm{C}\right)$ y salinidad superficial del mar en diciembre

En síntesis, la salinidad y la temperatura de las aguas superficiales de la CPC están determinadas por dos factores: las fuentes de agua dulce y la relación evaporaciónprecipitación; los cuales afectan las aguas costeras y los patrones de circulación que influyen en las aguas oceánicas.

Las aguas oceánicas presentan valores de temperatura entre $27-28^{\circ} \mathrm{C}$, las cuales se desplazan hacia la costa, donde la variación es mucho mayor $\left(25-29^{\circ} \mathrm{C}\right)$.

\subsection{DESCRIPCIÓN DE PERFILES VERTICALES DE} TEMPERATURA Y SALINIDAD PROMEDIO ANUALES

La información de temperatura y salinidad fue tomada de estaciones estándar definidas en una grilla (Fig. 3.1) y a profundidades estándar desde la superficie hasta los $500 \mathrm{~m}$ (Málikov, 1998). A partir de esta grilla, se seleccionaron cuatro transeptos perpendiculares a la costa sobre las latitudes $2^{\circ}, 3^{\circ}$, $4^{\circ}$ y $5^{\circ} \mathrm{N}$, y a partir de estos transeptos se realizó la descripción de la variación espacio-temporal de la temperatura y salinidad.

3.3.1. Descripción de la distribución vertical de temperatura promedio anual

En la parte superior del océano se encuentra una capa superficial que puede llegar hasta los 500 metros. En esta capa se presentan mayores variaciones espacio-temporales en sus características hidrológicas debido a su interacción con la atmósfera. La variabilidad encontrada en esta agua es muy amplia, es así como podemos encontrar capas muy homogéneas entre sí, como la capa superior (0-20 m), la cual depende de la mezcla por vientos, convección o circulación de aguas (Pickard, 1975) .

Por debajo del límite de la capa isotérmica se encuentran aguas poco homogéneas, presentándose una zona limítrofe con un brusco gradiente de temperatura llamada termoclina. Ésta divide a las aguas superficiales, más cálidas, menos densas y menos salinas de las aguas intermedias y profundas, más frías, más densas y más salinas (Egorov, 1966).

En las aguas tropicales, la termoclina puede ocupar una profundidad hasta los 100 y 200 metros y ser relativamente estable durante el año. En las aguas templadas de las latitudes medias se localiza a un poco más de profundidad, siendo un fenómeno estacional que ocurre solamente durante la primavera y el verano, y tiende a desaparecer en los mares polares, en los que la temperatura de toda la columna de agua es baja (Doronin, 1980).

En las zonas ecuatoriales y algunas regiones tropicales el balance radiactivo de calor externo es positivo durante todo el año, por lo que la termoclina estacional se conserva con recaídas de temperatura de hasta $10^{\circ} \mathrm{C}$ en sólo $10 \mathrm{~m}$ (Malinin, 1998).

En las latitudes ecuatoriales si la temperatura del agua es de $26^{\circ} \mathrm{C}$ en la superficie, suele ser sólo de $15^{\circ} \mathrm{C}$ en la termoclina 
estacional, que se encuentra de 10 a $150 \mathrm{~m}$ de profundidad (Pickard, 1975)

La termoclina estacional puede ser definida como la región determinada por el balance entre la energía potencial adquirida por el mar, a través de los flujos de flotabilidad en la superficie y la energía cinética transferida por el viento al mar, generando turbulencia y el hundimiento de la termoclina (Emery y Thomson, 1997). Una característica de la termoclina estacional en la zona ecuatorial es que su límite superior no se encuentra a grandes profundidades (Bubnov, 1990).

El límite entre la termoclina estacional y la termoclina permanente es definido como la profundidad máxima anual de la capa de mezcla local, de 50 a 100 m en la región ecuatorial hasta cerca de $700 \mathrm{~m}$ o más en el centro de los grandes giros del Atlántico y el Pacífico (Emery y Thomson, 1997).

La termoclina permanente es establecida por la advección y difusión diapicnal e isopicnal de larga escala. Bajo el límite inferior de la termoclina la temperatura es casi homogénea, disminuyendo lenta pero constantemente hasta llegar al frío del abismo (Teramoto, 1993).

La temperatura a $0 \mathrm{~m}$ en aguas costeras de la CPC es menor que en las capas subsuperficiales, mientras que en las otras regiones del área de estudio la temperatura siempre es mayor en superficie. Esto puede ser causado por los ríos, los cuales riegan aguas con menor temperatura y permanecen en la superficie expandiéndose sin mezclarse verticalmente (Málikov, 1998).

La misma forma de distribución de las oscilaciones entreanuales en las aguas costeras se observa en la capa 0-30 $\mathrm{m}$. En la región central del área de estudio se observa una estructura vertical homogénea en la capa 0-50 m y en las aguas más oceánicas esta capa homogénea de iguales oscilaciones mensuales se observa en toda la columna de agua 0-500 m (Málikov, 1998).

Desde los 50 hasta los $75 \mathrm{~m}$ ocurren cambios en la estructura de las oscilaciones entreanuales de temperatura y los cambios más grandes se observan en la zona costera del norte. Aquí se ven las oscilaciones medio-anual de temperatura donde se observa un mínimo en diciembre enero y un máximo en agosto. Desde $75 \mathrm{~m}$ las oscilaciones de las aguas tienen un desfase con respecto a la capa superficial, con un máximo en marzo abril y un mínimo en enero. Esta estructura se observa por la influencia de los caudales de los ríos. También puede ser que esta masa de agua se conforma por la dinámica vertical de las aguas profundas. La misma estructura se observa en aguas costeras del sur a los $500 \mathrm{~m}$ (Málikov, 1998).

En otras partes de la CPC la estructura de las oscilaciones en la capa de $50 \mathrm{~m}$ casi no cambia, pero aumenta su amplitud. Por ejemplo, desde enero hasta marzo la temperatura baja más de $10^{\circ} \mathrm{C}$. Desde los $75 \mathrm{~m}$ hasta los $500 \mathrm{~m}$ las oscilaciones de temperatura son similares a las presentadas en la capa superficial, pero tienen menor amplitud $\left(<6^{\circ} \mathrm{C}\right)$. La estructura que se observa en la zona costera a mayores profundidades es muy diferente a la de otras regiones del Pacífico colombiano (Málikov, 1998).

Las oscilaciones anuales de la temperatura en la CPC presenta dos máximos y dos mínimos: diciembre y junio son los meses de calentamiento de aguas y profundización de la termoclina; mientras que en marzo y septiembre las aguas se enfrían y se eleva la termoclina hacia aguas más superficiales.

En esta publicación se muestran únicamente las gráficas de junio, diciembre, marzo y septiembre, por ser los meses que representan los calentamientos y enfriamientos más significativos durante el año, respectivamente.

Se utilizan los transeptos: Latitud $2^{\circ} \mathrm{N}$, Latitud $3^{\circ} \mathrm{N}$, Latitud $4^{\circ} \mathrm{N}$ y Latitud $5^{\circ} \mathrm{N}$. El primero por estar influenciado por aguas de tipo oceánico en la parte occidental y aguas frías provenientes del sur, así como aguas del continente en la parte oriental, donde se encuentra la bahía de Tumaco. El segundo fue escogido porque en él se encuentra la isla de Gorgona y recibe la influencia del Sur y del Oeste.

El tercer transepto se seleccionó por ser el más extenso de los cuatro y por contar con el mayor número de observaciones. En él se encuentra la isla de Malpelo y la desembocadura del río San Juan; recibe las aguas provenientes del golfo de Panamá por medio de la corriente del Chocó al norte de la región de estudio, las aguas oceánicas por medio de la Contracorriente Ecuatorial, CCE, al occidente de la CPC y las aguas de la corriente fría del sur.

El último transepto fue elegido por ser el más nórdico, con mayor influencia de la CCE y de la corriente de Panamá. En él desemboca el río Baudó presentando variaciones costeras con respecto al resto del litoral Pacífico colombiano. 
Transepto en la Latitud $2^{\circ} \mathrm{N}$ (entre los $79^{\circ} \mathrm{W}$ y los $82^{\circ} \mathrm{W}$ )

Se observa que en la costa las isotermas horizontales permanecen constantes; en los primeros meses del año aparecen más profundas, y entre agosto y octubre se elevan a aguas más superficiales (Fig. 3.12 - 3.15).

En los primeros $20 \mathrm{~m}$ de profundidad, aparece casi durante todo el año una capa homogénea con temperaturas constantes de $27^{\circ} \mathrm{C}$ en la costa de la bahía de Tumaco y $26^{\circ} \mathrm{C}$ en las aguas oceánicas, variando mensualmente sólo en su grosor (10 - 20 m).

Por debajo de esta capa, se encuentra la termoclina, de 30 - $50 \mathrm{~m}$ de grosor, con isotermas poco oscilantes de Este a Oeste y una variación de la temperatura a nivel vertical entre $26^{\circ} \mathrm{C}$ a $18^{\circ} \mathrm{C}$. Cabe anotar que la isoterma que limita la parte inferior de la termoclina no es siempre la de $18^{\circ} \mathrm{C}$, sino que varía mensualmente entre 15 y $19^{\circ} \mathrm{C}$; observándose que en septiembre y octubre la isoterma $15^{\circ} \mathrm{C}$ se localiza a los 50 $\mathrm{m}$, pero el resto del año ésta se profundiza hasta más de 100 $\mathrm{m}$, principalmente en diciembre (Fig. 3.15) y febrero.

Después de la termoclina las isotermas no presentan grandes fluctuaciones, con algunas variaciones en la parte central, donde tiende a elevarse como en marzo (Fig. 3.12), abril, mayo y junio (Fig. 3.13). En la región oceánica se presenta un hundimiento de las isotermas similar al registrado en abril, mayo, junio (Fig. 3.13) y diciembre (Fig. 3.15).

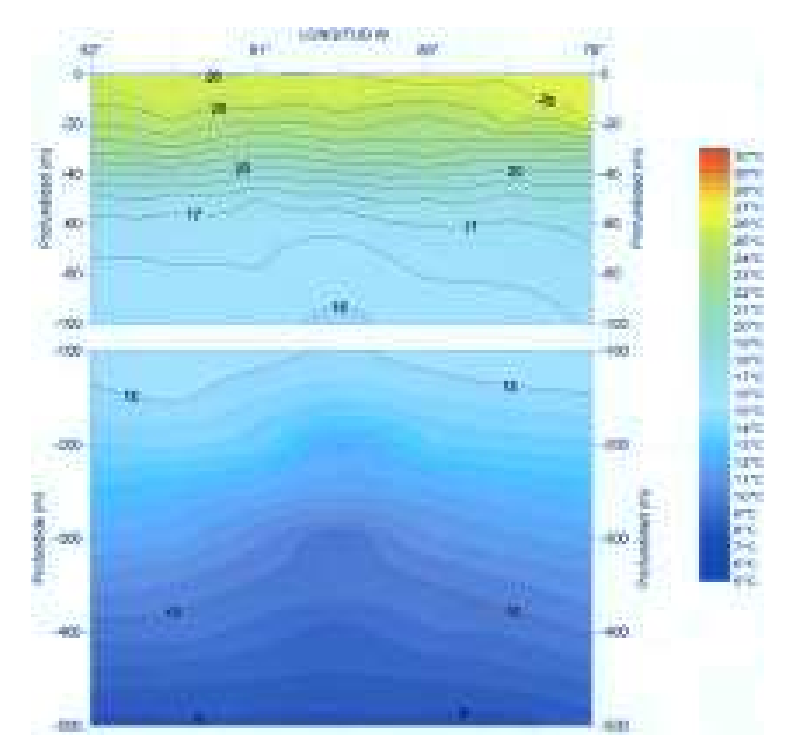

Figura 3.12. - Variación vertical de la temperatura $\left({ }^{\circ} \mathrm{C}\right)$ promedio en el transepto $2^{\circ} \mathrm{N}$, marzo

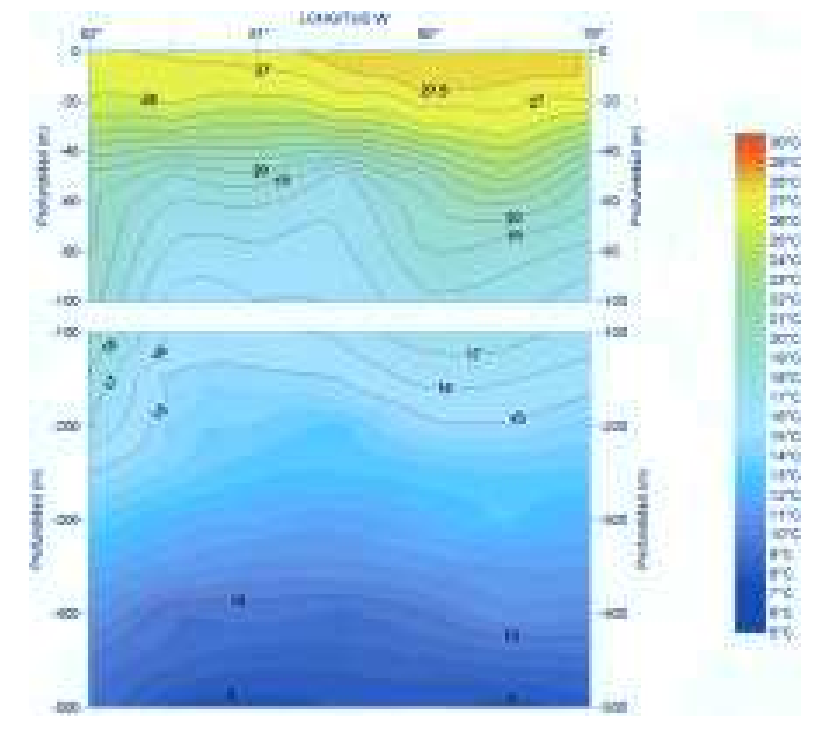

Figura 3.13. - Variación vertical de la temperatura $\left({ }^{\circ} \mathrm{C}\right)$ promedio en el transepto $2^{\circ} \mathrm{N}$, junio

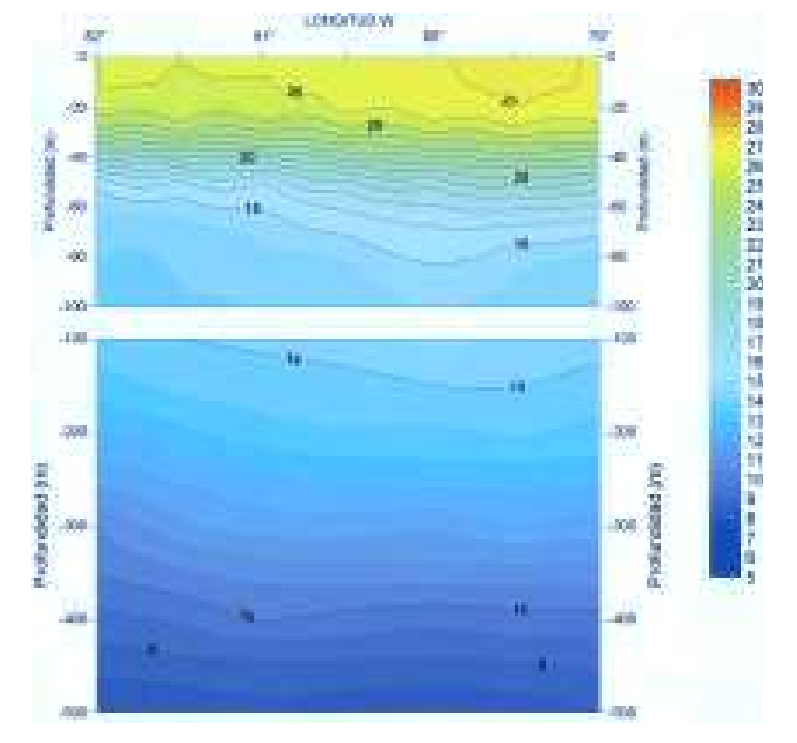

Figura 3.14. - Variación vertical de la temperatura $\left({ }^{\circ} \mathrm{C}\right)$ promedio en el transepto $2^{\circ} \mathrm{N}$, septiembre.

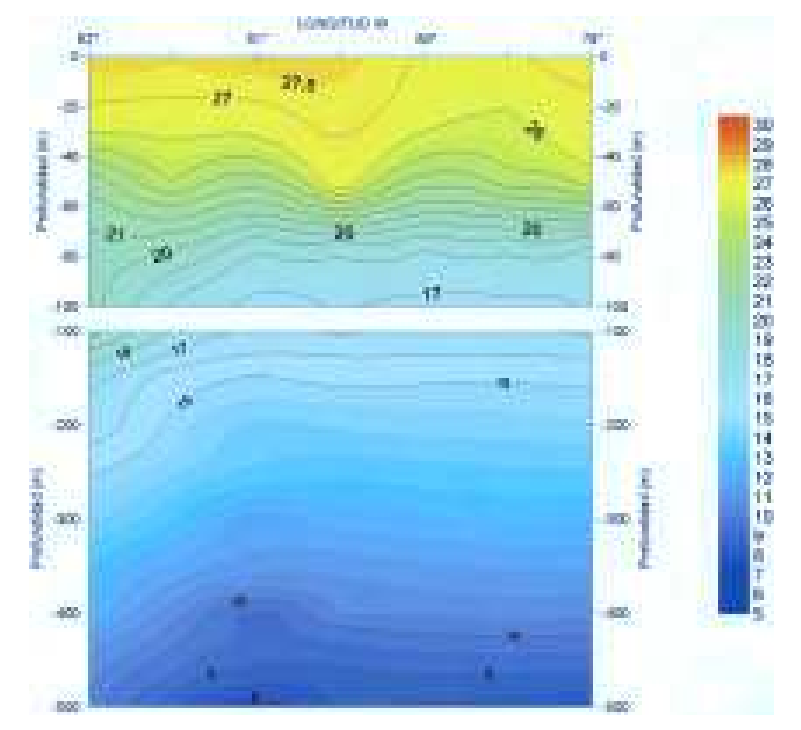

Figura 3.15. - Variación vertical de la temperatura $\left({ }^{\circ} \mathrm{C}\right)$ promedio en el transepto $2^{\circ} \mathrm{N}$, diciembre 
Transepto en la Latitud $3^{\circ} \mathrm{N}$ (entre los $78^{\circ} \mathrm{W}$ y los $82^{\circ} \mathrm{W}$ )

La capa homogénea característica de los primeros $20 \mathrm{~m}$ está bien identificada desde junio (Fig. 3.17) hasta diciembre (Fig. 3.19), con variaciones en la temperatura que separan la región costera $\left(27^{\circ} \mathrm{C}\right)$ y oceánica $\left(26^{\circ} \mathrm{C}\right)$. Esta capa se confunde o desaparece en marzo (Fig. 3.16), abril y mayo porque la termoclina se eleva hasta la superficie.

La termoclina varía de $26^{\circ} \mathrm{C}$ hasta $17^{\circ} \mathrm{C}$ en un espesor de $80 \mathrm{~m}$ aproximadamente (cerca de $1^{\circ} \mathrm{C}$ por cada $7 \mathrm{~m}$ ). En agosto, septiembre (Fig. 3.18) y octubre se presenta la isoterma de los $15^{\circ} \mathrm{C}$ como límite inferior de la termoclina, variando el resto del año entre $16^{\circ}-18^{\circ} \mathrm{C}$.

A partir de los $100 \mathrm{~m}$ no es visible la termoclina estacional. Aparecen isotermas con descensos de temperatura de $1^{\circ} \mathrm{C}$ cada 50 - $80 \mathrm{~m}$ y hundimientos en la región costera $\left(79^{\circ} \mathrm{W}\right) \mathrm{de}$ diciembre (Fig. 3.19) a febrero.

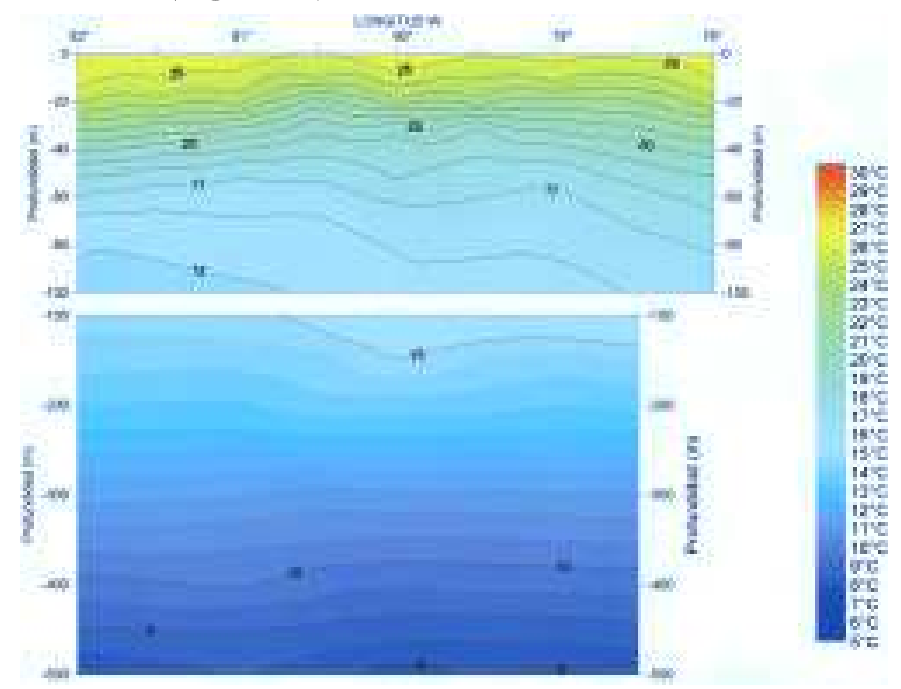

Figura 3.16. - Variación vertical de la temperatura $\left({ }^{\circ} \mathrm{C}\right)$ promedio en el transepto $3^{\circ} \mathrm{N}$, marzo.
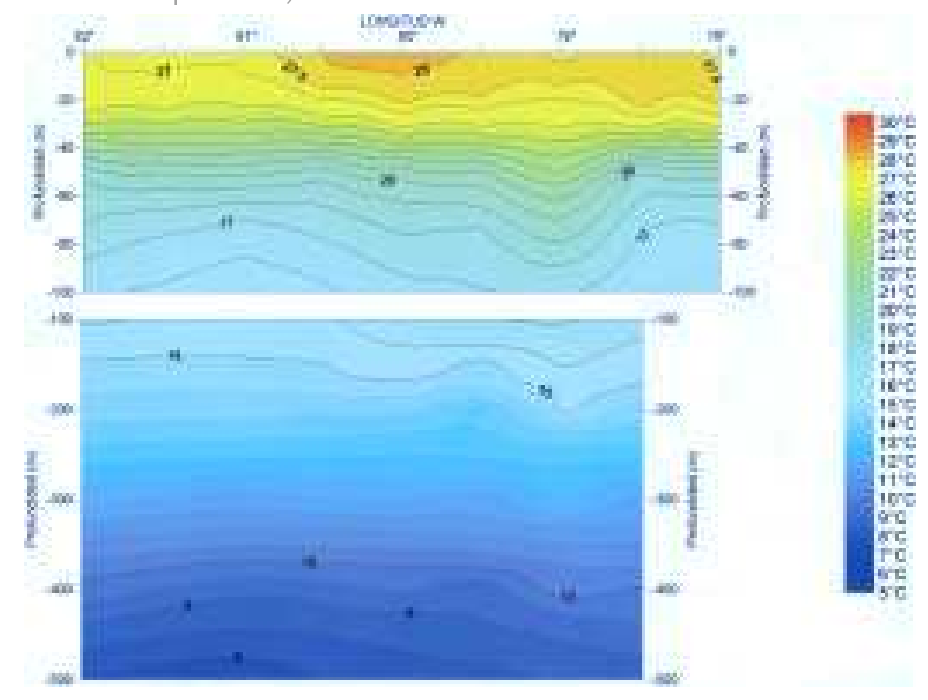

Figura 3.17. - Variación vertical de la temperatura $\left({ }^{\circ} \mathrm{C}\right)$ promedio en el transepto $3^{\circ} \mathrm{N}$, junio.
Se observa que de 0 -100 m la distancia horizontal es mayor que de $100-500 \mathrm{~m}$, debido a que de $78^{\circ}-78^{\circ} 30^{\prime} \mathrm{W}$ es una región costera donde se registran profundidades hasta $100 \mathrm{~m}$.

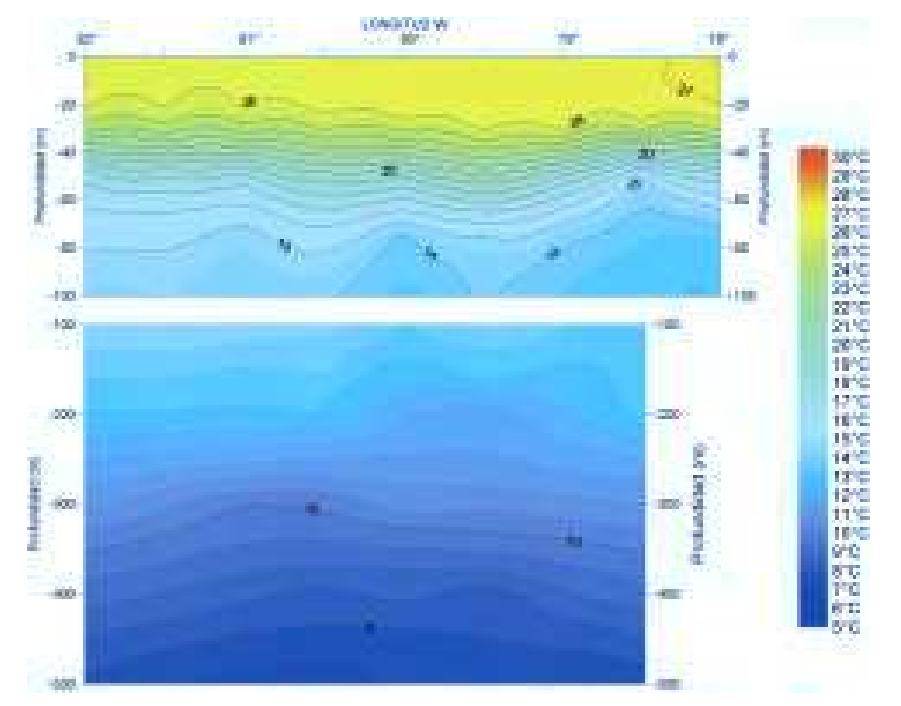

Figura 3.18. - Variación vertical de latemperatura $\left({ }^{\circ} \mathrm{C}\right)$ promedio en el transepto $3^{\circ} \mathrm{N}$, septiembre

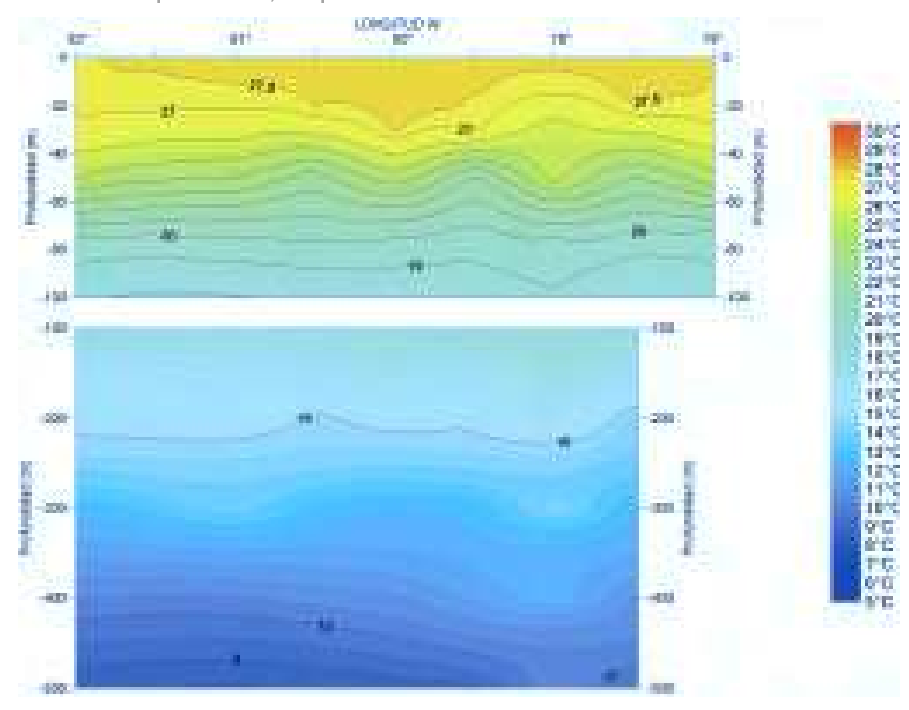

Figura 3.19. - Variación vertical de la temperatura $\left({ }^{\circ} \mathrm{C}\right)$ promedio en el transepto $3^{\circ} \mathrm{N}$, diciembre.

Transepto en la Latitud $4^{\circ} \mathrm{N}$ (entre los $77.75^{\circ} \mathrm{W}$ y los $82^{\circ} \mathrm{W}$ )

La primera capa de 0 - 20 metros es homogénea (mezclada), presenta diferencias con respecto a los transeptos 1 y 2 en que aparecen temperaturas máximas de $28^{\circ} \mathrm{C}$ de marzo a agosto (ver marzo y junio Fig. 3.20 y 3.21). Esta capa homogénea se observa más ancha en los meses de junio (Fig. 3.21) a diciembre (ver septiembre y diciembre Fig. 3.22 y 3.23), y casi desaparece de febrero a mayo (ver marzo Fig. 3.20), porque la termoclina se eleva hasta la superficie. 
En junio se observa una entrada de aguas cálidas (Fig. 3.21) proveniente del Oeste en los primeros $20 \mathrm{~m}$.

La termoclina varía de $26^{\circ} \mathrm{C}$ a $15^{\circ} \mathrm{C}$ en $60 \mathrm{~m}$ de espesor, excepto en mayo y junio cuando termina a $150 \mathrm{~m}$, siendo ésta la profundidad máxima (Fig. 3.20 - 3.23).

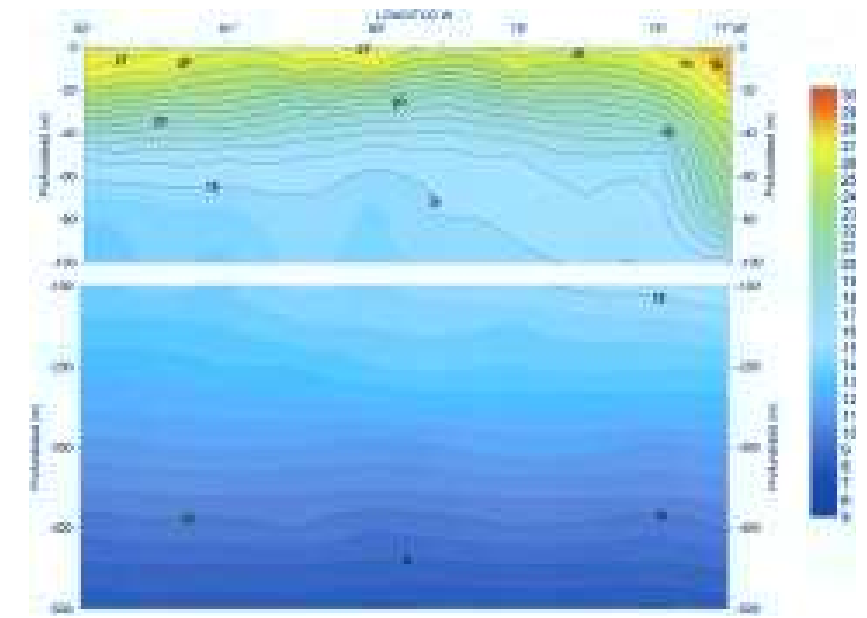

Figura 3.20 - Variación vertical de la temperatura $\left({ }^{\circ} \mathrm{C}\right)$ promedio en el transepto $4^{\circ} \mathrm{N}$, marzo

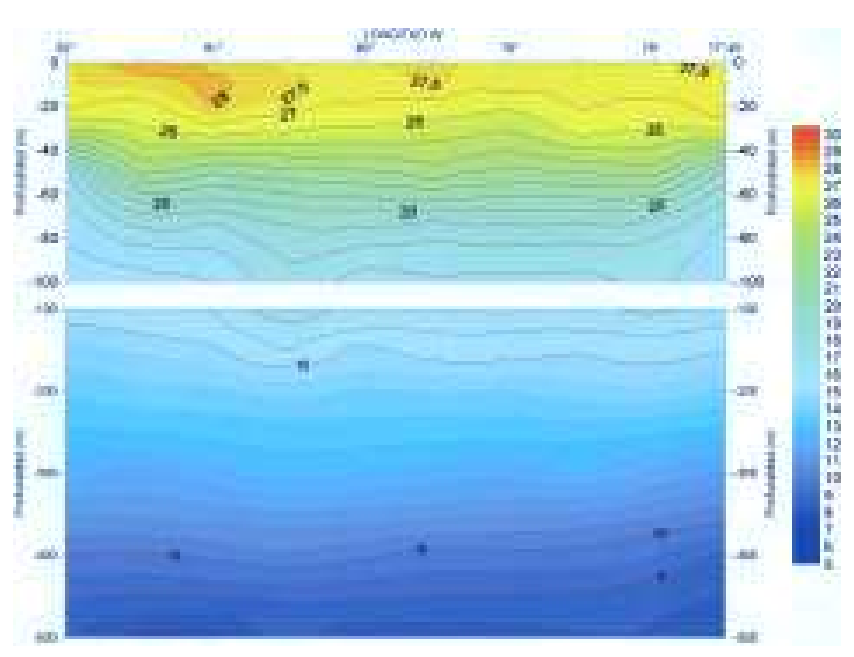

Figura 3.21 - Variación vertical de la temperatura $\left({ }^{\circ} \mathrm{C}\right)$ promedio en el transepto $4^{\circ} \mathrm{N}$, junio

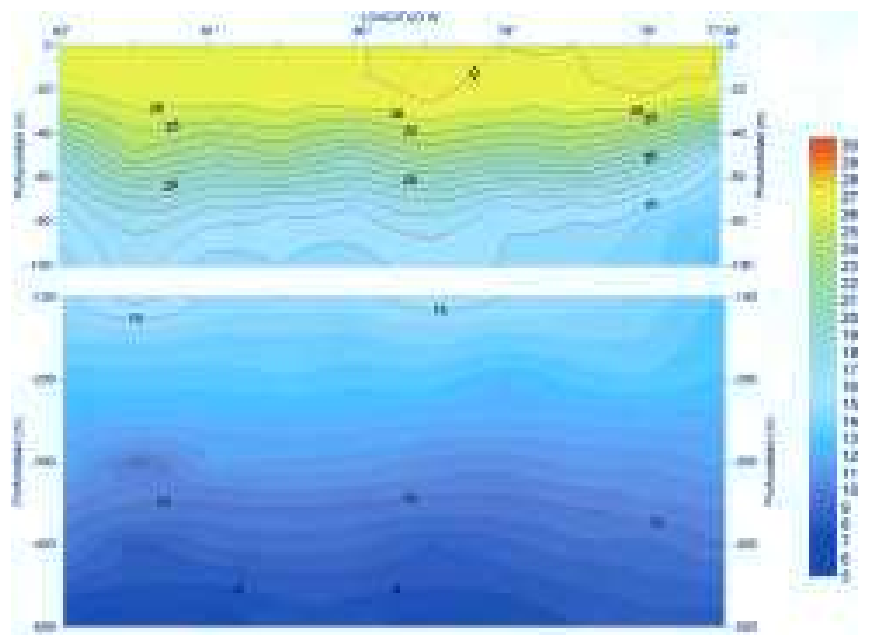

Figura 3.22 - Variación vertical de la temperatura $\left({ }^{\circ} \mathrm{C}\right)$ promedio en el transepto $4^{\circ} \mathrm{N}$, septiembre.
Las isotermas por debajo de la termoclina varían cada vez menos con respecto al aumento en la profundidad, sin detectarse hundimientos o elevaciones representativas.

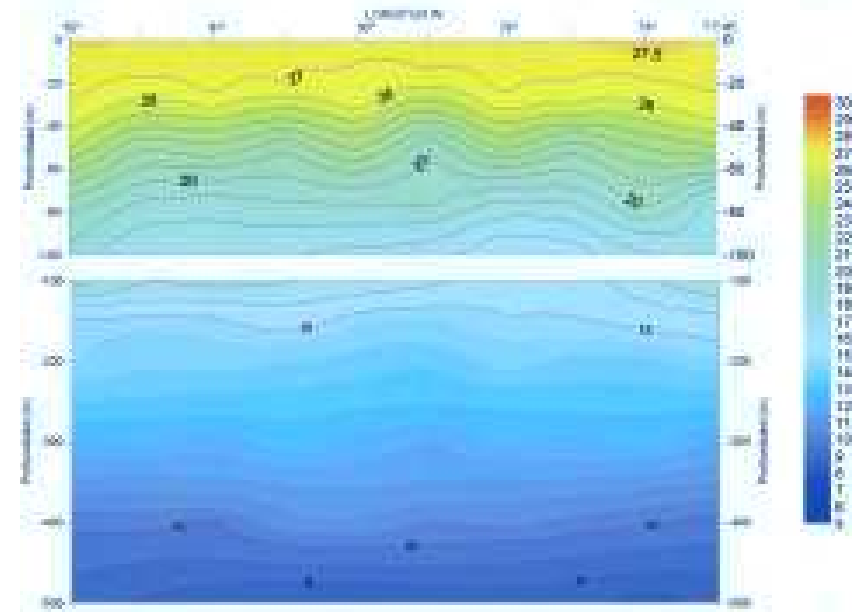

Figura 3.23 - Variación vertical de la temperatura $\left({ }^{\circ} \mathrm{C}\right)$ promedio en el transepto $4^{\circ} \mathrm{N}$, diciembre.

Transepto en la Latitud $5^{\circ} \mathrm{N}$ (entre los $77.75^{\circ} \mathrm{W}$ y los $82^{\circ} \mathrm{W}$ )

La capa homogénea (mezclada) de 0 - 20 m aparece claramente de junio a diciembre (Fig. 3.25 - 3.27); en este último se registra un valor máximo de temperatura de $28^{\circ} \mathrm{C}$. En febrero esta capa solamente se presenta en la región

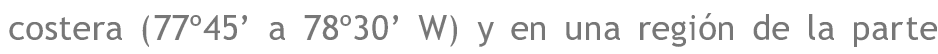
centroceánica $\left(79^{\circ} 30^{\prime}-81^{\circ} \mathrm{W}\right)$. En mayo esta capa es muy fina $(10 \mathrm{~m})$.

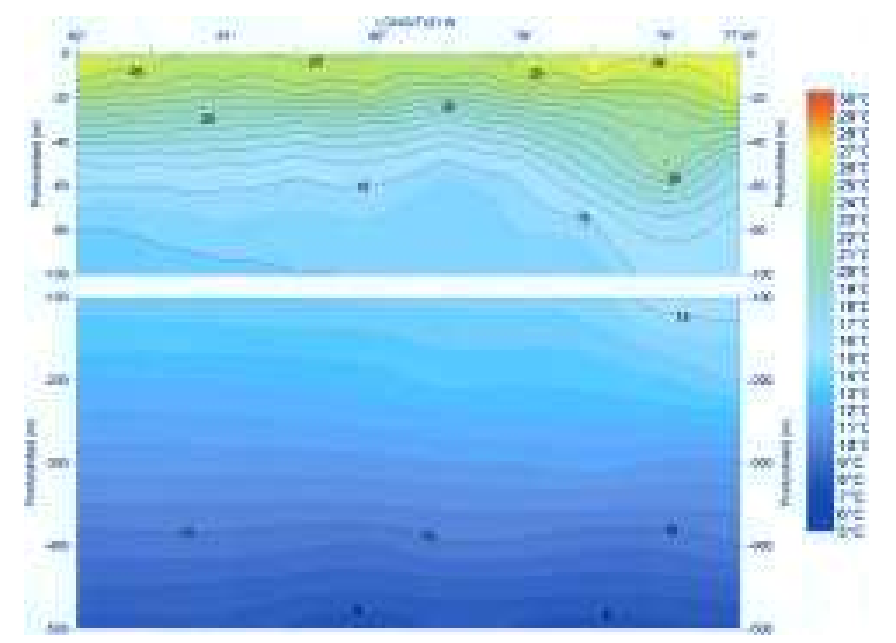

Figura 3.24 - Variación vertical de la temperatura $\left({ }^{\circ} \mathrm{C}\right)$ promedio en el transepto $5^{\circ} \mathrm{N}$, marzo. 
Por debajo de esta capa se encuentra la termoclina estacional (capa de mezcla activa) con variaciones principalmente en su grosor, ya que en febrero, mayo, junio y diciembre la termoclina es muy ancha ( $80-110 \mathrm{~m}$ ) con relación a los otros meses del año y a otros transeptos (Fig. 3.24 - 3.27).

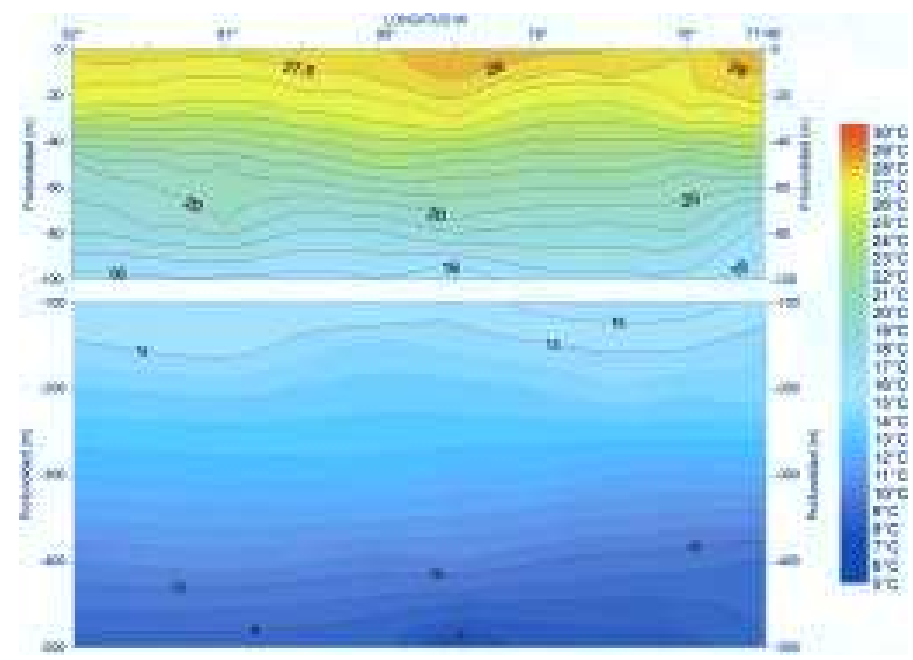

Figura 3.25 - Variación vertical de la temperatura $\left({ }^{\circ} \mathrm{C}\right)$ promedio en el transepto $5^{\circ} \mathrm{N}$, junio.

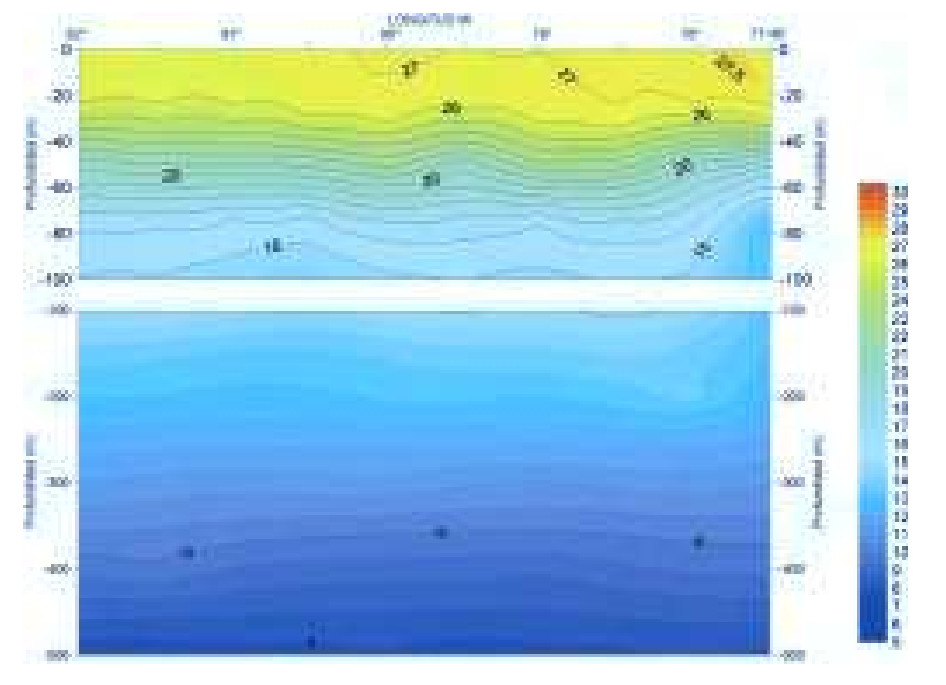

Figura 3.26 - Variación vertical de la temperatura $\left({ }^{\circ} \mathrm{C}\right)$ promedio en el transepto $5^{\circ} \mathrm{N}$, septiembre.

En general, en la mayoría de los meses se observa la isoterma de $15^{\circ} \mathrm{C}$ como el límite inferior de la termoclina, variando solamente en la ubicación con respecto a la profundidad. Por debajo de esta termoclina las variaciones de temperatura, con respecto a la profundidad, son menores $\left(1^{\circ} \mathrm{C} / 60 \mathrm{~m}\right)$ presentando isotermas con pocas oscilaciones. Se observa que la temperatura del agua disminuye con la profundidad y varía de mínima a máxima en la región oceánica y costera, respectivamente. La primera capa de agua es muy fina $(10-20 \mathrm{~m})$ con temperaturas poco variables. En diciembre y junio las aguas se calientan y en marzo y septiembre se enfrían.

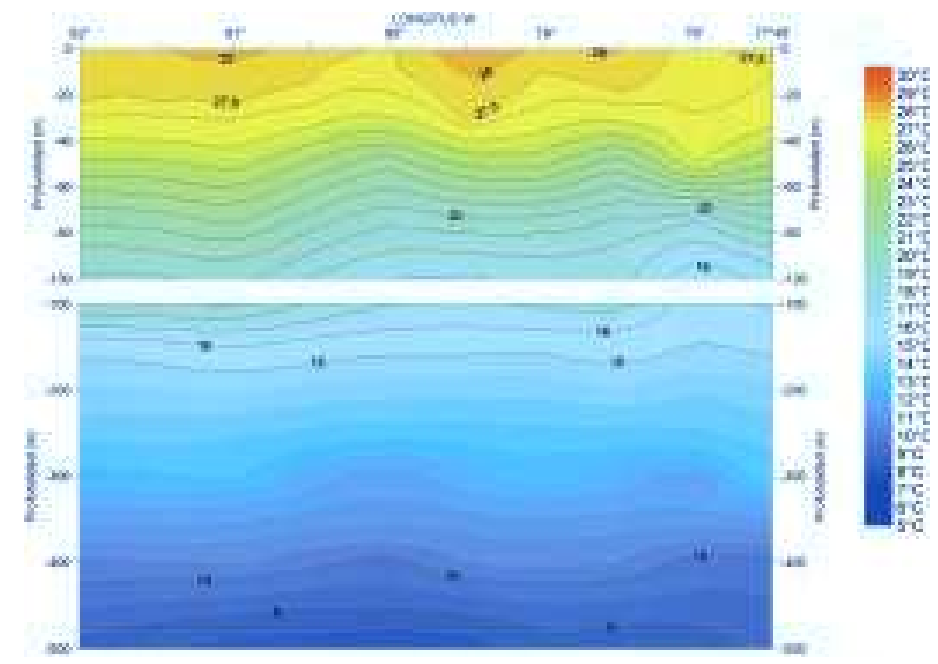

Figura 3.27 - Variación vertical de la temperatura $\left({ }^{\circ} \mathrm{C}\right)$ promedio en el transepto $5^{\circ} \mathrm{N}$, diciembre.

3.3.2. Descripción de la distribución vertical de salinidad promedio anual

La distribución de la salinidad en la superficie de los océanos del mundo está controlada por los patrones de lluvias y evaporación. La diferencia entre la evaporación y las precipitaciones es el principal factor para la formación del campo de salinidad en la capa superficial del océano.

En lugares donde llueve mucho y hay baja evaporación, como en regiones cercanas al Ecuador, se presentan menores salinidades superficiales por dilución de las aguas. En regiones de pocas lluvias, como en las cercanías a las zonas de altas presiones subtropicales ( $20-40^{\circ}$ latitud) se dan salinidades altas por la marcada evaporación (Beer, 1996).

La distribución vertical de salinidad es muy variable. La densidad es la que controla la distribución vertical del agua, presentándose aguas menos densas por encima de las más densas. En aguas lejos de la costa el rango de salinidad es normalmente pequeño, siendo la temperatura la que controla la densidad. En regiones estuarinas hay una fuerte transición entre agua dulce y salada, a esta línea divisoria se le denomina haloclina (Beer, 1996). 
Como una medida muy general, se dice que el aumento de salinidad de 1 produce más o menos el mismo cambio de densidad que $4^{\circ} \mathrm{C}$ de temperatura.

La distribución de salinidad a través de distintas profundidades depende de los procesos de circulación horizontal (advección de sales por las corrientes marinas) y vertical del agua. Al igual que la temperatura, en la distribución de salinidad se encuentra una capa homogénea en los primeros $10 \mathrm{~m}$ de profundidad denominada capa isohalina. Debajo de ésta se encuentra la haloclina, en donde se dan cambios muy bruscos de salinidad con la profundidad. Debajo de la haloclina la distribución de salinidad es casi constante, pero con una estratificación compleja.

En la capa superior del océano es posible encontrar máximos de salinidad subsuperficiales, estos pueden ser el resultado del hundimiento de aguas más densas que se formaron en superficie cuando predominan las precipitaciones ante la evaporación (o cuando aguas superficiales más frias y densas del sur chocan contra aguas superficiales más cálidas y menos densas del norte, produciendo el descenso de parches de aguas más densas). Cerca de la línea Ecuatorial estos máximos de salinidad subsuperficial se observan a los $50-100 \mathrm{~m}$.

En general, en las aguas superficiales de la CPC se presentan máximos de salinidad en marzo y mínimos en diciembre. La salinidad aumenta con la profundidad, variando con los meses el grosor de la haloclina; luego se presenta un máximo subsuperficial entre $80-150 \mathrm{~m}$, después del cual la salinidad disminuye poco $(0.2-0.4)$.

\section{Transepto en la Latitud $2^{\circ} \mathrm{N}$ (entre los $79^{\circ} \mathrm{W}$ y los $82^{\circ} \mathrm{W}$ )}

La capa superficial está fuertemente estratificada (haloclina) hasta los 50 metros entre marzo (Fig. 3.28) y junio (Fig. 3.29); a 70 metros en febrero y a 80 metros entre agosto y diciembre. Los valores superficiales son menores en la costa $\left(79^{\circ} 79^{\circ} 30^{\prime}\right.$ W) y van aumentando hacia la región oceánica (Fig. 3.28 - 3.31).

El límite inferior de la haloclina presente es 34.4 en febrero; 34.6 de marzo (Fig. 3.28) a junio (Fig. 3.29); 34.8 en agosto, noviembre y diciembre (Fig. 3.31), y 35 en septiembre (Fig. 3.30) y octubre. El límite inferior se incrementa a final del año, debido a que la temperatura superficial aumenta (Fig. 3.14 y 3.15).
El rango de salinidades (mínimo máximo) es para febrero (31.6 - 34.9); marzo (33.4 - 35.1); abril (32.6 - 34.9); mayo (31.4 - 35.1); junio (30.4 - 35.1); agosto (31.4 - 35.4); septiembre (32.2 - 35.5); octubre (32.6 - 35.5); noviembre (31.2 - 35.3), y diciembre (32.1 - 35.1).

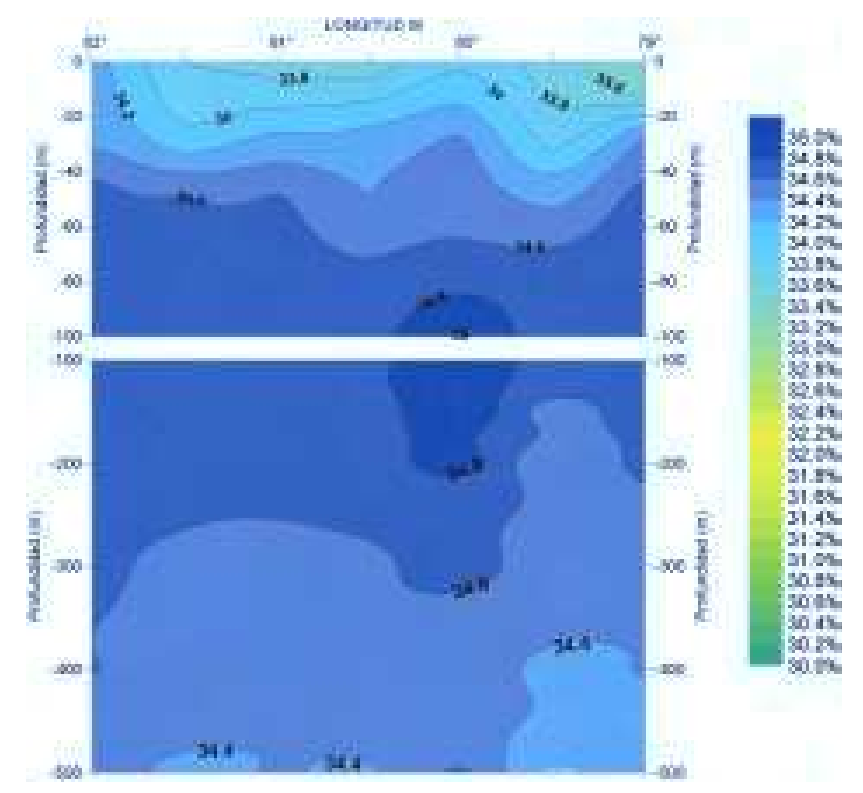

Figura 3.28 - Variación vertical de la salinidad promedio en el transepto $2^{\circ} \mathrm{N}$, marzo.

En los primeros meses (febrero-mayo) aparecen salinidades altas (34.6 -34.8) que vienen de la región oceánica y que se desplazan hacia la región central y costera (Fig. 3.28). En junio (Fig. 3.29) estas salinidades se profundizan y se presenta la intrusión de salinidades aún mayores (34.8 - 35.1).

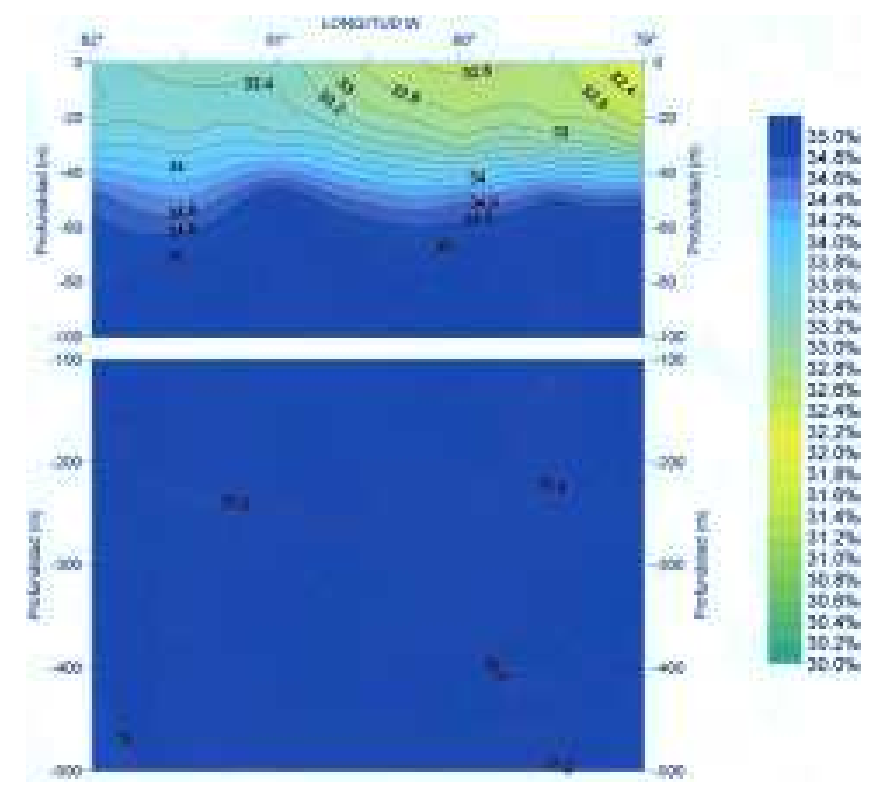

Figura No. 3.29 - Variación vertical de la salinidad promedio en el transepto $2^{\circ} \mathrm{N}$, junio 
Desde agosto la salinidad aumenta en toda la columna de agua y sigue así hasta un máximo de 35.5 en septiembre y octubre (Fig. 3.30), para luego disminuir en noviembre y diciembre a 35 (Fig. 3.31).

En la distribución, con respecto a la profundidad, se observa un aumento en los valores hasta un máximo subsuperficial a los $150 \mathrm{~m}$, a partir del cual disminuye aunque en menor proporción hasta los $500 \mathrm{~m}$.

En la distribución de salinidades subsuperficiales, con respecto a la longitud, se observa que son bajas en la costa y más altas hacia la región oceánica de febrero a junio.

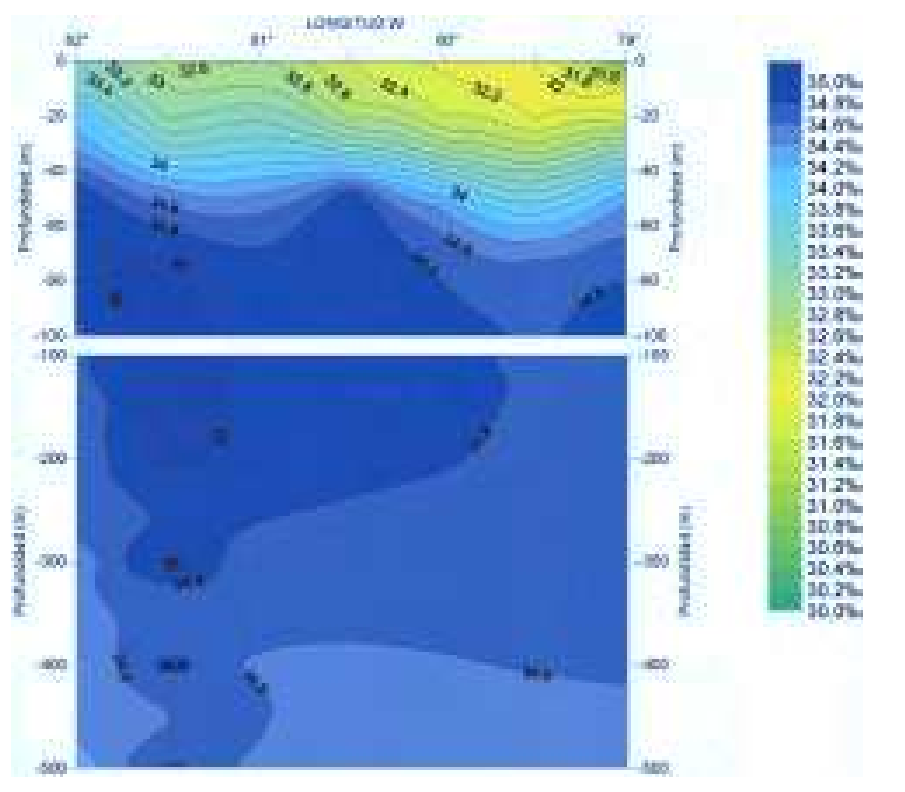

Figura No. 3.30 - Variación vertical de la salinidad promedio en el transepto $2^{\circ} \mathrm{N}$, septiembre.
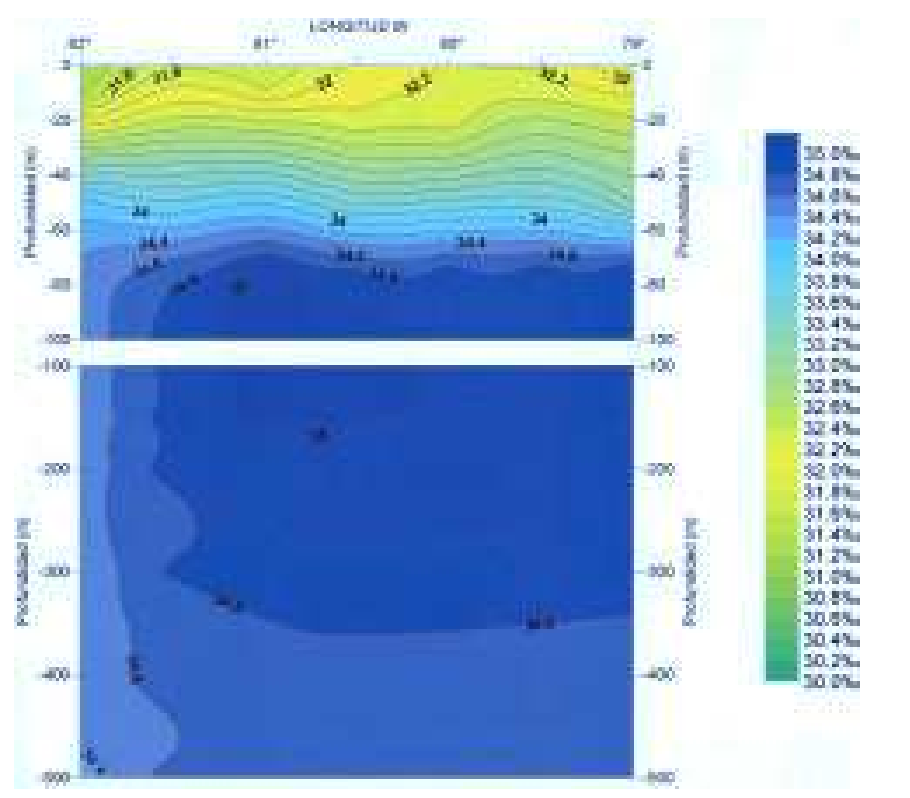

Figura No. 3.31 - Variación vertical de la salinidad promedio en el transepto $2^{\circ} \mathrm{N}$, diciembre.

\section{Transepto en la Latitud $3^{\circ} \mathrm{N}$ (entre los $78^{\circ} \mathrm{W}$ y los $82^{\circ} \mathrm{W}$ )}

La capa superficial muestra una marcada variabilidad horizontal hasta los $50 \mathrm{~m}$ en mayo, junio y agosto; $60 \mathrm{~m}$ en abril; $70 \mathrm{~m}$ en octubre; $80 \mathrm{~m}$ en septiembre, noviembre y diciembre, y $120 \mathrm{~m}$ en febrero. Los valores superficiales son menores en la costa y van aumentando hacia la región oceánica (Fig. 3.32-3.35)

En las gráficas se observa que de 0 - $100 \mathrm{~m}$ la distancia horizontal es mayor que de 100 - $500 \mathrm{~m}$, debido a que entre los $78^{\circ}$ y $78^{\circ} 30^{\prime} \mathrm{W}$ se encuentra la región costera que presenta una profundidad máxima de $100 \mathrm{~m}$.

El límite inferior de la haloclina es $\mathbf{3 4 . 6}$ en febrero, abril, mayo y junio (Fig. 3.33); 34 en marzo (Fig. 3.32), agosto, noviembre y diciembre (Fig. 3.35), y 35 en septiembre (Fig. 3.34) y octubre. Por debajo de la haloclina la variación es poco uniforme.

El rango de salinidades es para febrero (31 - 35.1); marzo (32.4 - 35.1); abril (32.4 - 34.9); mayo (31.6 - 34.9); junio (30.8 - 35.1); agosto (30 - 35.1); septiembre (29.4 - 35.4); octubre (30 - 35.1); noviembre (30.4 - 35.1), y en diciembre (30.4 - 35.1).

De febrero a junio (ver marzo y junio Fig. 3.32-3.33) aparecen salinidades similares en la región costera y oceánica; presentando esta última valores más elevados a los registrados

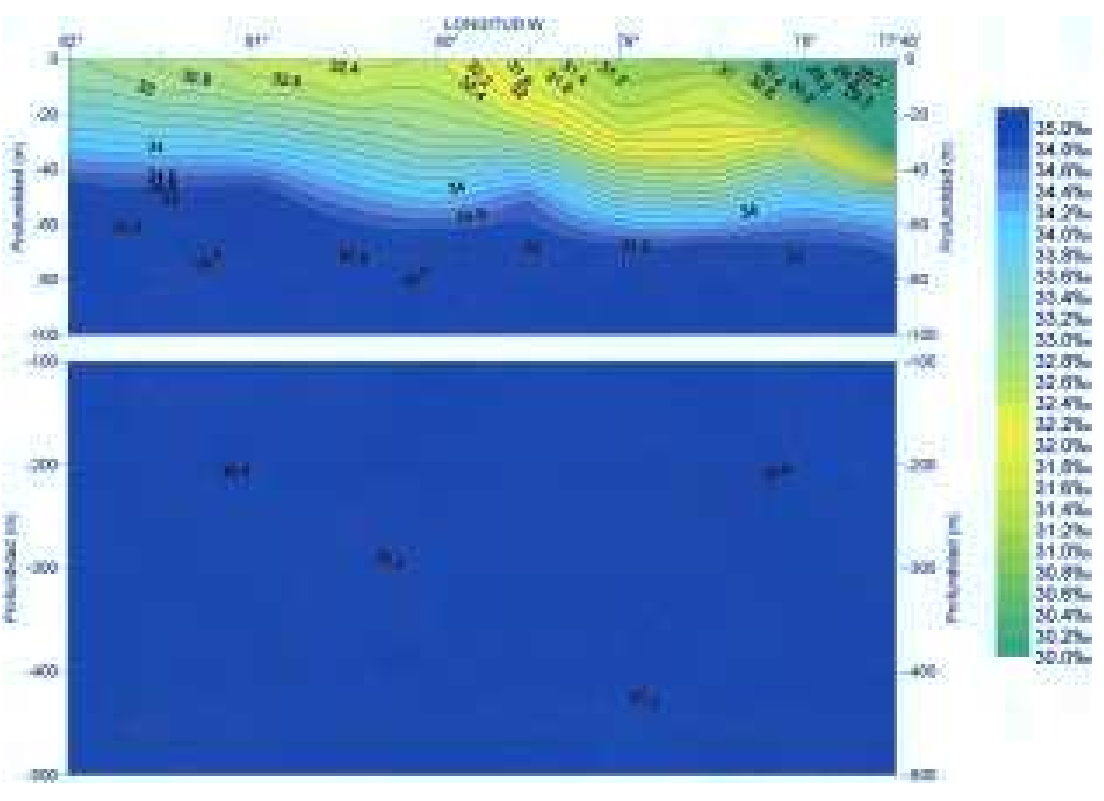

Figura No. 3.32- Variación vertical de la salinidad promedio en el transepto $3^{\circ} \mathrm{N}$, marzo. 


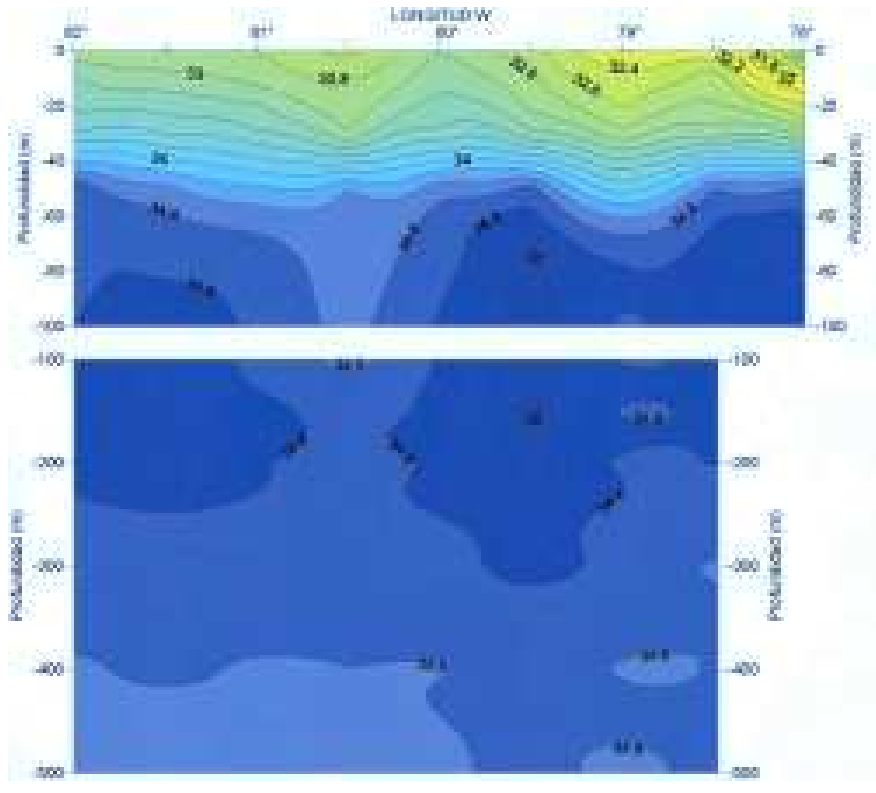

Figura No. 3.33 - Variación vertical de la salinidad promedio en el transepto $3^{\circ} \mathrm{N}$, junio

en la región central. De agosto a diciembre (Fig. 3.34-3.35) la salinidad en toda la CPC aumenta, comportándose de manera similar a los meses anteriores. Los valores máximos se dan en septiembre (Fig. 3.34).

En la distribución con respecto a la profundidad se observan unos frentes salinos en los primeros $30 \mathrm{~m}$. La salinidad aumenta hasta los $150 \mathrm{~m}$ y después disminuye aunque en menor proporción hasta los $500 \mathrm{~m}$.

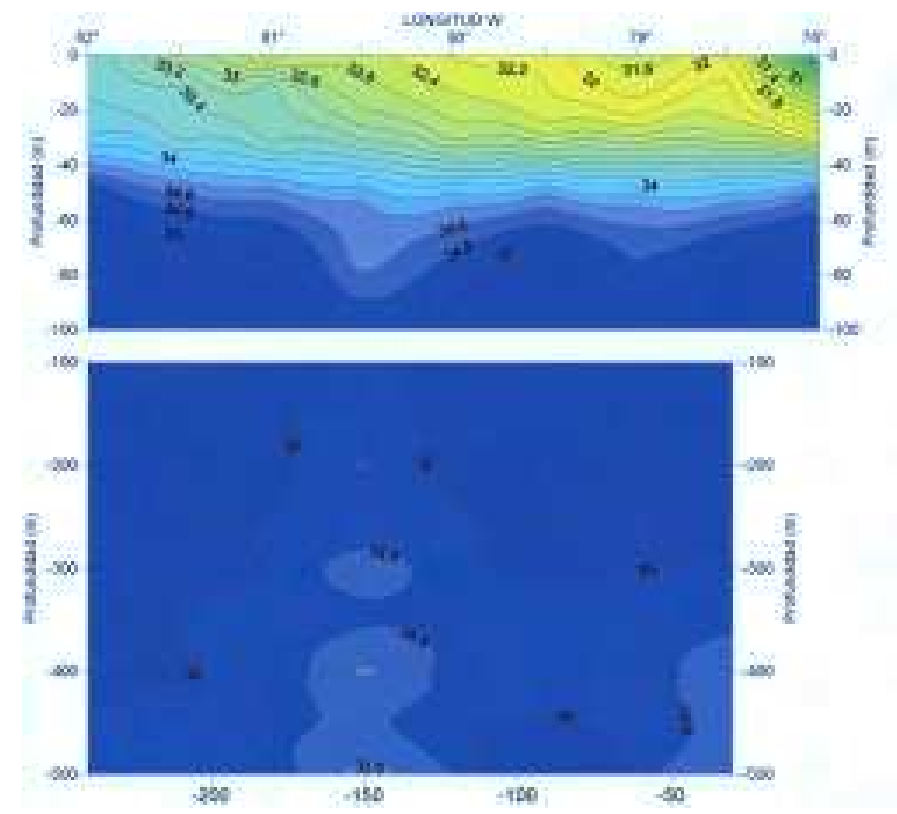

Figura No. 3.34 - Variación vertical de la salinidad promedio en el transepto $3^{\circ} \mathrm{N}$, septiembre

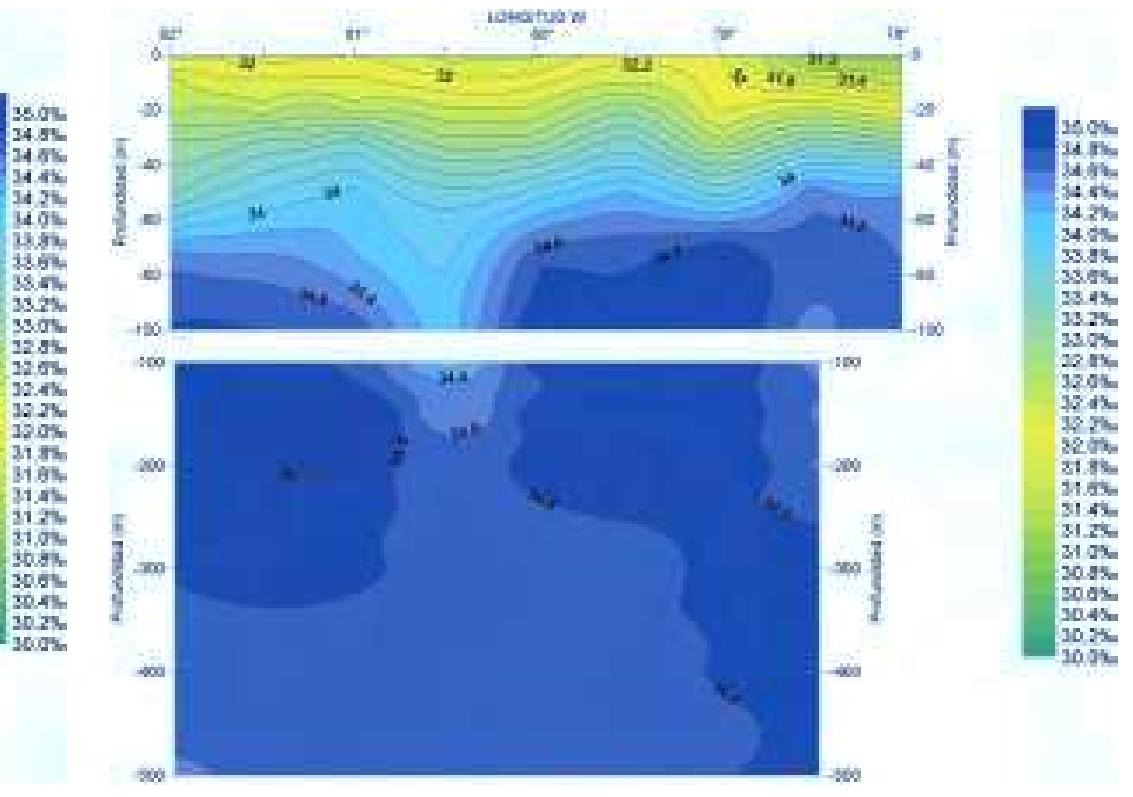

Figura No. 3.35- Variación vertical de la salinidad promedio en el transepto $3^{\circ} \mathrm{N}$, diciembre.

Transepto en la Latitud $4^{\circ} \mathrm{N}$ (entre los $77.75^{\circ} \mathrm{W}$ y los $82^{\circ} \mathrm{W}$ )

La capa superficial presenta una estratificación (haloclina) hasta los $60 \mathrm{~m}$ en marzo (Fig. 3.36) y abril; 75 metros en febrero, noviembre y diciembre (Fig. 3.39); 80 metros en mayo; 90 metros en agosto, septiembre (Fig. 3.38) y octubre, y 100 metros en junio (Fig. 3.37).

Las salinidades superficiales varían de menores en la costa a mayores en el sector oceánico (Fig. 3.36 - 3.39).

El límite inferior de la haloclina es de 34.4 en febrero; 34.6 entre marzo (Fig. 3.36) y junio (Fig. 3.37), y 34.8 entre agosto y diciembre (Fig. 3.38 - 3.39). Por debajo de esta haloclina la variación es poco uniforme y no cambia mucho 4\% con la profundidad.

El rango de salinidades es para febrero (30 - 34.5); marzo (32.4 - 35.3); abril (31.8 - 35.1); mayo (30 - 35.1); junio (27.4 - 35.1); agosto (25 - 35.1); septiembre (25 - 35.1); octubre (26.4 - 35.1); noviembre (28 - 35.1), y diciembre (29.5 - 35.1).

En febrero aparecen las salinidades más bajas de todo el año; de marzo a junio aumentan un poco (Fig. 3.36-3.37), y de agosto a diciembre éstas aumentan paulatinamente (ver septiembre y diciembre Fig. 3.38-3.39). En general, las salinidades son siempre más bajas en la costa que en la región oceánica. 


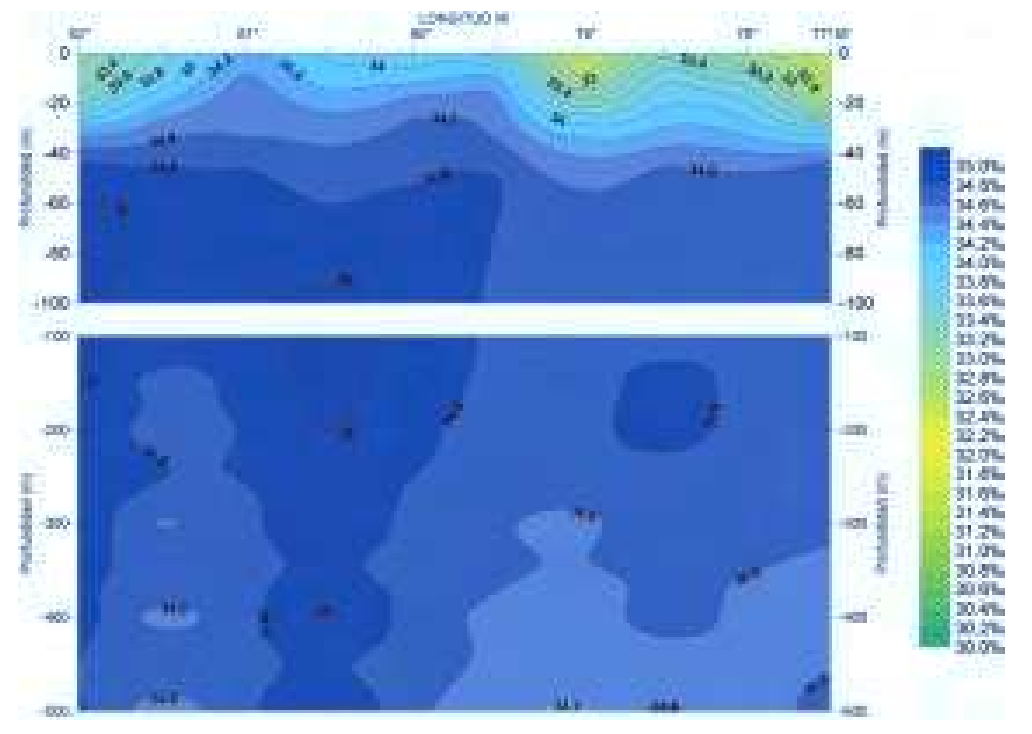

Figura No. 3.36 - variación vertical de la salinidad promedio en el transepto $4^{\circ} \mathrm{N}$, marzo.

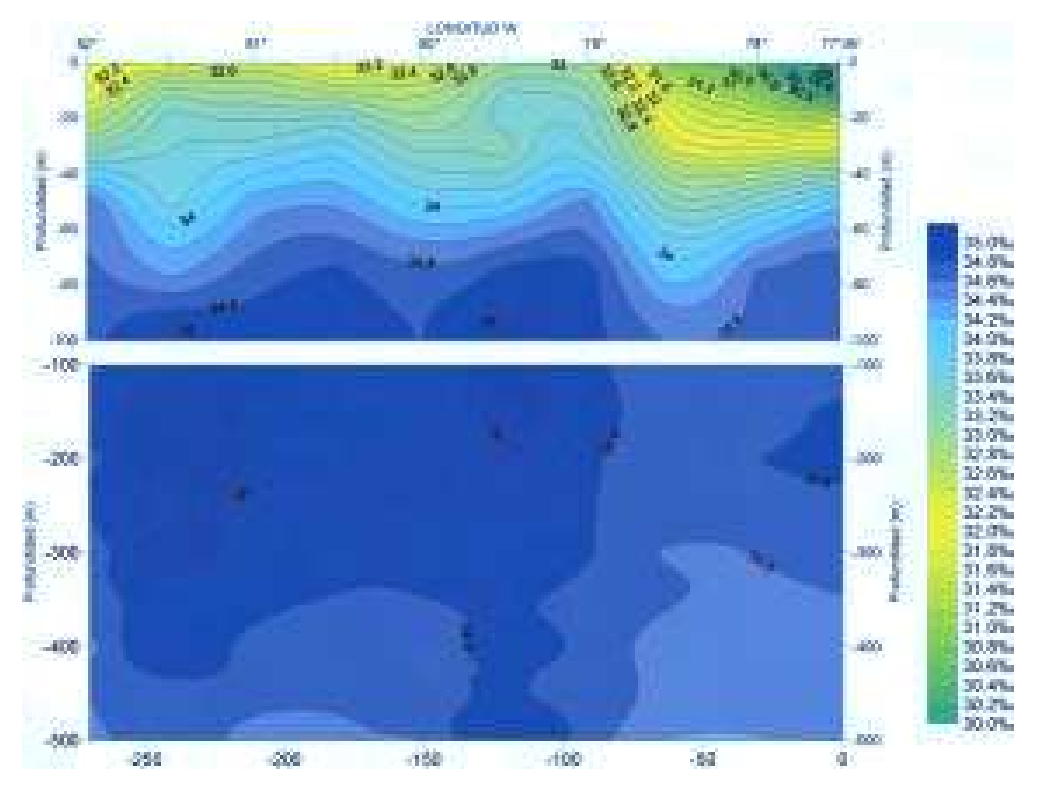

Figura No. 3.37- Variación vertical de la salinidad promedio en el transepto $4^{\circ} \mathrm{N}$, junio

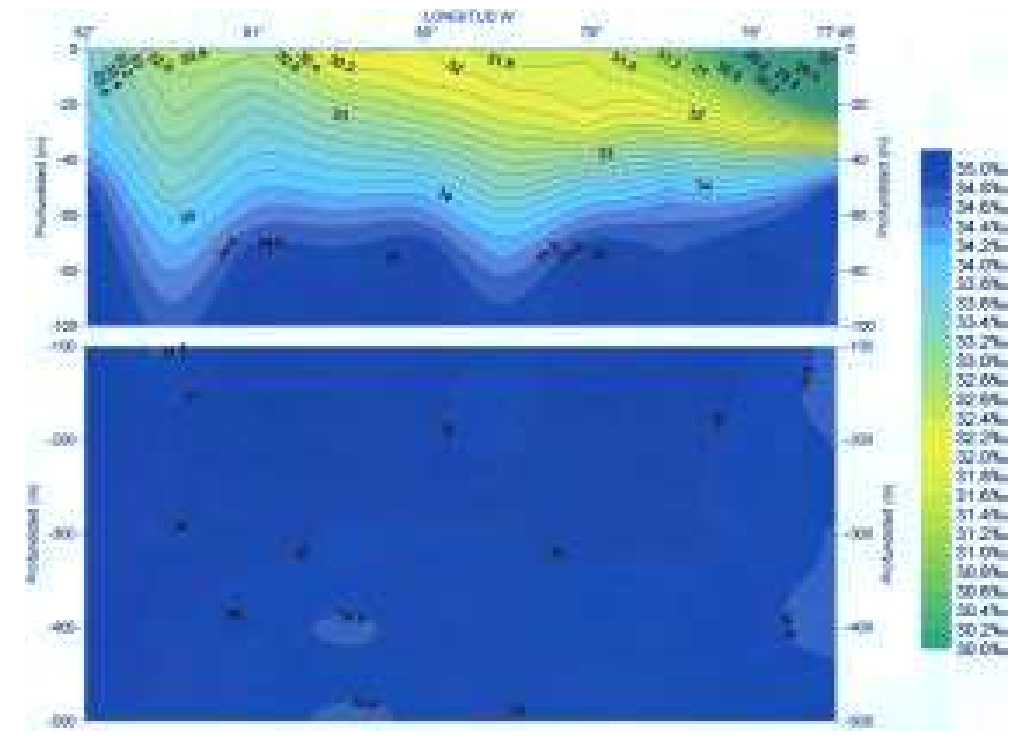

Figura No. 3.38- Variación vertical de la salinidad promedio en el transepto $4^{\circ} \mathrm{N}$, septiembre

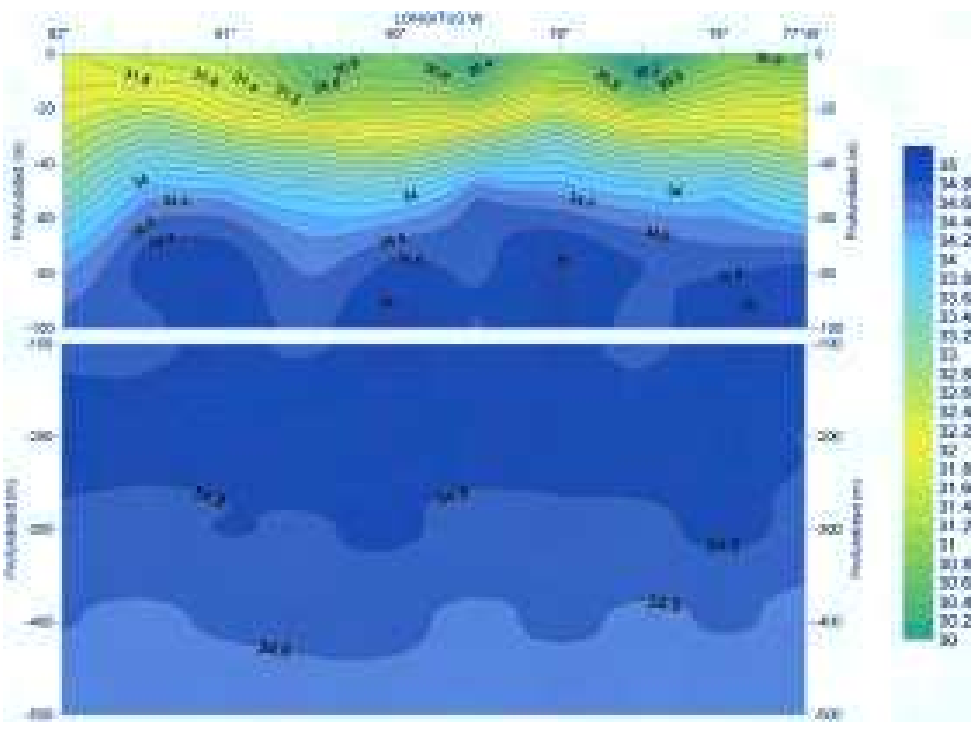

Figura No. 3.39 - Variación vertical de la salinidad promedio en el transepto $4^{\circ} \mathrm{N}$, diciembre.

En la distribución con respecto a la profundidad se observa un aumento en los valores hasta los $200 \mathrm{~m}$ y después disminuye aunque en menor proporción hasta los $500 \mathrm{~m}$.

En la distribución de salinidades subsuperficiales, con respecto a la longitud, se observa que son bajas en la costa y más altas hacia la región oceánica entre febrero y noviembre (Fig. 3.36 - 3.37 - 3.38).

\section{Transepto en la Latitud $5^{\circ} \mathrm{N}$ (entre los $77.75^{\circ} \mathrm{W}$ y los $82^{\circ} \mathrm{W}$ )}

La capa superficial está muy estratificada (haloclina) hasta los $50 \mathrm{~m}$ en marzo (Fig. 3.40) y abril; $70 \mathrm{~m}$ en septiembre (Fig. 3.42); 80 metros en mayo y octubre; $90 \mathrm{~m}$ en junio (Fig. 3.41), agosto, noviembre y diciembre (Fig. 3.43), y $100 \mathrm{~m}$ en febrero. Las salinidades superficiales son mucho menores en la costa que en el sector oceánico (Fig. 3.40 - 3.43).

El límite inferior de la haloclina varía en febrero (34.8 región costera y 34 región oceánica) y en junio (34.4 región costera y 34 región oceánica); en los demás meses los valores permanecen similares para el sector costero y oceánico: 34.5 en marzo (Fig. 3.40) y abril; 34 en mayo; 34.6 en agosto y diciembre (Fig. 3.43); 35 en septiembre (Fig. 3.42), octubre y noviembre. Por debajo de estas salinidades, después de los 50-100 m el comportamiento es muy poco uniforme. 


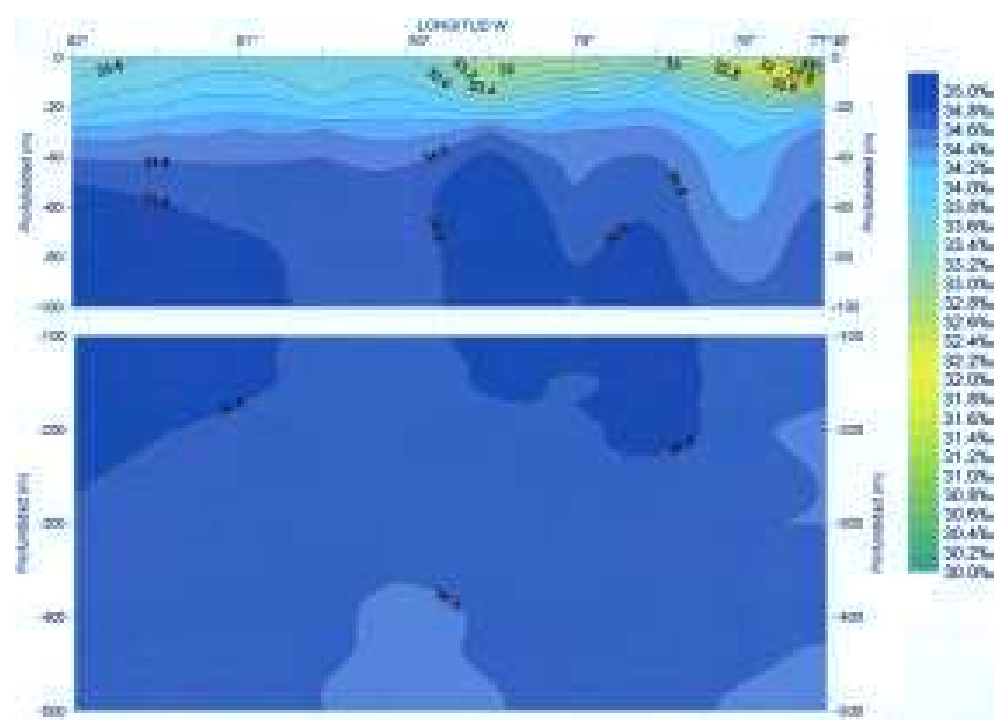

Figura No. 3.40 - Variación vertical de la salinidad promedio en el transepto $5^{\circ} \mathrm{N}$, marzo.

De febrero a marzo (Fig. 3.40) las salinidades son mayores en la región central y menores en la costa; en mayo y junio (Fig. 3.41) se observa una distribución con salinidades mayores en la región central, rodeadas por franjas de salinidades menores, las cuales cubren toda la cuenca.

En agosto aparecen salinidades más altas de manera generalizada para toda la CPC, con los mayores valores (35) en la región costera y central hasta los $80^{\circ} 30^{\prime}$ W. En septiembre se dan los máximos valores (35.5) entre los 100 $200 \mathrm{~m}$ en núcleos bien diferenciados (Fig. 3.42) y salinidad casi constante en el resto de la cuenca. De octubre a diciembre (Fig. 3.43) los valores más altos se dan en la región oceánica y disminuyen hacia la costa.

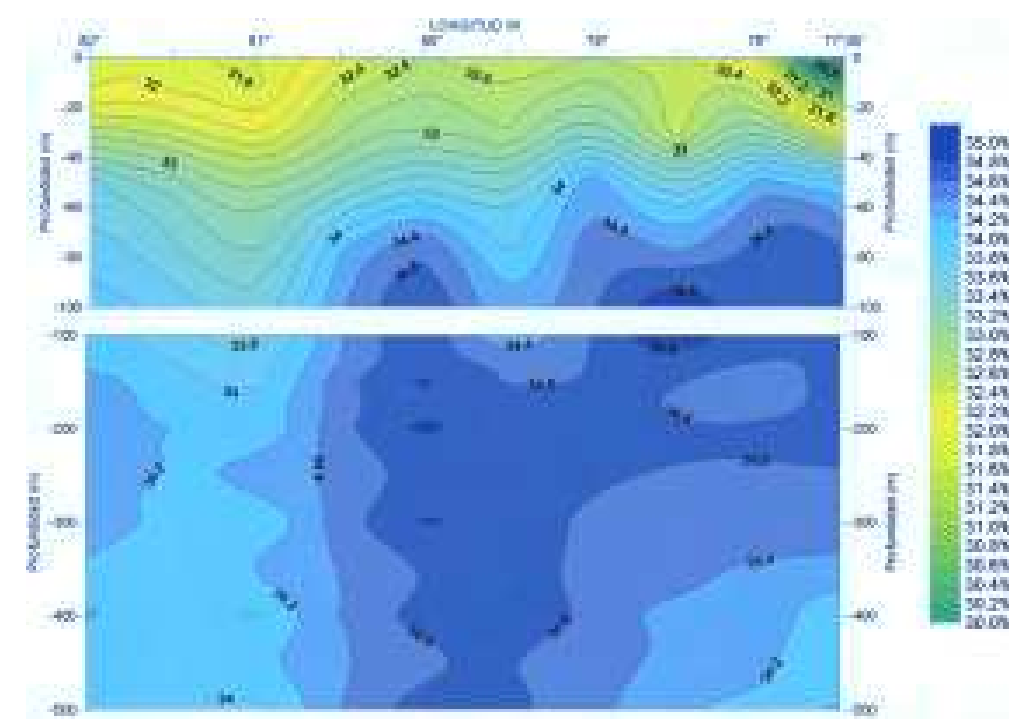

Figura No. 3.41 - Variación vertical de la salinidad promedio en el transepto $5^{\circ} \mathrm{N}$, junio.

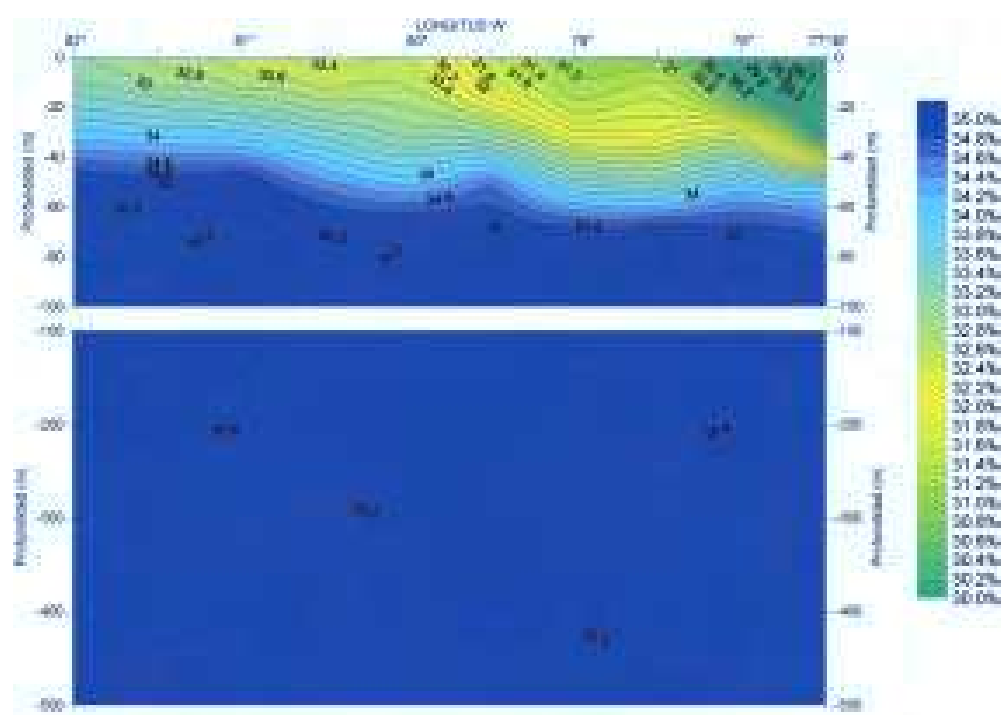

Figura No. 3.42 - Variación Vertical de la Salinidad Promedio en el Transepto $5^{\circ} \mathrm{N}$, septiembre.

El rango de salinidades es para febrero (27 - 35.1); marzo (29.4 - 34.4); abril (29 - 34.4); mayo (28 - 34.4); junio (27 34.4); agosto (25.4 - 35.1); septiembre (25.4 - 35.4); octubre (26.4 -35.4); noviembre (27.4 - 35.4), y diciembre (28.4 35.1).

En la distribución con respecto a la profundidad se observa un aumento en los valores hasta los 200 - $300 \mathrm{~m}$ y después disminuye aunque en menor proporción, hasta los $500 \mathrm{~m}$.

En la distribución de salinidades subsuperficiales, con respecto a la longitud, se observa que son bajas en la costa y más altas hacia la región oceánica en abril, mayo, septiembre, octubre y noviembre.

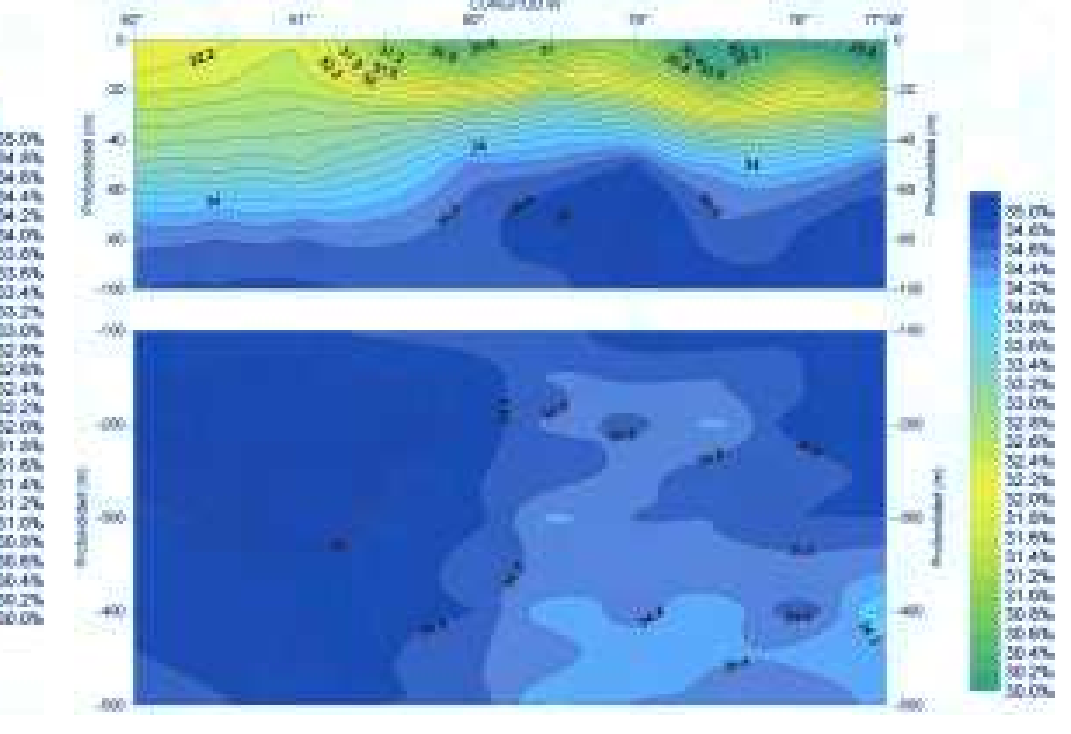

Figura No. 3.43 - Variación vertical de la salinidad promedio en el transepto $5^{\circ} \mathrm{N}$, diciembre. 
En síntesis, la salinidad se ve influenciada en la costa por los aportes continentales de aguas dulces y por las lluvias. Esto hace que las aguas costeras sean menos salinas que las oceánicas. Es posible observar una capa isohalina en los primeros metros de profundidad, sobretodo en la región oceánica, pero casi siempre ésta se confunde con la haloclina. Por debajo de la haloclina la distribución no es de capas horizontales, sino que se observan comportamientos de desplazamiento de salinidades altas que se mueven en sentido este-oeste y salinidades máximas subsuperficiales (80 - 150 $\mathrm{m})$, alrededor de las cuales se dan capas menos salinas.

En algunos meses se detecta la intrusión de salinidades altas (35) por el sector oceánico de la CPC, que posiblemente se hayan formado a causa de la advección por corrientes.

En general, la CPC se ubica en una región muy especial del Pacífico Oriental por ser la zona donde convergen los vientos Alisios del Norte y del Sur, los cuales se desvían luego hacia el oeste. Es por esto que el sistema climático y oceanográfico de esta cuenca depende, principalmente, de las variaciones de la ZCIT, que migra progresivamente durante el año, desde latitudes cercanas al Ecuador (en marzo) hasta los $15^{\circ} \mathrm{N}$ (en septiembre), donde sobrepasa Sudamérica y se posa sobre el mar Caribe. Este ciclo produce una estacionalidad en el clima, sobretodo en la región costera, donde se da un aumento en las precipitaciones a partir de marzo, cuando la ZCIT empieza su ascenso hacia el norte y los vientos Alisios del Sureste comienzan a tomar fuerza.

De la misma manera, las características oceanográficas de la CPC están regidas por la migración de la ZCIT, la cual permite que se presenten aguas de distintas temperaturas $\mathrm{y}$ salinidades, según la predominancia de los vientos y las corrientes principales.

La temperatura superficial varía durante el año. En diciembre se tienen las máximas temperaturas superficiales en toda la CPC, las cuales disminuyen hasta marzo; luego vuelven a aumentar, aunque en menor proporción, hasta junio, donde se da un segundo máximo de la TSM y, finalmente, de agosto a diciembre aumentan de nuevo. Así mismo, las salinidades varían durante el año con valores máximos en marzo y mínimos en diciembre.

En la CPC se presentan salinidades y temperaturas relacionadas inversamente. Se observa que en las épocas y regiones en donde existe una temperatura alta, las salinidades son siempre bajas y viceversa. Las variaciones espaciales son muy marcadas entre la zona costera y la región oceánica; y un poco menos entre la Zona Norte y Sur de la CPC. Esto se identifica por las altas salinidades existentes en la región oceánica y las bajas salinidades de la región costera. La Zona Norte cuenta con valores de temperatura mayores a los de la Zona Sur, debido a la influencia de las corrientes cálidas del norte y frías de Perú y Colombia, respectivamente.

La temperatura se comporta de manera típica respecto a la profundidad, con valores máximos en superficie, que disminuyen hacia el fondo, con una capa homogénea superficial $(0-20 \mathrm{~m})$, seguida por una termoclina estacional (20 $150 \mathrm{~m}$ ); por debajo de ésta la temperatura disminuye con la profundidad a razón de $1.6^{\circ} \mathrm{C} / 100 \mathrm{~m}$. Este gradiente varía para los meses de agosto, septiembre, octubre y diciembre, donde es de $2^{\circ} \mathrm{C} / 100 \mathrm{~m}$, y en diciembre $5^{\circ} \mathrm{N}$ que es de $2.3^{\circ}$ $\mathrm{C} / 100 \mathrm{~m}$. Esto se debe a que en los meses donde se presentan capas superficiales de mayor temperatura las isotermas se hunden.

El límite inferior de la haloclina y termoclina coincide regularmente a la misma profundidad, se observa una variación en los meses más cálidos, cuando la temperatura aumenta las isotermas e isohalinas se profundizan .

A 0 metros la salinidad es mayor en la región oceánica que en la costera. Esto puede ser a causa de los caudales de los ríos que aportan agua dulce a la cuenca. En la costa la haloclina se observa entre 30 - 50 m; en las aguas centrales y el sudoeste de las aguas oceánicas la capa de deformación se observa entre 50 - 70 m, y en la región oceánica noroeste las curvas de oscilaciones se observan similares desde los 0 a los $500 \mathrm{~m}$.

Por otra parte entre los 80 - $150 \mathrm{~m}$ aparecen salinidades más altas debido al hundimiento de aguas salinas muy densas que se forman en la superficie por evaporación o que provienen del sur, chocan contra masas cálidas menos densas del norte y se hunden hasta encontrar su densidad.

Finalmente, es necesario recordar que el CCCP continúa con las investigaciones oceanográficas y meteorológicas de la CPC, con el fin de conocer mejor esta región. A continuación se presentan algunos de los estudios que se han realizado hasta el momento. 


\subsection{ESTUDIO SOBRE LAS ZONAS HOMOGÉNEAS}

El medio oceánico es un sistema muy complicado para la investigación, ya que su estructura se conforma tanto de factores externos como internos. Por estructura del agua se entiende la interacción de diferentes masas de agua en toda la capa del océano, y masa de agua es el volumen de agua que se describe con un juego de características físicas, químicas y biológicas que conforman un sólo complejo.

La creación de una estructura racional de una red de estaciones para las observaciones de dichas características es uno de los problemas actuales en la oceanología experimental. La construcción de la estructura racional de una red de estaciones es la optimización de sus posiciones, de tal manera que se utilicen los mínimos gastos para su mantenimiento y se obtengan suficientes datos para el conocimiento de los procesos de estudio.

El problema de la construcción de una red racional de estaciones puede resolverse estadísticamente con el Análisis de Clúster a través de la división del área de estudio, separando en forma objetiva las regiones casi homogéneas teniendo en cuenta las características de las masas de agua.

El Análisis de Clúster o, en otras palabras, la clasificación de regiones es la división de una variedad de objetos (fenómenos, procesos) en diferentes clases agrupadas de acuerdo con sus características comunes.

El análisis se elaboró por medio de los datos promedios temperatura, T, y salinidad, S, (Málikov, 1998) los cuales fueron actualizados con la información del crucero de mayo del 2000 y con la determinación de las oscilaciones climáticas encontradas con la información de los cruceros desde 1997 hasta el 2000. En total fueron aumentados seis cruceros al trabajo realizado anteriormente en la consecución de los datos promedio climáticos, aunque después de esta actualización no se obtuvieron grandes cambios con respecto a los anteriores promedios. Además de T y $\mathrm{S}$ para el análisis se utilizó la anomalía de la densidad $(\sigma)$ y los coeficientes de variación de estos parámetros de estudio $(C)$

En general, el área del Pacífico Colombiano se puede dividir en dos zonas grandes, una costera y otra oceánica. La zona costera se caracteriza porque las oscilaciones de temperatura y salinidad son muy altas por la influencia de los aportes de ríos; sus flujos de calor y los movimientos horizontales y verticales, los cuales siempre son muy complicados en estas regiones. Como resultado de este estudio, se han detectado siete áreas homogéneas en la superficie, las cuales se aprecian en la Figura 3.44.

El área I presenta los promedios de $\mathrm{T}=27.38^{\circ} \mathrm{C}, \mathrm{S}=28.09, \sigma$ $=17.40, C_{T}=0.027, C_{S}=0.078$ y $C_{\sigma}=0.094$. El agua en esta área es el resultado de muchos procesos propios de la zona costera a causa de los ríos, los cuales disminuyen la salinidad y producen cambios de la densidad, generando a su vez movimientos horizontales y verticales. La mezcla del agua de los ríos con las aguas oceánicas empieza en los estuarios y produce circulaciones complicadas que causan la diversidad en la distribución de la salinidad. Estos procesos característicos de la zona costera complican los estudios en la región.

Bajo la gradiente de densidad, las aguas con menor salinidad en la superficie se mueven al oeste del océano y en las capas profundas las aguas con mayor salinidad entran al río. Las corrientes de marea producen movimientos verticales y mezclan a las capas de agua entre sí, disminuyendo la diferencia de salinidad. Para el conocimiento de esta área se necesita realizar estudios con una escala en el espacio mucho menor a la que se usa actualmente. Esta masa de agua es netamente local ya que se forma bajo procesos originados en la misma región.

Las áreas II y III se ubican en la zona de mezcla de las aguas costeras con las aguas oceánicas. Los parámetros de estas masas son I: $\mathrm{T}=27.27^{\circ} \mathrm{C}, \mathrm{S}=30.72, \sigma=19.41, C_{T}=0.026$, $C_{S}=0.042$ y $C_{\sigma}=0.052$ y II: $\mathrm{T}=27.21^{\circ} \mathrm{C}, \mathrm{S}=31.65, \sigma=20.13$, $C_{T}=0.028, C_{S}=0.032$ y $C_{\sigma}=0.04$. Por medio de estas características se aprecia cómo las aguas de la zona costera se mezclan con las aguas oceánicas: la salinidad y la densidad aumentan a medida que las aguas se desplazan al océano y los coeficientes de variación disminuyen, presentando la estabilidad de las variaciones de los parámetros dentro del año climático en esta zona, en comparación con el de la zona costera. Pero dentro de estas dos áreas la frontera presenta varios cambios durante el año, lo cual muestra una inestabilidad de masas de agua dentro de ellas.

El área IV presenta aguas con una temperatura cercana a la del área II, pero con mayor salinidad $\left(\mathrm{T}=27.24^{\circ} \mathrm{C}, \mathrm{S}=32.45\right.$, $\sigma=20.73, C_{T}=0.015, C_{S}=0.018$ y $\left.C_{\sigma}=0.023\right)$ y las variaciones 
de los parámetros dentro del año climático son pequeñas. Aunque esta área se encuentra en el sur-oeste del Pacífico colombiano, cerca a la costa, su masa de agua no tiene características de aguas dulces, lo cual puede sugerir que ésta se conforma por las aguas que llegan del océano abierto a través de las corrientes. La temperatura es alta debido a la poca profundidad de la zona.

En el área $\mathrm{V}$ se observa menor salinidad y mayor temperatura que la de las aguas oceánicas $T=27.07^{\circ} \mathrm{C}$, $\mathrm{S}=32.29, \sigma=20.66, C_{T}=0.022, C_{S}=0.026$ y $C_{\sigma}=0.035$.

Las áreas VI y VII representan las aguas oceánicas del Pacífico colombiano, $\mathrm{VI}: \mathrm{T}=26.96^{\circ} \mathrm{C}, \mathrm{S}=32.66, \sigma=20.97$, $C_{T}=0.027, C_{S}=0.019$ y $C_{\mathrm{\sigma}}=0.031$ y VII: $\mathrm{T}=26.65^{\circ} \mathrm{C}, \mathrm{S}=32.96$, $\sigma=21.30, C_{T}=0.029, C_{S}=0.029$ y $C_{\sigma}=0.044$.

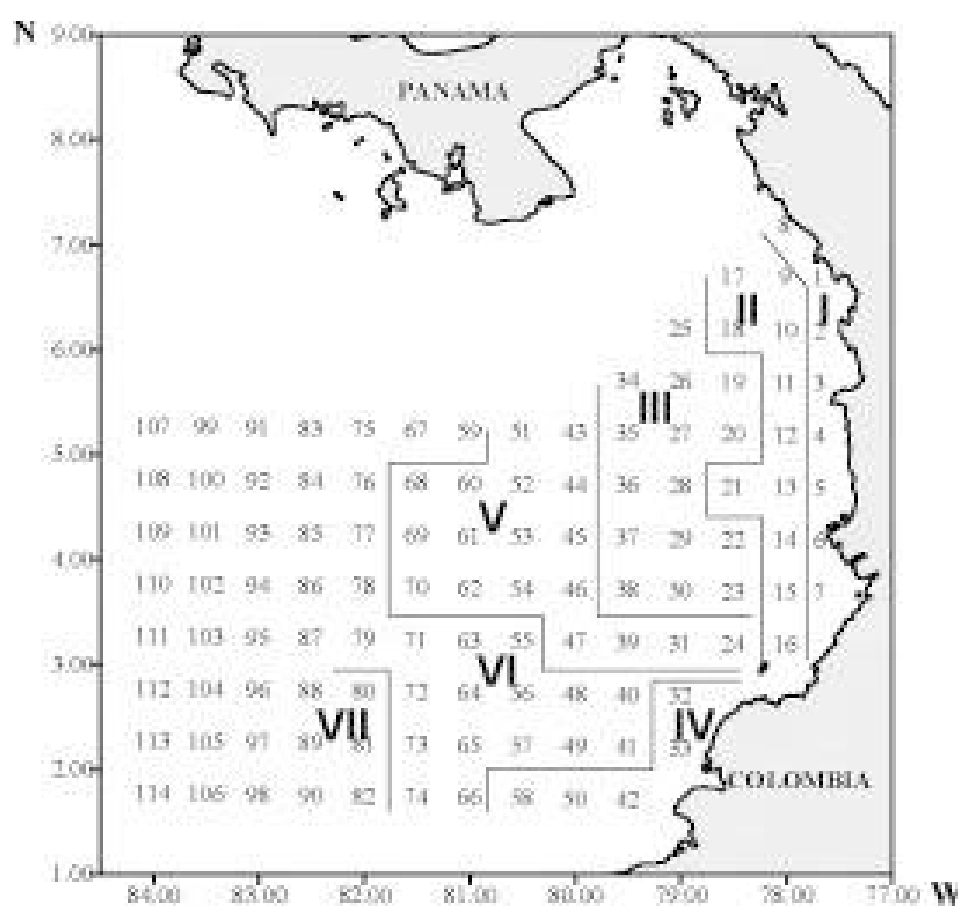

Figura No. 3.44 - Distribución de las zonas homogéneas en la CPC.

Por la distribución de las cuatro últimas áreas y de sus parámetros se puede decir, que las aguas oceánicas (aguas más densas) llegan a la cuenca del Pacífico colombiano desde el oeste a través de los movimientos horizontales.

La distribución de las tres primeras áreas se origina por la influencia de la costa con sus aguas dulces, lo cual hace que las oscilaciones de salinidad sean bruscas; en el resto de las zonas se origina por las oscilaciones de temperatura y salinidad, influenciadas por la migración de la ZCIT.

\subsection{Estudio de la variación del contenido de calor de la capa activa}

En el océano los cambios en la distribución de temperatura y salinidad a nivel horizontal y vertical dependen del intercambio de calor con el medio externo (intercambio dinámico con la atmósfera), y de la advección del calor y de sales a través de las corrientes. El carácter de interrelación varía a través del tiempo y origina la diferenciación en la distribución espacial de elementos hidrodinámicos, químicos y biológicos del océano (Doronin, 1980).

La mayor variación de los elementos hidrológicos se observa en la capa de aguas superficiales, ya que su formación se debe a la acción directa de la atmósfera (Kagan, 1992) y su espesor suele ser no mayor a $500 \mathrm{~m}$, a partir de los cuales se dejan de registrar oscilaciones estacionales (anuales) de temperatura. Debido a las significativas variaciones estacionales de sus elementos hidrológicos a esta capa se la denomina capa activa del océano y puede ser determinada por la profundidad máxima hasta donde se observa la termoclina estacional (Doronin, 1980 y Kraus y Businger, 1994).

Al aumentar la profundidad la oscilación de la temperatura disminuye y más abajo de la capa activa del océano, prácticamente, ya no se registra la variación anual de la temperatura. Debido a lo anterior, por medio del análisis del comportamiento anual de la temperatura en diferentes profundidades de un solo punto, es posible determinar el límite de la capa activa del océano y encontrar la cantidad de calor en esta capa y la pérdida o ganancia de calor mes a mes durante el año. Específicamente, para la CPC se elaboró por primera vez con datos de temperatura del mar un estudio sobre la distribución espacial y temporal del contenido de calor de la capa activa de esta región. La metodología utilizada fue el análisis del comportamiento anual de la temperatura en estaciones representativas del área de investigación de acuerdo con la clasificación de las siete zonas homogéneas de la capa superficial que se muestran en la Figura 3.44.

Se escogieron estaciones representativas de cada zona, teniendo en cuenta tanto la cantidad de observaciones realizadas desde 1970 hasta el año 2000 en cada estación (un total de 30 cruceros), como los meses en que éstas fueron observadas, obteniendo así 16 estaciones. 
En dicho estudio se analizó que las oscilaciones anuales de temperatura en la CPC presentan dos máximos y dos mínimos: diciembre y junio de calentamiento y, marzo y septiembre de enfriamiento, lo cual muestra la influencia de la migración ZCIT (Málikov, 1998). En cuanto al grosor de la capa activa se encontró que ésta varía entre los 150 - 200 m en las zonas cercanas a la costa y, entre 200 - 300 metros en las más oceánicas y que su fluctuación depende del desplazamiento de los procesos atmosféricos en cada zona observada.

La cantidad de calor se calculó para la columna de agua en la capa activa del océano sobre la unidad de área. Los cambios del flujo de calor se obtuvieron por medio de la distribución vertical de la temperatura limitando el cálculo a una profundidad total de $200300 \mathrm{~m}$. Los valores obtenidos de la cantidad de calor $Q$ se representaron gráficamente para observar su variación anual y, teniendo en cuenta la diferencia de $Q$ mes a mes, se obtuvo el flujo de calor saliente $q_{s}$ y entrante $q_{e}$.

Luego del análisis vertical del comportamiento anual de la temperatura de las aguas superficiales en las diferentes zonas homogéneas de la CPC se pudo ver que la capa activa se observa entre los 150 - 200 m (zonas I, II, III, IV y V) y hasta los 300 metros (zonas VI y VII), lo que señala la influencia de la cercanía o lejanía de la costa en la distribución de la temperatura.

Las características espaciales varían durante el año. En otras investigaciones se determina que los períodos de valores máximos son junio-julio y diciembre-enero; y los períodos de valores mínimos son febrero-marzo y septiembre-octubre y se explica la variabilidad anual debido al desplazamiento de la ZCIT (Málikov, 1998). De acuerdo con la apreciación de la investigación de la capa activa en la CPC se corroboró la existencia de dos máximos y dos mínimos.

Teniendo en cuenta lo anterior y excluyendo las estaciones que presentan menor frecuencia de observación se seleccionaron ocho de las 16 estaciones a fin de analizar la intensidad de mezcla que ellas presentan a nivel vertical, según el valor de su gradiente de temperatura en las épocas de mínimo (marzo) y máximo (diciembre) calentamiento de aguas. En marzo se presentó gran intensidad de mezcla de aguas en las estaciones 17, 29, 33, 47 y 79 (Fig. 3.44). En diciembre la mayor intensidad de mezcla de aguas se observó en las estaciones 29, 33, 47 y 49, mostrando mezcla desde la superficie. En algunas capas se observó inversión de temperatura presentada en ciertas zonas, lo cual, podría ser debido a la influencia atmosférica al paso de la ZCIT, lluvias y la advección de calor por corrientes.

Las estaciones que presentaron mayor intensidad de mezcla de aguas, de acuerdo al gradiente vertical de temperatura, son las que por su posición sienten la influencia de aguas empujadas por el desplazamiento de la ZCIT, en épocas de enfriamiento o calentamiento de aguas y que inician su interacción presentando oscilaciones verticales a lo largo de las diferentes capas (zonas III, IV, sector Este de la Zona VI y sector Sur de la Zona V).

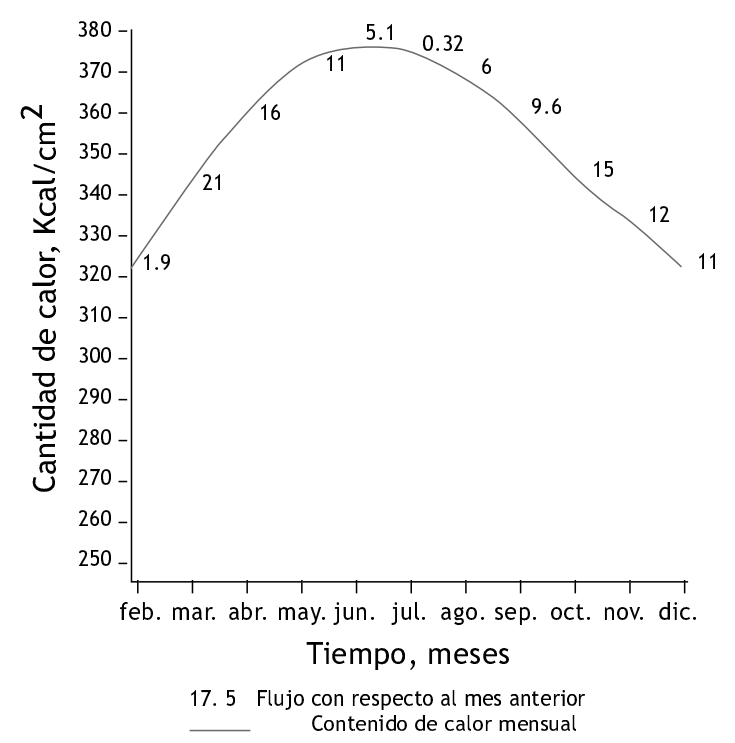

Figura No. 3.45 - Oscilaciones anuales cantidad de calor y flujo. Zona I CPC

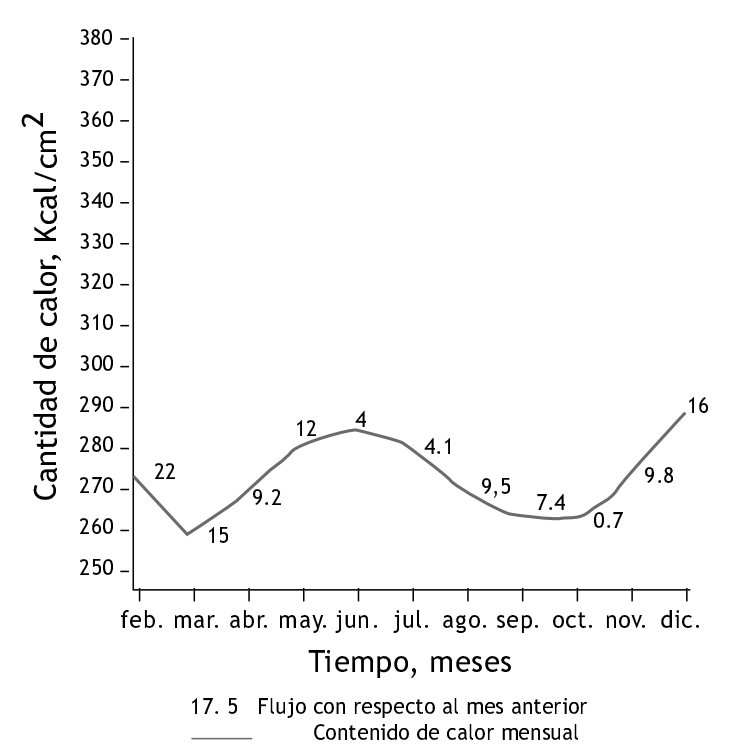

Figura No. 3.46 - Oscilaciones anuales cantidad de calor y flujo. Zona II CPC 


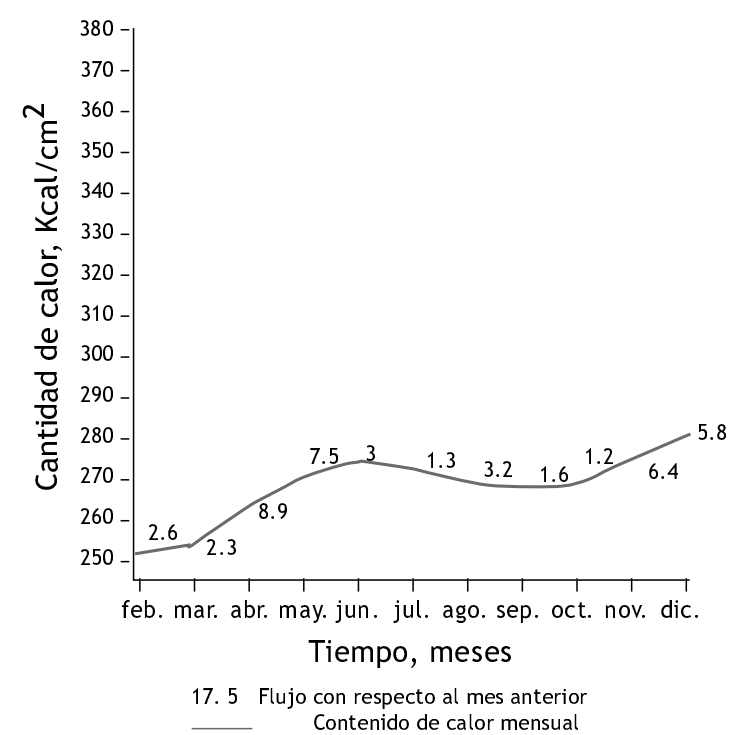

Figura No. 3.47 - Oscilaciones anuales cantidad de calor y flujo. Zona II CPC

El contenido de calor en la capa activa del océano de la Zona I (Fig. 3.45), aumenta de febrero a junio, cuando inicia su descenso hasta diciembre, lo cual no concuerda con otras zonas; además los valores fueron los más altos (322 $375 \mathrm{kcall}$ $\mathrm{cm}^{2}$ ). En la Zona II (Fig. 3.46) el valor $Q$ osciló entre 259289 $\mathrm{kcal} / \mathrm{cm}^{2}$ y presentó mínimos en marzo y septiembre-octubre, y máximos en junio y diciembre. Los valores negativos sobre la curva de $Q$ representan la pérdida de calor al final del mes (calor que fluye desde el océano hacia la atmósfera) y los valores positivos representan la ganancia de calor (calor que fluye de la atmósfera hacia el océano). La Zona II (Fig. 3.47) muestra que el flujo de calor es negativo en febrero y empieza su aumento hasta junio, cuando inicia la pérdida de calor hasta septiembre, momento en el cual al océano entra un nuevo flujo de calor con su máximo en diciembre. La cantidad total de $Q$ en el año varió entre 253 y $283 \mathrm{kcal} / \mathrm{cm}^{2}$.

En la Figura 3.48 de la Zona III se advierte una semejanza con lo observado en la Zona II, el mínimo de calor se apreció en marzo; el máximo en diciembre, y la cantidad de calor fluctuó entre 259 y $282 \mathrm{kcal} / \mathrm{cm}^{2}$.

La variación de $Q$ en la capa activa de la Zona IV se aprecia en la Figura 3.49. En general, se tuvo la misma fluctuación de las zonas II y III, con mínimos en marzo y septiembre, y máximos en junio y diciembre. La mínima cantidad de calor se presentó de una manera más acentuada en septiembre y no en marzo como en las anteriores, no en marzo como en las anteriores, lo cual muestra el desfase en el desplazamiento de los procesos

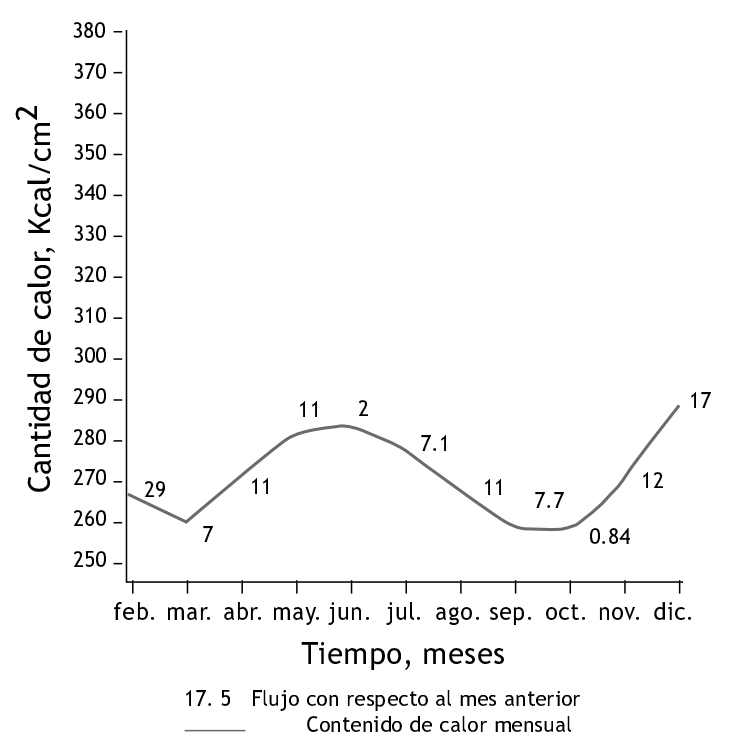

Figura No. 3.48 - Oscilaciones anuales cantidad de calor y flujo. Zona III CPC

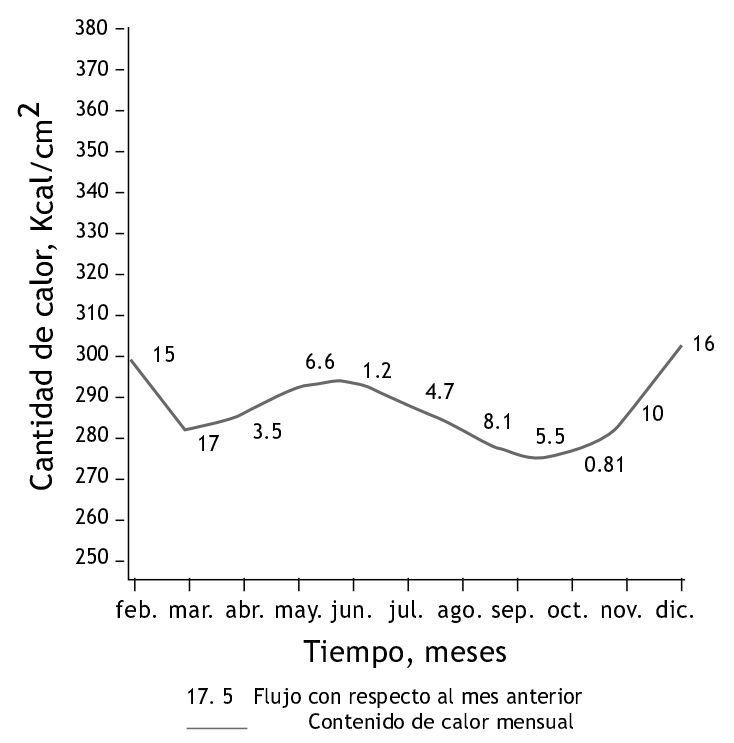

Figura No. 3.49 - Oscilaciones anuales cantidad de calor y flujo. Zona IV CPC

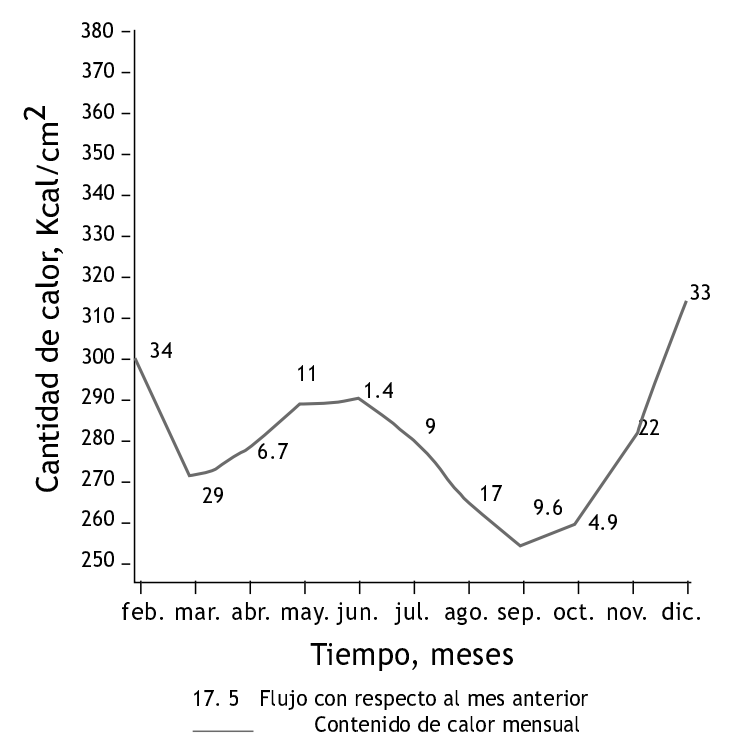

Figura No. 3.50 - Oscilaciones anuales cantidad de calor y flujo. Zona V CPC 
atmosféricos de una zona a otra. Los valores de $Q$ variaron en forma similar a los valores de las zonas anteriores con 264 y $291 \mathrm{kcal} / \mathrm{cm}^{2}$. Este mismo comportamiento se apreció en la Zona V (Fig. 3.50). Esta zona es cercana a la IV (sureste del Pacífico colombiano), por lo tanto los procesos de interacción océanoatmósfera se presentan en forma semejante. La cantidad de calor en la Zona V varió entre 248 y $306 \mathrm{kcal} / \mathrm{cm}^{2}$ y es la que presenta hasta el momento mayor amplitud en sus oscilaciones.

En la Zona VI (Fig. 3.51) se observaron los mínimos en marzo y octubre, y los máximos en junio y diciembre. El máximo valor no se presentó en diciembre sino en junio y, el mínimo observado en septiembre se retrasó un mes, observándose en octubre, cuya intensidad fue igual a la de marzo. La cantidad de calor varió entre 261 y $292 \mathrm{kcal} / \mathrm{cm}^{2}$.

La cantidad de calor en la Zona VII varió entre 257 y $305 \mathrm{kcal} / \mathrm{cm}^{2}$ (Fig. 3.52). Los procesos atmosféricos que influyen en este sector se desplazan hacia el noreste (pasando por la Zona IV) y noroeste (llegando hasta la Zona VII), lo cual hace que las fluctuaciones de la cantidad de calor en estas dos zonas sean similares.

En general, se observó que el valor promedio de $Q$ en la capa activa de la CPC fue de $275 \mathrm{kcal} / \mathrm{cm}^{2}$. Su fluctuación depende del desplazamiento de los procesos atmosféricos en cada zona observada, teniendo que los valores mínimos se observaron en marzo y septiembre, y los máximos en junio y diciembre. El máximo flujo de calor hacia el océano observado fue igual a 33 $\mathrm{kcal} / \mathrm{cm}^{2}$ en la Zona V, seguido por $25 \mathrm{kcal} / \mathrm{cm}^{2}$ en la Zona VI.

El máximo flujo de calor del océano hacia la atmósfera fue igual a $34 \mathrm{kcal} / \mathrm{cm}^{2}$ en la Zona $V$, seguido por $32 \mathrm{kcal} / \mathrm{cm}^{2}$ en la Zona VI. Lo que quiere decir, que las zonas V y VI son las

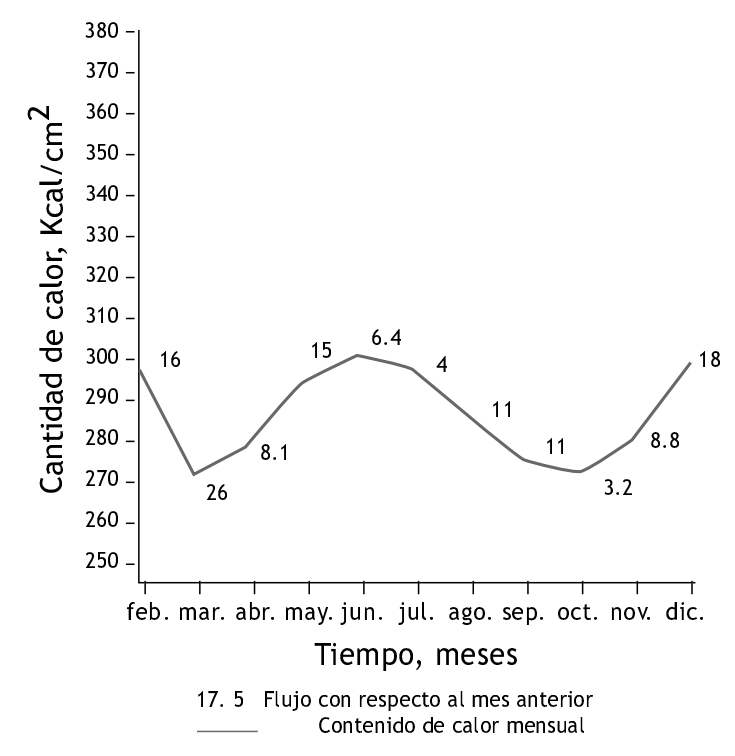

Figura No. 3.51 - Oscilaciones anuales cantidad de calor y flujo Zona VI CPC

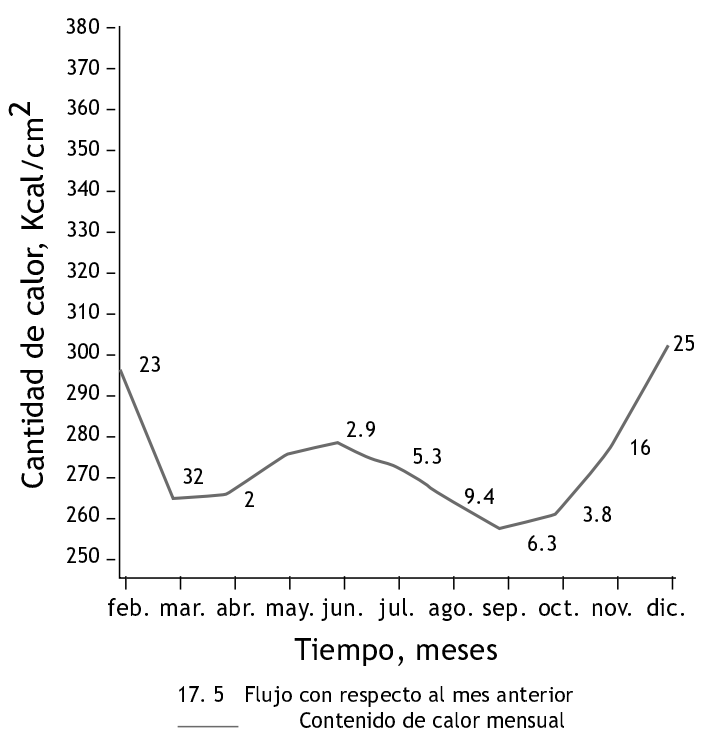

Figura No. 3.52 - Oscilaciones anuales cantidad de calor y flujo. Zona VII CPC

que manejan mayor cantidad de calor en la CPC. Los mínimos flujos de calor que llegan de la atmósfera y son retenidos por el océano se presentan en la Zona II con 8.9-16 $\mathrm{kcal} / \mathrm{cm}^{2}$ y la Zona IV con $16 \mathrm{kcal} / \mathrm{cm}^{2}$. Los mínimos flujos de calor que el océano entrega a la atmósfera se observan en las zonas I, II y IV con valores entre 0.32 y $4.7 \mathrm{kcal} / \mathrm{cm}^{2}$. Esto significa que estas zonas son las que intercambian menor cantidad de calor con la atmósfera en la CPC.

Las fluctuaciones de enfriamiento y calentamiento de aguas, permitieron corroborar la influencia del desplazamiento de la ZCIT en las zonas donde se registró mayor mezcla de aguas según el gradiente vertical de temperatura: zonas III, IV, sector este de la Zona VI y sector sur de la Zona V.

\subsection{LAS SURGENCIAS}

\section{Generalidades de las surgencias}

Son movimientos ascendentes mediante los cuales las aguas de los niveles subsuperficiales son llevadas hasta la superficie, desde profundidades, generalmente, menores de 100 - 200 metros y removidas desde el área de transporte por el flujo horizontal, produciéndose así un aporte de nutrientes a las aguas superficiales empobrecidas por el consumo biológico. 
Si bien el fenómeno puede ocurrir en cualquier parte del océano, sus características más destacadas se presentan a lo largo de los bordes orientales de los océanos (esto es en las costas occidentales de los continentes), como sucede en el noroeste y suroeste de África, en California, Perú y Chile. En éstas costas las aguas se caracterizan por sus relativamente bajas temperaturas y su alta producción de plancton (Fig. 3.53).

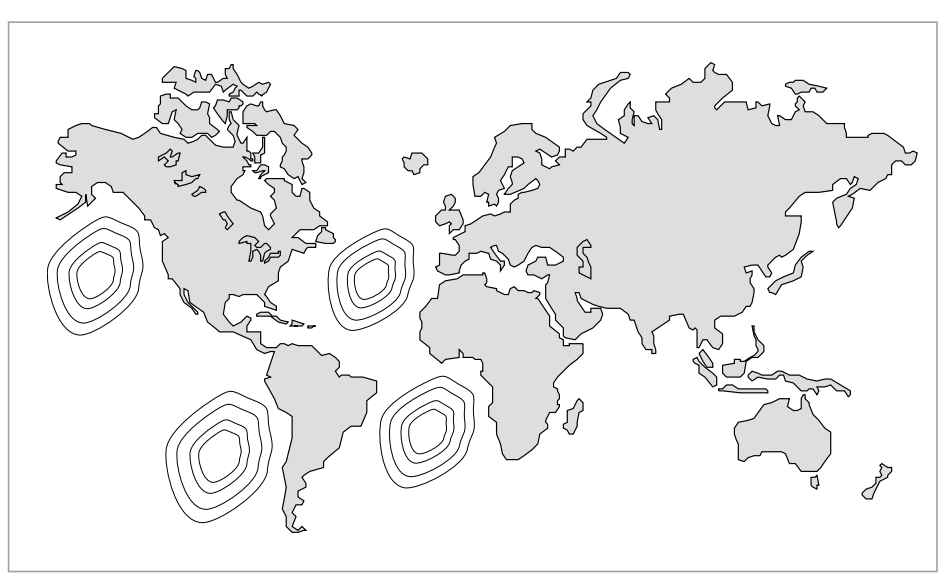

Figura 3.53 - Distribución global de las surgencias.

(Modificado de www.puc.cl/sw.educ/goe mar/)

Los sedimentos bajo estas áreas de fuerte surgencia son típicamente ricos en materia orgánica; estos aportan algunas guías para conocer la intensidad de la surgencia ya que las especies planctónicas (foraminíferos, diatomeas) tienden a indicar aguas frías.

Se pueden distinguir en el océano varios tipos de surgencias: oceánica, costera y ecuatorial. De ellas la surgencia costera o litoral es muy importante puesto que determina contrastes climáticos y biológicos notables y crea las condiciones para una gran productividad biológica (Tomczak y Godfrey, 1994).

\section{Tipos de Surgencias}

Por transporte de EKMAN: Debida al efecto de Coriolis por el cual las aguas se desvían hacia la izquierda en el hemisferio sur. El efecto de Coriolis hace que el agua que ha sido puesta en movimiento por los vientos sea desviada a la derecha en el hemisferio norte y a la izquierda en el hemisferio sur. Sin embargo, debido a la fricción las capas superficiales se mueven en un ángulo de $45^{\circ}$. Así, el cuerpo de agua puede pensarse como un conjunto de varios estratos, cada uno se mueve cada vez más lento por la fricción, en un movimiento en espiral cada vez más hacia la izquierda en el Hemisferio Sur hasta que la fricción es nula. La dirección del movimiento varía para cada capa, pero el flujo promedio es $90^{\circ}$ a la izquierda del viento prevaleciente.

Surgencia por acción de vientos continentales: Ocurre con vientos constantes que soplan desde el continente hacia el centro del océano y que alejan el agua próxima al borde costero, haciendo emerger aguas subsuperficiales. Ocurre en las costas españolas del Mediterráneo, por acción del Mistral (fuerte viento continental).

Surgencia en el océano abierto: Es el caso de la surgencia ecuatorial debida a la divergencia producida por los vientos Alisios que generan corrientes (Ecuatorial del Norte y Ecuatorial del Sur) que transportan agua hacia la derecha al norte del Ecuador y hacia la izquierda al sur, generando surgencia.

Surgencia por diferencias de densidad: Debidas a la circulación termohalina, en que el agua más densa se hunde y es reemplazada por aguas menos densas (Pontificia Universidad Católica de Chile, 1999).

Estudio de los movimientos verticales y zonas de surgencia

Desde 1997 en la CPC se han realizado estudios de los movimientos verticales del agua, teniendo en cuenta valores obtenidos en algunos cruceros oceanográficos (Villegas, 1997b). También se estudió en una oportunidad la variación de las zonas de surgencia y la velocidad de sus corrientes verticales tratando de relacionar al ciclo ENOS, de acuerdo con información de este fenómeno a nivel global, tomando como ejemplo tres años diferentes(Villegas, 1997b), pero no se ha discutido si existen ciclos de ascensos de agua dentro del año para la CPC.

Para la determinación de los movimientos verticales de las aguas de la CPC, a través del año, se utiliza la teoría de solución de problemas de diagnóstico con un modelo no lineal de cálculo de velocidades en regiones con dificultades dinámicas como es el caso de la zona Ecuatorial y sus alrededores, denominado Modelo D3, desarrollado por A.S. Sarkicián (Sarkician y Denima y 1986, Villegas, 1997b). 
Tabla No. 3.1 - Valores promedio de las corrientes verticales $\left(\times 10^{-5} \mathrm{~cm} / \mathrm{s}\right)$ en capas de 0-100 m - Cuenca del Pacífico Colombiano

\begin{tabular}{lccccccc} 
& $\mathbf{0 - 1 0 m}$ & $\mathbf{1 0 - 2 5 m}$ & $\mathbf{2 5 - 5 0 m}$ & $\mathbf{5 0 - 7 5 m}$ & $\mathbf{7 5 - 1 0 0 m}$ & Promedio \\
\hline Ascenso & 15.219 & 15.161 & 15.243 & 14.994 & 14.449 & 15.013 \\
Descenso & 13.929 & 13.937 & 13.736 & 13.764 & 13.937 & 13.861 \\
Promedio & 14.574 & 14.549 & 14.489 & 14.381 & 14.193 & 14.437 \\
\hline
\end{tabular}

Para los cálculos de los movimientos verticales y determinación de zonas de surgencia a través del año se tomó como información inicial datos de presión atmosférica resultantes de un modelo atmosférico elaborado para el océano Pacífico por el Centro Meteorológico de Europa, con datos de 1988-1998, de donde se interpoló un campo para la región de estudio (Climate Diagnostics Bulletin, 1988-1998); la elevación de la superficie que resultó de un modelo oceanológico de la Universidad Hidrometeorológica del Estado Ruso realizado para el océano Pacífico teniendo en cuenta datos de salinidad y temperatura del World Ocean Atlas 1994 CD-ROM Data set NOAA (Neelov, 2002) y valores promedio mensuales de la temperatura del mar y salinidad de la CPC (Málikov, 1998).

Las corrientes verticales por lo general deben aumentar con el incremento de la profundidad. Esta relación se señala claramente en cálculos de corrientes verticales realizados sobre la CPC con datos obtenidos de cruceros oceanográficos en los años de 1986, 1988, 1990 (Villegas, 1997a); 1996 (Villegas, 1997b) y 2000. En 1986 la velocidad vertical promedio en la capa 0 - 10 $\mathrm{m}$ fue $11.5 \times 10^{-5} \mathrm{~cm} / \mathrm{s}$ y en la capa $100-150 \mathrm{~m}$ fue $420 \times 10^{-5} \mathrm{~cm} /$ $\mathrm{s}$; en 1988 en la capa $0-10 \mathrm{~m}$ el promedio fue de $5 \times 10^{-5} \mathrm{~cm} / \mathrm{s}$; en la capa 100 - $150 \mathrm{~m}$ fue de $75 \times 10^{-5} \mathrm{~cm} / \mathrm{s}$; en $199015 \times 10^{-5} \mathrm{~cm} /$ s en la capa $0-10 \mathrm{~m}$, y $210 \times 10^{-5} \mathrm{~cm} / \mathrm{s}$ en la capa $100-150 \mathrm{~m}$. En junio y octubre de 1996 los promedios fueron de $20 \times 10^{-5} \mathrm{~cm} / \mathrm{s}$ en las capas 0 - $10 \mathrm{~m}$ y de $200 \times 10^{-5} \mathrm{~cm} / \mathrm{s}$ en $100-150 \mathrm{~m}$, teniendo que junio presentó velocidades relativamente más altas que octubre. Finalmente, en el año 2000 se tuvo $40 \times 10^{-5} \mathrm{~cm} / \mathrm{s}$ en la capa $10-10$ m y 250 en la capa $100-150$ m.

Los resultados en los cálculos de velocidades de corrientes verticales para todo el año se presenta en la Tabla 3.1. El valor promedio de la capa $0-10 \mathrm{~m}$ es de $14.6 \times 10^{-5} \mathrm{~cm} / \mathrm{s}$ y luego, disminuye en forma leve (en $0.4 \times 10^{-5} \mathrm{~cm} / \mathrm{s}$ ) con el incremento de la profundidad en lugar de aumentar, llegando a $14.2 \times 10^{-5} \mathrm{~cm} / \mathrm{s}$ en la capa $75-100 \mathrm{~m}$. Este comportamiento puede ser debido a que los datos con los cuales se realizaron los cálculos son insuficientes en profundidades mayores a los $100 \mathrm{~m}$ (especialmente los de salinidad) y, ya que el modelo utilizado se basa en la integración del factor baroclínico en la columna de agua, además del componente gradiental y eólico (Semionov, 1981; Sarkisian y Demina, 1986; Sarkisian, 1991 y Villegas, 1997b), los resultados se hacen sensibles a esta falta de información provocando inconsistencias capa a capa en los valores de las corrientes verticales, pero no afecta al sentido de las corrientes.

Se ha obtenido que la velocidad promedia de las corrientes verticales de la CPC es de aproximadamente $14 \times 10^{-5} \mathrm{~cm} / \mathrm{s}$ en las aguas superficiales $(0-100 \mathrm{~m})$. La variación mensual muestra que en la capa 0 - $100 \mathrm{~m}$ los valores de las velocidades de corrientes verticales en ascenso (intensidad de surgencia) son mayores que las de descenso en $2 \times 10^{-5} \mathrm{~cm} / \mathrm{s}$.

Los meses de valores máximos de velocidades de corrientes verticales son febrero y marzo, tanto en ascenso como en descenso. Los mínimos coinciden en ascenso y descenso, en octubre y noviembre. Las zonas de ascenso de aguas abarcan un mayor porcentaje del área de estudio en febrero, cuando el 56\% de la CPC presenta zonas de surgencia; en marzo, abril y mayo un $49 \%$ y en diciembre, cuando éstas abarcan un $51 \%$ de la CPC.

Para determinar cuáles son los sectores de la CPC en donde se presentan las zonas de surgencia y cómo varían sus posiciones en la capa 0 - $10 \mathrm{~m}$ de cada mes (a excepción de enero y julio) se ha graficado en gamas de color azul claro la distribución de las zonas de surgencia encerradas con una isolínea negra punteada. Los tonos más claros corresponden a los focos de surgencia, donde la velocidad de corriente vertical en ascenso es máxima.

En febrero (Fig. 3.54.a.) se aprecia que la zona de surgencia cubre una gran parte de la CPC. Ésta se extiende desde los $81^{\circ} 30^{\prime} \mathrm{W}-5^{\circ} \mathrm{N}$, pasando por la isla de Malpelo, hacia los $78^{\circ} 30^{\prime} \mathrm{W}-2^{\circ} 30^{\prime} \mathrm{N}$. Las dimensiones aproximadas de la zona de surgencia que se observa en las capas superficiales 
son: largo 260 millas y ancho 60 millas. Se observa la presencia de cinco focos de surgencia cuyas coordenadas son: $79^{\circ} \mathrm{W}$ $3^{\circ} \mathrm{N} ; 79^{\circ} \mathrm{W}-4^{\circ} \mathrm{N} ; 80^{\circ} \mathrm{W}-4^{\circ} \mathrm{N} ; 80^{\circ} \mathrm{W}-2^{\circ} 30^{\prime} \mathrm{N}$ y $81^{\circ} 30^{\prime} \mathrm{W}-2^{\circ} \mathrm{N}$. El foco de surgencia que tiene mayor velocidad de corrientes verticales se encuentra en el suroeste de la CPC.

En marzo (Fig. 3.54.b) las dimensiones de la surgencia que se encontraba alrededor de la isla de Gorgona disminuyen y ésta se desplaza hacia los $79^{\circ} \mathrm{W}-3^{\circ} \mathrm{N}$. La distribución de las aguas en ascenso cambia ya que se aprecia una división de la zona, dejando al sector central con aguas en descenso. Una zona de surgencia se ubica al noreste de la CPC entre los $78^{\circ} 30^{\prime} \mathrm{W}-79^{\circ} 30^{\prime} \mathrm{W}$ y $3^{\circ} 45^{\prime} \mathrm{N}-5^{\circ} 45^{\prime} \mathrm{N}$ y otra al suroeste, en forma de anillo semicerrado, que rodea un área con aguas de descenso. Los focos de surgencia en marzo son cuatro, los cuales muestran el desplazamiento de los encontrados en el mes anterior. Sus coordenadas son: $79^{\circ} \mathrm{W}-3^{\circ} \mathrm{N} ; 79^{\circ} \mathrm{W}-4^{\circ} 30^{\prime} \mathrm{N}$; $80^{\circ} \mathrm{W}-2^{\circ} 30^{\prime} \mathrm{N}$ y $80^{\circ} 45^{\prime} \mathrm{W}-2^{\circ} \mathrm{N}$.

Las zonas de ascenso de aguas en abril (Fig. 3.54.c) muestran un cambio en sus dimensiones, prácticamente se reparte en cinco zonas por la CPC con los focos ubicados así: 79³0’ $\mathrm{W}$ $2^{\circ} \mathrm{N} ; 79^{\circ} 30^{\prime} \mathrm{W}-3^{\circ} \mathrm{N} ; 80^{\circ} \mathrm{W}-2^{\circ} 30^{\prime} \mathrm{N} ; 81^{\circ} \mathrm{W}-2^{\circ} \mathrm{N}$ y $79^{\circ} \mathrm{W}-5^{\circ} \mathrm{N}$.

En mayo (Fig. 3.54.d) se aprecia cómo las zonas de ascenso de aguas se han desplazado unas 30 millas en dirección sureste. Alrededor de la isla de Malpelo se observa ascenso de aguas pero alrededor de la isla de Gorgona no. Se pueden definir en forma general dos zonas de surgencia: una diago-

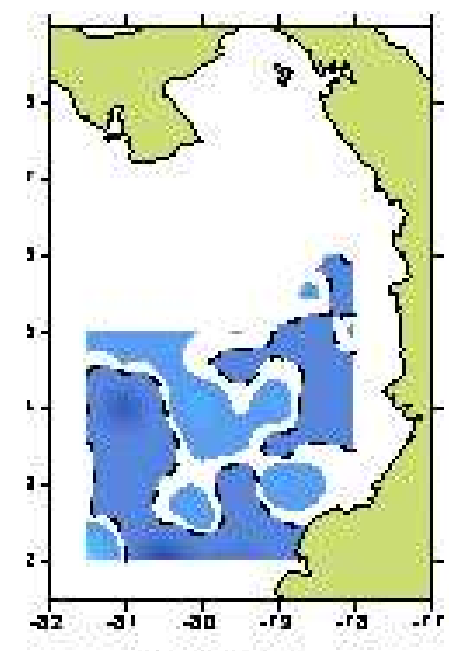

a) Febrero

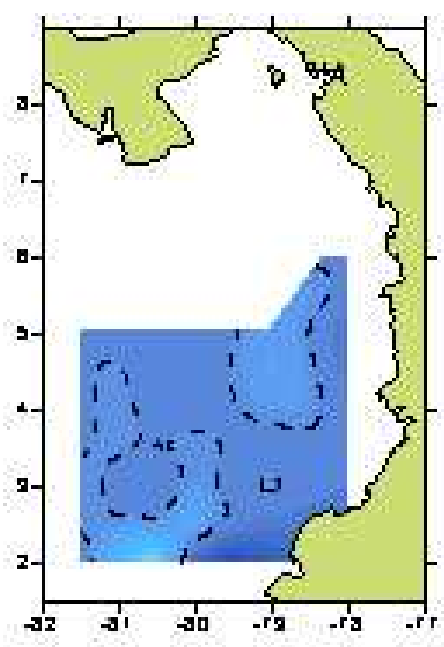

b) Mazo nal de 216 millas de largo por 30 millas de ancho y otra correspondiente a la línea del meridiano $81^{\circ} 30^{\prime} \mathrm{W}$, la cual avanza tomando mayores áreas al norte y sur de la misma. Los núcleos de surgencia (focos) siguen siendo cinco, ubicados así: $78^{\circ} 30^{\prime} \mathrm{W}-4^{\circ} 30^{\prime} \mathrm{N} ; 79^{\circ} \mathrm{W}-4^{\circ} \mathrm{N} ; 79^{\circ} 30^{\prime} \mathrm{W}-3^{\circ} \mathrm{N} ; 80^{\circ} 30^{\prime} \mathrm{W}$ $2^{\circ} 15^{\prime} \mathrm{N}$ y $81^{\circ} 30^{\prime} \mathrm{W}-2^{\circ} 30^{\prime} \mathrm{N}$.

En el mes de junio, las zonas de surgencia tienen menores dimensiones que las del mes de mayo (figura No. 3.55.a) y se presenta en las capas superiores con cinco focos de surgencia: $78^{\circ} 30^{\prime} \mathrm{W}-4^{\circ} 30^{\prime} \mathrm{N} ; 79^{\circ} 45^{\prime} \mathrm{W}-3^{\circ} \mathrm{N}$; $80^{\circ} 30^{\prime} \mathrm{W}-2^{\circ} \mathrm{N} ; 81^{\circ} 30^{\prime} \mathrm{W}-2^{\circ} \mathrm{N}$ y $80^{\circ} 30^{\prime} \mathrm{W}-4^{\circ} 30^{\prime} \mathrm{N}$.

Para los meses de agosto, septiembre y octubre (Fig. 3.55.b, 3.55.c y 3.55.d) las zonas de ascenso de aguas se asemejan en cuanto a su centralización. Alrededor de la isla de Malpelo se siguen observando surgencias, pero alrededor de la isla de Gorgona éstas no se presentan. En estos meses la zona de surgencia que se destaca atraviesa a la CPC sobre el meridiano $80^{\circ} \mathrm{W}$ con un largo de 180 millas y un ancho de 60 millas. A lo largo del meridiano $81^{\circ} 30^{\prime} \mathrm{W}$ el ascenso de aguas se vuelve leve como en los primeros meses del año y se concentra en el sureste. En agosto y septiembre se observan solamente dos focos extensos de surgencia en el meridiano $80^{\circ} \mathrm{W}$ : uno entre $4^{\circ}-5^{\circ} \mathrm{N}$ y otro entre $2^{\circ} 30^{\prime} \mathrm{N}-3^{\circ} 45^{\prime} \mathrm{N}$. En octubre se acentúa un nuevo foco en este mismo meridiano dividiendo en dos al de $2^{\circ} 30^{\prime} \mathrm{N}-3^{\circ} 45^{\prime} \mathrm{N}$.

En noviembre y diciembre las zonas surgencia nuevamente se distribuyen por varios sectores de la CPC (Fig. 3.56.a y 3.56.b),

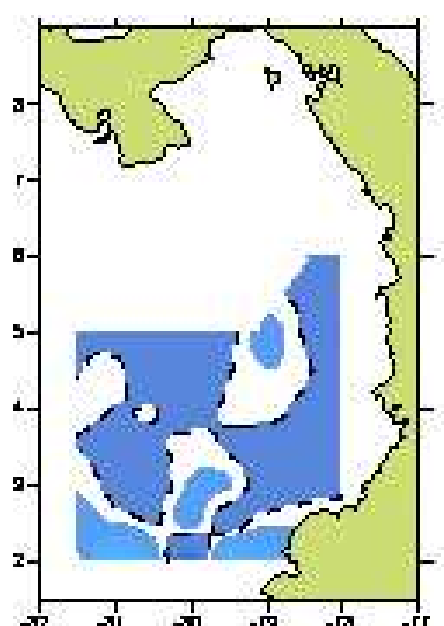

c) Abril

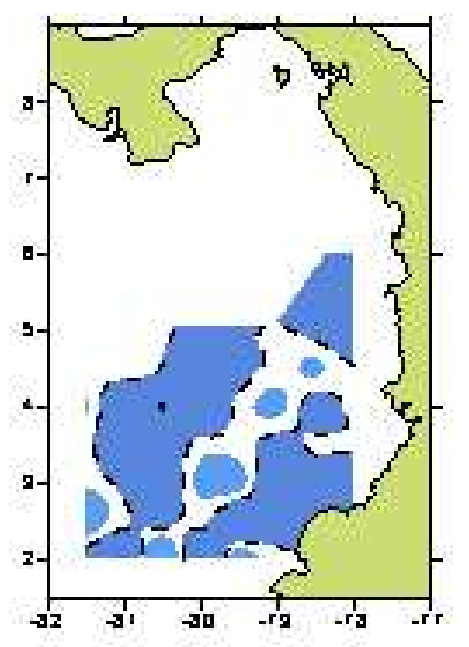

d) Majo
Vebcidedes vertic =les $\times 10^{-2} \mathrm{~cm} / \mathrm{s}$

Figura No. 3.54 - Zonas de surgencia capa de 0-10 m. Febrero-mayo, CPC. 


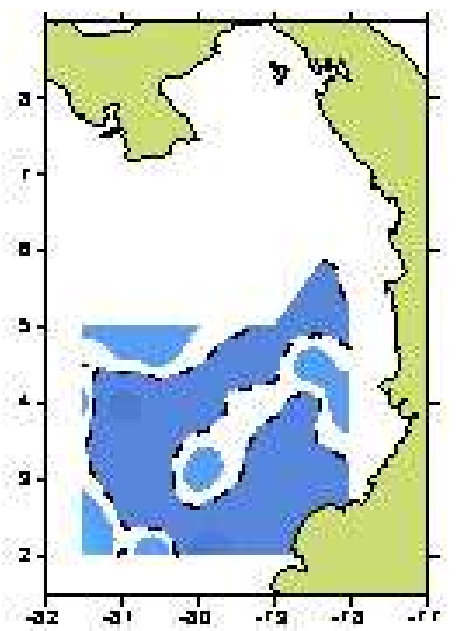

a) Junio

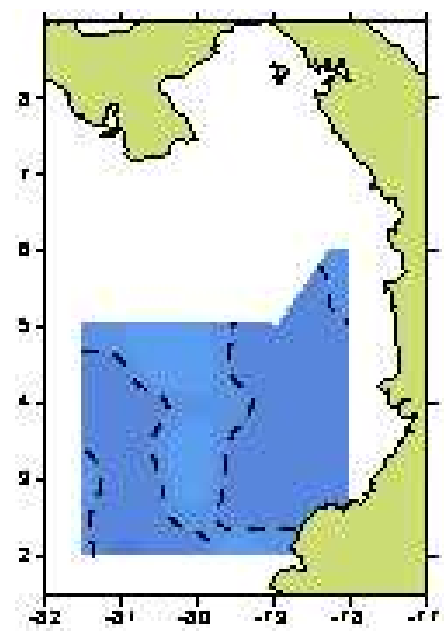

b) Agosto

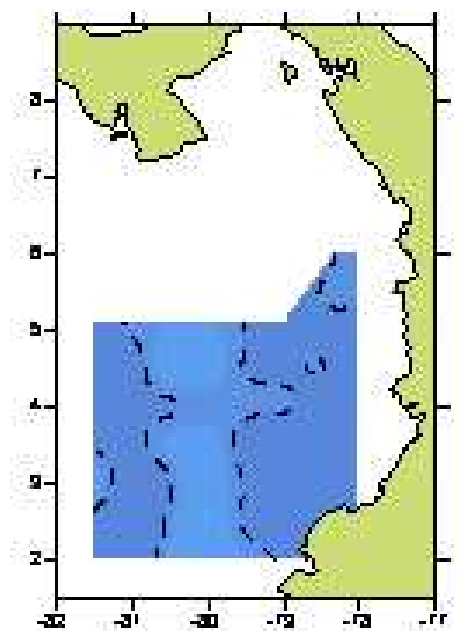

c) Septiembre

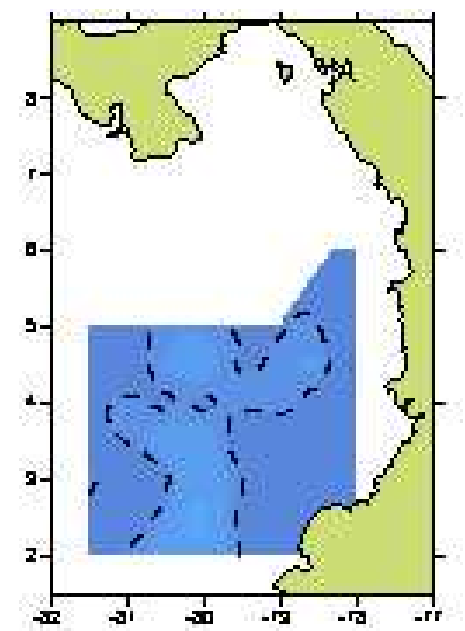

d) Octubre

Veboidedes verticales $\times 10^{-3} \mathrm{~cm} / \mathrm{s}$

Figura No. 3.55 - Zonas de surgencia capa de 0-10 m. Junio-octubre, CPC.

pero aún no se aprecian ascensos de aguas en los alrededores de la isla de Malpelo y Gorgona. Aparecen nuevamente ascensos de aguas en el noreste y a lo largo del meridiano $81^{\circ} 30^{\prime} \mathrm{W}$, aunque en forma leve. El meridiano $80^{\circ} \mathrm{W}$ sigue siendo el centro de la zona de surgencia, la cual se presenta en noviembre con 180 millas de largo y 60 millas de ancho y en diciembre se vuelve más pequeña (120 millas de largo con 60 millas de ancho), pero aparecen dos nuevas zonas con, aproximadamente, las mismas dimensiones ( $120 \times 60$ millas) entre los meridianos $78^{\circ} \mathrm{W}$ $79^{\circ} \mathrm{W}$ y otra sobre el meridiano $81^{\circ} 30^{\prime} \mathrm{W}$.

Los focos de surgencias en noviembre son cuatro: $78^{\circ} 30^{\prime} \mathrm{W}$ $4^{\circ} 30^{\prime} \mathrm{N}$; $80^{\circ} \mathrm{W}-3^{\circ} 30^{\prime} \mathrm{N}$; $80^{\circ} \mathrm{W}-2^{\circ} 30^{\prime} \mathrm{N}$ y $81^{\circ} 30^{\prime} \mathrm{W}-2^{\circ} \mathrm{N}$. En diciembre los focos son los mismos, pero aumenta uno a los $79^{\circ} \mathrm{W}-3^{\circ} \mathrm{N}$, el cual se apreciaba en forma leve también en noviembre en las capas superficiales.

En general, en la CPC se observan zonas de surgencia durante todo el año. Los ascensos de agua se perciben en todos los meses y se puede suponer que inician su movimiento ascendente desde profundidades superiores a los $400 \mathrm{~m}$. Existen zonas de surgencia que se observan siempre desde la capa 300 $400 \mathrm{~m}$ y se ubican en el noreste (excepto de agosto a octubre), sobre el meridiano $80^{\circ} \mathrm{W}$ (a excepción de junio) y a lo largo del meridiano $81^{\circ} 30^{\prime} \mathrm{W}$ (excepto en octubre). A partir de los $100 \mathrm{~m}$ de profundidad los sectores de ascenso de aguas aumentan sus dimensiones y perduran hasta alcanzar la superficie. La mayor intensidad y extensión de zonas de surgencia se aprecia entre febrero-abril y noviembrediciembre.

Las zonas de afloramiento empiezan a disminuir en mayo y son menores entre agosto-octubre. La distribución e intensidad de los ascensos de agua presentan concordancia con el desplazamiento de los frentes atmosféricos creados con la migración de la ZCIT. Los primeros meses del año las zonas de surgencia se encuentran distribuidas por toda la CPC y aparecen con mayor intensidad desde el suroeste. A partir de mayo se cubre el meridiano $81^{\circ} 30^{\prime} \mathrm{W}$ y las zonas se desplazan 30 millas hacia el interior; de agosto a octubre se concentran en el centro de la CPC sobre el meridiano $80^{\circ} \mathrm{W}$ y en noviembre-diciembre empiezan, nuevamente, a distribuirse por toda la CPC.

Las mayores concentraciones de zonas de surgencia se encontraron en los primeros meses con 296 millas de largo por 90 millas de ancho. Las menores se observaron a mitad de año y sus dimensiones son 120 millas de largo y 60 millas de ancho. Esto da un promedio aproximado de 208 millas de largo por 75 millas de ancho, o sea 15600 millas cuadradas; lo cual, comparado con la zona de surgencia más cercana a esta región (la surgencia del Perú) con 25250 millas cuadradas, muestra que la CPC puede ocupar un puesto importante en la economía del país.

Es claro que la surgencia peruana es más intensa, con un espesor de $200 \mathrm{~m}$ presentada en forma continua a lo largo del 

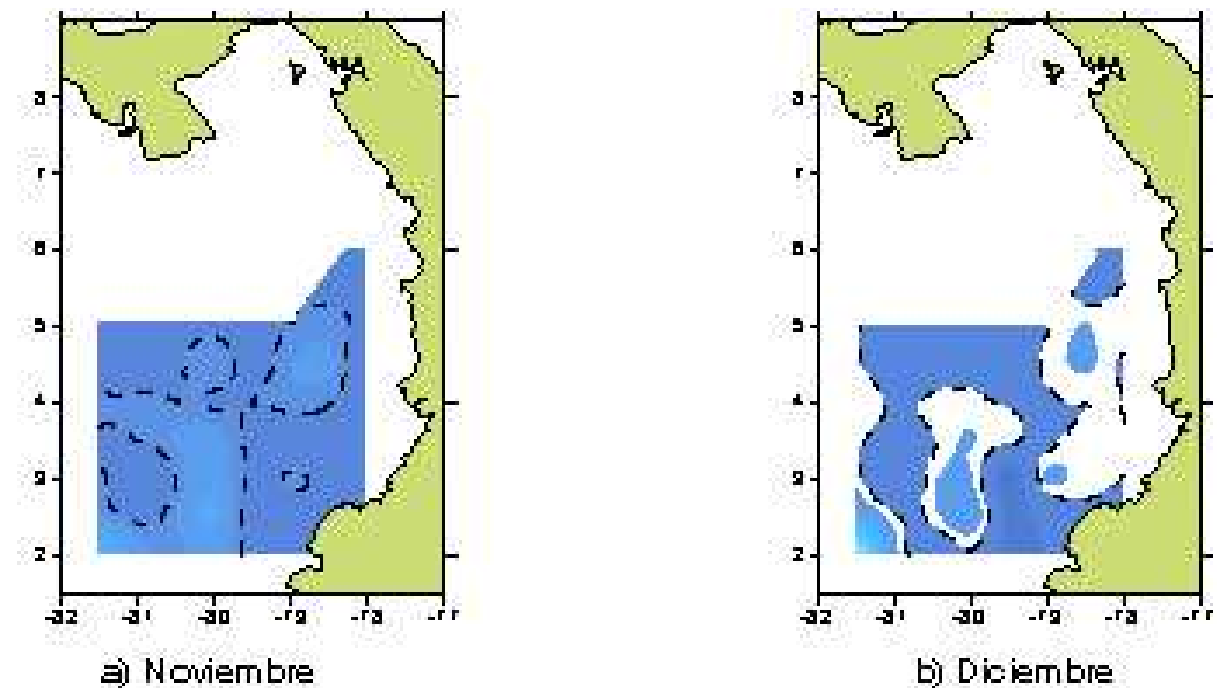

b) Diciembre

Velocidades werticales $\times 10^{-3} \mathrm{~cm} / \mathrm{s}$

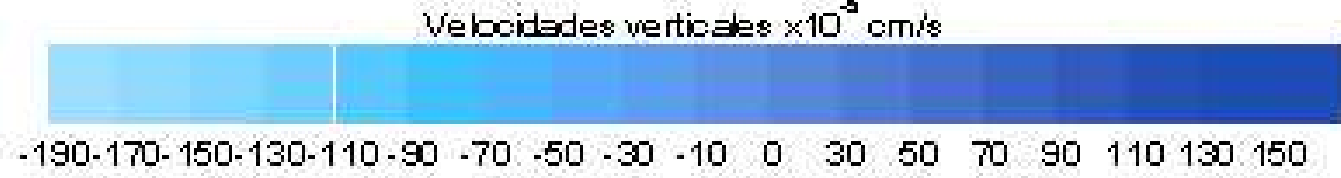

Figura No. 3.56 - Zonas de surgencia capa de 0-10 m. Noviembre-diciembre cuenca del Pacífico colombiano

año por la permanente influencia de los vientos (Wyrtki, 1965); en cambio en la CPC, aunque parece ser que las aguas ascienden desde profundidades mayores a $400 \mathrm{~m}$, el espesor medio de la capa de surgencia es, aproximadamente, de 100 $\mathrm{m}$ variando durante el año por la presencia y desplazamiento de la ZCIT.

La cantidad de focos de surgencia encontrados varía entre cinco y dos, los cuales aparecen y desaparecen durante el año y ubicándose por lo general alrededor de las coordenadas: $78^{\circ} 30^{\circ} \mathrm{W}$ $-4^{\circ} 30^{\prime} \mathrm{N} ; 79^{\circ} \mathrm{W}-3^{\circ} \mathrm{N} ; 80^{\circ} \mathrm{W}-2^{\circ} 30^{\prime} \mathrm{N} ; 80^{\circ} \mathrm{W}-3^{\circ} 30^{\prime} \mathrm{N}$ y $81^{\circ} 30^{\circ} \mathrm{W}-2^{\circ} \mathrm{N}$.

Dentro del área costera no se han encontrado zonas de surgencia, lo que puede deberse a que en los cálculos esta área no ha sido cubierta, totalmente, por insuficiencia de información y, por lo tanto, se ve la necesidad de realizar monitoreos puntuales para estudios de surgencia costera en la CPC. La ascensión comienza en la parte más alejada de la costa (a profundidades medias de unos 100400 m) y está determinada por el paso de la ZCIT, por lo tanto, el movimiento ascendente alrededor de las islas Malpelo y Gorgona varían durante el año. Cerca de la isla de Malpelo el ascenso de aguas se observa en todo el año, excepto en noviembre y diciembre. Alrededor de la isla de Gorgona no se apreciaron surgencias en todos los meses, pero se encontraron en forma intensa en febrero y abril. En trabajos anteriores alrededor de esta isla se encontraron surgencias bien definidas (Villegas, 1997b).
Los cálculos de corrientes verticales y determinación de zonas de surgencia realizados en el presente trabajo son una aproximación de lo que se podría ver mes a mes en diferentes capas en la CPC y sirven como referencia para la continuación de esta investigación pero con aumento de la información inicial.

Debido a que en el océano mundial se ha visto que las regiones de surgencia son muy diferentes en cuanto a sus causas y al comportamiento de las oscilaciones de los movimientos verticales, es necesario realizar más estudios sobre este tema para conocer mejor la región. También sería importante crear un proyecto enfocado a la búsqueda de zonas de productividad en la CPC como alternativa para el desarrollo económico de la región por medio de un estudio completo que determine las características particulares de la CPC, utilizando tanto métodos de monitoreo de zonas de afloramiento (transeptos oceanográficos e hidrobiológicos en la costa; monitoreo oceánico de temperatura y color por imágenes satelitales), como métodos de cálculos de corrientes verticales.

En el presente capítulo se dieron a conocer algunos de los estudios oceanográficos de la CPC, elaborados por el CCCP, consciente de la necesidad de seguir investigando toda el área de la cuenca, por lo tanto, continúa con el monitoreo y análisis de datos actualizados que permitan complementar la información inicial, avanzar en la caracterización de la CPC y apoyar las investigaciones que se han realizado hasta el momento por su grupo de investigadores. 


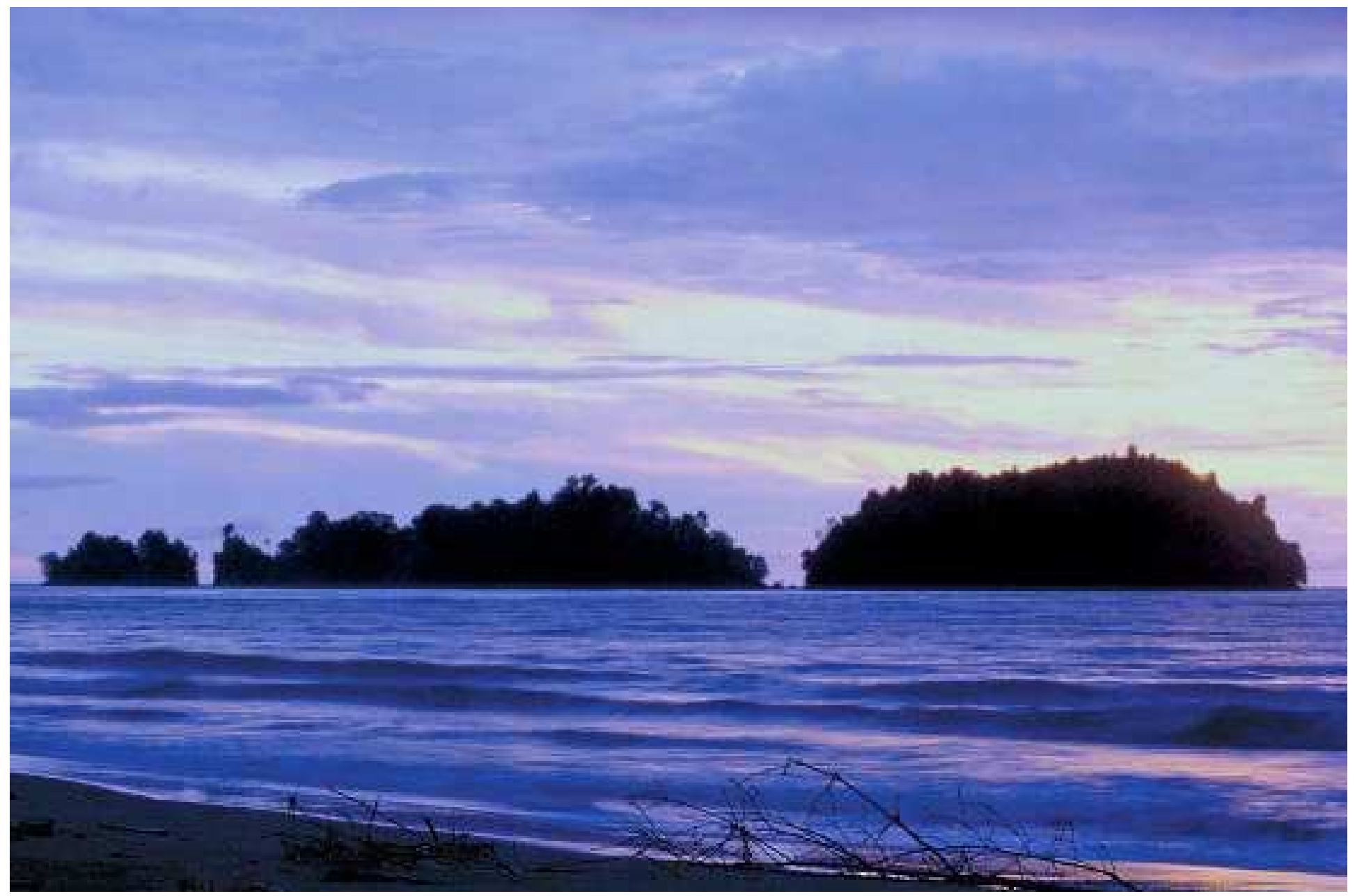

Islas rocosas en inmediaciones de Nuquí, Chocó. 


\section{CAPÍTULO IV - Búsqueda de la Relación de las Condiciones Oceanográficas de la Cuenca Pacífica Colombiana con El Ciclo Enos}

\section{EL NIÑO Y LA NIÑA}

El Fenómeno El Niño-Oscilación del Sur, ENOS, es una manifestación de la variabilidad climática del sistema océanoatmósfera en el océano Pacífico; su duración (10-18 meses) lo ubica en la escala interanual y el área que cubre permite situarlo en la escala regional. Sin embargo, se ha comprobado que sus efectos alteran el comportamiento normal de las condiciones climáticas en otros lugares de la Tierra, haciendo posible afirmar también que es de carácter global (Pontificia Universidad Católica de Chile, 1999).

La explicación global con que se le estudia actualmente es de gran interés, puesto que ofrece a la Meteorología un marco de explicaciones para comprender cambios de largo plazo; a la Oceanografía Física visiones globales y de conjunto destinadas a interpretar diversos hechos organizados espacialmente, y a la Geografía, en general, argumentos para comprender la compleja interacción entre eventos naturales, biológicos, económicos y humanos.

En 1924 sir Gilbert Walker descubrió el Enlace Transpacífico de Sistemás de Presiones, el cual explicaba que cuando la presión aumenta en el sistema de altas presiones (centrado en la isla de Pascua), desciende en el sistema de bajas presiones (centrado en Indonesia y el Norte de Australia) (Fig. 4.1). Para cuantificar este fenómeno definió el Índice de Oscilación Sur, restando la presión en el Pacífico Occidental de la oriental. Este índice es positivo y se denomina Período Estable, cuando la diferencia es más alta de lo normal,

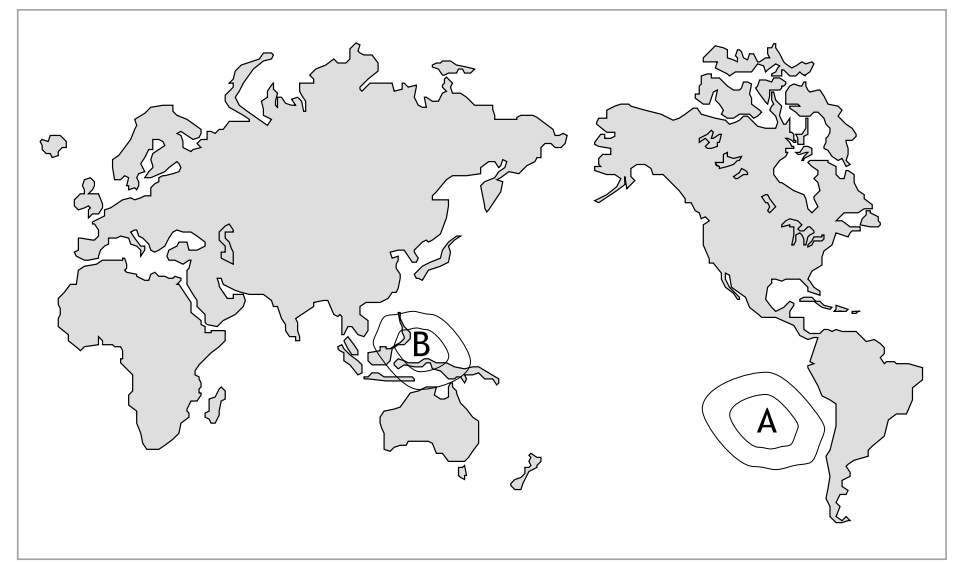

Figura 4.1 - Centros de diferencia de presión en el océano Pacífico. (Modificado de www.puc.cl/sw.educ/goe mar/) ocasionando vientos intensos. En este caso, los vientos Alisios y la Corriente Ecuatorial del Sur son intensos, hay un aumento del nivel del mar en el borde occidental del Pacífico, mientras que en el borde oriental el nivel del mar es más bajo y se presentan aguas frías como afloramientos (surgencias) (Fig. 4.2 - 4.3)

Es negativo cuando es inferior a lo habitual, ocasionando disminución en lluvias monzónicas de verano y disminución en los vientos.

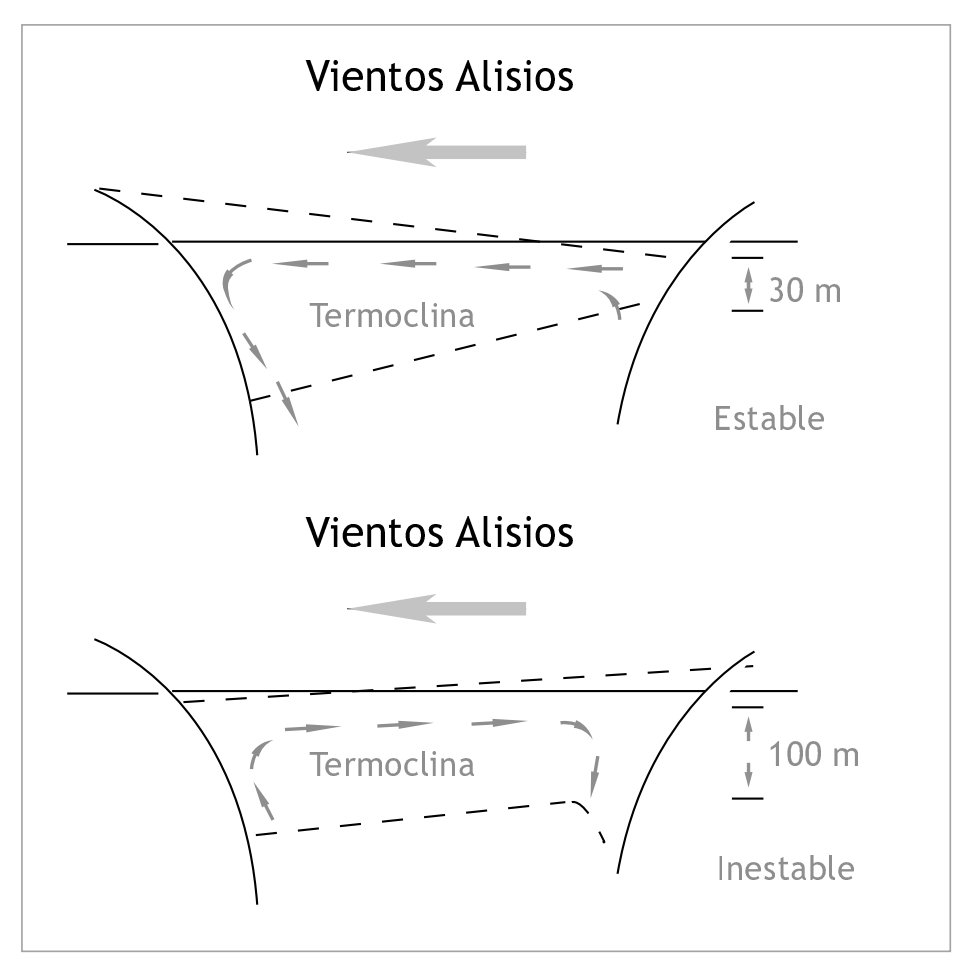

Figura 4.2 - Estabilidad de las aguas en el océano Pacífico Ecuatorial. (Modificado de www.puc.cl/sw.educ/goe mar/)

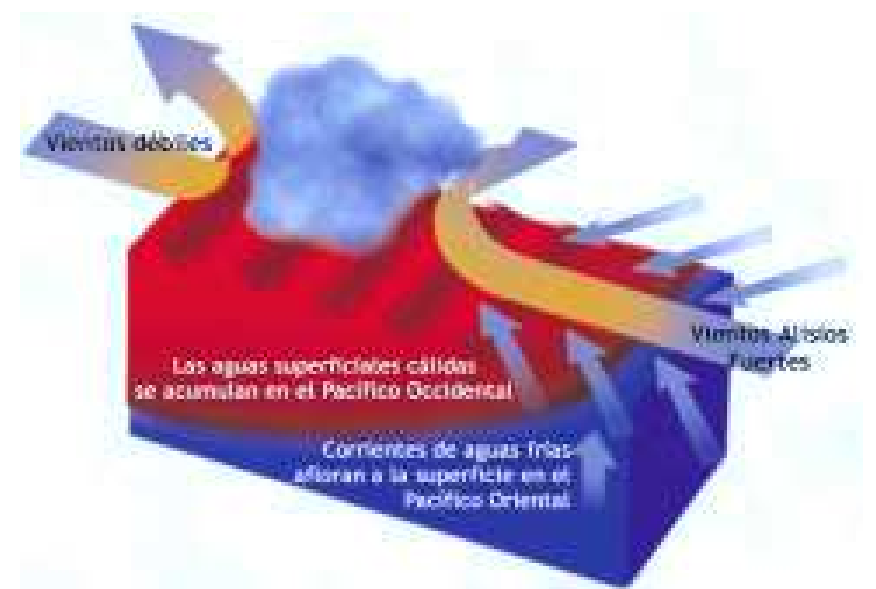

Figura 4.3 - Condiciones normales en las aguas del Pacífico Ecuatorial. (Modificado de www.puc.cl/sw.educ/goe mar/) 
Una diferencia de presiones más alta y positiva implica la acentuación de las condiciones anticiclónicas, su extensión hacia el sur y como resultado el bloqueo al acceso de las perturbaciones, provocando sequías en la región costera. Dicha intensificación genera un incremento en la frecuencia y velocidad de los vientos provenientes del sur; un mayor flujo de aguas hacia el norte, generalizándose frente a las costas suramericanas al sur del Ecuador, y un ascenso de aguas frías Subantárticas. Este fenómeno corresponde a un evento La Niña, el cual se manifiesta en valores de largo plazo como anomalías positivas en la presión atmosférica de superficie; anomalías negativas en las temperaturas superficiales del mar y del aire, y reducción en los montos de precipitaciones (Fig. 4.4).

En la situación contraria, cuando se debilita la diferencia de presión, el Índice de Oscilación es negativo. En este caso hay una inversión generalizada de los patrones barométricos provocando el fenómeno El Niño, manifestado de manera general como descensos de la presión atmosférica superficial y anomalías positivas de las temperaturas superficiales del mar y del aire, así como un aumento en las precipitaciones. Durante este fenómeno se produce un debilitamiento generalizado de los vientos Alisios del Sureste que impulsan la corriente del Perú mar adentro (Pacífico Central y Occidental) sobre el Ecuador, provocando que las aguas que se apilaban en el oeste y que aumentaban el espesor de la capa superficial caliente adquieran la forma de ondas subsuperficiales, llamadas de Kelvin, las cuales viajan de regreso por el Ecuador hacia costas orientales ecuatoriales del Pacífico (costa occidental de Sudamérica) (Fig. 4.5).

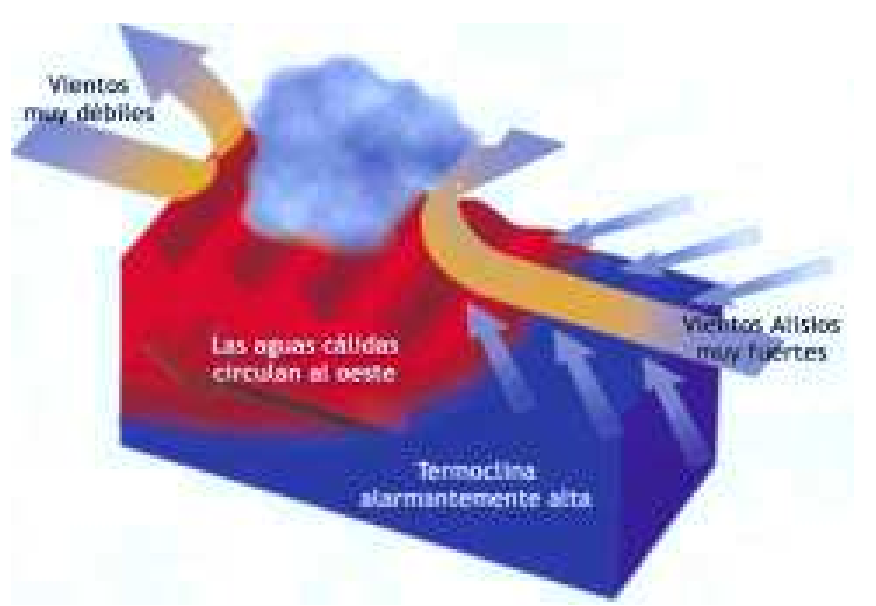

Figura 4.4 - Fenómeno La Niña o Condiciones Frías en las aguas del Pacífico Ecuatoria. (Modificado de www.puc.cl/sw.educ/goe mar/)

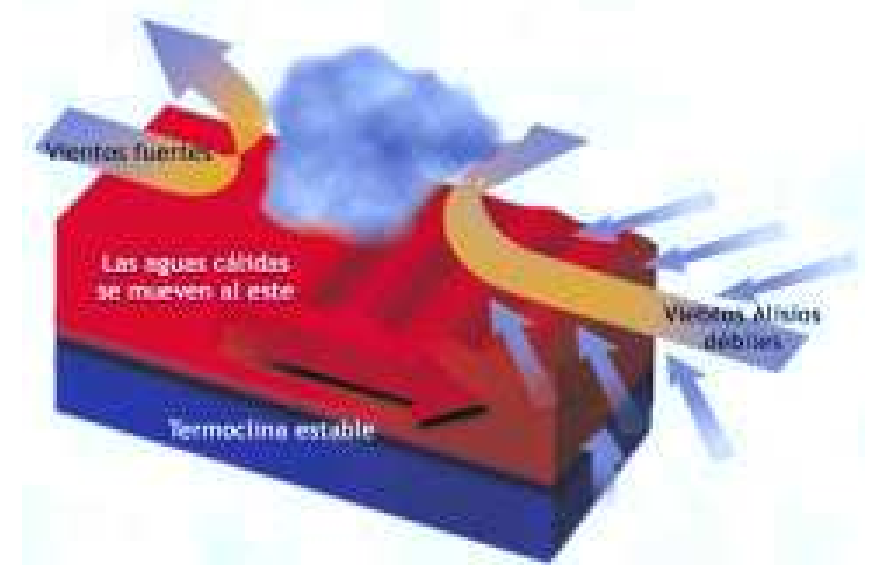

Figura 4.5 - Fenómeno El Niño o Condiciones Cálidas en las aguas del Pacífico Ecuatorial. (Modificado de www.puc.cl/sw.educ/ goe mar).

\section{EL FITOPLANCTON MARINO}

El estudio de los organismos fitoplanctónicos es de gran importancia ecológica, ya que ellos comprenden la mayor proporción de productores primarios en el mar, constituyéndose así en la alimentación básica para los consumidores. El entendimiento de cómo se efectúa la regulación de su desarrollo es esencial para construir modelos predictivos del ciclo global del carbono, y para una mejor comprensión de cómo la vida en los océanos podría responder a cambios en patrones globales de circulación oceánica inducidos por cambios climáticos (Moiseev, 1989).

El fitoplancton está compuesto por distintos grupos de algas diversamente especializadas para aprovechar las condiciones del medio. Las más abundantes en el plancton son las diatomeas y los dinoflagelados (Fotos 1.1 y 1.2), las cuales presentan características antagónicas. Las diatomeas son pequeñas algas muy vistosas, provistas de un caparazón silíceo, son capaces de reproducirse vertiginosamente cuando las condiciones ambientales son favorables y los elementos nutritivos son muy abundantes. En cuanto cesan estas condiciones su número decae rápidamente. Los dinoflagelados, por el contrario, pueden desarrollarse en situaciones un poco más adversas y aprovechar al máximo los ambientes caracterizados por la escasez de elementos nutritivos.

En los últimos años el conocimiento del fitoplancton marino ha adquirido especial interés debido a la importancia que cobra en los estudios orientados a predecir el fenómeno de El Niño y evaluar su efecto sobre la producción biológica 
(Avaria, 1984). Dicho interés se basa, principalmente, en la necesidad de establecer organismos o grupos de organismos planctónicos que puedan considerarse como indicadores biológicos, los cuales tienden a desplazarse junto con determinadas masas de agua; siendo necesario, además, que los organismos cumplan con la condición de bio-indicar cambios en las modificaciones de los componentes físicos y químicos durante la ocurrencia del fenómeno Cálido del Pacífico Tropical (Jordán, 1993).

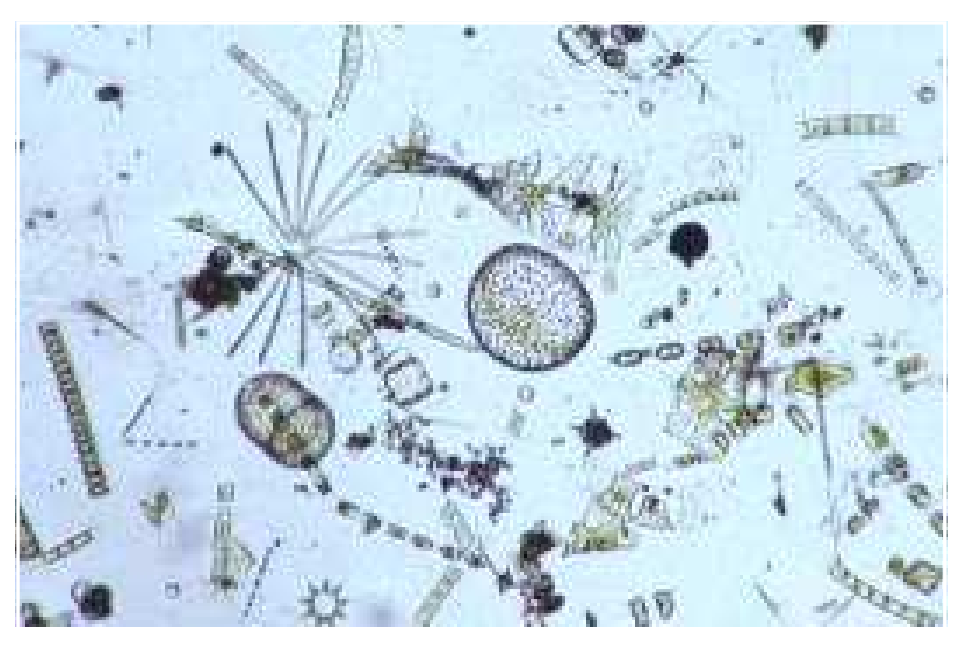

Comunidad planctónica dominada por diatomeas (Foto Y. Fukuyo, 2000).

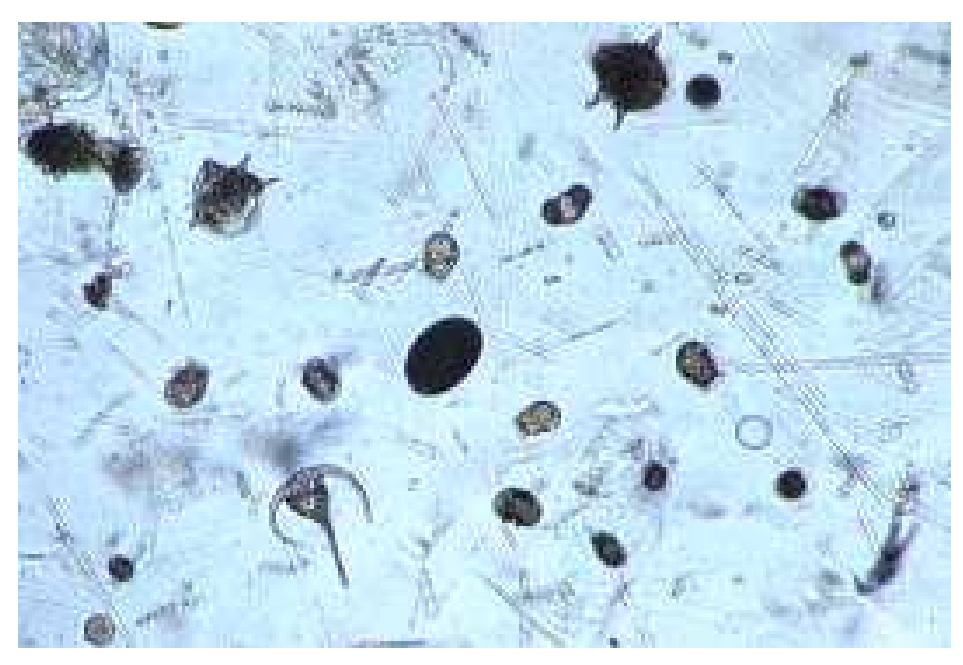

Comunidad planctónica dominada por dinoflajelados (Foto Y. Fukuyo, 2000).

Algunos grupos planctónicos como los dinoflagelados han sido reconocidos por varios autores como bioindicadores de masas de agua, debido a que son organismos estrictos en sus requerimientos de temperatura y salinidad. Estas características los hacen ideales para su seguimiento en el tiempo y espacio (Antonietti et-al, 1993).
Hasta el momento se ha corroborado la estrecha relación que existe entre los cambios poblacionales de diatomeas y dinoflagelados con respecto a las variaciones en parámetros físicoquímicos tales como la temperatura, la salinidad y el oxígeno. Según Avaria (1984) y Ochoa et al. (1985) una de las características de los eventos cálidos es la disminución de las poblaciones de diatomeas y el incremento de dinoflagelados en las áreas de influencia; comportamiento que se ha verificado en el Pacífico colombiano durante los eventos El Niño y el cual a su vez siempre se ha visto invertido con el cambio de las condiciones térmicas de las aguas (condiciones normales).

Los estudios que evidencian cambios en la comunidad microalgal (especies bioindicadoras) en la CPC constituyen una importante aproximación a futuras predicciones sobre el advenimiento del fenómeno de El Niño.

Condiciones oceanográficas de la CPC ante las variaciones causadas por el desarrollo de eventos Enos en el Pacífico Ecuatorial

Desde el año 1970 la Armada Nacional viene realizando cruceros oceanográficos en las aguas territoriales colombianas, tanto en el mar Caribe como en el océano Pacífico, proyectados desde el Centro de Investigaciones Oceanográficas e Hidrográficas, $\mathrm{ClOH}$. A partir de 1994 proyecta la realización de cruceros de investigación oceanográfica en la CPC, bajo la orientación del Centro Control Contaminación del Pacífico, CCCP, en los cuales se ha recolectado información de carácter oceanográfico, meteorológico, químico y biológico, con el fin de conocer las condiciones presentes en la zona y evaluar los efectos causados por los eventos Enos desarrollados en el océano y su afectación sobre las aguas de la CPC.

A partir de 1998 se inició el intercambio científico entre los países que forman parte de la Comisión Permanente del Pacífico Sur, CPPS, para la realización de Cruceros Regionales Conjuntos, lo que ha permitido diagnosticar las condiciones en esta extensa área, con el fin específico de recolectar información durante la aparición de eventos anómalos de naturaleza climática, principalmente los que tienen que ver con el evento Enos del Pacífico Ecuatorial. 
De la información recolectada se seleccionaron tres cruceros ejecutados durante el mismo mes (mayo) en años distintos, desarrollados en presencia de eventos ENOS sobre la CPC. Con el fin de caracterizar las condiciones de El Niño se escogió el crucero de mayo de 1998, para La Niña fue seleccionado el de mayo de 1999 y para condiciones normales el de mayo de 2000.

Durante la realización de cada uno de los cruceros se emplea una metodología estándar para la toma de muestras. El posicionamiento de las estaciones oceanográficas se efectúa por medio de un Navegador por Satélite, SI-TEX Modelo NAVAD D7000 AMKII.

La medición de temperatura superficial del mar, TSM, se hace directamente con un termómetro de cazoleta. La temperatura y salinidad en la columna de agua se miden con un CTD Sea Bird Electronics (SBE-19) hasta una profundidad de $850 \mathrm{~m}$ aproximadamente, en las estaciones que la profundidad lo permite.

Los parámetros químicos y biológicos se obtienen a partir de muestras de agua colectada a profundidades estándar $(0,25$, $50,75,100$ y 150) con botellas Niskin. El oxígeno disuelto se determina a bordo por el método de Winkler, mientras que las muestras de nutrientes, clorofilas y fitoplancton son preservadas y almacenadas para su posterior análisis en los laboratorios del CCCP. Los nutrientes se preservan a una temperatura de $4^{\circ} \mathrm{C}$; para la determinación de clorofilas se filtran $1800 \mathrm{ml}$ de agua en un set de filtración preparado con filtros de celulosa, adicionando carbonato de magnesio, los filtros se almacenan en sobres de papel aluminio rotulados y se mantienen en un desecador; y las muestras de fitoplancton se envasan en recipientes plásticos y se fijan con formalina al $10 \%$.

\subsection{CONDICIONES NORMALES}

Los resultados presentados en esta sección corresponden a los obtenidos del muestreo, procesamiento y análisis de la información recolectada a bordo del Buque ARC Gorgona en mayo de 2000, crucero escogido para representar las condiciones normales de la CPC. Se desarrolló en una grilla de 66 estaciones oceanográficas y 33 químicobiológicas.
La toma de muestras y mediciones se efectuó en el área comprendida entre los meridianos $77^{\circ} 45^{\prime} \mathrm{W}$ a $84^{\circ} 00^{\prime} \mathrm{W}$ y entre las latitudes $1^{\circ} 30^{\prime} \mathrm{N}$ a $6^{\circ} 30^{\prime} \mathrm{N}$ (Fig. 4.6). Sobre la región costera que va hasta los $80^{\circ} 00^{\prime} \mathrm{W}$ y desde los $01^{\circ} 30^{\prime} \mathrm{N}$ hasta los $06^{\circ} 30^{\prime} \mathrm{N}$, las estaciones están distanciadas 30 millas náuticas entre sí y en la región oceánica, que va desde los $81^{\circ} 00^{\prime} \mathrm{W}$ hasta los $82^{\circ} 00^{\prime} \mathrm{W}$ y desde los $01^{\circ} 30^{\prime} \mathrm{N}$ hasta los $05^{\circ} 00^{\prime} \mathrm{N}$, en 60 millas náuticas.

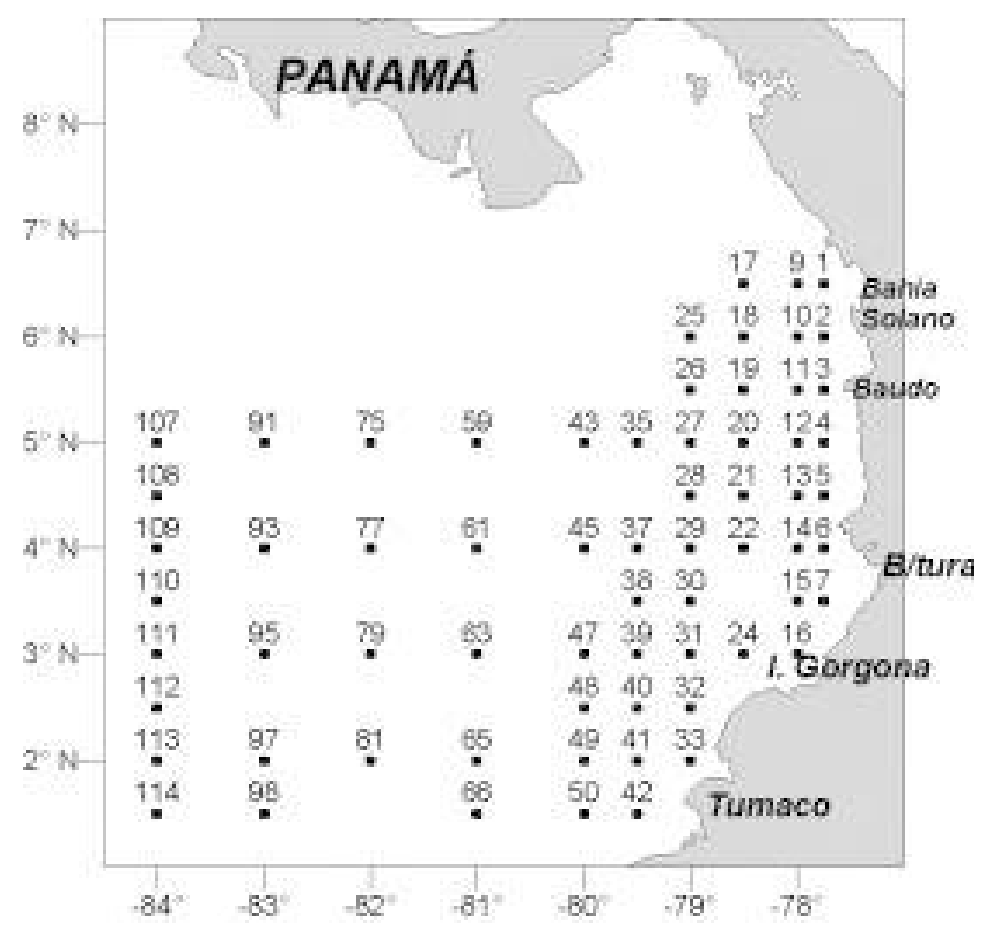

Figura 4.6 - Grilla de muestreo, Crucero PACíFICO XXXII-ERFEN XXX - Mayo de 2000.

\subsubsection{Características Físicas}

Temperatura

Distribución horizontal y vertical de temperatura por capas a $0,25,50,100$ y $500 \mathrm{~m}$ de profundidad

La temperatura superficial (Fig. 4.7) aumenta de sur a norte en la CPC presentando valores superiores a $27^{\circ} \mathrm{C}$ entre los 3 y $5^{\circ} \mathrm{N}$ e inferiores a $25^{\circ} \mathrm{C}$ en la región suroeste entre los $1.5^{\circ}$ y $2.5^{\circ} \mathrm{N}$. En el sector suroeste (área oceánica) se aprecian temperaturas menores en $2^{\circ} \mathrm{C}$ respecto a la zona costera. 


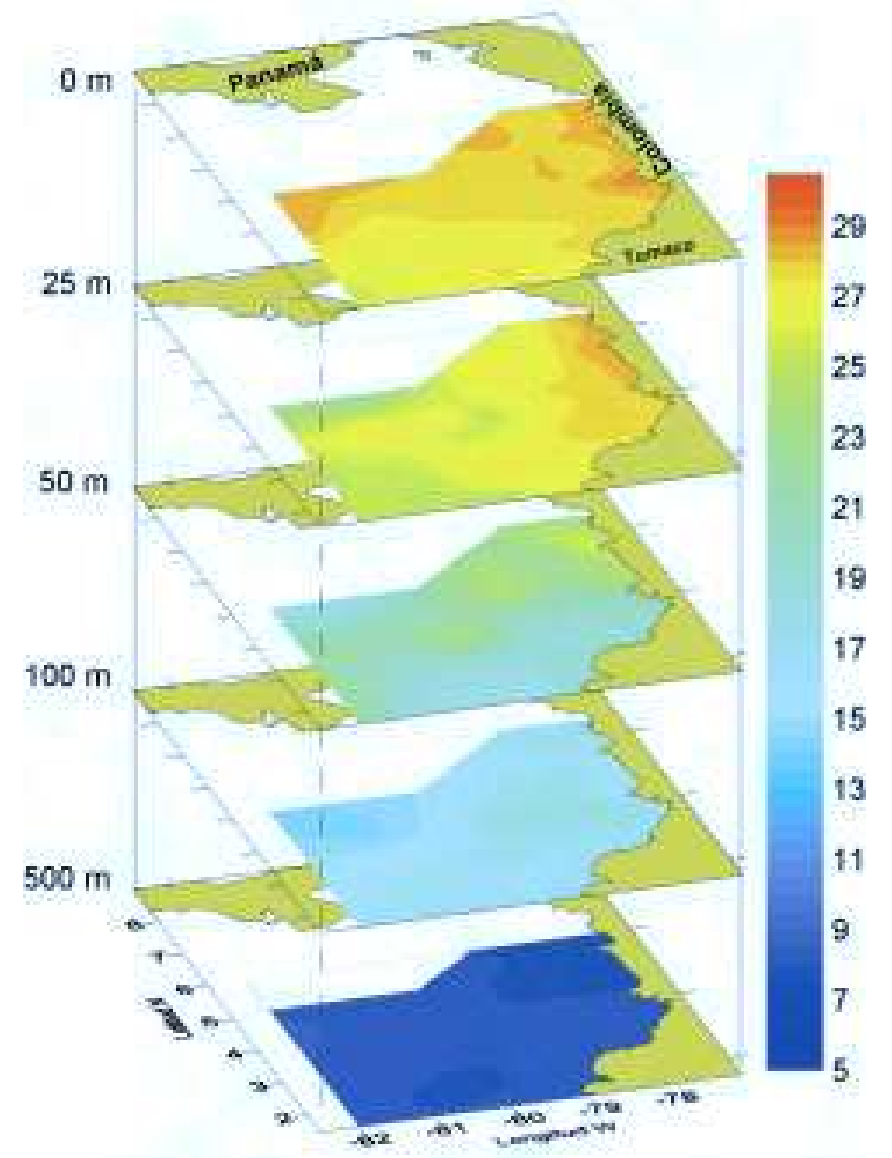

Figura 4.7 - Distribución de temperatura horizontal y vertical por capas, mayo de 2000 .

El comportamiento general de las isotermas sugiere la intrusión (por advección) de aguas frías $\left(24.5^{\circ} \mathrm{C}\right)$, desde el suroeste de la cuenca hasta los $2.5^{\circ} \mathrm{N}$ y $81^{\circ} \mathrm{W}$. Más al norte aguas de mayor temperatura $\left(27^{\circ} \mathrm{C}\right)$ parecen ser aportadas desde el Noroeste. Al Norte de la isla de Gorgona $\left(3^{\circ} \mathrm{N}\right)$, hasta los $6^{\circ} \mathrm{N}$ sobre el área costera $\left(78^{\circ} \mathrm{W}\right)$ se observa un foco de altas temperaturas, superiores a $28^{\circ} \mathrm{C}$.

A lo largo de la columna de agua hasta una profundidad de $100 \mathrm{~m}$ se observa la misma distribución horizontal que se presenta en superficie, es decir, los valores más bajos se registraron en el área suroeste y los mayores en el área costera de la CPC.

Sobre los 25 y $50 \mathrm{~m}$ de profundidad se presentan dos núcleos de agua, uno en el sector suroeste sugiriendo la entrada de aguas frías entre los $1.5^{\circ} \mathrm{N}$ y $3^{\circ} \mathrm{N}$; y el otro núcleo se localiza en la región noroeste con temperaturas mayores a las registradas en el suroeste, dirigiéndose de NW a SE, entre los $5^{\circ} \mathrm{N}$ y $4^{\circ} \mathrm{N}$. En la capa de $100 \mathrm{~m}$ se presenta una distribución que muestra la diferencia entre dos áreas (la oceánica y la costera). Sobre los $500 \mathrm{~m}$ se presenta una variación horizontal menor que en las demás capas.
Distribución vertical de temperatura por transeptos latitudinales

La distribución vertical de la temperatura en el perfil de Tumaco $\left(2^{\circ} \mathrm{N}\right)$ presenta una termoclina estacional bien desarrollada (Fig. 4.8), centrada alrededor de los $80 \mathrm{~m}$ de profundidad. El gradiente de temperatura presentado es de $1.2^{\circ} \mathrm{C} / 10 \mathrm{~m}$ en el área oceánica y de $1.0^{\circ} \mathrm{C} / 10 \mathrm{~m}$ en la zona costera. El límite inferior de la termoclina es la isoterma de $18^{\circ} \mathrm{C}$, ubicada sobre los $120 \mathrm{~m}$. La profundidad de la isoterma de $15^{\circ} \mathrm{C}$ es mayor en el área oceánica $(320 \mathrm{~m})$ que en la costa(300 m). A nivel superficial sobre el área costera se observan aguas cálidas $\left(27^{\circ} \mathrm{C}\right)$ hasta los $50 \mathrm{~m}$.

El transepto de la isla Gorgona $\left(3^{\circ} \mathrm{N}\right)$ presenta la termoclina entre los 50 y $70 \mathrm{~m}$ (isoterma de $18^{\circ} \mathrm{C}$ ), con un gradiente de $1.1^{\circ} \mathrm{C} / 10 \mathrm{~m}$ sobre la zona costera y entre los 25 y $60 \mathrm{~m}$ con un gradiente de $1.0^{\circ} \mathrm{C} / 10 \mathrm{~m}$ en el área oceánica. La isoterma de $15^{\circ} \mathrm{C}$ se encuentra más superficial alrededor de los $150 \mathrm{~m}$ en la zona costera. A nivel superficial se observa agua más cálida en la costa que en el océano abierto, mostrando una diferencia de temperaturas en $2^{\circ} \mathrm{C}$. Se observa una pendiente de las isotermas cerca de la costa, la cual puede estar indicando una señal baroclínica correspondiente a un flujo de sur a norte.

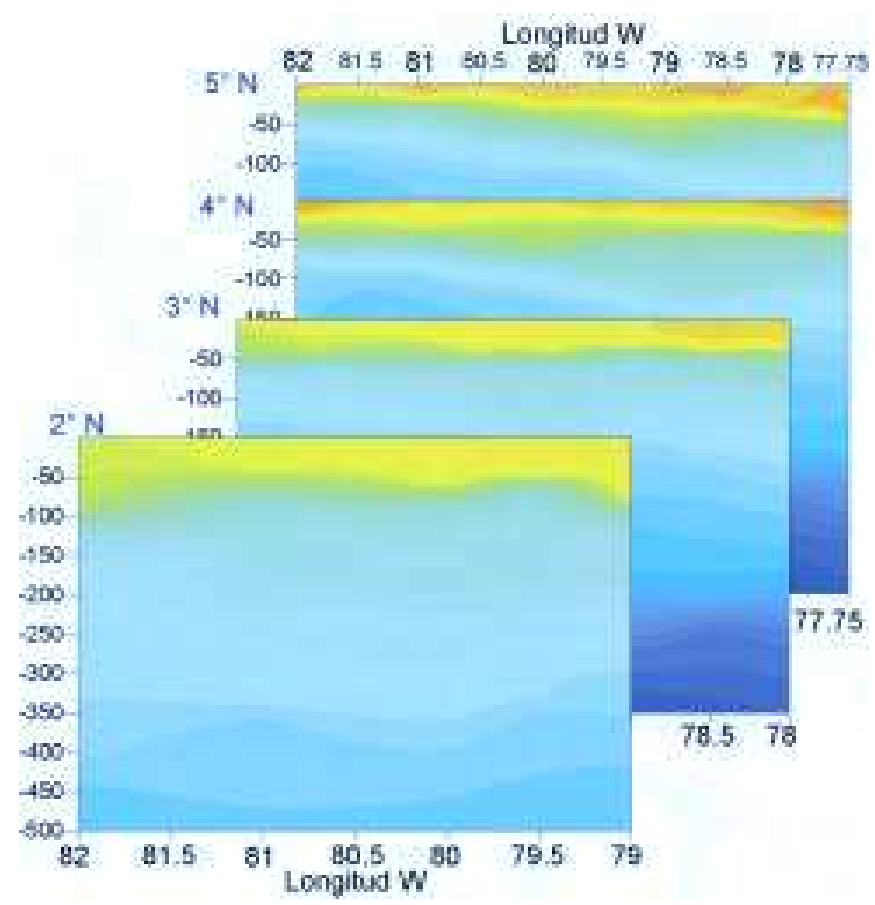

Figura 4.8 - Distribución de temperatura por transeptos latitudinales, mayo de 2000 
En el transepto de Buenaventura y Malpelo $\left(4^{\circ} \mathrm{N}\right)$ el comportamiento de la termoclina presenta diferencias entre la costa y el área oceánica, debido a que se observa una separación de la isoterma de $18^{\circ} \mathrm{C}$ la cual se profundiza de 50 a $100 \mathrm{~m}$. La isoterma de $15^{\circ} \mathrm{C}$ presenta un desnivel horizontal, siendo más profunda en la región costera $(160 \mathrm{~m})$. Se dan máximas temperaturas superficiales de $28^{\circ} \mathrm{C}$ en una pequeña región de la costa y el sector oceánico

En el transepto de Baudó $\left(5^{\circ} \mathrm{N}\right)$ la termoclina se localiza desde la superficie hasta los $50 \mathrm{~m}$ en la parte oceánica y hasta los $75 \mathrm{~m}$ en la costera. El gradiente de temperatura en la región oceánica fue de $1.1^{\circ} \mathrm{C} / 10 \mathrm{~m}$ y en la costera de $1.5^{\circ} \mathrm{C} / 10 \mathrm{~m}$, observándose las isotermas más juntas. La isoterma de $15^{\circ} \mathrm{C}$ se profundizó de 75 m en mar abierto hasta alrededor de los 150 m en la costa. A nivel superficial en la zona oceánica se aprecian temperaturas menores en $1^{\circ} \mathrm{C}$ con respecto a la zona costera.

Salinidad

Distribución horizontal y vertical de salinidad por capas a $0,25,50,100$ y $500 \mathrm{~m}$ de profundidad

Los valores de salinidad superficial (Fig. 4.9) oscilaron entre 34.9 y 30 , disminuyendo de sur a norte y desde el océano hacia la costa. Hacia el sector Sur de la CPC se observa la entrada de aguas con concentraciones de alta salinidad provenientes del suroeste, con valores superiores a 34.5, alcanzando los $3^{\circ} \mathrm{N}$. Entre los $2.5^{\circ} \mathrm{N}$ y $4^{\circ} \mathrm{N}$ se presentó una variación muy marcada de salinidad, con valores de 34.5 a 33 . Sobre el sector costero existe un franja de baja salinidad (30 a 32), debido al aporte de agua dulce proveniente de ríos y lluvias. Al noroeste se aprecia la formación de una entrada de agua salina dirigida hacia el Este, con valores alrededor de 32.5.

Observando la columna de agua en la profundidad de 25 m (Fig. 4.9) los valores más bajos corresponden a la costa y los más altos al océano, presentándose dos entradas de aguas con salinidades superiores en el sector suroeste y noroeste. Las salinidades son mayores en toda esta capa y se puede distinguir que la masa de salinidad alta que proviene del sur cubre toda el área oceánica y central de sur a norte, a diferencia de la capa superficial, en donde sólo está al sur.
La distribución a $50 \mathrm{~m}$ presenta valores promedios de 34.3 para la costa y 34.8 para el sector oceánico. En el área Sur se observa el transporte de agua salina proveniente del Ecuador, con un valor de 34.9, dirigiéndose hacia el norte hasta la altura de Buenaventura. En la parte central se presenta la formación de un núcleo con valores de 34.4 a 34.6. En la región Norte se registra una entrada con tendencia hacia el Este y valores de salinidad de 34.2. Sobre la región central se observa longitudinalmente una variación de salinidad, sugiriendo que hacia el Norte se localizan aguas menos salinas y del Sur provienen aguas de mayor salinidad.

En las capas de 100 y 500 m la variación horizontal es mínima. Las mayores concentraciones se encuentran en estas dos capas, siendo mayor la de los $100 \mathrm{~m}$, debido a la influencia de la corriente subsuperficial de Cromwell, la cual trae consigo aguas frías y salinas.

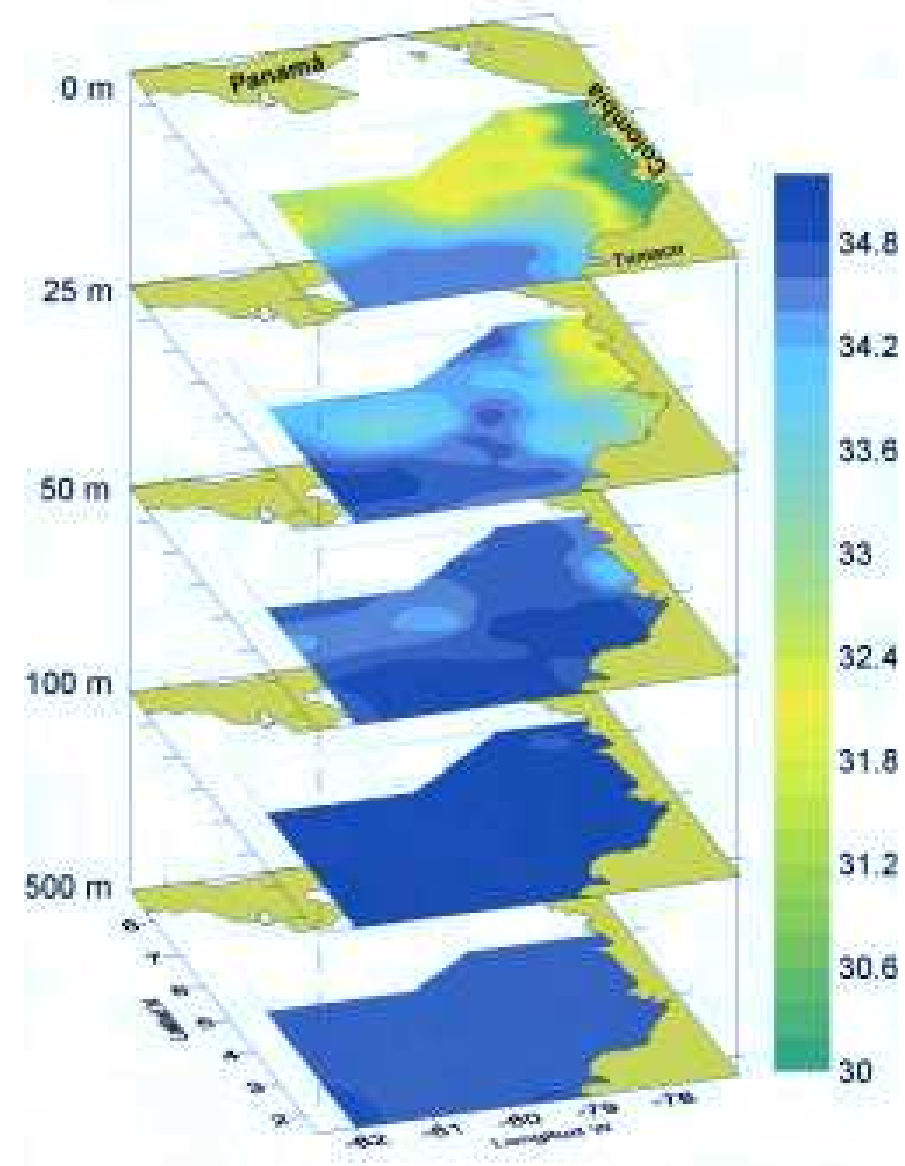

Figura 4.9 - Distribución de salinidad horizontal y vertical por capas, mayo de 2000 
Distribución vertical de salinidad por transeptos latitudinales

La distribución vertical de la salinidad sobre el perfil de Tumaco $\left(2^{\circ} \mathrm{N}\right)$ presenta un gradiente fuerte entre los 20 y 80 $\mathrm{m}$, sobre las estaciones más cercanas a la costa. Sobre la región central y oceánica del transepto el gradiente por debajo de los 100 m es, prácticamente, inexistente (Fig. 4.10).

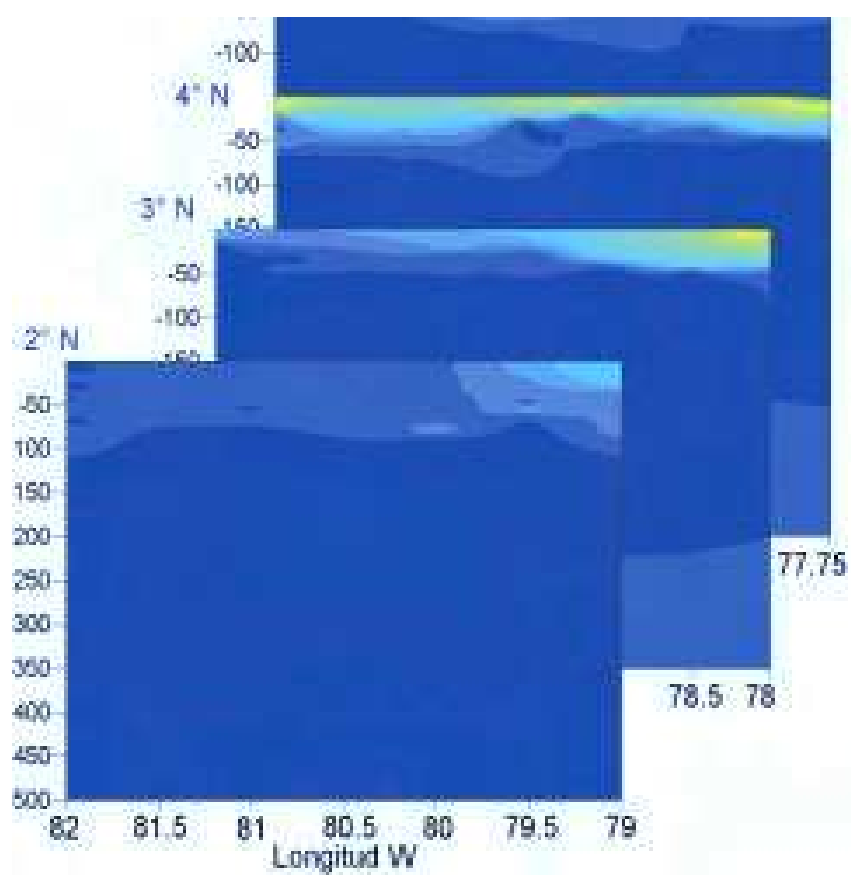

Figura 4.10 - Distribución vertical de salinidad por transeptos latitudinales, mayo de 2000.

El transepto de la isla de Gorgona $\left(3^{\circ} \mathrm{N}\right)$ presenta una haloclina con pocas isohalinas en el área oceánica y central de la cuenca hasta los $50 \mathrm{~m}$. El gradiente salino a nivel costero coincidió con la termoclina, observando una marcada variación de los valores desde la superficie hasta los $50 \mathrm{~m}$, con valores muy bajos debido a la influencia de los aportes continentales y las precipitaciones. El máximo salino (34.95) se encuentra entre los 75 y $200 \mathrm{~m}$.

En el transepto de Buenaventura y Malpelo $\left(4^{\circ} \mathrm{N}\right)$ se observa la haloclina de 0 a $50 \mathrm{~m}$, con un levantamiento de las isohalinas en la región central. Por debajo de esta capa se encuentra una región de salinidad máxima de 34.8, que abarca desde 60 hasta $350 \mathrm{~m}$, a partir de donde disminuye hasta 34.6 a $500 \mathrm{~m}$.

El transepto de Baudó $\left(5^{\circ} \mathrm{N}\right)$ presenta una haloclina hasta los $50 \mathrm{~m}$ en el área oceánica y costera. Entre los 100 y 300 m predominan aguas salinas con valores de 34.9; en la capa de 150 a 225 m y cerca de la costa se localizó el máximo salino subsuperficial (34.9).

\subsubsection{Características Químicas}

Oxígeno Disuelto (OD)

Distribución horizontal y vertical del OD por capas a 0 , $25,50,100$ y $150 \mathrm{~m}$ de profundidad

El comportamiento del oxígeno disuelto a nivel superficial (Fig. 4.11) presenta en el sector sur la entrada de agua con valores de 5.8 a $6.2 \mathrm{mg} / \mathrm{l}$, entre las latitudes $82^{\circ} \mathrm{W}$ y $80^{\circ}$ $\mathrm{W}$, lo cual se mantiene hasta los $50 \mathrm{~m}$ oscilando entre $3.5 \mathrm{y}$ $5.5 \mathrm{mg} / \mathrm{l}$ de OD.

Sobre la parte central del área de estudio y longitudinalmente se observa la formación de dos núcleos con valores que fluctúan entre 6 y $6.8 \mathrm{mg} / \mathrm{l}$, los cuales permanecieron elevados con casi $6.0 \mathrm{mg} / \mathrm{l}$ hasta el nivel de los $50 \mathrm{~m}$. En la parte noroeste se presenta una entrada con valores menores de 5.4 a $6.0 \mathrm{mg} / \mathrm{l}$, obteniéndose los registros más bajos de $\mathrm{OD}$ en esta zona a medida que se profundizó en la columna de agua hasta llegar a $1.4 \mathrm{mg} / \mathrm{l}$, a partir de los $100 \mathrm{~m}$.

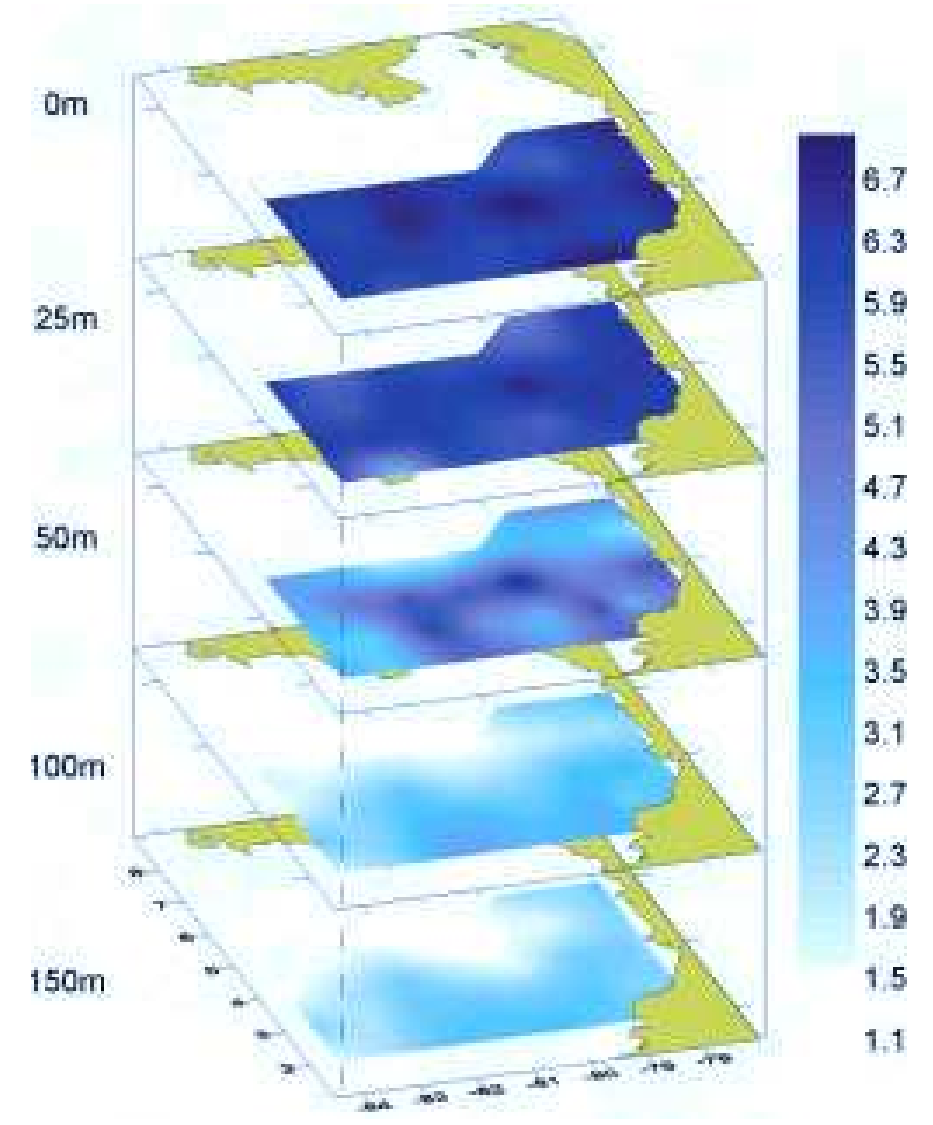

Figura 4.11 - Distribución horizontal y vertical de Oxígeno Disuelto (mg/l) por Capa, mayo de 2000. 
A lo largo de la costa se presentaron valores de 6.1 a 6.3 $\mathrm{mg} / \mathrm{l}$ en la superficie, donde los mayores registros desde 0 hasta $100 \mathrm{~m}$ se presentaron en las zonas de Tumaco y Buenaventura.

\section{Nutrientes}

\section{Amonio}

Distribución horizontal y vertical del Amonio por capas a $0,25,50,100$ y $150 \mathrm{~m}$ de profundidad

En la superficie este parámetro muestra concentraciones del orden de los 0 a $0.95 \mu \mathrm{g}$-at/l hasta alcanzar los registros más altos hacia los $150 \mathrm{~m}$ con valores entre 2.0 y $9.1 \mu \mathrm{g}$-at/l. Es claro observar que las mayores concentraciones se presentan a nivel costero y hacia el noroeste de la CPC, en la zona correspondiente a la isla de Malpelo, ampliándose estos dos núcleos a medida que se van profundizando en la columna de agua, sobre todo a partir de los $100 \mathrm{~m}$ (Fig. 4.12).

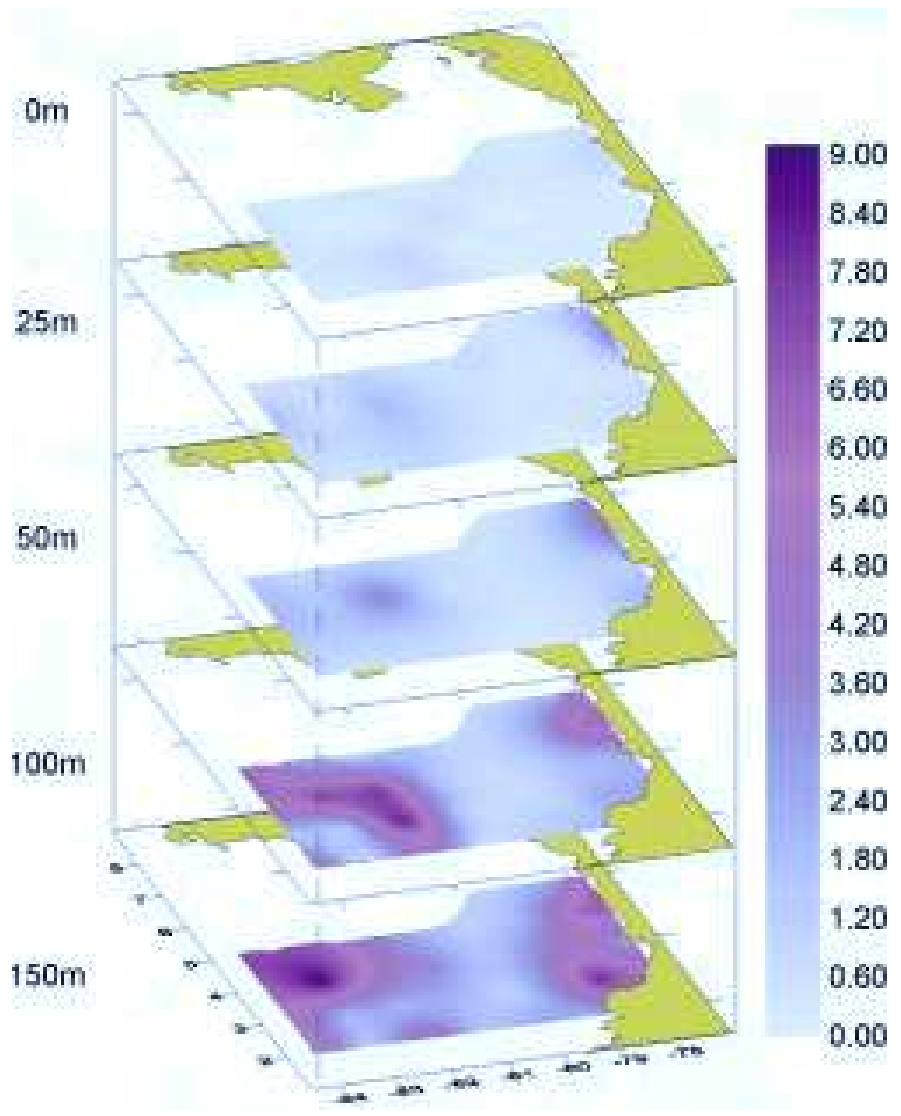

Figura 4.12 - Distribución horizontal y vertical del Amonio (NH4 $\mu \mathrm{g}$-at/l) por capas, mayo de 2000.
Nitrato

Distribución horizontal y vertical del Nitrato por capas a $0,25,50,100$ y $150 \mathrm{~m}$ de profundidad

A nivel superficial se presentan valores bajos sobre todo hacia la zona costera con registros de 0.02 a $0.21 \mu \mathrm{g}$-at/l, al sur se presenta una entrada de agua caracterizada por valores más elevados con 2.97 a $3.2 \mu \mathrm{g}$-at/l. Hacia los $25 \mathrm{~m}$ se observan más núcleos con registros mayores en un rango de 0.43 a $5.0 \mu \mathrm{g}$-at/l, presentándose una entrada al norte y manteniéndose las concentraciones bajas hacia la costa, a excepción de un núcleo que se desarrolló cerca a Tumaco (Fig. 4.13). Entre los 50 y los $150 \mathrm{~m}$ las concentraciones van aumentando hasta obtenerse los máximos registros hacia el norte y sur de la cuenca con valores entre 6 y $21 \mu \mathrm{g}$-at/l.

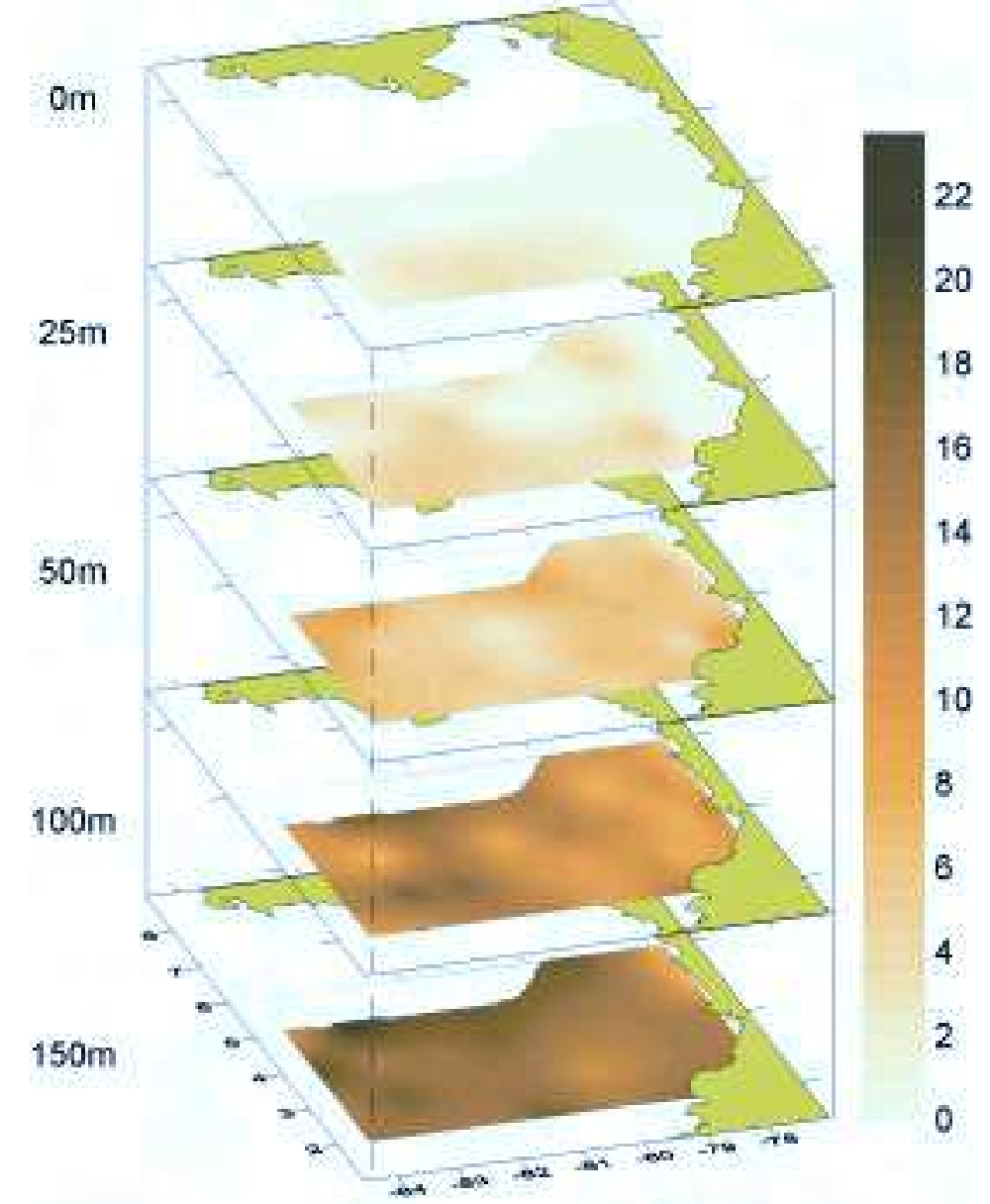

Figura 4.13 - Distribución horizontal y vertical del Nitrato (NO3 $\mu \mathrm{g}$-at/l) por capas, mayo de 2000 . 


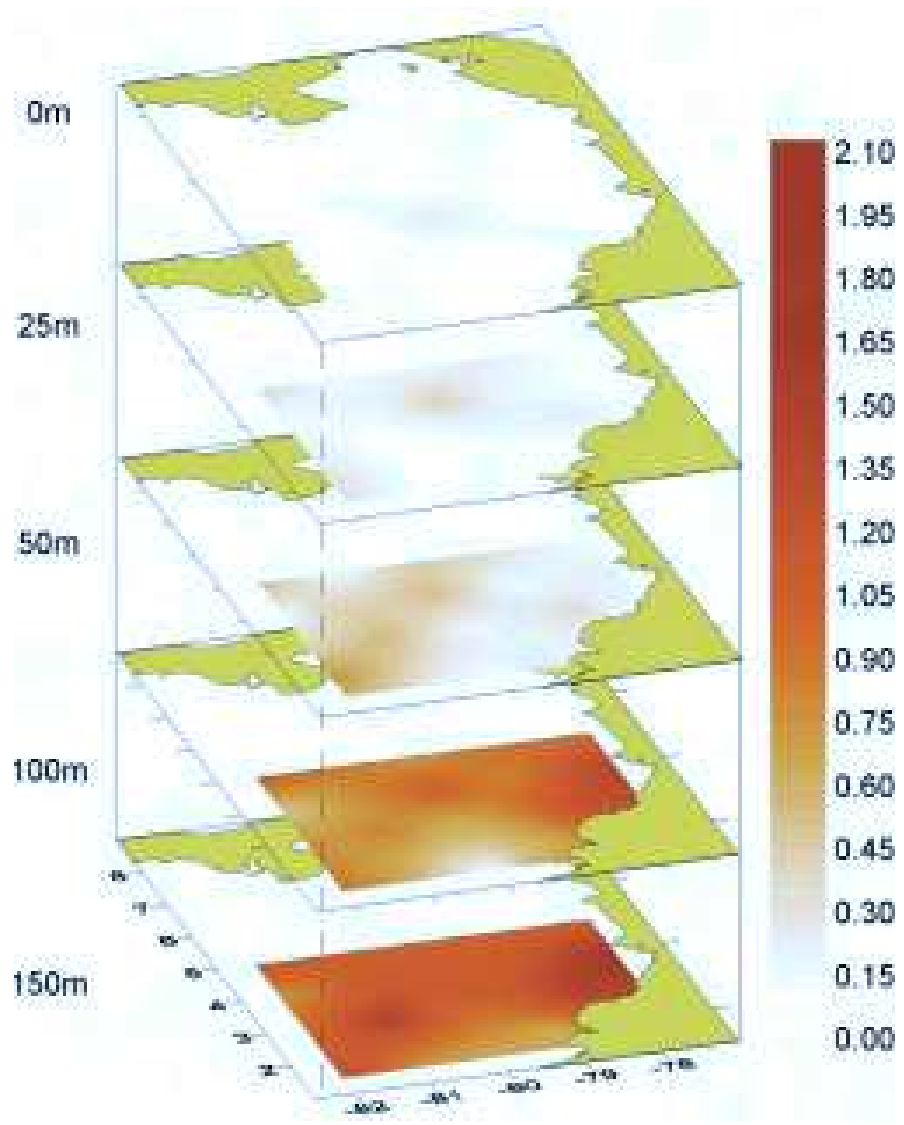

Figura 4.14 - Distribución horizontal y vertical de Fosfato (po4 $\mu \mathrm{g}$-at/l) por capas, mayo de 2000.

\section{Fosfato}

Distribución horizontal y vertical del Fosfato por capas a $0,25,50,100$ y $150 \mathrm{~m}$ de profundidad

En superficie presenta valores entre 0 y $0.8 \mu \mathrm{g}$-at/l, registrando sus máximos sobre el sector sureste y la formación de un núcleo hacia el centro. A $25 \mathrm{~m}$ se observa una distribución más homogénea, aunque se mantuvieron estos mismos núcleos. En el perfil de $100 \mathrm{~m}$ se presenta un mayor incremento de este nutriente con un promedio de $1.2 \mu \mathrm{g}$-at/ I, para finalmente detectarse concentraciones entre $1.1 \mathrm{y}$ $2.0 \mu \mathrm{g}$-at/l al fondo (Fig. 4.14).

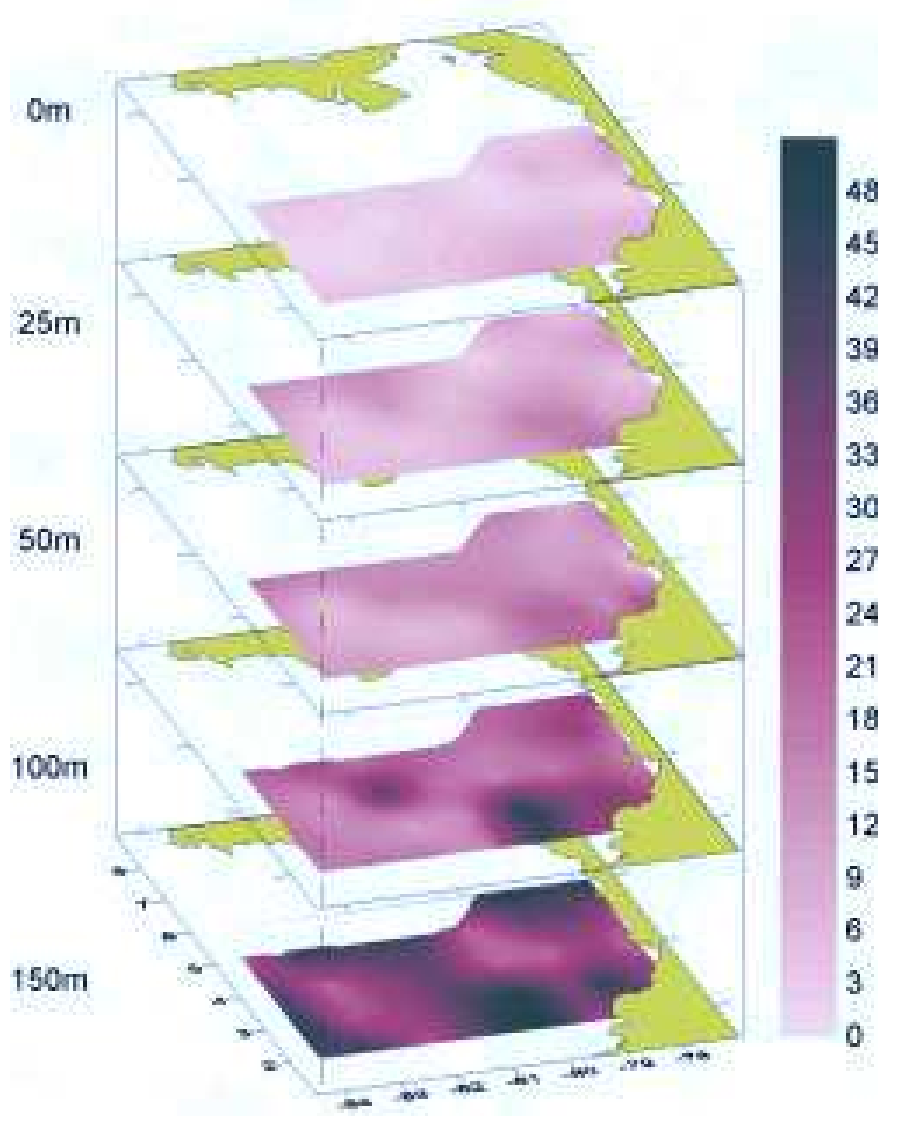

Figura 4.15 - Distribución horizontal y vertical de Silicato ( $\mathrm{SiO}_{3}$ $\mu \mathrm{g}$-at/l) por capas, mayo de 2000.

\section{Silicato}

Distribución horizontal y vertical de Silicato por capas a $0,25,50,100$ y $150 \mathrm{~m}$ de profundidad

Superficialmente se presentan registros de 0.75 a $12 \mu \mathrm{g}$ at/l, encontrándose las mayores concentraciones hacia el sureste y noroeste de la CPC. Hacia el litoral se presentan valores altos entre Buenaventura y Bahía Solano y entre la isla de Gogona y Tumaco. Esta misma distribución se mantuvo hacia el fondo, pero con valores mayores (Fig. 4.15). A 150 $\mathrm{m}$ se detectan las máximas concentraciones que alcanzaron $52 \mu \mathrm{g}$-at/l. 


\subsubsection{Características Biológicas}

Clorofila "a"

Distribución horizontal y vertical de Clorofila "a" por capas a $0,25,50,100$ y $150 \mathrm{~m}$ de profundidad

A nivel superficial se registran valores entre 0 y $4.6 \mathrm{mg} / \mathrm{m}^{3}$. Las mayores concentraciones se presentan al sureste en la región costera, entre la Bahía de Tumaco y la isla de Gorgona, donde a la vez se detectan los mayores valores de abundancia de diatomeas (Fig. 4.16). Este mismo patrón de distribución espacial se mantiene desde la superficie hasta los $150 \mathrm{~m}$ de profundidad, donde la concentración mínima es de $0.32 \mathrm{mg} / \mathrm{m}^{3}$.

De igual forma se observa otro núcleo aunque de concentraciones menores hacia el centro de la cuenca entre los $82^{\circ} \mathrm{W}$ y los $4^{\circ} \mathrm{N}$, con valores que oscilan entre $2.75 \mathrm{mg} / \mathrm{m}^{3}$ a nivel superficial y hasta $0.3 \mathrm{mg} / \mathrm{m}^{3}$ en el fondo. El resto del área presenta valores bajos con un promedio de $2.1 \mathrm{mg} / \mathrm{m}^{3}$, en superficie, hasta alcanzar concentraciones de $0 \mathrm{mg} / \mathrm{m}^{3}$ entre los 100 y 150 m.

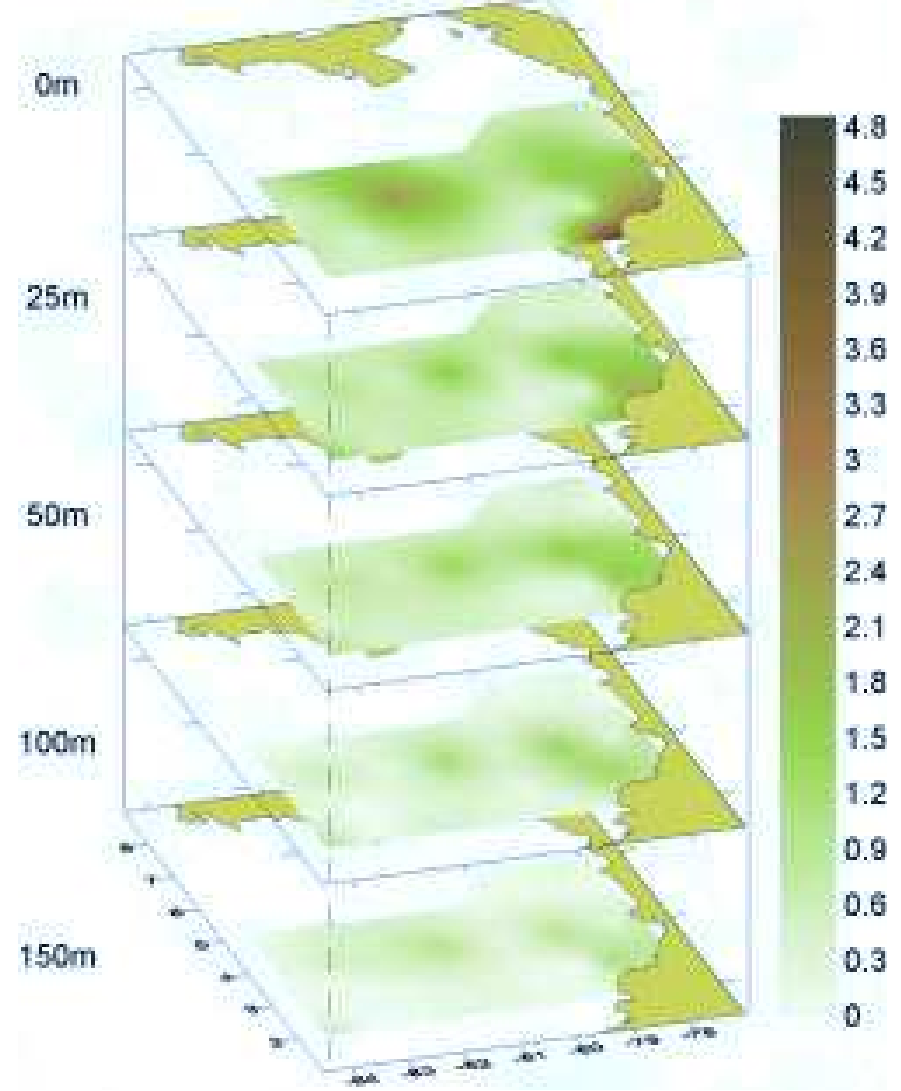

Figura 4.16 - Distribución horizontal y vertical de Clorofila "a" $\left(\mathrm{mg} / \mathrm{m}^{3}\right)$ por capas, mayo de 2000.
Fitoplancton

Para cada época climática se tienen en cuenta los resultados obtenidos para los dos grupos principales que componen el fitoplancton (diatomeas y dinoflagelados), puesto que estos presentan afinidades térmicas opuestas, lo cual permite observar diferencias importantes en la composición específica y abundancia de estas microalgas en presencia de un evento climático. Estas diferencias permiten tipificar el área a nivel biológico y establecer la presencia de organismos que actúan como indicadores de cambios de temperatura en el agua.

\section{Diatomeas}

\section{Composición Especiológica}

Se han identificado para esta condición un total de 193 especies agrupadas en 68 géneros (Tabla 4.1), dentro de los cuales según el orden de importancia se destacan: Dactyliosolen fragilissimus, Thalassiosira anguste lineata, T. allenii, Leptocylindrus danicus, Planktoniella sol, Pseudo-nitzschia pungens, $P$. pseudodelicatissima, P. fraudulenta, P. lineola, $P$. delicatissima, P. pacifica, P. seriata, Chaetoceros diadema, C. compressus, C. lorenzianus, C. affinis, Skeletonema costatum, Eucampia cornuta, Guinardia flaccida, G. striata, Licmophora abbreviata, Thalassionema nitzschioides, T. bacillare, $T$. delicatula, Pseudoeunotia doliolus, Navicula directa, Cylindrotheca closterium, Nitzschia longissima, Hemiaulus hauckii, Detonula confervacea, Fragilaria sp, Coscinodiscus marginatus, Grammatophora marina y Rhizosolenia imbricata, las cuales, según Hasle y Syvertsen (1996), en su mayoría presentan hábitos cosmopolitas.

Distribución horizontal y vertical de abundancia de Diatomeas por capas a 0, 25, 50, 100 y $150 \mathrm{~m}$ de profundidad

Las mayores abundancias (3900 - $48750 \mathrm{cel} / \mathrm{l}$ ) se presentan hacia la región costera y sureste de la cuenca, observándose los 
máximos valores en las estaciones 33 (frente a la Bahía de Tumaco, $2^{\circ} 00^{\prime} \mathrm{N}$ ) y 24 (Isla Gorgona, $3^{\circ} 00^{\prime} \mathrm{N}$ ); sobre las isotermas de 27 a $27.5^{\circ} \mathrm{C}$ y fueron disminuyendo en dirección sur-norte mostrando un comportamiento opuesto a la temperatura (Fig. 4.7). Aunque hacia el noroeste de la región oceánica es posible observar a nivel superficial, valores elevados de abundancia (3150 - $19200 \mathrm{cel} / \mathrm{l}$ ) relacionados con altas temperaturas (28 a $28.5^{\circ} \mathrm{C}$ ), que coinciden con el arribo al área de las especies Leptocylindrus danicus y Licmophora abbreviata, las cuales son de hábitos cosmopolitas (Carmelo, 1995).

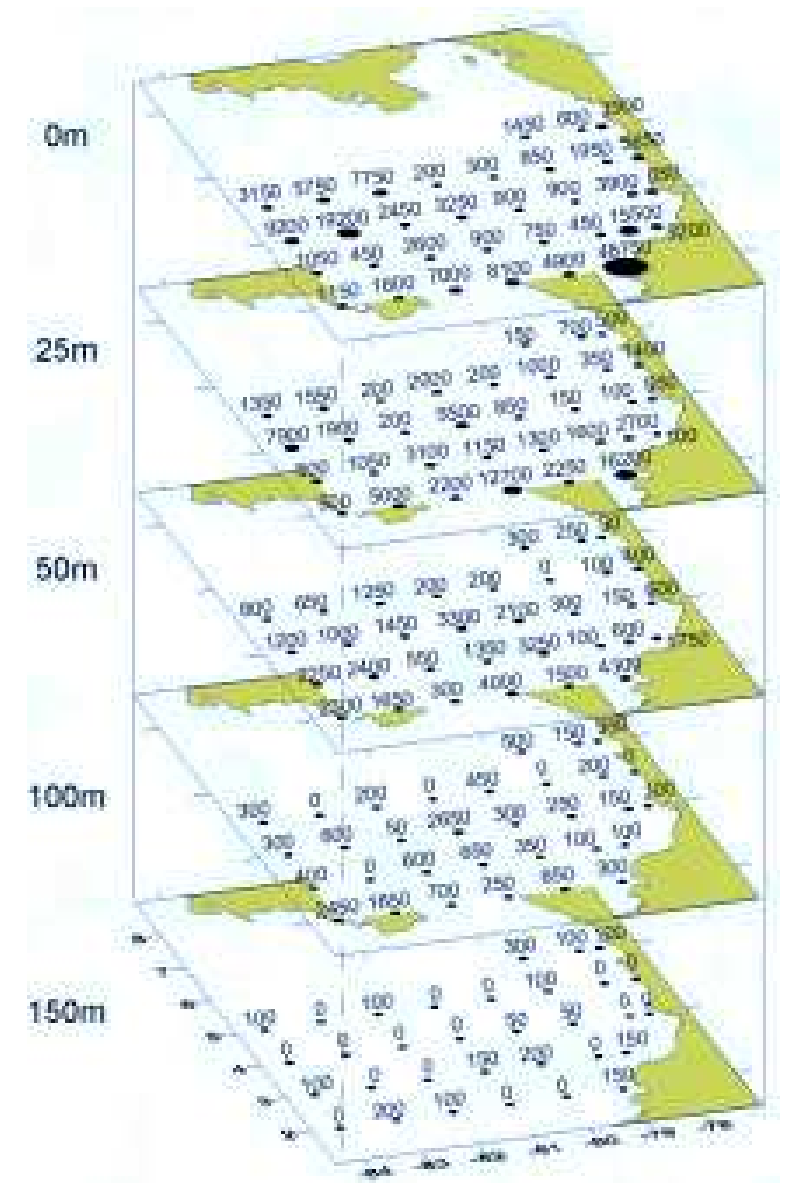

Figura 4.17 - Distribución horizontal y vertical de abundancia de Diatomeas (cel/l) por capas, mayo de 2000.

(El tamaño del símbolo corresponde con el valor de abundancia).

En las aguas que rodean la isla de Malpelo $\left(81^{\circ} 82^{\circ} \mathrm{W}\right.$ y $4^{\circ} \mathrm{N}$ ) también es posible observar desde la superficie hasta los $100 \mathrm{~m}$ abundancias relativamente altas para la zona oceánica con especies como Thalassiosira anguste-lineata, Rhizosolenia imbricata y varias del género Pseudo-nitzschia, detectándose a $100 \mathrm{~m}$ el valor más elevado de abundancia para esta profundidad (Fig. 4.17).

A 25 y $50 \mathrm{~m}$, nuevamente, se registraron cantidades elevadas hacia el sureste, presentándose las mayores concentraciones de organismos en la estación 33 con 16200 cel/l y 4300 cel/l, respectivamente (Fig. 4.17). Hacia la región noroeste los valores decrecieron notablemente entre los $0 y$ los $25 \mathrm{~m}$. A partir de los $100 \mathrm{~m}$ los registros de abundancia son muy bajos en toda la zona, a excepción del punto más cercano a la isla Malpelo con 2650 cel/l, y a $150 \mathrm{~m}$ se observa una ausencia casi total de individuos.

\section{Dinoflagelados}

\section{Composición Especiológica}

Para esta condición se identificaron 123 especies agrupadas en 30 géneros, en donde las más importantes fueron: Scrippsiella trochoidea, Ptychodiscus inflatus, Oxytoxum minimun, 0. scolopax, Prorocentrum micans, P. brochii, P. compressum, Gonyaulax polygramma, G. fusiformis, G. spinifera, Protoperidinium cerasus, P. abei, P. conicum, P. kofoidii, Paleophalacroma verrucosum, P. unicinctum, Dinophysis brevisulcus, Pyrocystis banulus, Alexandrium tropicale, Cladopyxis brachiolata, Gonyaulax scrippsae, Ceratium macroceros, C. furca, C. fusus, C. kofoidii, C. lineatum, C. pentagonum, Ceratocorys horrida, Dinophysis caudata, $D$. exigua, D. parvula, Preperidinium meunieri, Diplopelta symmetrica, Pyrophacus steinii y Podolampas palmipes.

Para este período no se presentaron especies nuevas, ni se observaron cistos o especies tóxicas que pudieran causar posibles discoloraciones nocivas (mareas rojas) en el área, a diferencia de años anteriores. La mayoría de las reportadas corresponden a especies de aguas tropicales y temperadas (Balech, 1988 y Steidinger y Tangen, 1996).

Distribución horizontal y vertical de abundancia de Dinoflagelados por capas a 0, 25, 50, 100 y $150 \mathrm{~m}$ de profundidad

Al igual que para el grupo de las diatomeas, este grupo presentó sus máximos valores de abundancia a nivel superficial en dos zonas, uno hacia el sector noroeste con $3650 \mathrm{cel} /$ l en relación con la temperatura más elevada $28.5^{\circ} \mathrm{C}$, y otro 
al sureste en la estación 33 (frente a la bahía de Tumaco) con $1650 \mathrm{cel} / \mathrm{l}$. Para el resto del área se obtuvieron bajos registros de abundancia ( 0 a $850 \mathrm{cel} / \mathrm{l}$ ) con una distribución homogénea (Fig. 4.18).

A $25 \mathrm{~m}$ se mantuvieron abundancias elevadas en el sector noreste $(1150$ - $2050 \mathrm{cel} / \mathrm{l})$, presentándose un patrón de distribución diferente al registrado durante mayo/98 y mayo/ 99, durante los cuales las mayores abundancias se obtuvieron en el sector costero cerca de la isla de Gorgona y bahia de Tumaco. Hacia los $50 \mathrm{~m}$ se observó una distribución muy homogénea de las poblaciones, en general para toda la zona, con valores bajos de 0 a $1000 \mathrm{cel} / \mathrm{l}$. Por debajo de esta profundidad las abundancias fueron muy bajas, presentándose valores que no sobrepasan las $150 \mathrm{cel} / \mathrm{l}$ a $150 \mathrm{~m}$.

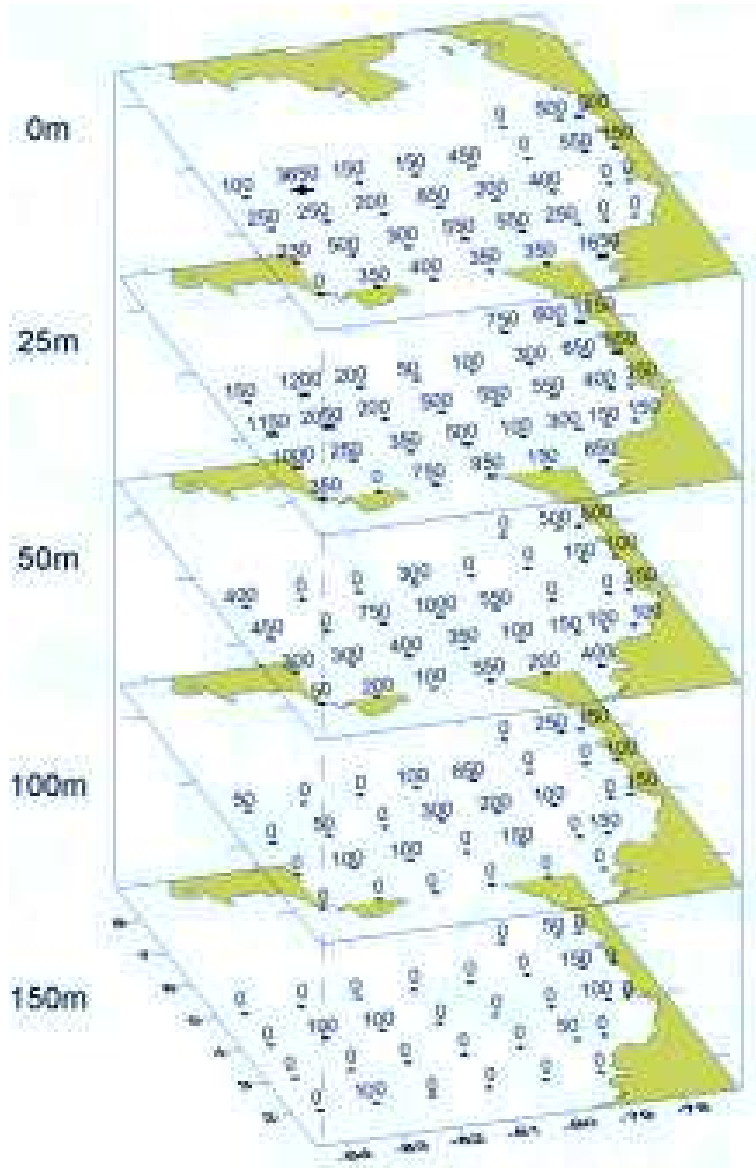

Figura 4.18 - Distribución horizontal y vertical de abundancia de Dinoflagelados (cel/l) por capas, mayo de 2000.

(El tamaño del símbolo corresponde con el valor de abundancia)

Nuevamente cerca de la isla de Malpelo se registraron valores un poco más altos que se mantienen hasta los $50 \mathrm{~m}$ de profundidad (Fig. 4.18). Las especies detectadas para esta zona fueron Oxytoxum scolopax, Scrippsiella trochoidea y
Prorocentrum compressum, todas según Carmelo (1995) de características cosmopolitas.

\subsubsection{Análisis general condición normal}

En general se observa que durante la época normal la temperatura varía horizontalmente de mayor, en la costa, a menor en la región oceánica. En las capas superficiales la temperatura es mayor en la zona norte que en el sur de la cuenca, debido principalmente a una corriente que proviene del norte y fluye hacia el sur transportando altas temperaturas. A medida que aumenta la profundidad se puede distinguir la influencia de otras corrientes; una menos cálida a $50 \mathrm{~m}$ proveniente del oeste, y otra fría del sur que enfría en su totalidad la capa de $100 \mathrm{~m}$. Esto se relaciona estrechamente con los cambios de salinidad en la CPC, con valores bajos en la costa y altos a medida que se aleja hacia el sur y oeste, con una corriente de alta salinidad que influencia todas las capas desde el sur hacia el norte afectando una región menor en la capa superficial y de manera general a 100 m. Es común, además, encontrar surgencias alrededor de las islas Malpelo y Gorgona debido a una divergencia de corrientes que producen la elevación de la termoclina y el afloramiento de aguas frías y salinas.

Para este período el OD registra los valores más elevados a lo largo de la costa, hacia el sur y en dos núcleos ubicados en la región central de la cuenca. A nivel superficial el OD oscila entre 5.4 y $6.8 \mathrm{mg} / \mathrm{l}$ y va disminuyendo con la profundidad hasta alcanzar valores mínimos de $0.8 \mathrm{mg} / \mathrm{l}$ al fondo (150 m). Los datos registrados durante este período coinciden con los obtenidos para la época normal en otros años de observación.

Los nutrientes, por su parte, muestran altas concentraciones al sur de la cuenca y en la porción oceánica que rodea la isla de Malpelo. En la zona costera se encuentran por lo general las concentraciones más elevadas entre la isla de Gorgona y la bahía de Tumaco. El comportamiento de los nitritos es opuesto al resto de las sales, presentando las concentraciones más bajas hacia la costa y cerca de la isla de Malpelo, áreas donde las abundancias poblacionales de microalgas son más altas. Estas mismas zonas coinciden con los máximos registros de clorofila "a". 
Para la época normal se destacan las diatomeas más típicas del fitoplancton nerítico tales como Rhizosolenia imbricata, Leptocylindrus danicus, Skeletonema costatum y Chaetoceros compressus, las cuales presentan elevadas abundancias y una amplia distribución a lo largo de todo el litoral. Los dinoflagelados en cambio muestran abundancias bajas dominando a nivel costero, las especies más comunes como Ceratium fusus var seta, $C$. furca, Prorocentrum micans, $P$. rostratum y Ceratocorys horrida. En la porción oceánica el número de especies de dinoflagelados aumenta y el de diatomeas disminuye, sin embargo, este último grupo siempre mantuvo los mayores registros de abundancia y diversidad.

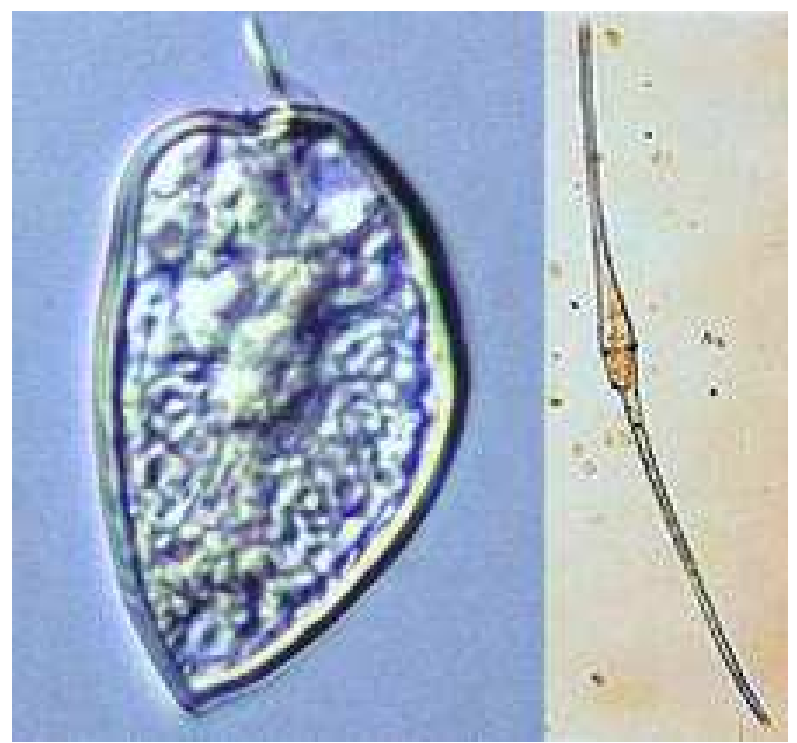

Prorocentrum nicans y Ceratium fusus. (Dinoflagelados) (Foto: Y. Fukuyo, 2000)

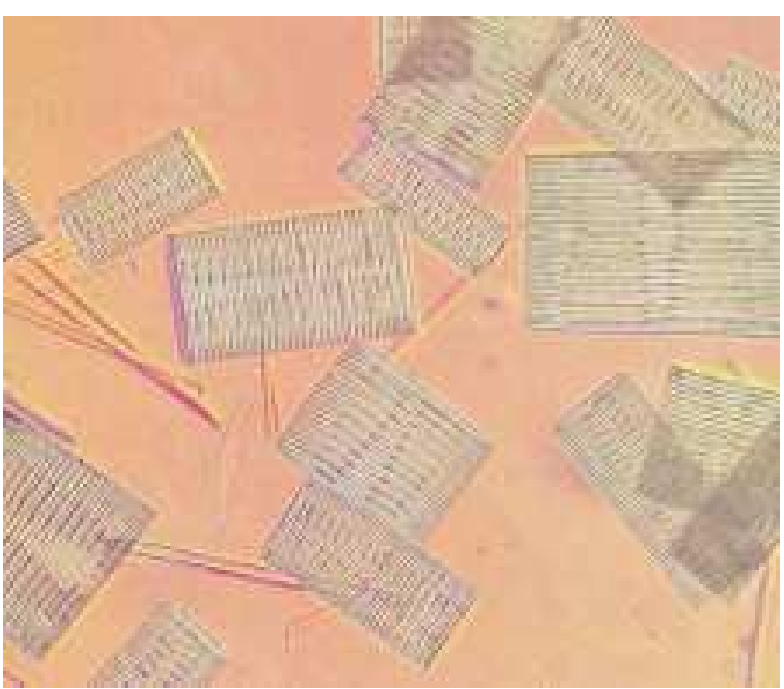

Trieratium. (Diatomeas) (Foto: Tomada de NGM, febrero de 1999)

\subsection{CONDICIONES EN PRESENCIA DE EL NIÑO}

Los resultados presentados en esta sección corresponden a los obtenidos del muestreo, procesamiento y análisis de la información recolectada a bordo del Buque Oceanográfico ARC Malpelo durante mayo de 1998, crucero escogido para representar las condiciones de la CPC durante un evento cálido El Niño, debido a la anomalía positiva de temperatura.

Se desarrolló una grilla de 65 estaciones oceanográficas y 28 químico-biológicas. El área de estudio estuvo comprendida entre las longitudes $77^{\circ} 45^{\prime} \mathrm{W}$ y $82^{\circ} 00^{\prime} \mathrm{W}$ y las latitudes $1^{\circ}$ $30^{\prime} \mathrm{N}$ y 63' N (Fig. 4.19).

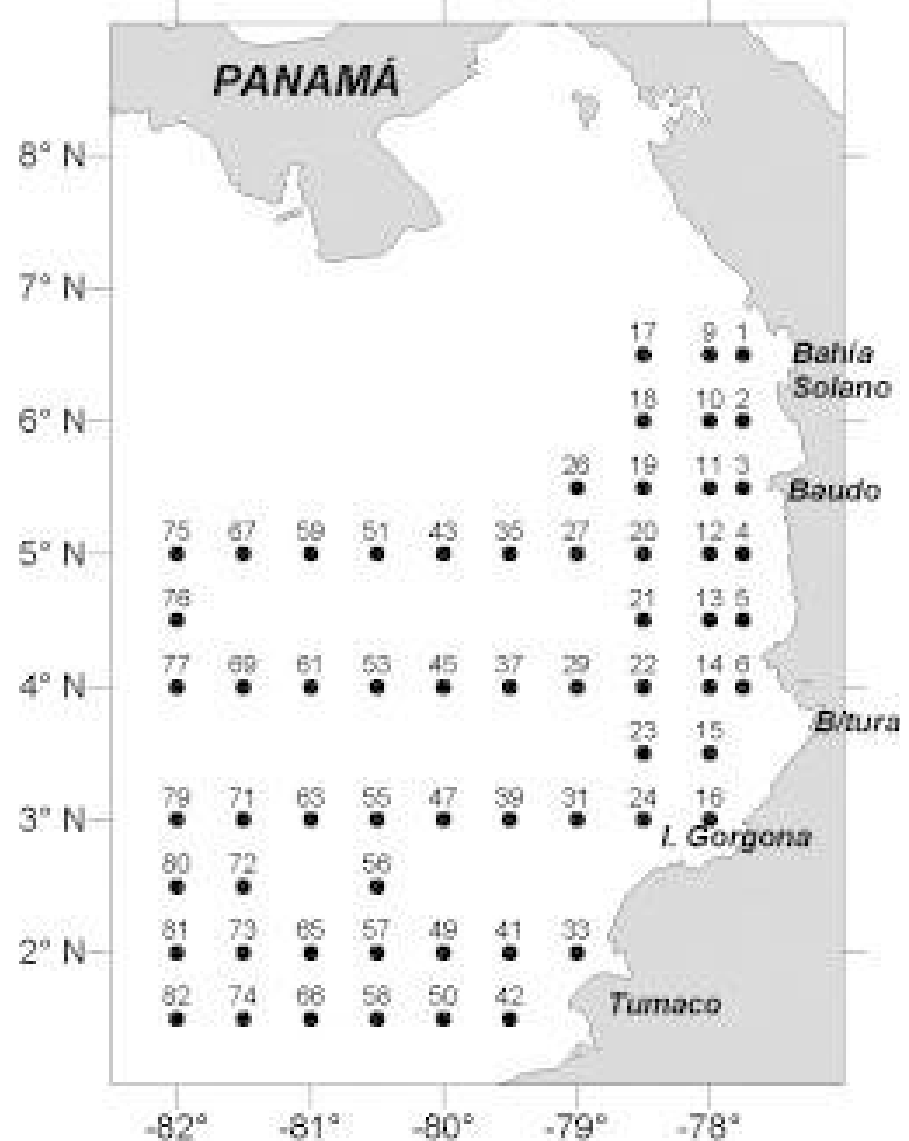

Figura 4.19 - Grilla de muestreo Crucero PACíFICO XXIX-ERFEN XXVII - Mayo de 1998 


\subsubsection{Características Físicas}

Temperatura

Distribución horizontal y vertical de Temperatura por capas a $0,25.50,100$ y $500 \mathrm{~m}$ de profundidad

El comportamiento general de la temperatura superficial del mar, TSM, en la CPC para este período presenta valores entre 29 y $30.4^{\circ} \mathrm{C}$. Los valores más bajos se observan hacia el sector de la isla de Gorgona con promedios entre 29.1 y $29.5^{\circ} \mathrm{C}$ y sobre el sector Norte $\left(5^{\circ} \mathrm{N}\right)$ con temperaturas de 29 a $29.4^{\circ} \mathrm{C}$. Las temperaturas más altas se registran sobre el perfil de Tumaco entre los $79^{\circ}$ y $80^{\circ} \mathrm{W}$, con rangos entre 29.7 y $30.2^{\circ} \mathrm{C}$. Así mismo, se presentan valores altos sobre el sector central (perfil de Buenaventura) con promedios de 29.7 a $30.4^{\circ} \mathrm{C}$ (Fig. 4.20).

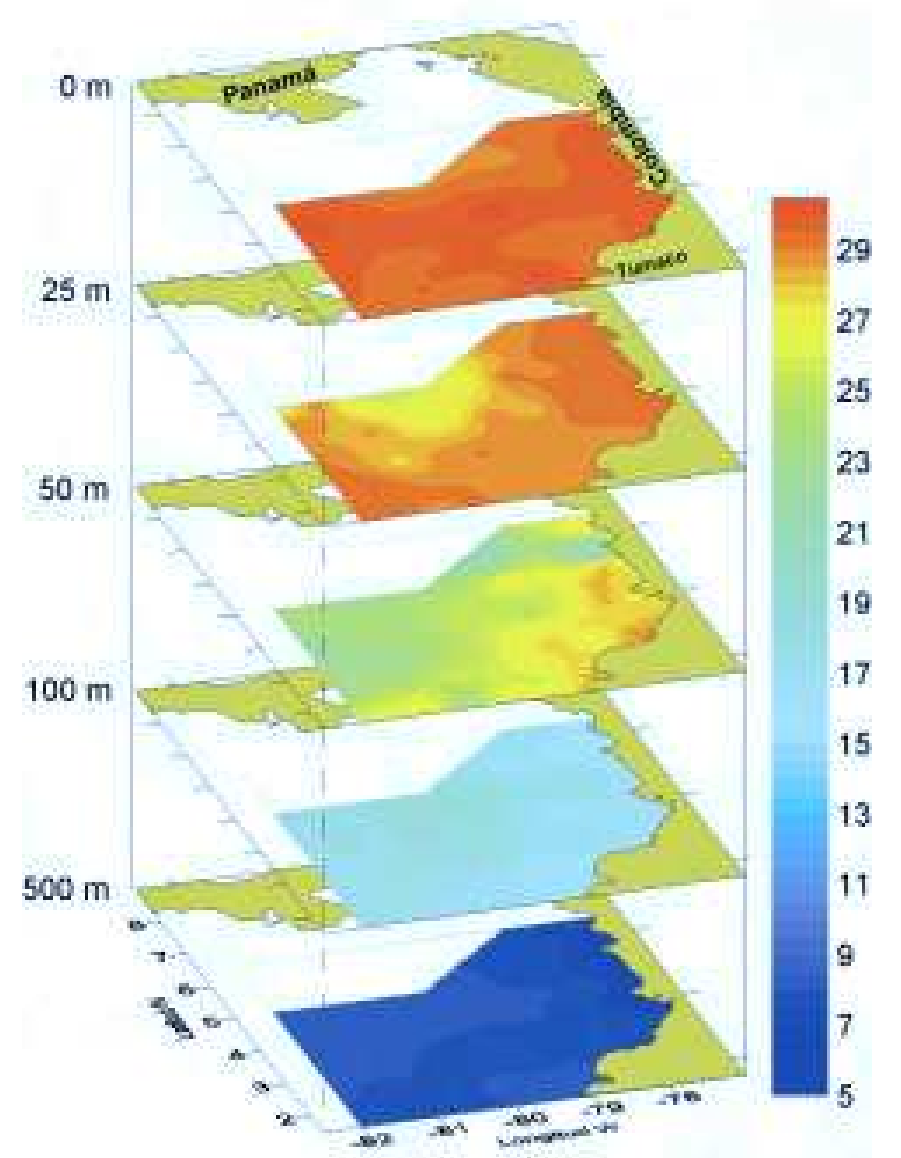

Figura 4.20 - Distribución de Temperatura horizontal y vertical por capas, mayo de 1998.
De acuerdo con las características térmicas del mar se determinó sobre el sector norte y suroeste la formación de dos cuñas de agua entrantes. La primera con temperaturas menores $\left(28,9 \mathrm{a} 29.4^{\circ} \mathrm{C}\right)$ y la segunda con temperaturas más altas (de 29.7 a $30.3^{\circ} \mathrm{C}$ ). A lo largo de las longitudes $78^{\circ} \mathrm{y}$ $80^{\circ} \mathrm{W}$ se presentó la formación de tres núcleos, dos ciclónicos y uno anticiclónico. Los dos primeros se forman sobre los perfiles de Buenaventura y Tumaco, respectivamente, con temperaturas entre los 29.7 y $30.2^{\circ} \mathrm{C}$. El otro núcleo, de carácter ciclónico, se localiza sobre Gorgona con temperaturas más bajas del orden de 29.1 a $29.4^{\circ} \mathrm{C}$. Sobre el sector suroeste se observó el desplazamiento de una lengua de agua cálida con valores de 29.1 a $29.5^{\circ} \mathrm{C}$ (Fig. 4.20).

Las condiciones sobre los $25 \mathrm{~m}$ son de valores altos en la costa y el suroeste de la cuenca. La temperatura ha disminuido en comparación a la TSM pero se mantiene muy cálida en comparación al año normal (2000). Sólo aparece una masa de aguas más bajas al norte $\left(27^{\circ} \mathrm{C}\right)$.

Las características térmicas a $50 \mathrm{~m}$ de profundidad presentan valores del orden de 22 a $28.5^{\circ} \mathrm{C}$. Hacia el sector oeste se observa la entrada de agua con temperaturas bajas de 22 a $25.5^{\circ} \mathrm{C}$, en tanto que las temperaturas más cálidas se registran a lo largo del Litoral (abarcando, aproximadamente, unas 100 millas mar afuera), con promedios de 26.5 a $28.5^{\circ}$ C. El descenso de los valores de las isotermas muestra el calentamiento paulatino que éstas sufren al dirigirse del sector oceánico hacia el sector costero, con excepción de la región de isla Gorgona, marcando una diferencia importante entre la zona oceánica y la costera de 3 a $4^{\circ} \mathrm{C}$.

Sobre las capas de los 100 y 500 m se observa el comportamiento propio de las aguas más profundas. La variación horizontal en la capa de los $100 \mathrm{~m}$ es de alrededor de $3^{\circ} \mathrm{C}$ para toda la cuenca, mientras que para la de $500 \mathrm{~m}$ es de $1^{\circ} \mathrm{C}$.

Distribución vertical de Temperatura por transeptos latitudinales

El transepto vertical de Tumaco $\left(2^{\circ} \mathrm{N}\right)$ presenta una capa superficial $(0-20 \mathrm{~m})$ con temperaturas mayores a $30^{\circ} \mathrm{C}$. La termoclina estacional se ubica a una profundidad de 25 a $100 \mathrm{~m}$ 
(Fig. 4.21), con las isotermas de 26 a $18^{\circ} \mathrm{C}$ entre los 79³0' y $79^{\circ}$ $\mathrm{W}$, entre los 50 y $75 \mathrm{~m}$, con un cambio en el gradiente de temperatura de $8^{\circ} \mathrm{C}$. A partir de esta capa las masas de agua se comportan estables, la isoterma de $15^{\circ} \mathrm{C}$ se encuentra a $150 \mathrm{~m}$ y a partir de esta profundidad la variación es cada vez menor, $1^{\circ} \mathrm{C} / 45 \mathrm{~m}$.

En el transepto de Isla Gorgona $\left(3^{\circ} \mathrm{N}\right)$ el comportamiento es más variable que el de Tumaco (Fig. 4.21). La temperatura superficial es homogénea a $29^{\circ} \mathrm{C}$, excepto en una región oceánica. La termoclina se ubica entre 25 y 100 m de profundidad con valores entre $28^{\circ}$ a $20^{\circ} \mathrm{C}$, presentando un cambio en el gradiente de temperatura de $1^{\circ} \mathrm{C}$ en $9 \mathrm{~m}$. Se observa una surgencia de las isotermas en isla Gorgona. Al igual que el transepto de Tumaco, a partir de los $200 \mathrm{~m}$ el comportamiento de las isotermas es uniforme a lo largo de la sección transversal.

En el transepto de Buenaventura y Malpelo $\left(4^{\circ} \mathrm{N}\right)$ se observa una capa de $0-15 \mathrm{~m}$ muy cálida de $30^{\circ} \mathrm{C}$; seguida por una de $28^{\circ} \mathrm{C}$ con un espesor de $25 \mathrm{~m}$, a nivel oceánico, y de $50 \mathrm{~m}$ a nivel costero (Fig. 4.21). La termoclina $\left(27-18^{\circ} \mathrm{C}\right)$ se ubica entre 25 y $75 \mathrm{~m}$ de profundidad en la mayoría de estaciones oceánicas, agrupándose cuando se aproximan a la costa sobre la longitud $78^{\circ} 30^{\prime}$ W.

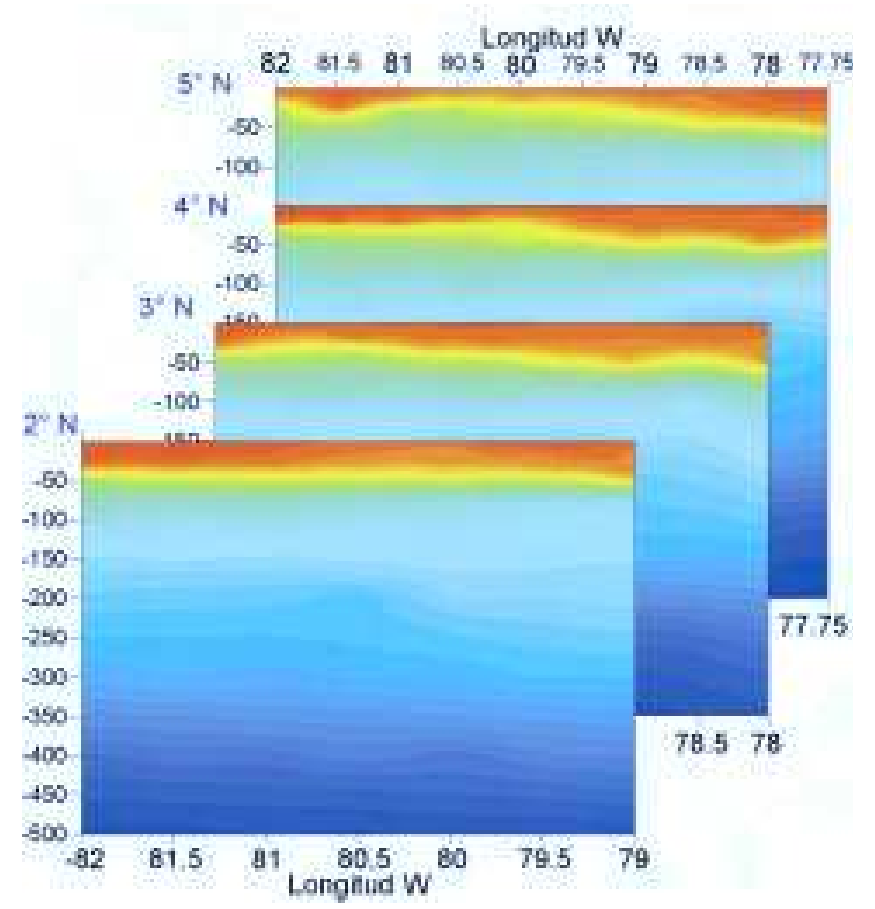

Figura 4.21 - Distribución de Temperatura por transeptos latitudinales, mayo de 1998.
En el transepto de Baudó $\left(5^{\circ} \mathrm{N}\right)$ la capa con temperaturas altas es menos gruesa en comparación con los otros transeptos. Del océano hacia la costa la termoclina presenta una variación entre 20-120 m y de 50-100 m, respectivamente. La isoterma de $15^{\circ} \mathrm{C}$ se encuentra más profunda en el norte que en el sur (transeptos anteriores).

\section{Salinidad}

Distribución horizontal y vertical de Salinidad por capas a $0,25.50,100$ y $500 \mathrm{~m}$ de profundidad

El comportamiento de la salinidad del agua a nivel superficial en la CPC registra promedios entre 31 y 33.4 (Fig. 4.22). Los valores máximos se observaron en la parte oceánica de la cuenca con promedios de 33.2 a 33.4, los valores más bajos a lo largo del litoral Pacífico con registros del orden de 31 a 33. Sobre el sector oceánico se presenta la entrada de agua sobre el sector oeste entre los $2^{\circ} \mathrm{N}$ y $4^{\circ} 30^{\prime} \mathrm{N}$, abarcando gran parte del área de estudio con un promedio de 33.2. Sobre el sector central se observa el corte longitudinal de la isohalina 33.2, dividiendo el área de estudio en dos zonas, una hacia el sector oceánico con salinidades más altas y otra hacia el sector costero con salinidades más bajas.

Observando la columna de agua de la cuenca (Fig. 4.22) se puede establecer la estratificación de la salinidad, donde los menores valores se ubican en la superficie y hacia la costa. La influencia de la superficie alcanza hasta la capa de los 50 $\mathrm{m}$, de ahí en adelante el comportamiento es típico de aguas profundas. En los $25 \mathrm{~m}$ se observa mucho mejor la masa de agua en el sector noreste de la cuenca.

A $50 \mathrm{~m}$ se observa un aumento de salinidades en relación con la superficie, con promedios entre los 33 y 34.8. A lo largo de todo el litoral se presentan los valores más bajos con registros comprendidos entre 33 y 34 . Los valores más altos se obtienen en el sector oceánico con promedios de 34.5 a 34.8 . Sobre el área de influencia oceánica (sector oeste) se observa la formación de un núcleo bajo en salinidad entre los 3 y $5^{\circ} \mathrm{N}$, con valores del orden de 33.7 a 34.8. En la parte central del área de estudio se presenta una gran concentración 


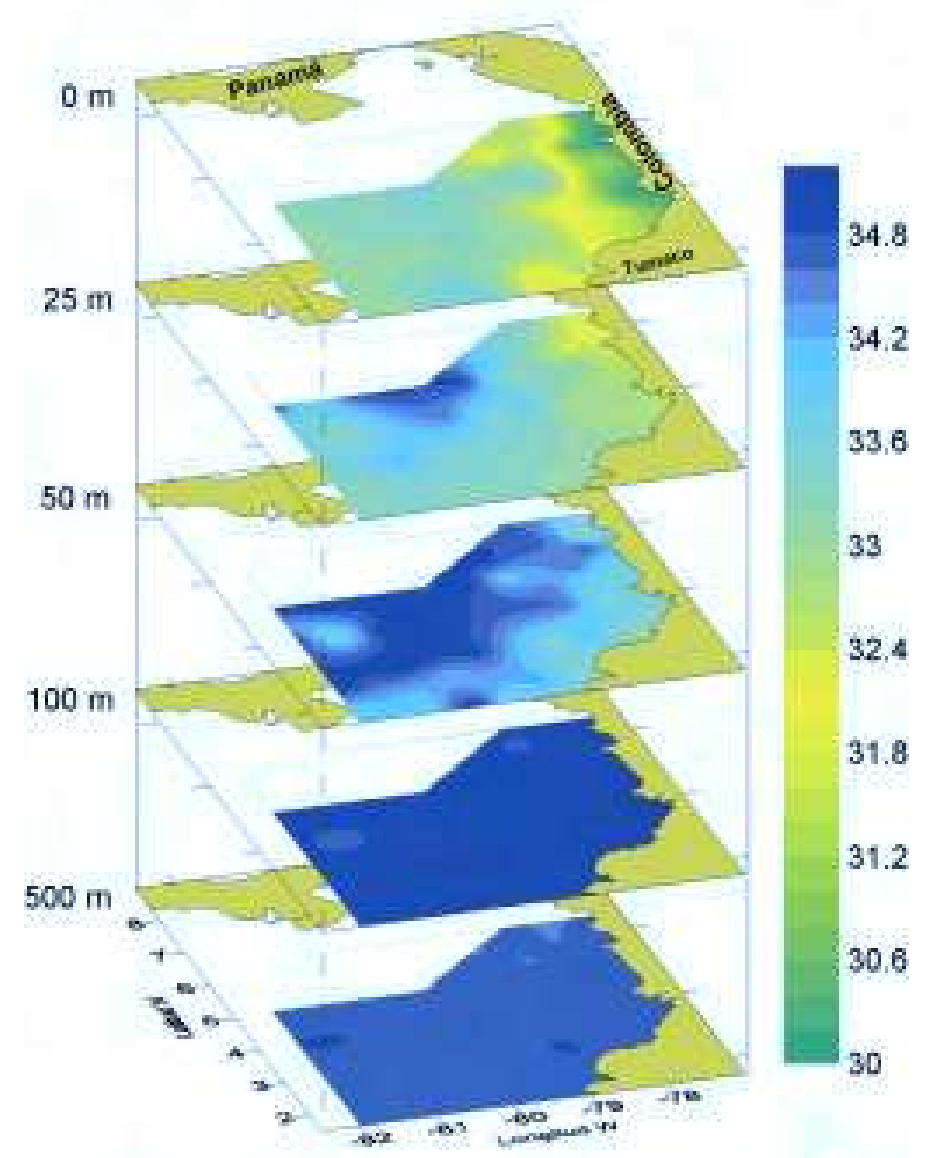

Figura 4.22 - Distribución de Salinidad horizontal y vertical por capas, mayo de 1998.

de las isohalinas, dividiendo el área en dos partes, noroeste y sureste. En las capas de 100 y $500 \mathrm{~m}$ la variación horizontal es menor en sus valores de 0.6 para $100 \mathrm{~m}$ y 0.3 en la capa de $500 \mathrm{~m}$.

Distribución vertical de Salinidad por transeptos latitudinales

En el transepto de Tumaco $\left(2^{\circ} \mathrm{N}\right)$ se observa que en el sector oceánico y entre los 79 y $80^{\circ} \mathrm{W}$ se introducen aguas con valores de máximos subsuperficiales de salinidad (35). Los mínimos se registran en la superficie entre los meridianos $79^{\circ} 30^{\prime}$ y $79^{\circ} \mathrm{W}$, con índices halinos entre 31 y 33 influenciados por la desembocadura del río Mira. Entre los 500 y $900 \mathrm{~m}$ se presenta un núcleo con salinidades de 34.6 entre las longitudes $80^{\circ}$ y $81^{\circ} \mathrm{W}$ (Fig. 4.23).
Los mayores valores se observan hacia el sector oceánico y los menores en proximidades a la costa, lo cual demuestra la influencia de los diversos sistemas estuarinos de la costa Pacífica colombiana.

En el transepto de isla Gorgona $\left(3^{\circ} \mathrm{N}\right)$ se presentó una capa de menor salinidad sobre el sector costero, entre la isla y el continente, con valores de 31.4 a 32.6 , como consecuencia del aporte continental de los ríos Yurumanguí, Tapaje, Iscuandé y Sanquianga, que enfrían la capa superficial y producen convección y un flujo hacia el norte. Esto se proyecta hasta el meridiano $79^{\circ} 30^{\prime} \mathrm{W}$, donde aparece una entrada de aguas con mayor salinidad (33). En los niveles de 50 a $300 \mathrm{~m}$ de profundidad se observan aguas con valores de 34.8, provenientes del océano Pacífico Ecuatorial, que son desplazadas por la subcorriente Ecuatorial de Cromwell (Fig. 4.23).

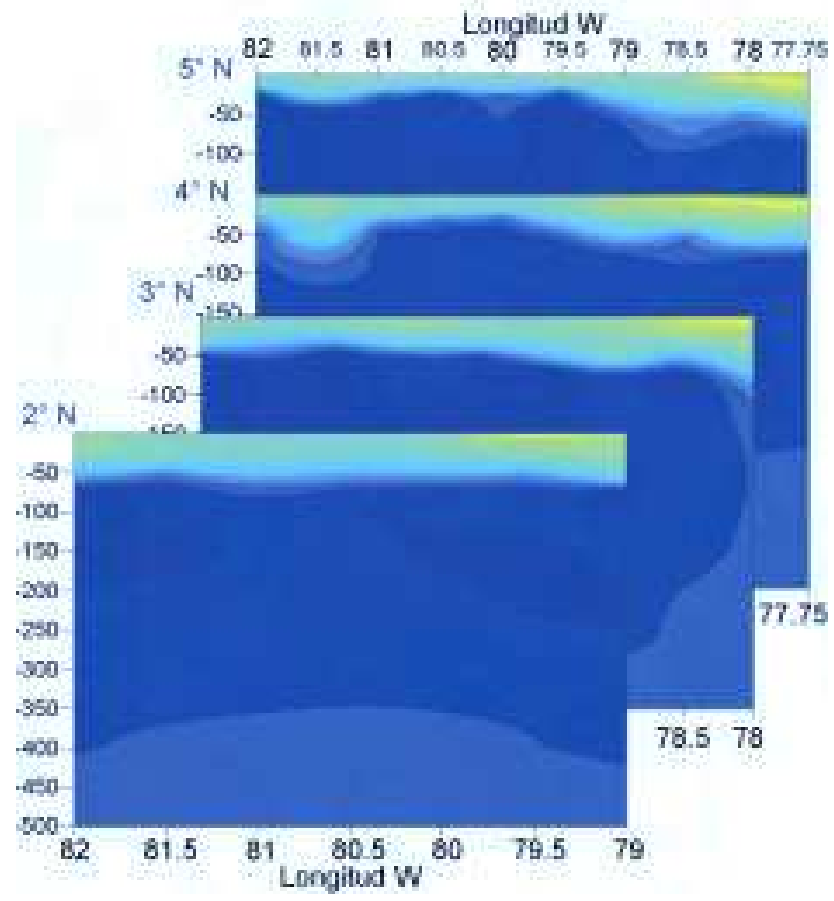

Figura 4.23 - Distribución vertical de Salinidad por transeptos latitudinales, mayo de 1998.

En el transepto de Buenaventura e isla Malpelo $\left(4^{\circ} \mathrm{N}\right)$ sobre la costa y hasta el meridiano $79^{\circ} 30^{\prime} \mathrm{W}$ se observa la influencia de una masa de agua menos salina proveniente de los sistemas estuarinos de la costa del Valle del Cauca, con valores del orden de 30.8 a 32. A nivel oceánico se presenta una capa superficial salina de 33.2 hasta una profundidad de $20 \mathrm{~m}$. En la capa de los 25 a 50 m se registra una concentración de las isohalinas entre 33.8 y 34.8 . Por debajo de los $50 \mathrm{~m}$ la salinidad 
muestra una homogeneidad en su comportamiento, con un valor de 34.8 hasta una profundidad de $300 \mathrm{~m}$. Por debajo de esta capa se presenta la intrusión de agua con salinidades de 34.6, entre los 500 y $900 \mathrm{~m}$ y longitudes 79 a $81^{\circ} \mathrm{W}$ (Fig. $4.23)$. En la región que rodea la isla de Malpelo $\left(82^{\circ} \mathrm{W}\right)$ se observa una elevación de las isohalinas.

En el transepto de Baudó $\left(5^{\circ} \mathrm{N}\right)$ el comportamiento de la salinidad es similar al de la temperatura en la misma latitud; la variación del océano hacia la costa tuvo como característica en los primeros $100 \mathrm{~m}$ la tendencia de profundización de las isohalinas. Por debajo de los $100 \mathrm{~m}$ el comportamiento es muy homogéneo hasta la máxima profundidad observada (500 m) (Fig. 4.23).

\subsubsection{Características Químicas}

Oxígeno Disuelto (OD)

Distribución horizontal y vertical de OD por capas a 0 , $25,50,100$ y $150 \mathrm{~m}$ de profundidad

El OD a nivel superficial exhibe un comportamiento homogéneo a lo largo de la cuenca con un promedio de 6.6 $\mathrm{mg} / \mathrm{l}$. En el sector noroeste se presentan los valores más bajos con $6.05 \mathrm{mg} / \mathrm{l}$, manteniéndose concentraciones bajas a lo largo de la columna de agua en esta misma zona hasta alcanzar valores de $1.1 \mathrm{mg} / \mathrm{l}$ a los $150 \mathrm{~m}$. De igual manera, hacia el sector noreste es posible observar valores muy similares a este último en esta profundidad (Fig. 4.24).

Los datos más altos de oxígeno tanto a nivel superficial como en la columna de agua se presentan hacia el suroeste y centro de la CPC con valores que van de $7.1 \mathrm{mg} / \mathrm{l}$, en superficie, a $3.8 \mathrm{mg} / \mathrm{l}$, en el fondo. A lo largo del litoral también se presentan valores altos, resaltándose la elevada concentración de OD hacia la zona de Tumaco con $6.8 \mathrm{mg} / \mathrm{l}$, a nivel superficial, hasta llegar a $3.1 \mathrm{mg} / \mathrm{l}$, a $150 \mathrm{~m}$ (Fig. 4.24).

Los valores de OD reportados para este período son altos, ya que normalmente sobre la CPC fluctúan entre $5.5 \mathrm{mg} / \mathrm{l}$ y $6.0 \mathrm{mg} / \mathrm{l}$.

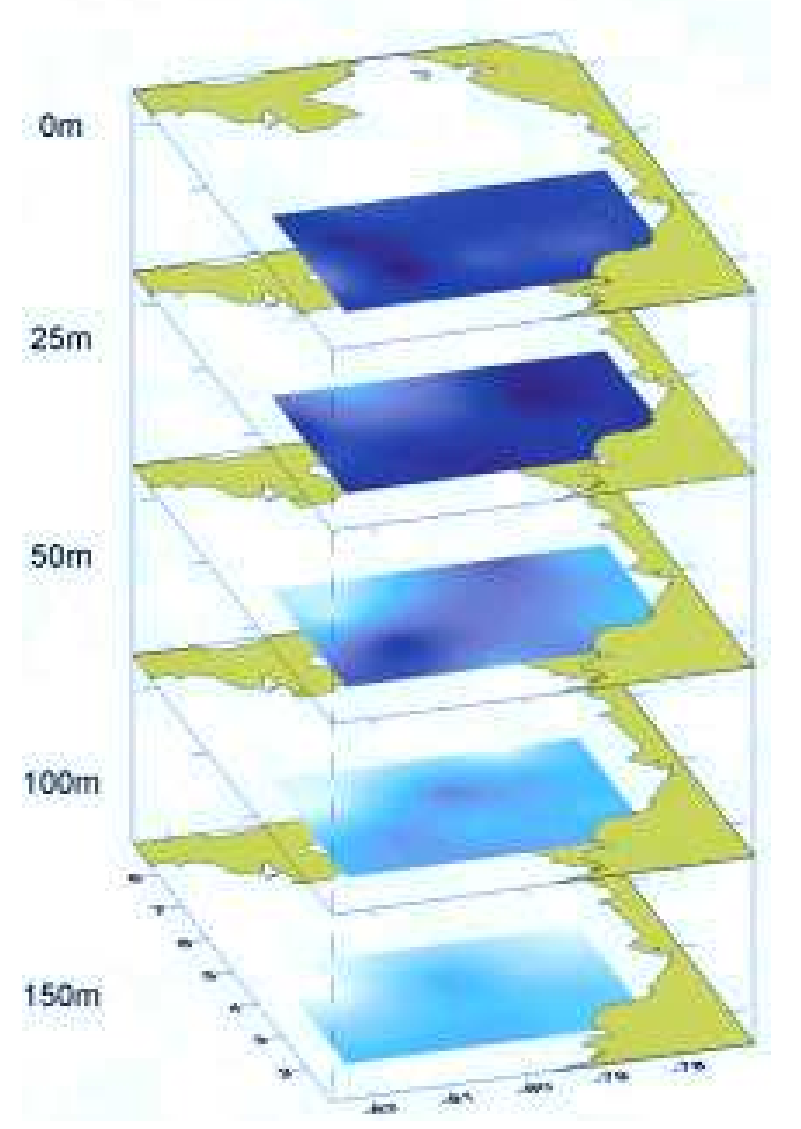

Figura 4.24 - Distribución horizontal y vertical de OD (mg/l) por capas, mayo de 1998.

\section{Nutrientes}

Amonio

Distribución horizontal y vertical de Amonio por capas a $0,25,50,100$ y $150 \mathrm{~m}$ de profundidad

El amonio a nivel superficial (Fig. 4.25) presentó sus máximos valores en un núcleo ubicado en el sector sureste con 1.2 a $1.8 \mu \mathrm{g}$-at/l y sobre el área oceánica que circunda Malpelo con 0.7 a $1.0 \mu \mathrm{g}$-at/l. Hacia el sector costero se registraron las menores concentraciones $(0.06 \quad 0.2 \mu \mathrm{g}$-at/l $)$ en relación con altas temperaturas y la mayor abundancia de organismos.

Por debajo de la superficie se mantuvieron estos mismos núcleos, los cuales fueron aumentando su concentración con la profundidad, presentándose un nuevo núcleo en la costa hacia la isla de Gorgona con valores de 0.6 a $1.0 \mu$ g-at/l. Las concentraciones más altas de amonio se detectaron a partir de los 50 m (3.5 a $6.6 \mu$ g-at/l) en los núcleos del suroeste de 


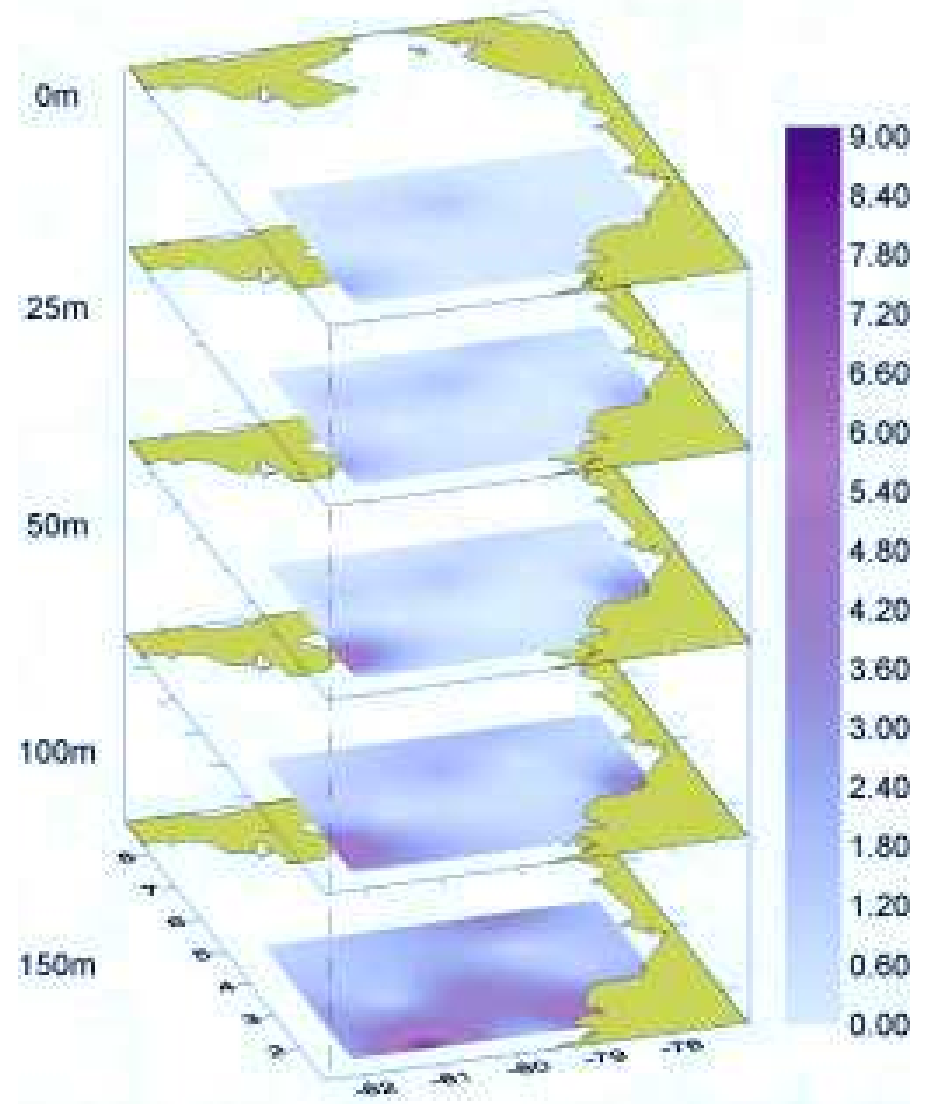

Figura 4.25 - Distribución horizontal y vertical de Amonio (nh4 ug-at/l) por capas, mayo de 1998.

la isla de Gorgona, conservando esta misma distribución hasta los $100 \mathrm{~m}$. En el perfil de los $150 \mathrm{~m}$ se amplió su distribución por toda la Zona Sur de la cuenca con concentraciones altas que alcanzaron los $7.8 \mu \mathrm{g}$-at/l.

Nitrato

Distribución horizontal y vertical de Nitrato por capas a $0,25,50,100$ y $150 \mathrm{~m}$ de profundidad

El nitrato a nivel superficial y hasta los $25 \mathrm{~m}$ mostró valores muy bajos cercanos a $0 \mu \mathrm{g}$-at/l, a excepción de la zona sureste y extremo noroeste, donde se presentaron concentraciones entre 2.8 y $4.5 \mu \mathrm{g}$-at/l (Fig. 4.26). Sobre el sector costero se detectaron los menores valores en relación con las mayores abundancias de microalgas. A nivel de los 50 m (Fig. 4.26) se amplió su distribución y aumentó la concentración en un rango entre 0.7 a $10.28 \mu \mathrm{g}$-at/l. Los mayores registros de esta sal (11.5 a $17.6 \mu \mathrm{g}$-at/l) se obtuvieron a partir de los $100 \mathrm{~m}$, distribuyéndose de forma casi homogénea en este perfil;

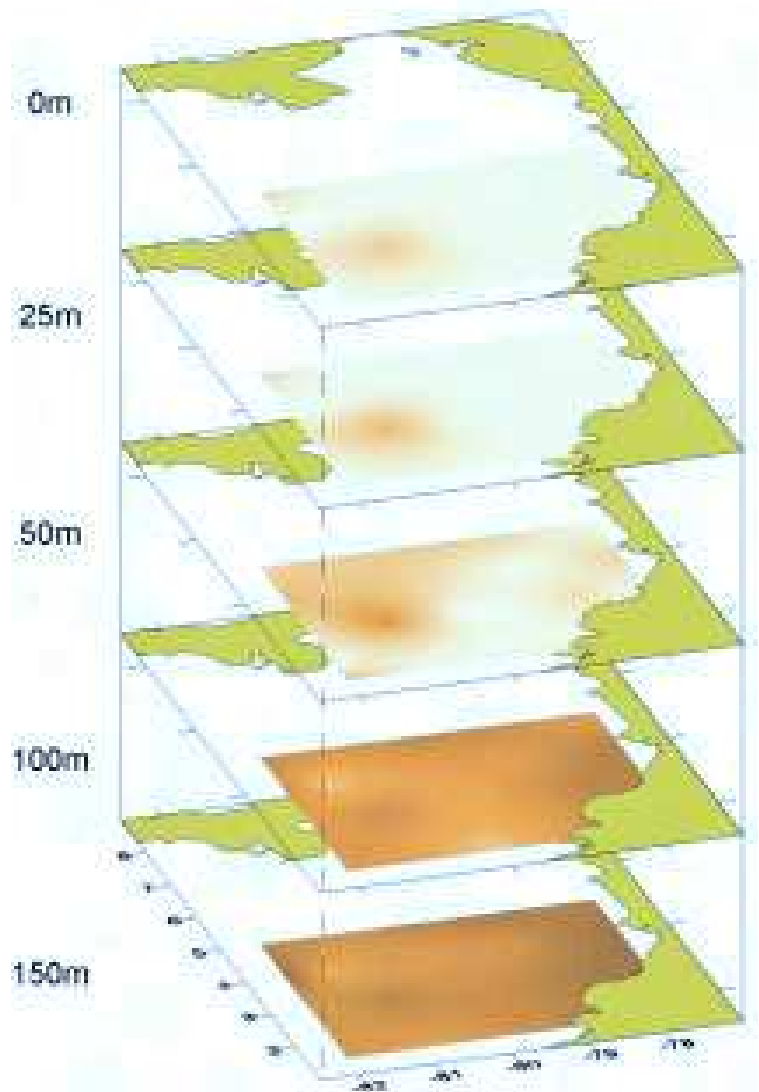

Figura 4.26 - Distribución horizontal y vertical de Nitrato (no3 $\mu \mathrm{g}$-at/l) por capas, mayo de 1998.

conservándose el mismo núcleo observado en la zona sureste y aumentando un poco la concentración hacia la costa. A 150 m se presentó la máxima concentración con $19.8 \mu \mathrm{g}$-at/l.

\section{Fosfato}

Distribución horizontal y vertical de Fosfato por capas a $0,25,50,100$ y $150 \mathrm{~m}$ de profundidad

El fosfato a nivel superficial presentó valores muy bajos entre 0 y $0.21 \mu \mathrm{g}$-at/l, donde el registro más alto correspondió a un núcleo ubicado en cercanías de la isla de Malpelo (Fig. 4.27). La concentración de este nutriente aumentó con la profundidad, al igual que su distribución, por lo que a partir de los $25 \mathrm{~m}$ fue posible observar valores más elevados al norte, extremo sureste e isla Gorgona. A los $50 \mathrm{~m}$ se amplió aún más la disposición de esta sal con registros entre 0.12 a $0.68 \mu \mathrm{g}$ at/l. Las concentraciones más altas se obtuvieron en los perfiles de 100 y 150 m (Fig. 4.27) en un rango entre $0.33 \quad 1.65 \mu$ g-at/ I. Los menores valores se mantuvieron siempre hacia el sur. 


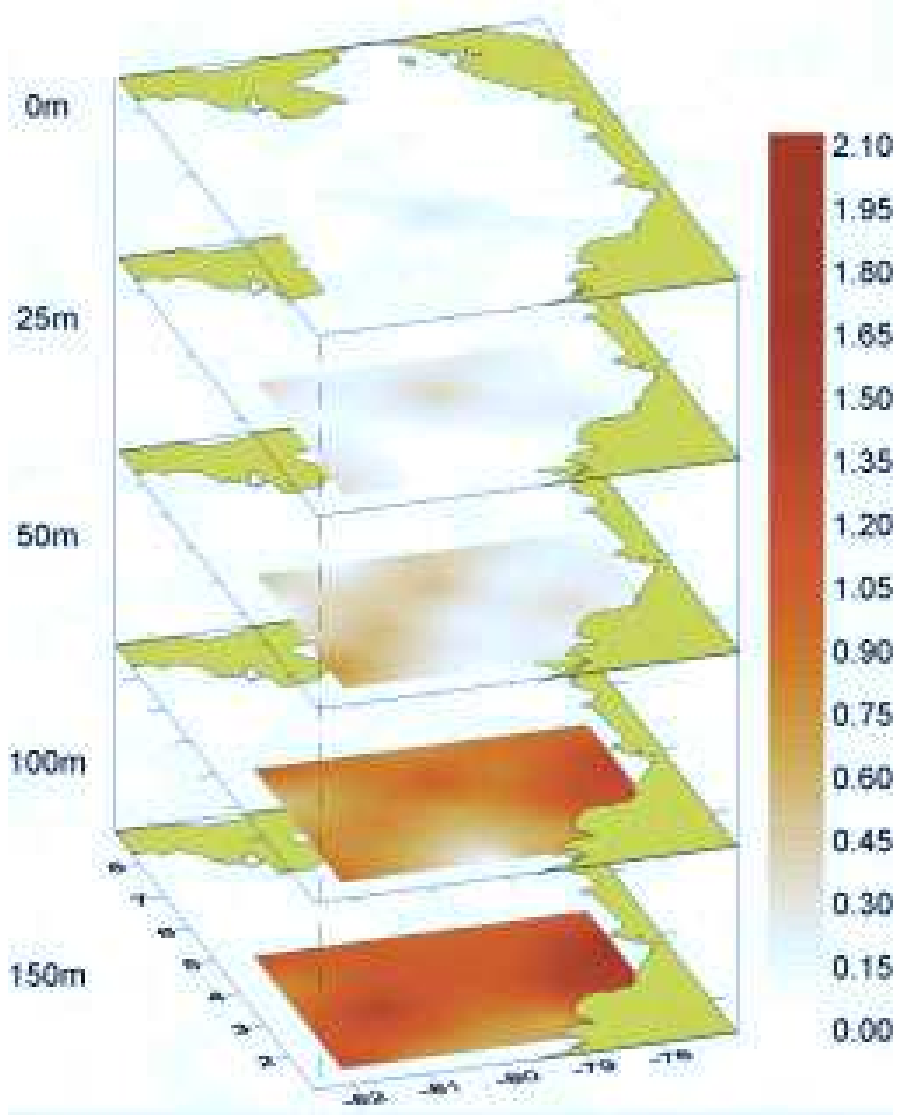

Figura 4.27 - Distribución horizontal y vertical de Fosfato (po4 $\mu \mathrm{g}$-at/l) por capas, mayo de 1998.

Silicato

Distribución horizontal y vertical de Silicato por capas a $0,25,50,100$ y $150 \mathrm{~m}$ de profundidad

Al igual que para el caso de los fosfatos este nutriente presentó un núcleo de mayores concentraciones cerca de Malpelo (2.4 a $3.0 \mu \mathrm{g}$-at/l), mostrando valores bajos en el resto del área ( 0 a $2.2 \mu \mathrm{g}$-at/l). Este mismo núcleo se mantuvo a lo largo de la columna de agua, ampliándose un poco hacia el sector norte y presentando los más altos registros a $150 \mathrm{~m}$ (34.3 a $48.8 \mu \mathrm{g}$-at/l) (Fig. 4.28).

En general para todas las profundidades esta sal se mantuvo en concentraciones bajas a excepción del núcleo mencionado.

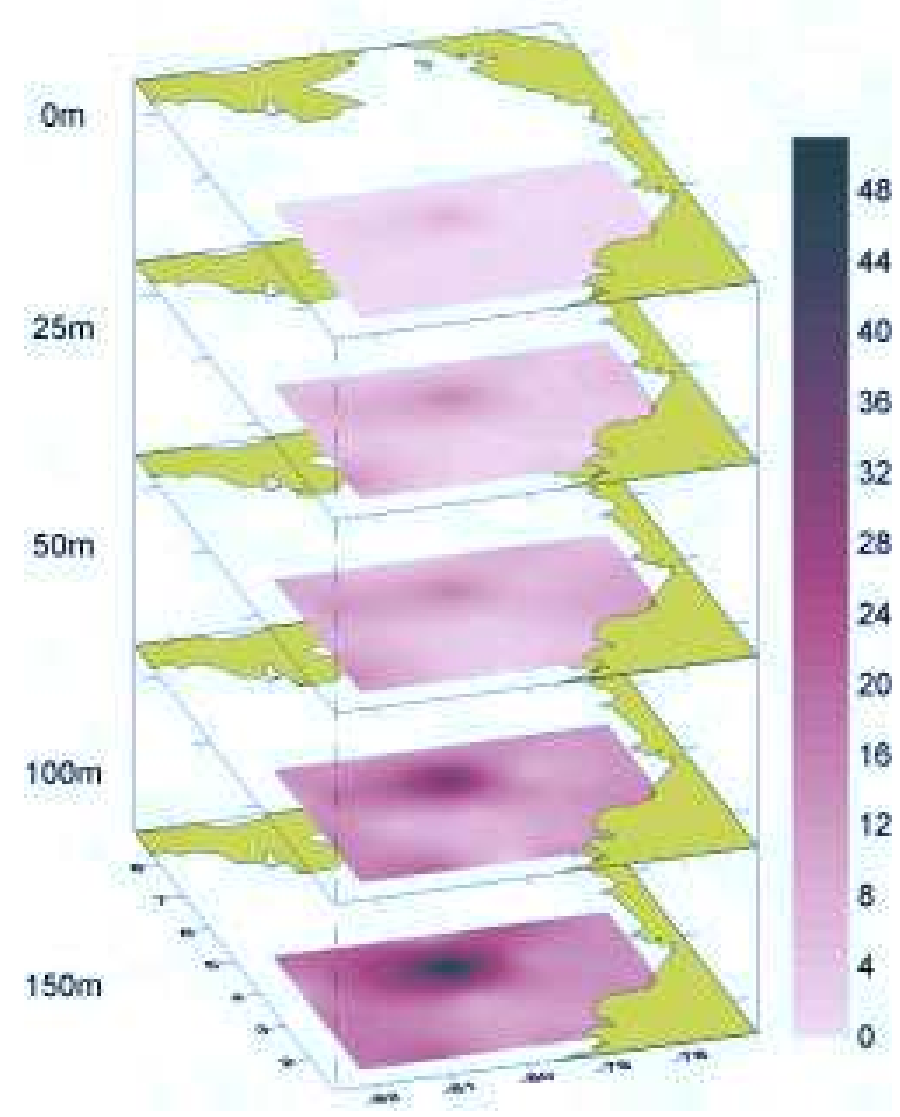

Figura 4.28 - Distribución horizontal y vertical de Silicato (sio3 $\mu \mathrm{g}$-at/l) por capas, mayo de 1998.

\subsubsection{Características Biológicas}

\section{Clorofila "a"}

Distribución horizontal y vertical de Clorofila "a" por capas a $0,25,50,100$ y $150 \mathrm{~m}$ de profundidad

Durante este período se encuentran los niveles más bajos de clorofila "a" en la cuenca con valores que van entre 0 y $3.0 \mathrm{mg} / \mathrm{m}^{3}$. A nivel superficial se registran tres núcleos, uno en el sector noreste $\left(1.8\right.$ a $\left.3.0 \mathrm{mg} / \mathrm{m}^{3}\right)$, otro más pequeño al sureste $\left(1.6\right.$ a $\left.2.8 \mathrm{mg} / \mathrm{m}^{3}\right)$ y un tercero hacia la región costera en el área de isla Gorgona con concentraciones menores (1.8 a $\left.2.1 \mathrm{mg} / \mathrm{m}^{3}\right)$. Estos núcleos mantienen casi la misma distribución espacial hasta el nivel de los 100 a $150 \mathrm{~m}$, donde registran concentraciones entre 0.6 y $0.3 \mathrm{mg} / \mathrm{m}^{3}$ (Fig. 4.29). El resto del área se caracteriza por presentar concentraciones muy bajas del orden de $0.6 \mathrm{mg} / \mathrm{m}^{3}$ en promedio en superficie hasta $0 \mathrm{mg} / \mathrm{m}^{3}$ a partir de los $100 \mathrm{~m}$. 


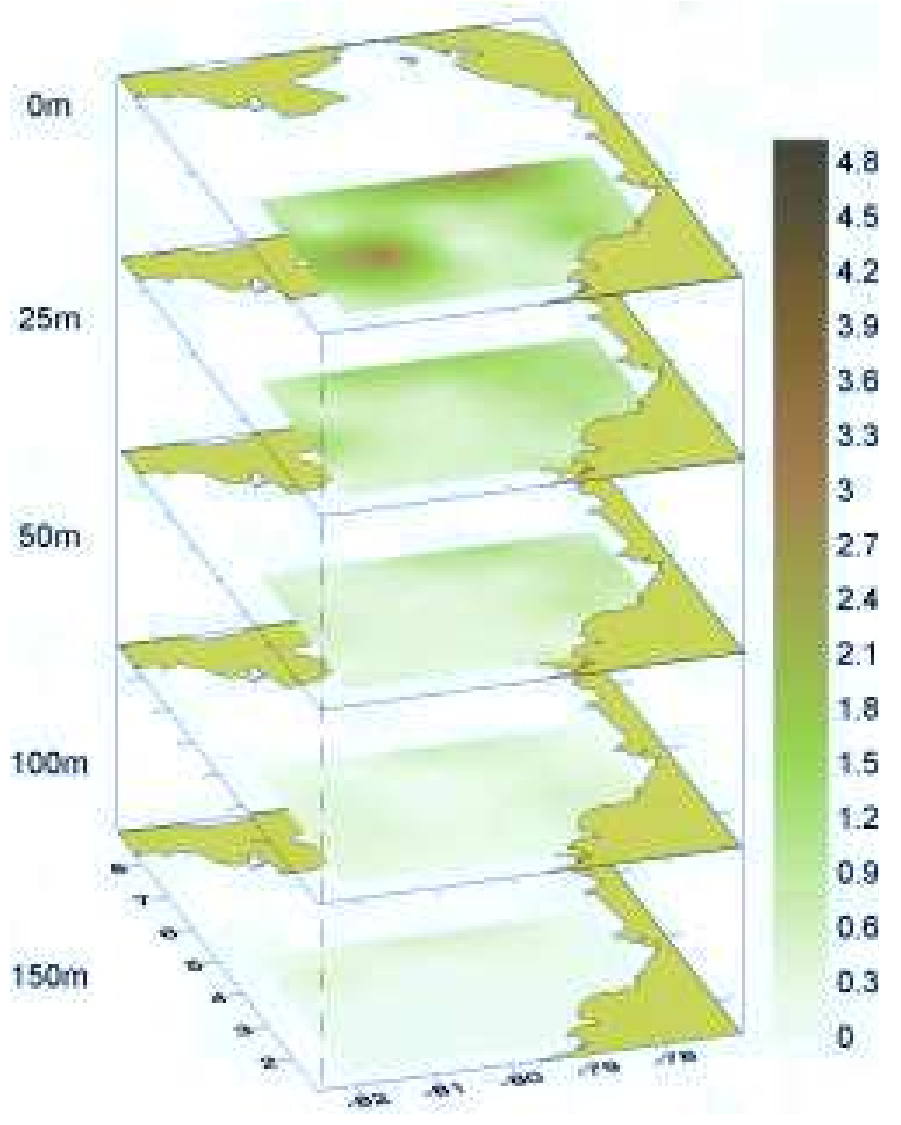

Figura 4.29 - Distribución horizontal y vertical de clorofila "a" $\left(\mathrm{mg} / \mathrm{m}^{3}\right)$ por capas, mayo de 1998

\section{Fitoplancton}

\section{Diatomeas}

Composición Especiológica

El número tanto de géneros como de especies para este grupo es menor que lo reportado durante la época normal, identificándose 53 géneros y un total de 136 especies (Tabla 4.1), siendo los más representativos en su orden: Chaetoceros: C. affinis, C. cinctus, C. curvisetus, C, dichaeta, C. didymus var anglica, C. eibenii, C. laevis, C. lorenzianus, C. peruvianus, y C. socialis; Odontella: 0 . alternans, O. aurita, O. dubia, O. longicruris, O. mobiliensis, O. pulchella, O. regia y $O$. sinensis; Coscinodiscus: $C$. concinnus, $C$. eccentricus, C. granii, C. marginatus, $C$. nitidus y $C$. radiatus; Nitzschia: $N$. angularis, N. bicapitata, N. brevissonii, N. longissima, $N$. pacifica y $N$. recta; Rhizosolenia: $R$. castracanei, $R$. hebetata, $R$. hyalina, $R$. robusta y $R$. setigera; Asteromphalus: $A$. arachne, A. bookeri, A. elegans y A. heptactis; Bacteriastrum:
B. furcatum, B. elongatum y $B$. hyalinum y finalmente Melosira: M. fausta y M. mayor.

Se observa la presencia de nueve especies con aparición única para este período (Asteromphalus claveanus, Actinoptychus mediterraneum, Chaetoceros atlanticus var napolitanus, C. brevissonii, Gyrosigma balticum, G. spencerii, Melosira fausta, Odontella longissma y Pleurosigma heros).

Distribución horizontal y vertical de abundancia de Diatomeas por capas a 0, 25, 50, 100 y $150 \mathrm{~m}$ de profundidad

Para el año Niño las abundancias de diatomeas fueron bajas comparadas con los períodos normal y Niña, observándose los máximos registros hacia el área de Gorgona con valores entre 17100 y $29050 \mathrm{cel} / \mathrm{l}$ y al extremo sureste con 16900 cel/l, en correlación con un núcleo de temperaturas un poco menores que las registradas en el resto del área.

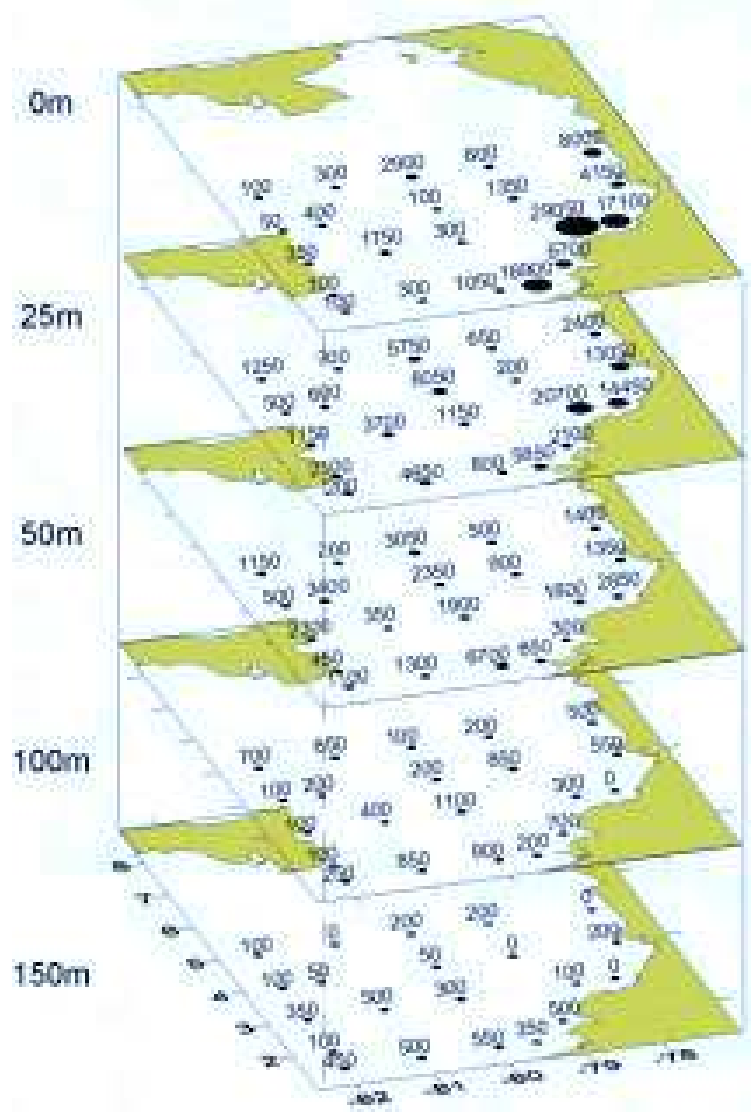

Figura 4.30 - Distribución horizontal y vertical de abundancia de Diatomeas (cel/l) por capa, mayo de 1998

(El tamaño del símbolo corresponde con el valor de abundancia) 
Hacia los $25 \mathrm{~m}$, nuevamente, los mayores valores se hicieron presentes en el sector aledaño a Gorgona (14450 $20700 \mathrm{cel} / \mathrm{l}$ ) y extremo sureste (5850 cel/l), extendiéndose hacia Buenaventura con $13050 \mathrm{cel} / \mathrm{l}$. Cerca de la isla de Malpelo se observó otro foco de elevadas abundancias con $8050 \mathrm{cel} / \mathrm{l}$. A esta profundidad fue posible encontrar mayor cantidad de microalgas en casi toda el área (Fig. 4.30), pues estos organismos son afines con temperaturas menores que las halladas en superficie.

Por debajo de los $50 \mathrm{~m}$ la cantidad de individuos disminuyó hasta presentar registros que oscilaron entre 0 y $550 \mathrm{cel} / \mathrm{l}$ a $150 \mathrm{~m}$ (Fig. 4.30).

\section{Dinoflagelados}

\section{Composición Especiológica}

Durante este período comparado con el año normal se presentó un aumento en el número de géneros con 31 y el de especies con 136 (Tabla 4.1), siendo las siguientes las más importantes: Ceratium: C. extensum, C. furca, C. furca var furca, C. fusus var fusus, C. fusus var seta, C. kofoidii, C. macroceros var gallicum, $C$. macroceros var macroceros, $C$. mássiliense var armatum, C. mássiliense var mássiliense, $C$. paradoxides, $C$. pentagonum var pentagonum, $C$. pentagonum var tenerum, C. pulchellum, $C$. teres, $C$. trichoceros, $C$. tripos var breve y $C$. tripos var tripos; Protoperidinium: $P$. claudicans, $P$. conicum, $P$. depressum, $P$. elegans, $P$. joubini, $P$. pellucidum, $P$. pentagonum y $P$. quarnerense; Prorocentrum: $P$. compressum, $P$. emarginatum, $P$. euarcuatum, $P$. gracile, $P$. mexicanum, $P$. micans, $P$. minimum, $P$. rostratum, $P$. scutellum, y P. triestinum; Gonyaulax: G. fragilis, G. nigricans, $G$. pacifica, G. polygramma y G. sphaeroidea; Dinophysis: $D$. acuminata, D. caudata, D. exigua y D. hastata; Gymnodinium: G. agiliforme, G. catenatum y G. sanguineum.

Se reportan además 30 especies nuevas (Tabla 4.1). En su mayoría las microalgas encontradas corresponden a especies de aguas cálidas reportadas durante la ocurrencia de eventos El Niño en otros países (Balech, 1988; Ochoa, et al., 1985 y Vizcaíno, 1993).
Distribución horizontal y vertical de abundancia de Dinoflagelados por capas a 0, 25, 50, 100 y $150 \mathrm{~m}$ de profundidad

A diferencia de las diatomeas el grupo de los dinoflagelados presentó las abundancias más altas para este período de observación. En este caso los mayores registros también se obtuvieron en la región costera con valores entre 2800 y 15600 cel/l (Fig. 4.31).

A 25 m se mantuvieron valores relativamente altos entre la zona de isla Gorgona y el suroeste donde se registraron abundancias de 2400 a 3700 cel/l. De igual manera fue posible encontrar valores altos en la zona cercana a isla Malpelo (2200 $2400 \mathrm{cel} / \mathrm{l})$. Hacia los $50 \mathrm{~m}$ se presentaron, nuevamente, las cantidades más elevadas de organismos en el suroeste de isla Malpelo. En el resto de la zona los valores fueron bajos y en muchas estaciones hubo ausencia de individuos.

A $100 \mathrm{~m}$ las abundancias fueron muy bajas ( 0 a $300 \mathrm{cel} / \mathrm{l}$ ) y a $150 \mathrm{~m}$ se registró la ausencia parcial de dinoflagelados en todo el perfil.

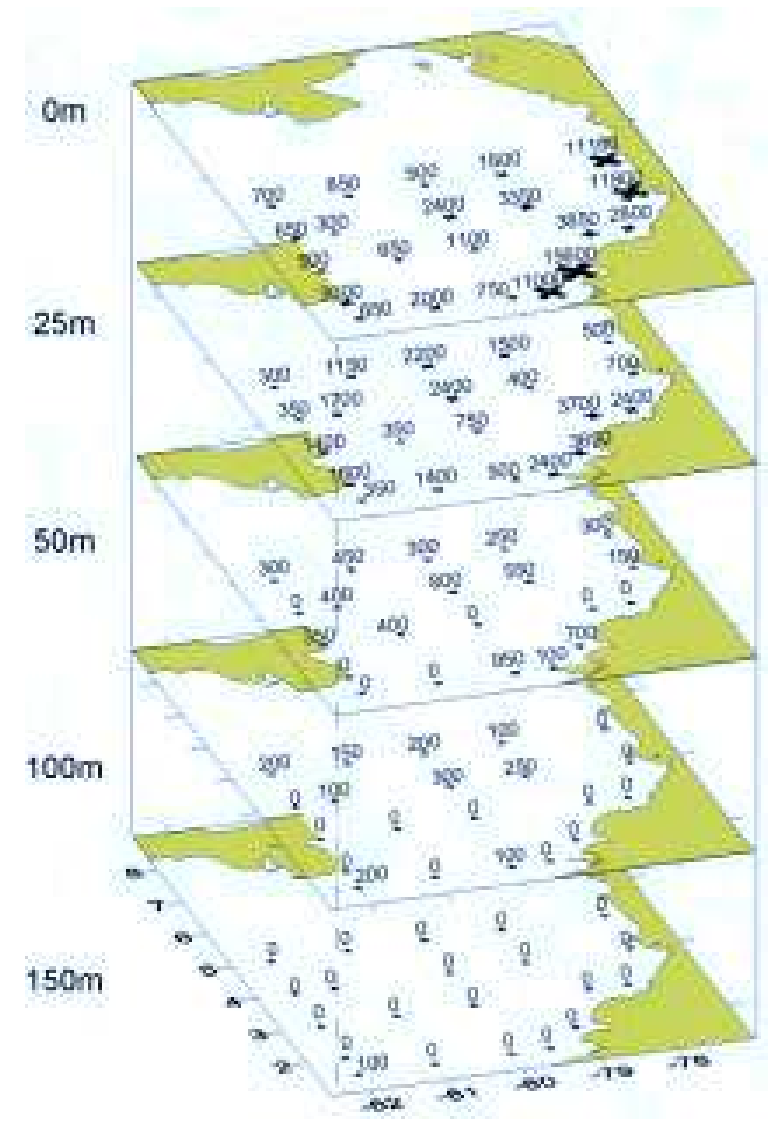

Figura 4.31 - Distribución horizontal y vertical de abundancia de Dinoflagelados (cel/l) por capas, mayo de 1998.

(El tamaño del símbolo corresponde con el valor de abundancia) 


\subsubsection{Análisis general condición Niño}

En general, durante el desarrollo de un fenómeno El Niño la temperatura aumenta sensiblemente en la CPC, especialmente en las capas superiores a los $100 \mathrm{~m}$, siendo mayor en la costa y al norte de la cuenca. La salinidad disminuye en toda la región Pacífica colombiana, especialmente en la superficie. Las corrientes superficiales que, generalmente, influyen sobre la parte sur de la cuenca y que modifican la salinidad no se presentan durante esta época. Las surgencias se hacen menos notorias pero pueden apreciarse afloramientos de agua con valores ligeramente menores en cercanías de la isla de Gorgona y en la isla de Malpelo, aunque de menor intensidad.

Durante el Niño el OD en la CPC presenta los registros más altos en comparación con el evento La Niña e incluso bajo condicones normales, con valores que oscilan entre $6.05 \mathrm{y}$ $6.95 \mathrm{mg} / \mathrm{l}$ en superficie y entre 1.4 y $3.8 \mathrm{mg} / \mathrm{l}$ al fondo (150 $\mathrm{m})$. Al igual que en la época normal las concentraciones más elevadas se observan en la región costera, y al suroeste y centro de la porción oceánica.

A diferencia de los años Niña y normal los nutrientes, en general, exhiben bajas concentraciones en los primeros 50 $\mathrm{m}$, observándose en todos los casos un núcleo ubicado en cercanías de la isla de Malpelo y una intrusión de aguas al suroeste. A lo largo de la costa la presencia de sales nutritivas es muy baja.

Normalmente las aguas que caracterizan el año Niño son pobres en nutrientes, lo cual se refleja en la baja cantidad de organismos presentes en el área. Durante este período también se registran los valores más bajos de clorofila "a".

Para esta condición el grupo de las diatomeas muestra una reducción tanto en cantidad de células como en diversidad de especies. Presentando, además, una distribución anómala, viéndose restringidas a la región costera, sobre todo en el área comprendida entre la isla de Gorgona y Tumaco. Por su parte el grupo de los dinoflagelados amplía su distribución, registrándose para este grupo 30 nuevas especies, con aparición única para este período.

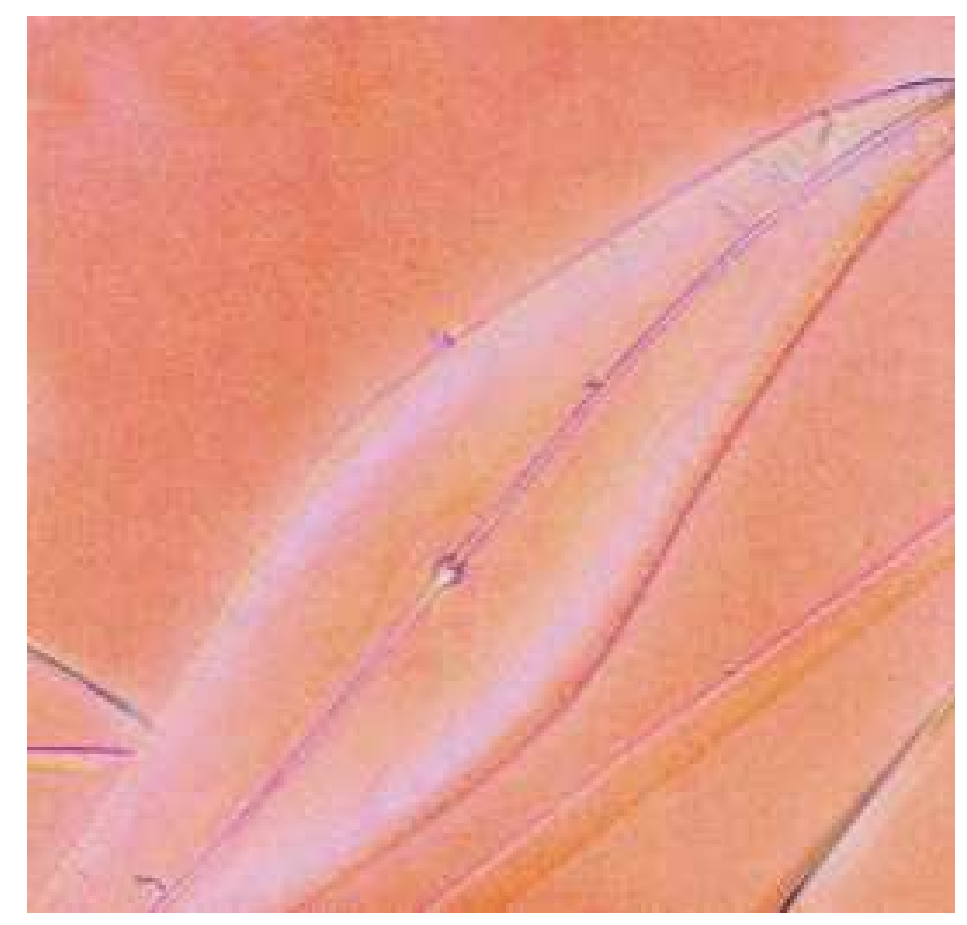

Pleurosigma sp (Diatomeas). (Foto: Tomada de NGM, febrero 1999).

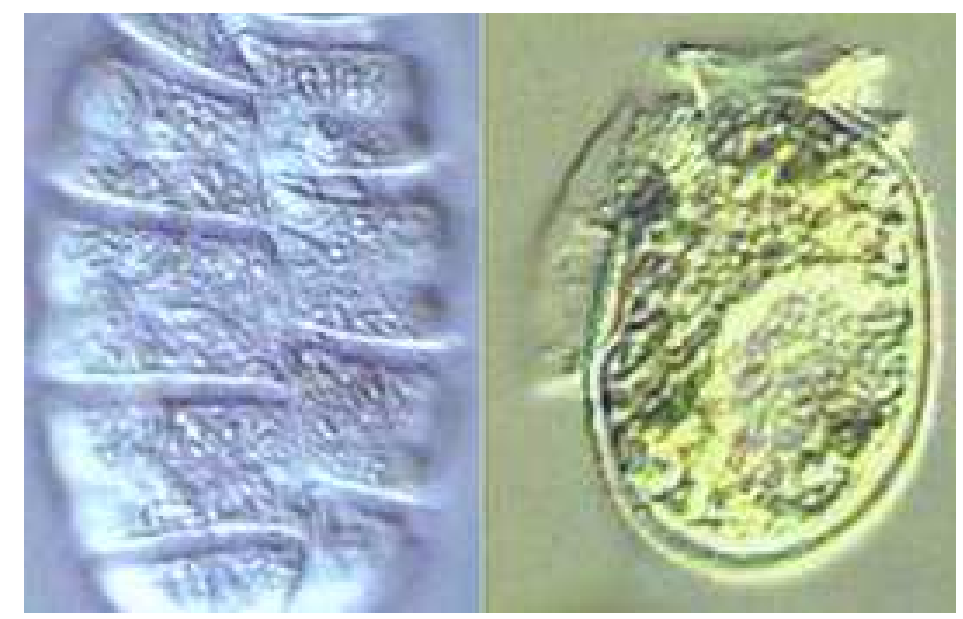

Polykrikos kofoidii y Dinophysis acuminata (Dinoflagelados). (Foto: Y. Fukuyo, 2000)

\subsection{CONDICIONES EN PRESENCIA DE LA NIÑA}

Los resultados presentados en esta sección corresponden a los obtenidos del muestreo, procesamiento y análisis de la información recolectada a bordo del Buque Oceanográfico ARC Malpelo en mayo de 1999, crucero escogido para representar las condiciones La Niña en la CPC. Su desarrolló se orientó sobre una grilla de 82 estaciones oceanográficas y 23 


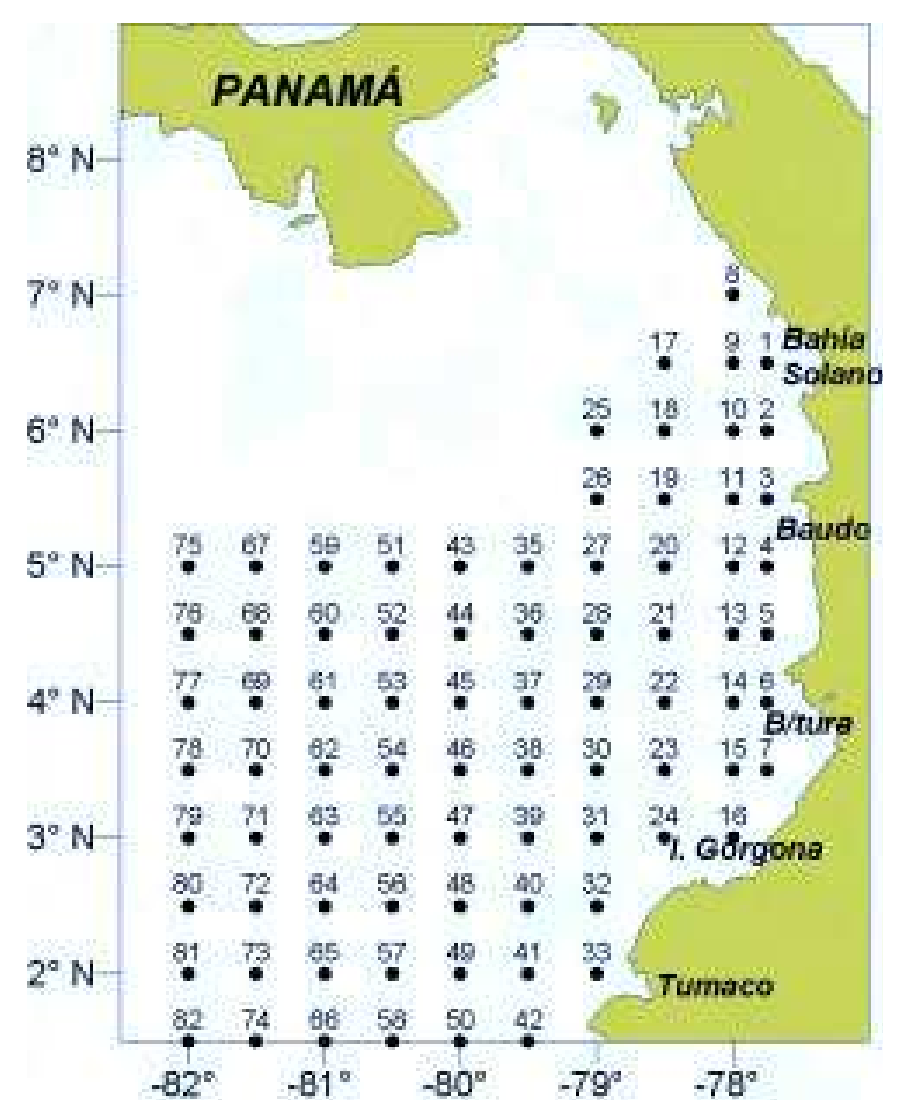

Figura 4.32 - Grilla de muestreo, Crucero PACífICO XXXI-ERFEN XXIX - Mayo de 1999.

químico-biologicas. El área de estudio se ubicó entre los meridianos $77^{\circ} 45^{\prime} \mathrm{W}$ y $82^{\circ} 00^{\prime} \mathrm{W}$ y los paralelos $1^{\circ} 30^{\prime} \mathrm{N}$ y $7^{\circ} 00^{\prime} \mathrm{N}$ (Fig. 4.32).

\subsubsection{Características Físicas}

Temperatura

Distribución horizontal y vertical de temperatura por capas a $0,25,50,100$ y 500 m de profundidad

El campo superficial de temperatura (TSM) presenta valores entre $26.0^{\circ} \mathrm{C}$ y $28.4^{\circ} \mathrm{C}$. Los mayores se registran hacia el sector costero de la CPC, en tanto que los menores se hallan en el sector Suroeste (Fig. 4.33). En general, a lo ancho de la CPC la temperatura de la superficie oscila entre $27.0^{\circ} \mathrm{C}$ y $27.8^{\circ}$ C. Se observan, además, tres núcleos, dos sobre el meridiano $82^{\circ} 00^{\prime} \mathrm{W}$, entre paralelos $4^{\circ} \mathrm{N}$ y $5^{\circ} \mathrm{N}$, y un tercero sobre los $5^{\circ} \mathrm{N}$ entre los meridianos $79^{\circ} 00^{\prime} \mathrm{W}$ y $80^{\circ} 00^{\prime} \mathrm{W}$, los cuales presentan valores por encima de $28.0^{\circ} \mathrm{C}$.

Al revisar la información del tiempo en cada estación y compararla con el mapa de temperatura ambiente, se concluye que dichos núcleos obedecen a la intensa radiación solar a la cual estuvo sometido en el lapso del monitoreo.

A 25 m las variaciones son zonales, de temperaturas altas al sureste de la cuenca, frente a la costa de Tumaco, más bajas al norte e intermedias al centro.

A $50 \mathrm{~m}$ de profundidad se observa una variación de temperatura bastante clara que indica, aparentemente, una inversión del patrón de distribución en la cuenca (las aguas cálidas que se encuentran por el noroeste a nivel superficial, se aprecian ahora frías a nivel subsuperficial y las aguas frías que ingresaban por el suroeste, aparecen ahora como una gran masa cálida que se dirige al interior de la (PC).

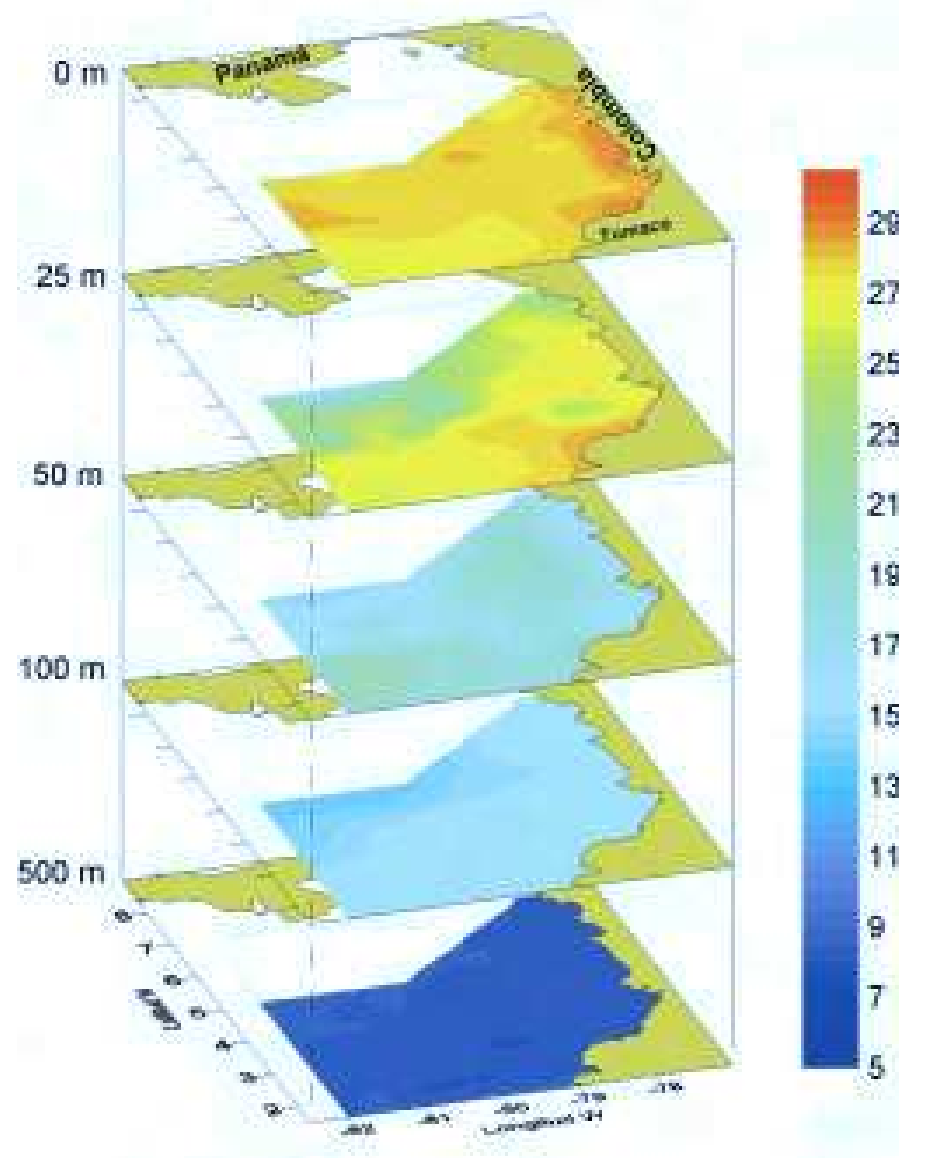

Figura 4.33 - Distribución de Temperatura horizontal y vertical por capas, mayo de 1999.

Sobre el sector del litoral, donde normalmente la TSM es más alta, las temperaturas a $50 \mathrm{~m}$ de profundidad son bajas en comparación con las otras medidas en el área central de la CPC. En la Figura 4.33 se destaca una piscina de agua 
cálida contigua a la costa, entre los meridianos $78^{\circ} \mathrm{W}$ y $80^{\circ}$ W, con valores entre $18.5^{\circ} \mathrm{C}$ y $20.5^{\circ} \mathrm{C}$. Al Norte, cerca a la frontera marítima con Panamá, las aguas presentan valores entre $17.5^{\circ} \mathrm{C}$ y $19.0^{\circ} \mathrm{C}$. Las estaciones del noroeste se caracterizan por presentar temperaturas entre 14.5 y $16.0^{\circ} \mathrm{C}$, incluyendo la isla de Malpelo.

En la capa de $100 \mathrm{~m}$ la distribución presentada en la superficie es de temperaturas más bajas en el sector noroeste y de toda la cuenca. La variación de esta capa para toda la cuenca se encuentra entre 13.7 y $16.9^{\circ} \mathrm{C}$. Para la capa de $500 \mathrm{~m}$ las condiciones presentes son características de aguas profundas, en donde las variaciones horizontales son mínimas ya que no superan el rango de $1.2^{\circ} \mathrm{C}$.

Distribución vertical de temperatura por transeptos latitudinales

En el transepto de Tumaco $\left(2^{\circ} \mathrm{N}\right)$ la distribución de temperatura presenta diferencias de Este a Oeste. Cerca a los sistemas de estuarios (Este) los gradientes son extremadamente marcados, del orden de $1.70^{\circ} \mathrm{C} / \mathrm{m}$, hasta el meridiano $81^{\circ} \mathrm{W}$; mientras que en la región oceánica los gradientes son del orden de 0.5 y $0.8^{\circ} \mathrm{C} / \mathrm{m}$.

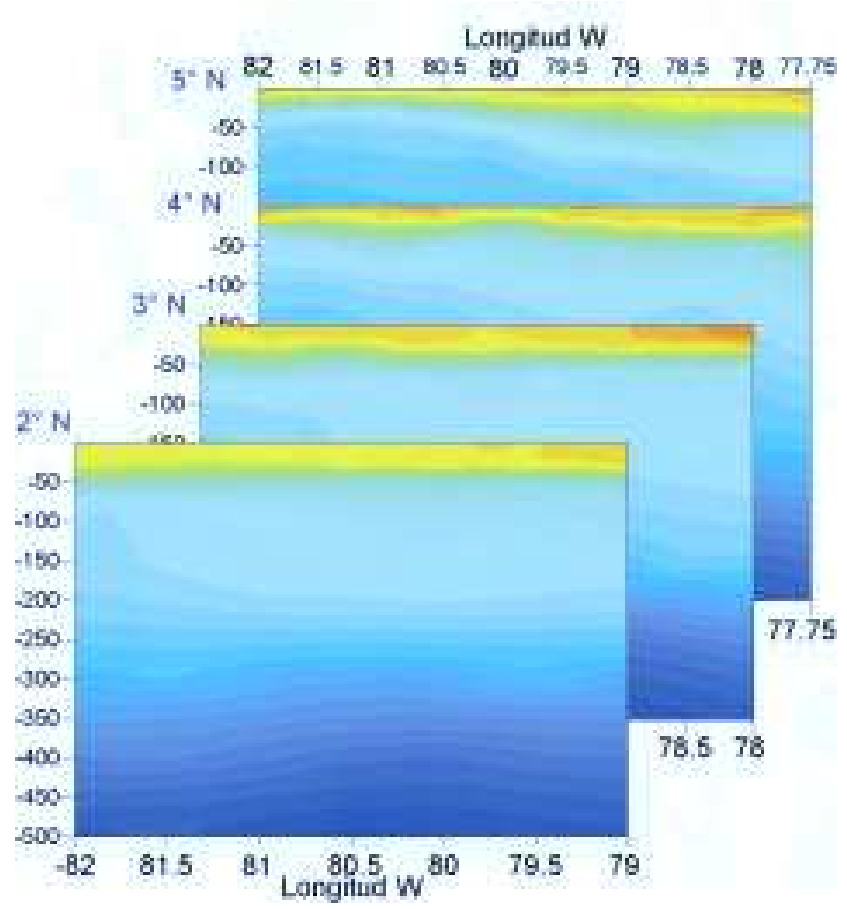

Figura 4.34 - Distribución de Temperatura por transeptos latitudinales, mayo de 1999.
La termoclina oscila a lo ancho del perfil entre 25 y $65 \mathrm{~m}$ de profundidad (Fig. 4.34). En general los gradientes de la termoclina se encuentran entre los mismos valores de temperatura, aproximadamente, 18.0 y $26.5^{\circ} \mathrm{C}$. La isoterma de $15^{\circ} \mathrm{C}$ se encuentra alrededor de los $150 \mathrm{~m}$ de profundidad, donde el gradiente es cada vez menor.

En el transepto de la isla de Gorgona ( $3^{\circ} \mathrm{N}$ ) (Fig. 4.34) se observa una capa superficial homogénea en los primeros 20 $\mathrm{m}$, con una variación en la costa, con temperaturas superiores a $27^{\circ} \mathrm{C}$. Desde los 25 hasta los $75 \mathrm{~m}$ se registra la termoclina estacional con un gradiente de 26 a $18^{\circ} \mathrm{C}$, haciéndose más gruesa de Este a Oeste. Sobre el meridiano $78.5^{\circ} \mathrm{W}$ la temperatura varió $2.8^{\circ} \mathrm{C}$ en un metro, con un promedio de $1.60^{\circ} \mathrm{C} / \mathrm{m}$ en los $8 \mathrm{~m}$ subsiguientes, mientras que en los $82^{\circ} \mathrm{N}$ lo hizo en $1^{\circ} \mathrm{C} / \mathrm{m}$ con un promedio de $0.85^{\circ} \mathrm{C} / \mathrm{m}$ en un intervalo continuo de $4 \mathrm{~m}$. Cerca a la isla las isotermas se levantan y se agrupan.

En el transepto de Buenaventura y Malpelo $\left(4^{\circ} \mathrm{N}\right)$ (Fig. 4.34) se aprecian temperaturas altas en algunos puntos superficiales de la cuenca, por debajo de ellos una capa homogénea de $20 \mathrm{~m}$ seguida por la termoclina estacional de 25 a $40 \mathrm{~m}$, siendo más superficial que en otras latitudes. A partir de los $50 \mathrm{~m}$ la estratificación es menor.

Sobre el litoral se observan variaciones promedio del orden de $0.90^{\circ} \mathrm{C} / \mathrm{m}$ y cambios puntuales en las estaciones 14 y 22 de 1.6 y $2^{\circ} \mathrm{C} / \mathrm{m}$.

En el transepto de Baudó ( $5^{\circ} \mathrm{N}$ ) (Fig. 4.34) se aprecia una concentración cálida contigua a la costa, extendiéndose hasta los $80^{\circ} 30^{\prime} \mathrm{W}$, con temperaturas entre 26.4 y $28.6^{\circ} \mathrm{C}$. La termoclina estacional varía su grosor de Este a Oeste, disminuyendo desde los $80^{\circ} 30^{\prime} \mathrm{W}$ hacia los $82^{\circ} \mathrm{W}$. En el Este (cerca a la costa) se presenta la termoclina entre 25 y $50 \mathrm{~m}$. Hacia el centro del transepto $\left(80.5^{\circ} \mathrm{W}-81.5^{\circ} \mathrm{W}\right)$ la termoclina se ensancha hasta los $70 \mathrm{~m}$ y, finalmente, entre los meridianos $82^{\circ} \mathrm{W}$ y $84^{\circ} \mathrm{W}$ la termoclina se profundiza entre 35 y $45 \mathrm{~m}$, con cambios ligeros de temperatura en profundidad.

El mayor gradiente se observa sobre el sector costero en la estación 4 con $2.1^{\circ} \mathrm{C} / \mathrm{m}$ a $36 \mathrm{~m}$ de profundidad. En la capa entre 100 y $500 \mathrm{~m}$ la temperatura es más homogénea, con gradientes entre 100 y $200 \mathrm{~m}$ que oscilan alrededor de 0.001 $0.002^{\circ} \mathrm{C} / \mathrm{m}$ mientras que a profundidades de 400 y 500 m este parámetro se hace más estable $\left(0.006 \mathrm{a} 0.008^{\circ} \mathrm{C} / \mathrm{m}\right)$. 
Salinidad

Distribución horizontal y vertical de Salinidad por capas a $0,25,50,100$ y $500 \mathrm{~m}$ de profundidad

El mapa de salinidad superficial del mar, SSM, presenta índices entre 26.2 y 33.6. En la Figura 4.35 se aprecia que los menores valores se ubican hacia el sector del litoral (29.2 a 30.0) como consecuencia del aporte continental característico de esta región del Pacífico Sudeste, que se encuentra bañada por un considerable número de ríos. El sector oeste de la CPC se caracteriza por contar con salinidades más altas que en la costa, en especial en la isla de Malpelo.

En la columna de agua se aprecia la variación de la salinidad en donde los menores registros se alcanzan sobre la superficie y los mayores se observan a medida que se profundiza la columna hasta los $100 \mathrm{~m}$.

Después de la capa superficial se encuentra la capa de 25 $\mathrm{m}$ que presenta registros de salinidades superiores a 34 en el sector noroeste; aunque predominan los bajos valores en la

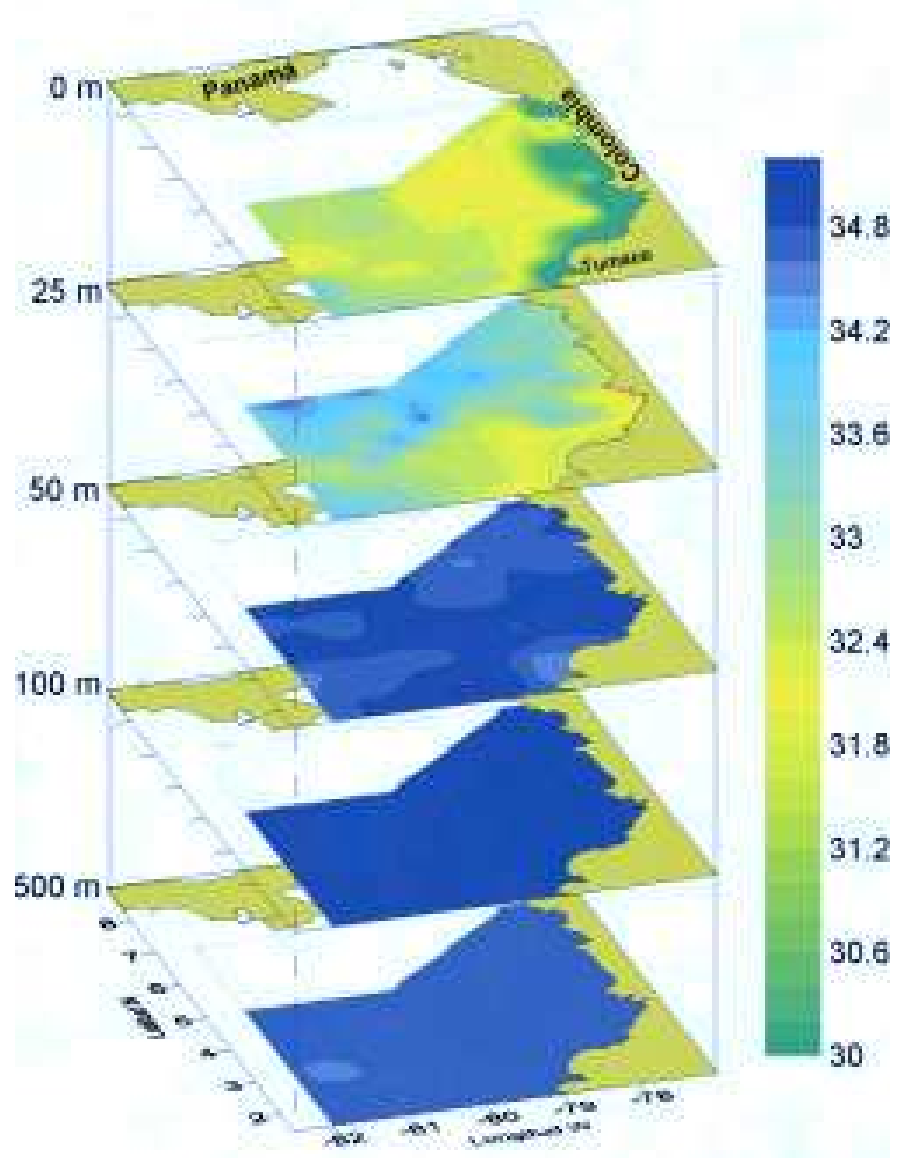

Figura 4.35 - Distribución de Salinidad horizontal y vertical por capas, mayo de 1999. región, propios de la influencia de los aportes continentales y atmosféricos de la superficie. La oscilación de los valores en esta capa va de 31.3 a 34.7, presentando, como es normal, los menores valores en el sector sureste y a lo largo de costa.

A 50 m de profundidad la salinidad se observa más uniforme (Fig. 4.35) y sus mediciones varían en un rango estrecho entre 34.1 y 35.0. Las aguas de influencia oceánica presentan en este caso menores concentraciones halinas (entre $34.2 \mathrm{y}$ 34.6) que las aguas del centro y el sureste del litoral (entre 34.7 y 34.9). En el Noreste de la cuenca se presentan dos núcleos de salinidades bajas cercanos a los 34.5.

Las capas de 100 y $500 \mathrm{~m}$ de profundidad no presentan mayores variaciones a nivel horizontal, por consiguiente sus gradientes no son significativos. Los valores registrados en estas dos capas no superan los 35 y no disminuyen más allá de los 34.5.

Distribución vertical de salinidad por transeptos latitudinales

En el transepto de Tumaco $\left(2^{\circ} \mathrm{N}\right)$ el agua de más baja salinidad (29.5) se observa muy cerca a la superficie (entre 0 y $12 \mathrm{~m}$ ), entre los $79^{\circ} \mathrm{W}$ y los $79.5^{\circ} \mathrm{W}$. El valor máximo de salinidad (35.0) se presenta entre los 100 y 200 m, para una región comprendida entre los $79.5^{\circ} \mathrm{W}$ y $82^{\circ} 30^{\prime} \mathrm{W}$ (Fig. 4.36). En la parte superficial del transepto la salinidad registra variaciones en el intervalo de 29.5 a 35.

En el perfil de Tumaco la distribución de la salinidad a mayores profundidades se mantiene, relativamente, homogénea a lo largo de todo el transepto. En el sector intermedio, alrededor de los $300 \mathrm{~m}$, se observa una salinidad de 34.7 y en el sector superior, entre 100 y $200 \mathrm{~m}$, se ubica la región de más alta salinidad de todo el perfil.

Para el transepto de isla Gorgona $\left(3^{\circ} \mathrm{N}\right)$ el sector con menores valores salinos (entre 29.6 y 31.5 ) se ubica en la región costera, entre los $78^{\circ} 00^{\prime} \mathrm{W}$ y los $79^{\circ} 30^{\prime} \mathrm{W}$ a profundidades entre 0 y $25 \mathrm{~m}$ (Fig. 4.36). Los mayores registros (de 34.8 a 35 ) se observan entre $78^{\circ} 00^{\prime} \mathrm{W}$ y $82^{\circ} 00^{\prime}$ W a profundidades entre 100-300 m. En la capa superficial, entre los 0 y $75 \mathrm{~m}$, la salinidad oscila entre 29.6 y 35.0. Se observa una masa de agua salada (35) de $25 \mathrm{~m}$ de ancho (de 50 a $75 \mathrm{~m})$, que se angosta ligeramente $(5 \mathrm{~m})$ en sentido Oeste 
$\left(82^{\circ} \mathrm{W}\right)$. En este mismo perfil se observa sobre el margen del litoral $\left(78^{\circ} 00^{\prime} \mathrm{W}\right)$ una capa de agua menos salada de 34.0 a 34.5 , entre 37 y $47 \mathrm{~m}$ la cual se va ampliando hacia el oeste hasta alcanzar un grosor de, aproximadamente, $17 \mathrm{~m}$ en $82^{\circ}$ W. La mayor parte del transepto entre $79.5^{\circ} \mathrm{W}$ y $82^{\circ} \mathrm{W}$ a nivel superficial se mantiene entre 32 y 33.5 .

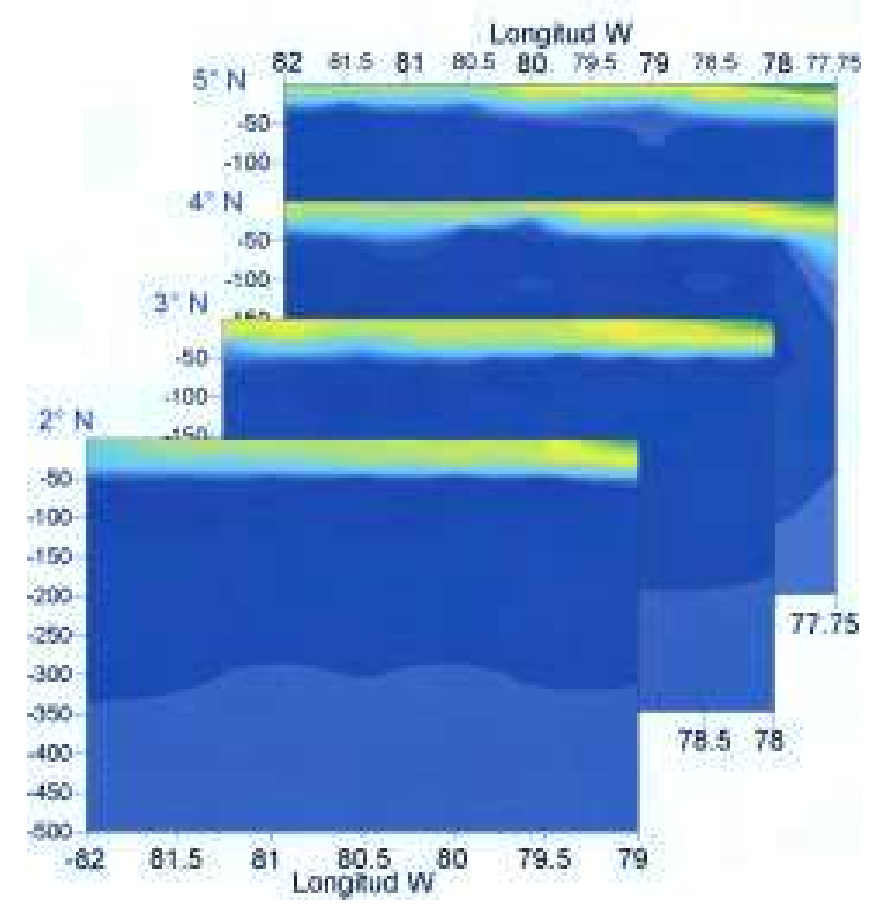

Figura 4.36 - Distribución vertical de Salinidad por transeptos latitudinales, mayo de 1999.

Los valores de salinidad dentro del transepto de Buenaventura $\left(4^{\circ} \mathrm{N}\right)$ están distribuidos en un rango que va desde 29 hasta 35. El agua más dulce del transepto (Fig. 3.31) se ubica en $77.75^{\circ} \mathrm{W}$ y $78^{\circ} \mathrm{W}$ entre $(0$ y $4 \mathrm{~m})$ y el agua más salada se observa de $79^{\circ}$ $\mathrm{W}$ a $80^{\circ} \mathrm{W}$ entre 100 y $200 \mathrm{~m}$. En la capa superior $(0-75 \mathrm{~m})$ la salinidad está comprendida entre 29 y 35.

En la costa se observa una banda de 34.9 entre 50 y 75 m que crece cerca de $10 \mathrm{~m}$ a medida que se desplaza hacia el oeste (Fig. 4.36). Entre 20 y $40 \mathrm{~m}$ se aprecia una banda de salinidad de 33.5 , dentro de la cual hay dos pequeñas intrusiones de 34.5 , ubicadas en la región comprendida entre $79^{\circ} 30^{\prime} \mathrm{W}$ y $80^{\circ} 30^{\prime} \mathrm{W}$. En la mayor parte del transepto la franja entre 0 y $25 \mathrm{~m}$ presenta una salinidad de 32.5. En la parte más profunda del perfil (entre 100 y $500 \mathrm{~m}$ ) la salinidad asume valores entre 34.5 y 34.9. En todo el transepto, a mayor profundidad se presentan dos capas halinas principales separadas por un valor de salinidad de 34.7, la banda de salinidad superior a este valor se encuentra entre
100 y $450 \mathrm{~m}$, mientras que la de valor inferior se ubica por debajo de los $450 \mathrm{~m}$.

En el transepto de Baudó $\left(5^{\circ} \mathrm{N}\right)$ la región que presenta el menor valor de salinidad (28.5) del perfil está ubicada sobre un rango de profundidades de 0 a $3 \mathrm{~m}$, entre los $77.75^{\circ} \mathrm{W}$ y los $78^{\circ} \mathrm{W}$ (sector litoral). El agua de más alto valor de salinidad, cerca de 35, se encuentra 100 y 200 m de profundidad y se ubica entre los $77^{\circ} 30^{\prime} \mathrm{W}$ y los $84^{\circ} 00^{\prime} \mathrm{W}$ (Fig. 4.36). En el perfil superior, con profundidades menores a $75 \mathrm{~m}$, presenta salinidades que varían entre 26.2 y 34.9 .

La distribución de salinidad a mayor profundidad (100 a $500 \mathrm{~m}$ ) se presenta de manera más homogénea. Hay dos bandas de salinidad bien delimitadas por un valor promedio de 34.8. La banda con valores por encima de este índice está comprendida entre 100 y 300 m, la que presenta registros por debajo ocupa el resto del perfil, entre 300 y 500 m.

\subsubsection{Características Químicas}

\section{Oxígeno Disuelto}

Distribución horizontal y vertical de OD por capas a 0 , $25,50,100$ y 150 m de profundidad

Para esta condición se reportaron los valores más bajos de OD con registros entre $4.8 \mathrm{mg} / \mathrm{l}$ en la superficie hasta $0.8 \mathrm{mg} /$ l a $150 \mathrm{~m}$ de profundidad. Hacia la región suroeste y centro de la CPC se registraron las concentraciones más elevadas, presentándose un núcleo entre los $81^{\circ} \mathrm{W}$ y $3^{\circ} \mathrm{N}$ que se profundiza hasta los $100 \mathrm{~m}$. Al comparan los tres períodos, nuevamente, es posible observar hacia la región noroeste la presencia de una entrada de agua con menores concentraciones de OD desde los $25 \mathrm{~m}$ con $2.5 \mathrm{mg} / \mathrm{l}$ hasta los $150 \mathrm{~m}$ con 0.8 $\mathrm{mg} / \mathrm{l}$ (Fig. 4.37).

En la porción costera se detectan los valores más altos entre Tumaco e isla Gorgona con un promedio de $4.5 \mathrm{mg} / \mathrm{l}$, en superficie, hasta $1.8 \mathrm{mg} / \mathrm{l}$, en el fondo, en contraste con el resto del litoral donde se registran valores inferiores a 1.0 $\mathrm{mg} / \mathrm{l}$ a los $150 \mathrm{~m}$ 


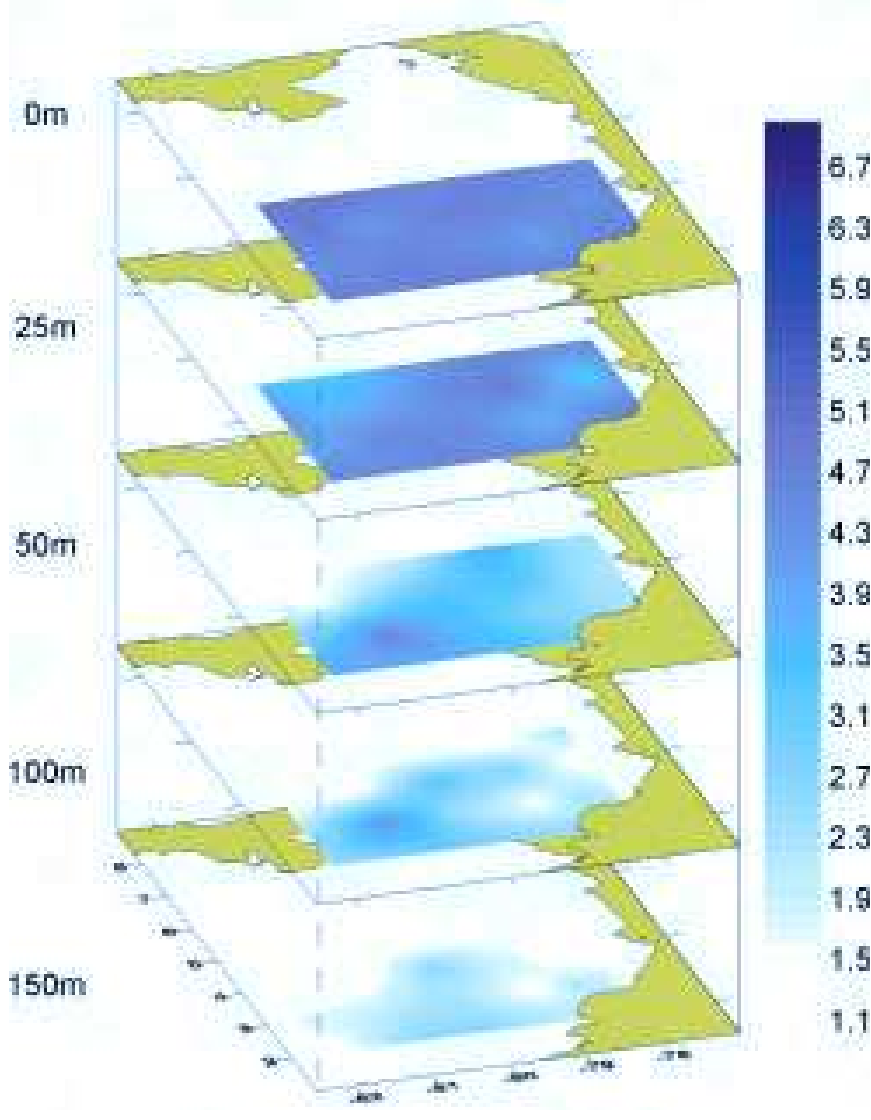

Figura 4.37 - Distribución horizontal y vertical de OD (mg/l) por capas, mayo de 1999.

Nutrientes

Amonio

Distribución horizontal y vertical de Amonio por capas a $0,25,50,100$ y $150 \mathrm{~m}$ de profundidad

A nivel superficial (Fig. 4.38), este nutriente presentó concentraciones muy bajas del orden de 0 a $0.27 \mu$ g-at/l, considerándose como los valores mínimos para los tres períodos de observación; los registros más altos se encontraron hacia la zona costera. Por debajo de la superficie a $25 \mathrm{~m}$ se ubicó un núcleo en el sector noreste a $79^{\circ} \mathrm{W}$ y $4^{\circ} \mathrm{N}$, el cual fue aumentando su concentración con la profundidad, partiendo de $1.8 \mu \mathrm{g}$-at/l hasta alcanzar los $3.2 \mu \mathrm{g}$-at// a $150 \mathrm{~m}$.

En la porción sureste y en la costa también se observa la presencia de concentraciones un poco más elevadas que para el resto del área, las cuales se mantuvieron con la profundidad. En comparación con el período Niño y normal, el amonio presentó para esta época las concentraciones más bajas en general para toda el área y todas las profundidades (Fig. 4.38).

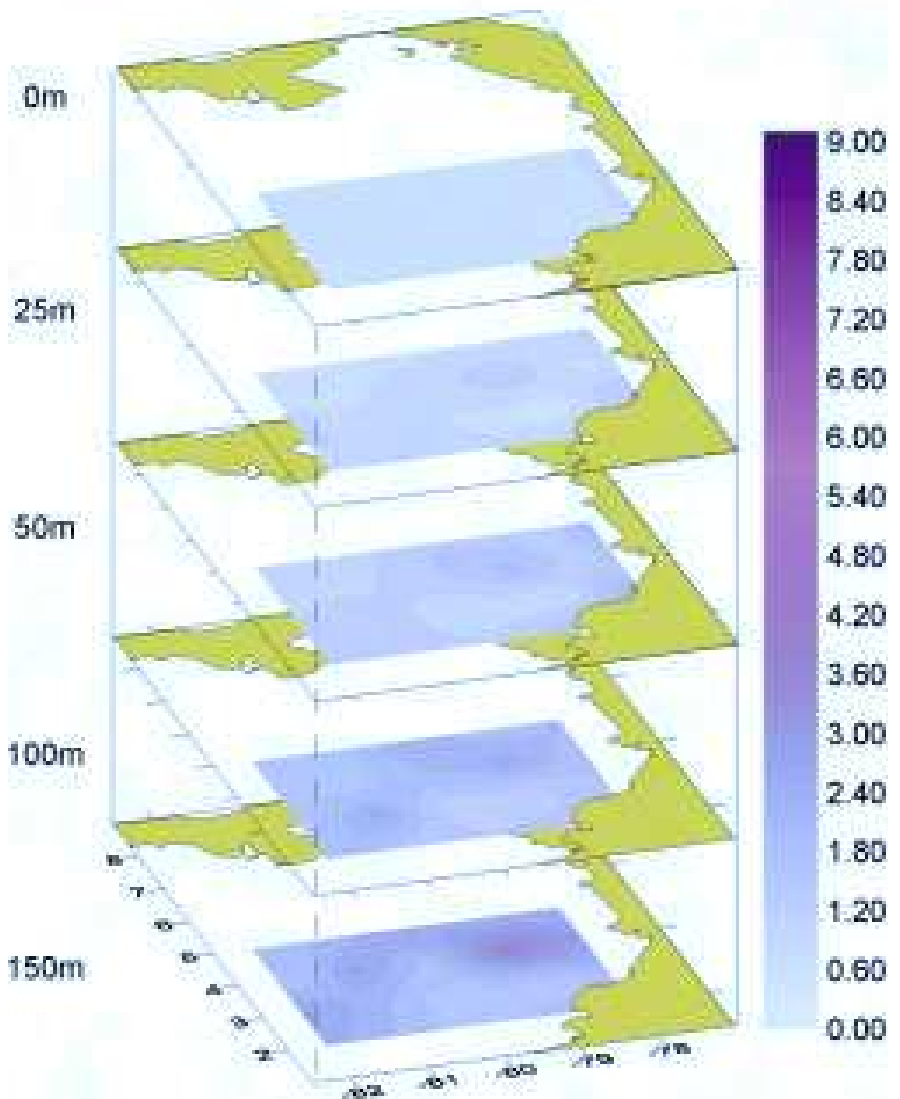

Figura 4.38 - Distribución horizontal y vertical de Amonio (nh4 $\mu \mathrm{g}$-at/l) por capas, mayo de 1999.

\section{Nitrato}

Distribución horizontal y vertical de Nitrato por capas a $0,25,50,100$ y $150 \mathrm{~m}$ de profundidad

A nivel superficial y hasta los $25 \mathrm{~m}$, el nitrato presentó valores muy bajos cercanos a $0 \mu \mathrm{g}$-at/l en gran parte del área, observándose los registros más altos hacia el noroeste y extremo sureste, donde se presentaron concentraciones entre 1.7 y $6.5 \mu \mathrm{g}$-at/l (Fig. 4.39). Sobre el sector costero se detectaron valores de 0.5 a $1.2 \mu \mathrm{g}$-at/l.

A nivel de los $50 \mathrm{~m}$ se amplió su distribución y aumentó la concentración en un rango entre 3.2 a $16.5 \mu \mathrm{g}$-at/l, ubicándose los mayores valores en la costa entre los 3 y $5^{\circ} \mathrm{N}$ y al noreste. En el perfil de los $100 \mathrm{~m}$ esta misma distribución se mantiene, presentándose otro núcleo al sur, hasta obtenerse los más altos registros a $150 \mathrm{~m}$ con un valor máximo de $23 \mu \mathrm{g}$-at/l (Fig. 4.39). 


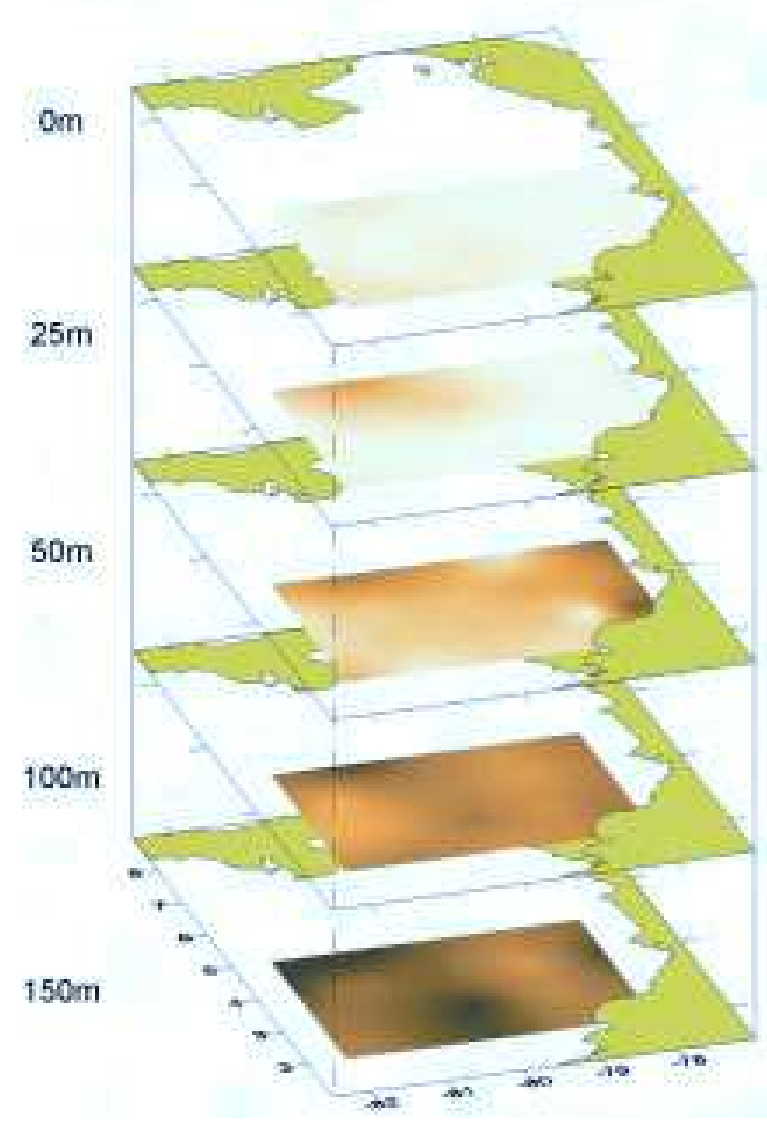

Figura 4.39 - Distribución horizontal y vertical de Nitrato (n03 $\mu$-at/l) por capas, mayo de 1999.

\section{Fosfato}

Distribución horizontal y vertical de Fosfato por capas a $0,25,50,100$ y $150 \mathrm{~m}$ de profundidad

Al igual que para el Niño el fosfato a nivel superficial presentó valores muy bajos entre 0 y $0.3 \mu \mathrm{g}$-at/l, observándose los registros más altos en la costa y extremo sureste (Fig. 4.40). La concentración de este nutriente aumentó con la profundidad, al igual que su distribución, registrándose un núcleo hacia el noreste, dentro del cual se señalaron los valores más altos para esta profundidad ( 0.6 a $0.82 \mu \mathrm{g}$-at/l).

A los $50 \mathrm{~m}$ se mantuvo este núcleo y las concentraciones aumentaron hacia la costa y centro de la cuenca con valores entre 0.12 a $1.45 \mu \mathrm{g}$-at/l. Las concentraciones más altas se obtuvieron en los perfiles de 100 y 150 m, observándose la disposición de este nutriente en toda el área para estas profundidades con un registro máximo de $2.10 \mu \mathrm{g}$-at// (Fig. 4.40).

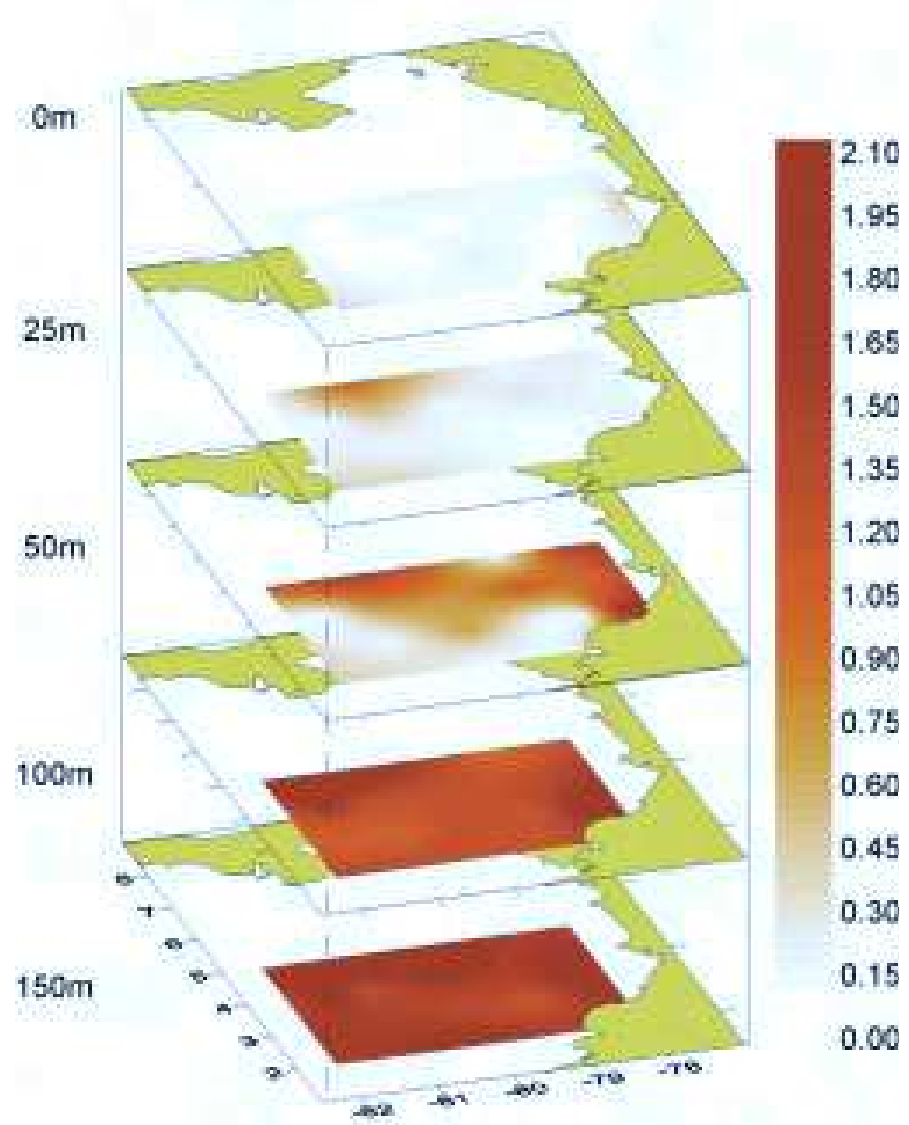

Figura 4.40 - Distribución horizontal y vertical de Fosfato (p04 $\mu \mathrm{g}$-at/l) por capas, mayo de 1999.

\section{Silicato}

Distribución horizontal y vertical de Silicato por capas a $0,25,50,100$ y $150 \mathrm{~m}$ de profundidad

De igual forma que para el caso de los fosfatos este nutriente presentó un núcleo de mayores concentraciones en la porción noreste que se mantuvo a lo largo de la columna de agua, ampliándose con la profundidad, y registrando los valores más altos a los $150 \mathrm{~m}$ con $28 \mu \mathrm{g}$-at/l. En la región costera, entre Gorgona y Tumaco, también se obtuvieron registros un poco más elevados que para el resto del área, la cual en general mostró valores bajos (Fig. 4.41). 


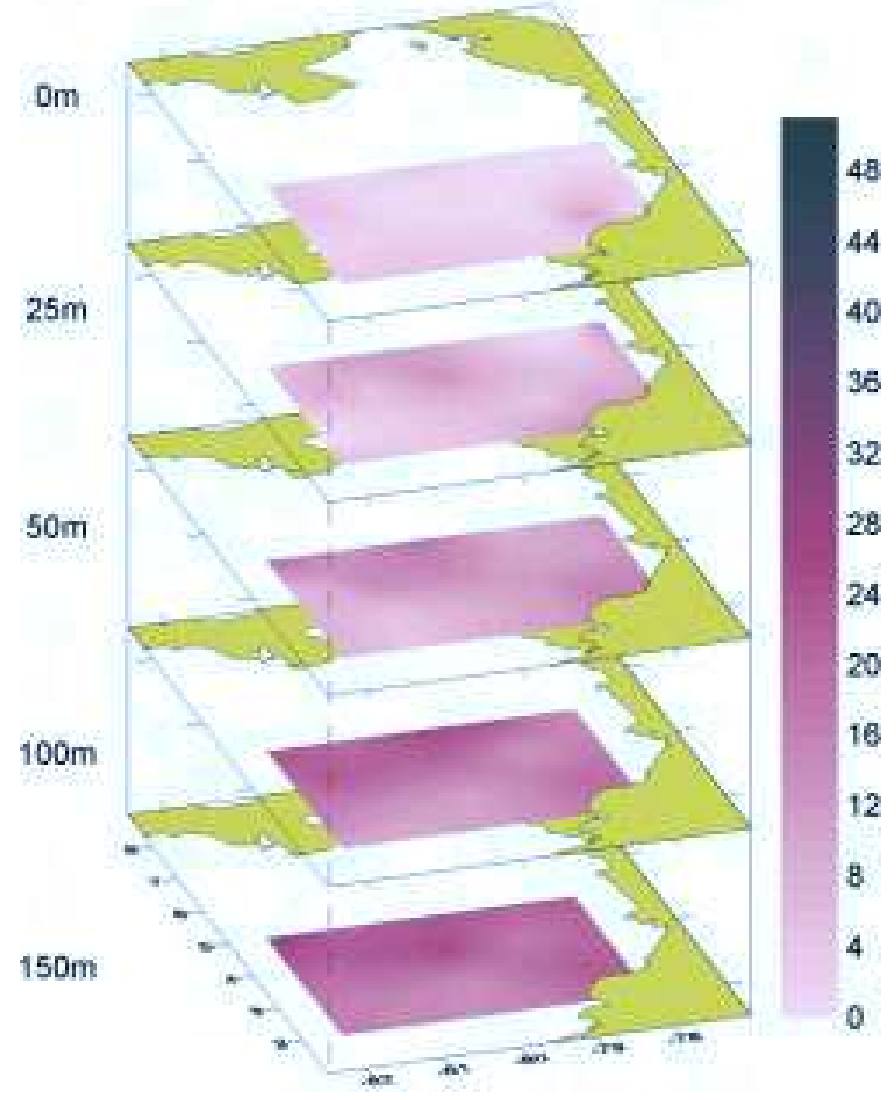

Figura 4.41 - Distribución horizontal y vertical de Silicato (si03 $\mu \mathrm{g}$-at/l) por capas, mayo de 1999.

\subsubsection{Características Biológicas}

\section{Clorofila "a"}

Distribución horizontal y vertical de Clorofila "a" por capas a $0,25,50,100$ y $150 \mathrm{~m}$ de profundidad

Durante el evento La Niña se presentan los más altos registros de clorofila "a" en el área con concentraciones entre 4.6 y 4.85 $\mathrm{mg} / \mathrm{m}^{3}$ en superficie, las cuales disminuyeron gradualmente hasta obtener valores de 0.1 a $0.4 \mathrm{mg} / \mathrm{m}^{3}$ en el fondo. En la capa superficial el valor promedio de clorofila es de $4.75 \mathrm{mg} /$ $\mathrm{m}^{3}$ distribuida de forma bastante homogénea en el área.

A partir del perfil de $25 \mathrm{~m}$ es posible detectar bajos registros frente a Buenaventura, ampliándose esta área hacia los $50 \mathrm{~m}$. A esta misma profundidad se observa una drástica disminución del pigmento hacia el sector noroeste con valores de $1.5 \mathrm{mg} / \mathrm{m}^{3}$ (Fig. 4.42).

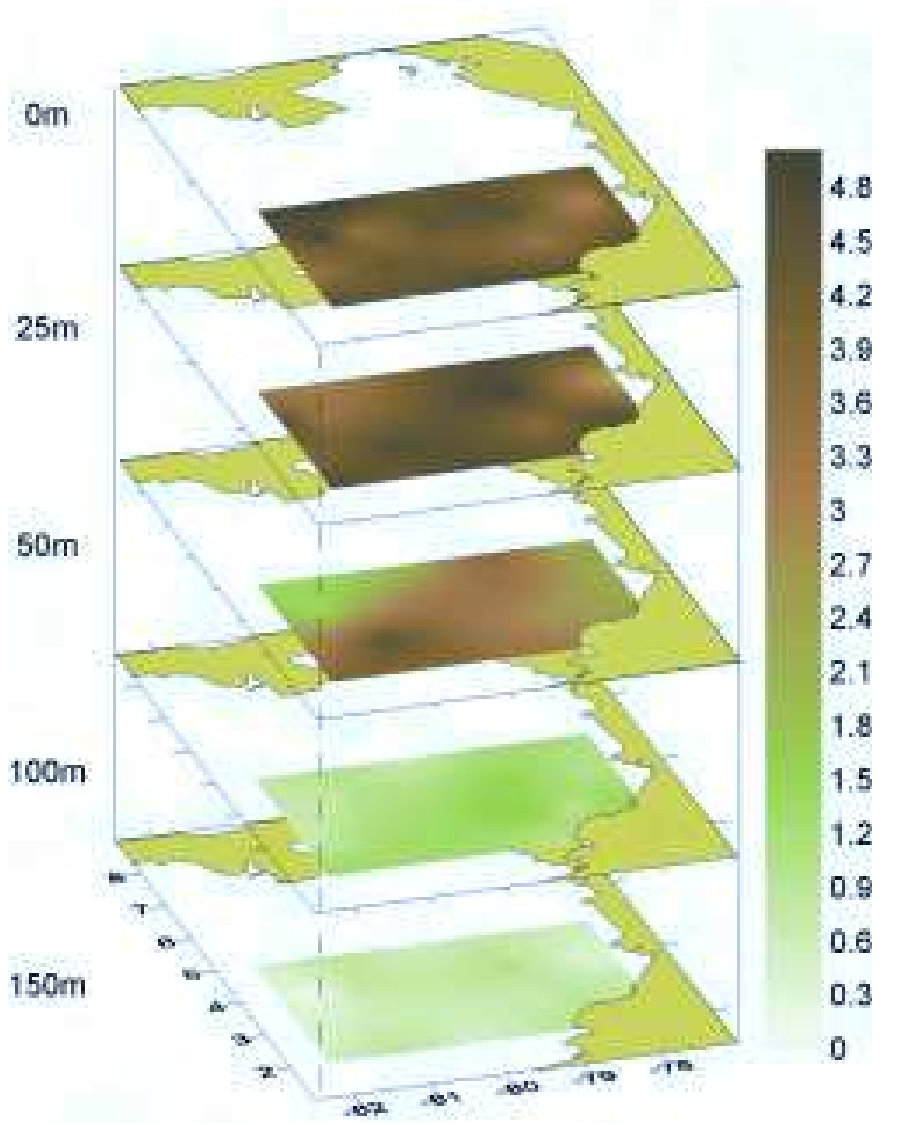

Figura 4.42 - Distribución horizontal y vertical de Clorofila "a" $\left(\mathrm{mg} / \mathrm{m}^{3}\right)$ por capas, mayo de 1999.

\section{Fitoplancton}

\section{Diatomeas}

\section{Composición Especiológica}

Se reportan 57 géneros, identificándose un total de 157 especies (Tabla 4.1). De estos son los más representativos en su orden: Chaetoceros: C. aequatorialis, C. affinis, C. atlanticus var naepoliatanus, $C$. cinctus, $C$. curvisetus, $C$, dichaeta, $C$. didymus, C. didymus var anglica, C. eibenii, C. laevis, C. lorenzianus, C. peruvianus, C. radicans y C. tetrastichon; Rhizosolenia: $R$. bergonii, $R$. delicatula, $R$. hebetata, $R$. hyalina $y$. robusta; Nitzschia: N. angularis, N. bicapitata, N. brebissonii, $N$. pacifica y $N$. recta; Coscinodiscus: $C$. concinnus, $C$. eccentricus, C. granii y C. nitidus; Asteromphalus: A. arachne, A. flabellatus, y A. heptactis; Cyclotella: C. meneghiniana, C. stylorum y C. striata; Pleurosigma: P. angulatum, P. nicobaricum y P. normanii; Pseudo-nitzschia: P. pseudodelicatissima, P. pungens y P. seriata. 
Como especies reportadas por primera vez se encuentran Asteromphalus hyalinus, Chaetoceros anastomosans, Campylodiscus undulatus, Cymbella parva, Nitzschia lineata, Pinnularia brevicostata y Pixidicula striata, las cuales presentan hábitos cosmopolitas (Hasle y Syverten, 1996).

Distribución horizontal y vertical de abundancia de Diatomeas por capas a 0, 25, 50, 100 y $150 \mathrm{~m}$ de profundidad

Al igual que para los años normal y Niño en este período se presentaron a nivel superficial los valores más altos en la porción costera, aunque desplazados más hacia el norte, registrándose las máximas concentraciones frente a Buenaventura (43250 cel/l), Cabo Corrientes (33600 cel/l) y una vez más hacia la isla de Gorgona (12850 a 37500 cel/l). De igual manera se registraron abundancias significativas, aunque más bajas, en la región sur de la cuenca con valores entre 4700 y $12700 \mathrm{cel} / \mathrm{l}$ (Fig. 4.43).

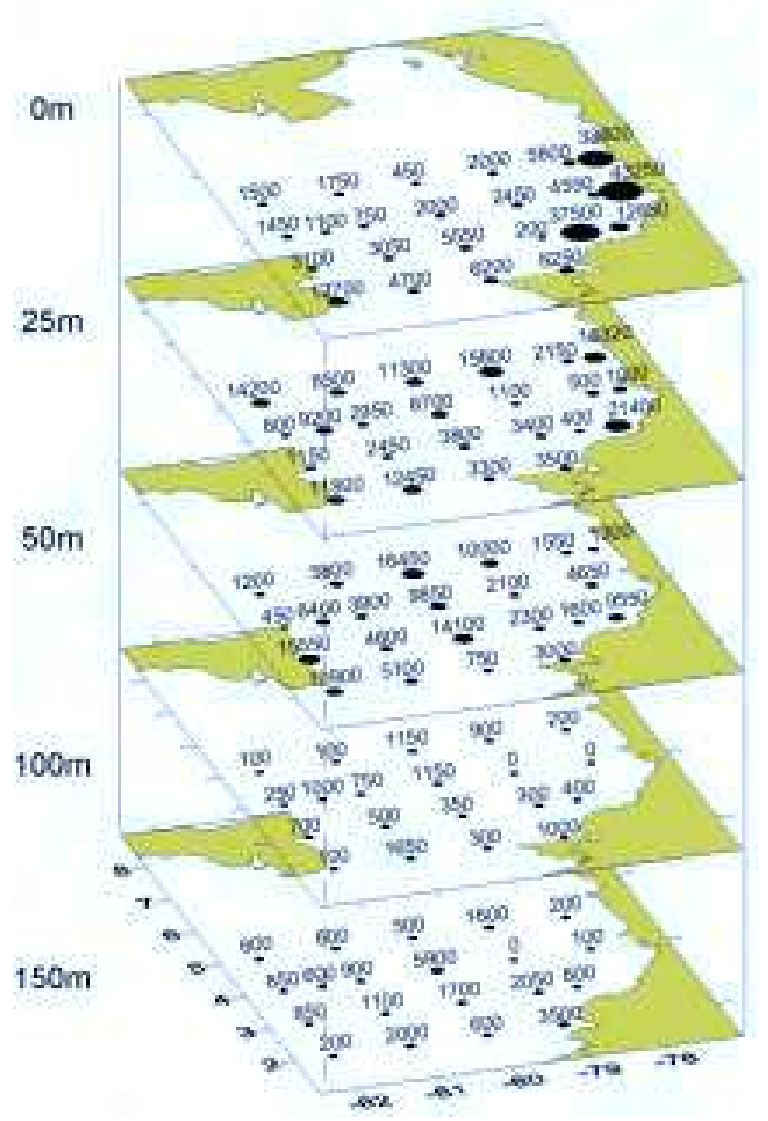

Figura 4.43 - Distribución horizontal y vertical de abundancia de Diatomeas (cel/l) por capas, mayo de 1999.

(El tamaño del símbolo corresponde al valor de abundancia)
A 25 y $50 \mathrm{~m}$ de profundidad las densidades poblacionales se mantuvieron bastante altas en casi toda el área, a diferencia de las otras dos épocas, oscilando entre $450 \mathrm{y}$ $21400 \mathrm{cel} / \mathrm{l}$. En el perfil de los $100 \mathrm{~m}$ se observó una disminución de la comunidad con valores que van de 0 a 1650 cel/l, presentándose cantidades mayores hacia los $150 \mathrm{~m}$, con registros de 0 a $5900 \mathrm{cel} / \mathrm{l}$; mientras que para los períodos Niño y normal la cantidad de diatomeas a este nivel se redujo a la presencia de unas cuantas células o a la ausencia parcial para la mayor parte del área. La especie representativa a esta profundidad fue Fragilariopsis rombica la que según Carmelo (1995) corresponde a una microalga de aguas frías del Pacifico Sur; el resto de los organismos encontrados a este nivel corresponden a especies cosmopolitas como Bacteriastrum elongatum, Proboscia alata, Chaetoceros radicans y Thalassionema nitzschioides, entre otras.

Dinoflagelados

\section{Composición Especiológica}

Se reportan en total 30 géneros con el menor número de especies (96) identificadas para este grupo, en relación con el Niño y la época normal (Tabla 4.1), siendo su orden: Protoperidinium: P. conicum, P. cristatum, P. depressum, $P$. grande, $P$. joubini, $P$. ovum, $P$. pellucidum, $P$. pentagonum, $P$. steinii y P. crassipes; Ceratium: $C$. carriense, $C$. contortum, $C$. furca, C. fusus var seta, C. kofoidii, C. macroceros var gallicum, C. macroceros var macroceros, $C$. pentagonum var pentagonum, $C$. teres y C. tripos var tripos; Prorocentrum: $P$. compressum, $P$. euarcuatum, $P$. dentatum, $P$. gracile, $P$. lima, $P$. micans, $P$. minimum y P. rostratum; Gonyaulax: G. fragilis, G. polygramma, G. scrippsae, G. sphaeroidea, G. spinifera y G. turbynei; Oxytoxum: O. mediterraneum, O. ovum y O. scolopax; Phalacroma: $P$. argus, $P$. doryphorum, $P$. rapa y $P$. rotundatum; Gymnodinium: G. breve, G catenatum y G. sanguineum.

Como especies reportadas por primera vez para el área de estudio se encuentran: Amphidinium curcubita, Goniodoma sphaericum, Gonyaulax sceptum, Lingulodinium polyedrum, Peridinium punctulatum, Phalacroma doryphorum, P. Rotundatum. Según Balech (1988) y Steidinger 
y Tangen (1996), la mayoría de estas especies corresponden a individuos de aguas tropicales cálidas a temperadas. De igual manera, se registra la presencia de cistos de las especies: Diplopelta parva, Gymnodinium catenatum, Protoperidinium claudicans, Protoperidinium leonis y Polykrikos schwartzii. Estos cistos en la zona ponen de manifiesto el riesgo de desarrollo de procesos de discoloración (marea roja) en la zona y su efecto nocivo.

Distribución horizontal y vertical de abundancia de Dinoflagelados por capas a 0, 25, 50, 100 y $150 \mathrm{~m}$ de profundidad

Las máximas abundancias a nivel superficial se presentaron hacia la zona costera, frente a Buenaventura, con $13250 \mathrm{cel} / \mathrm{l}$. En el área restante se registraron valores entre 0 y $4800 \mathrm{cel} / \mathrm{l}$. A $25 \mathrm{~m}$ se mantuvieron las altas densidades de organismos en la costa con cantidades entre 3000 y 17200 cel/l, presentándose el valor más alto cerca de la isla de Gorgona (Fig. 4.44).

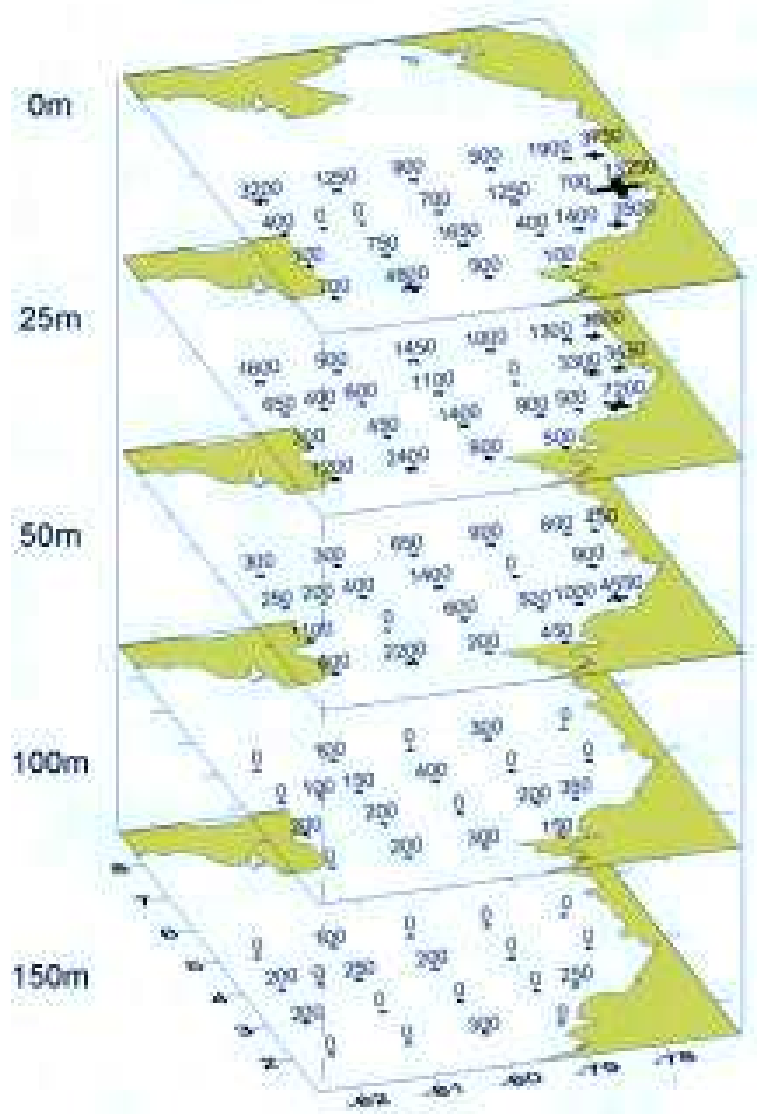

Figura 4.44 - Distribución horizontal y vertical de abundancia de Dinoflagelados (cel/l) por capas, mayo de 1999.

(El tamaño del símbolo corresponde al valor de abundancia)
A partir de los $50 \mathrm{~m}$ la cantidad de organismos fue disminuyendo y se obtuvo, nuevamente, el dato más alto hacia la isla Gorgona con 4550 cel/l. Entre los 100 y 150 m se observaron las abundancias más bajas que oscilaron entre $0 \mathrm{y}$ $400 \mathrm{cel} / \mathrm{l}$.

\subsubsection{Análisis general condición La Niña}

Para el mes de mayo de 1999 se observa un enfriamiento de las capas superficiales y un aumento en la salinidad. La TSM presenta valores mayores en la costa y el Norte, haciéndose menor hacia el Suroeste de la CPC. A medida que aumenta la profundidad las regiones cálidas se limitan al Sureste y se observa mayor influencia de aguas frías.

La salinidad es menor en la costa por aporte de los ríos y la alta pluviosidad. Los valores son mayores en el sector oceánico y se mezclan con la zona costera produciendo una región de salinidades intermedias, la cual es muy marcada en superficie, perdiéndose con la profundidad, donde las capas se vuelven más homogéneas.

A diferencia de condiciones normales o Niño, el OD presenta las concentraciones más bajas durante este período con valores en un rango entre 4 y $4.8 \mathrm{mg} / \mathrm{l}$, en superficie, y entre 0.8 y 2.6 $\mathrm{mg} / \mathrm{l}$ a los $150 \mathrm{~m}$. Nuevamente, las concentraciones más altas se presentan al Sur y centro de la cuenca. Al igual que para las condiciones Niño y normal, las menores concentraciones se registran al Noreste de la región oceánica.

Esta condición resulta ser la más productiva de las tres, obteniéndose durante este período los registros más elevados de clorofila "a" y reportes de mayor cantidad de organismos fitoplanctónicos. Esto coincide con la presencia de aguas con un alto contenido de nutrientes.

La alta abundancia de microalgas es notable desde la superficie hasta los $150 \mathrm{~m}$, pudiéndose encontrar cantidades muy elevadas de organismos a esta última profundidad con 5900 cel/l, mientras que durante la época normal las abundancias a $150 \mathrm{~m}$ no superan las 300 cel/l. La especie dominante a este nivel corresponde a la diatomea Fragilariopsis rombica, la cual fue reportada únicamente durante este período y según Carmelo (1995) pertenece a aguas frías del Pacífico Sur.

Los nutrientes, por su parte, muestran altas concentraciones al Sur de la cuenca y en la porción oceánica 
que rodea Malpelo. En la zona costera se encuentran por lo general las concentraciones más elevadas entre la isla de Gorgona y la bahía de Tumaco. El comportamiento de los nitritos es opuesto al resto de las sales y presentan concentraciones más bajas hacia la costa y cerca de la isla Malpelo, áreas donde las abundancias poblacionales de microalgas son más altas. Estas mismas zonas coinciden con los máximos registros de clorofila "a".

Para esta condición se destacan las diatomeas más típicas del fitoplancton nerítico tales como Rhizosolenia imbricata, Leptocylindrus danicus, Skeletonema costatum y Chaetoceros compressus; las cuales presentaron elevadas abundancia y una amplia distribución a lo largo de todo el litoral. Los dinoflagelados en cambio muestran abundancias bajas dominando a nivel costero las especies más comunes como Ceratium fusus var seta, C. furca, Prorocentrum micans, P. rostratum y Ceratocorys horrida. En la porción oceánica el número de especies de dinoflagelados aumenta y el de diatomeas disminuye, sin embargo, este último grupo siempre mantiene los mayores registros de abundancia celular.

En esta condición se reportan seis especies nuevas de diatomeas y siete de dinoflagelados. Además de ser detectadas seis especies de dinoflagelados tóxicos, los cuales resultan ser potencialmente peligrosos, ya que de presentarse las condiciones adecuadas podrían originar mareas rojas.

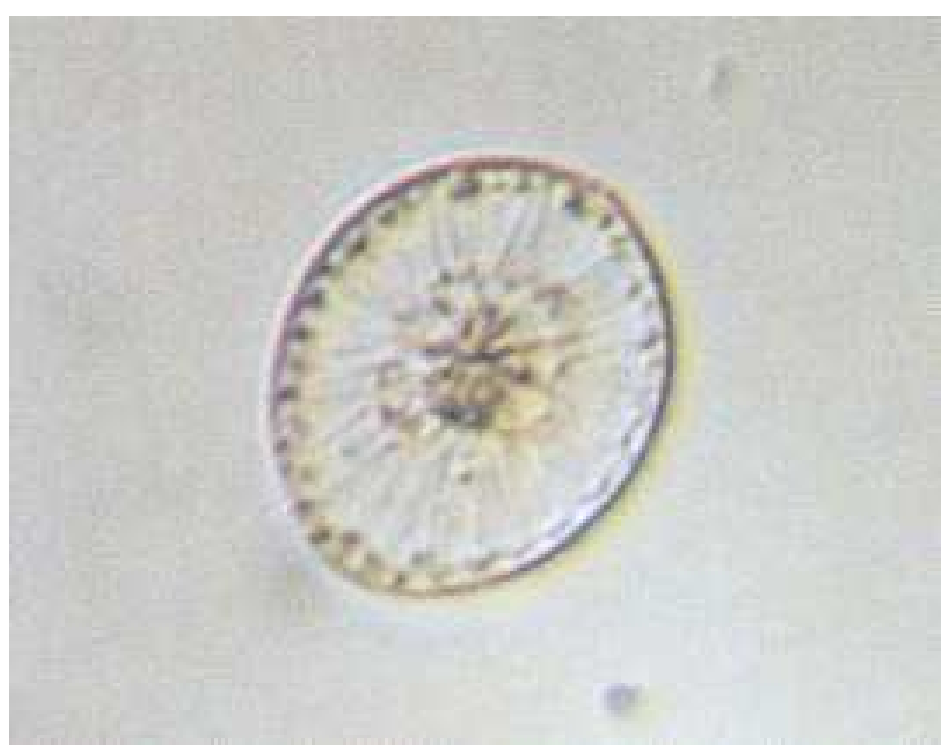

Asteromphalus flabellatus (diatomeas). (Foto: CCCP).

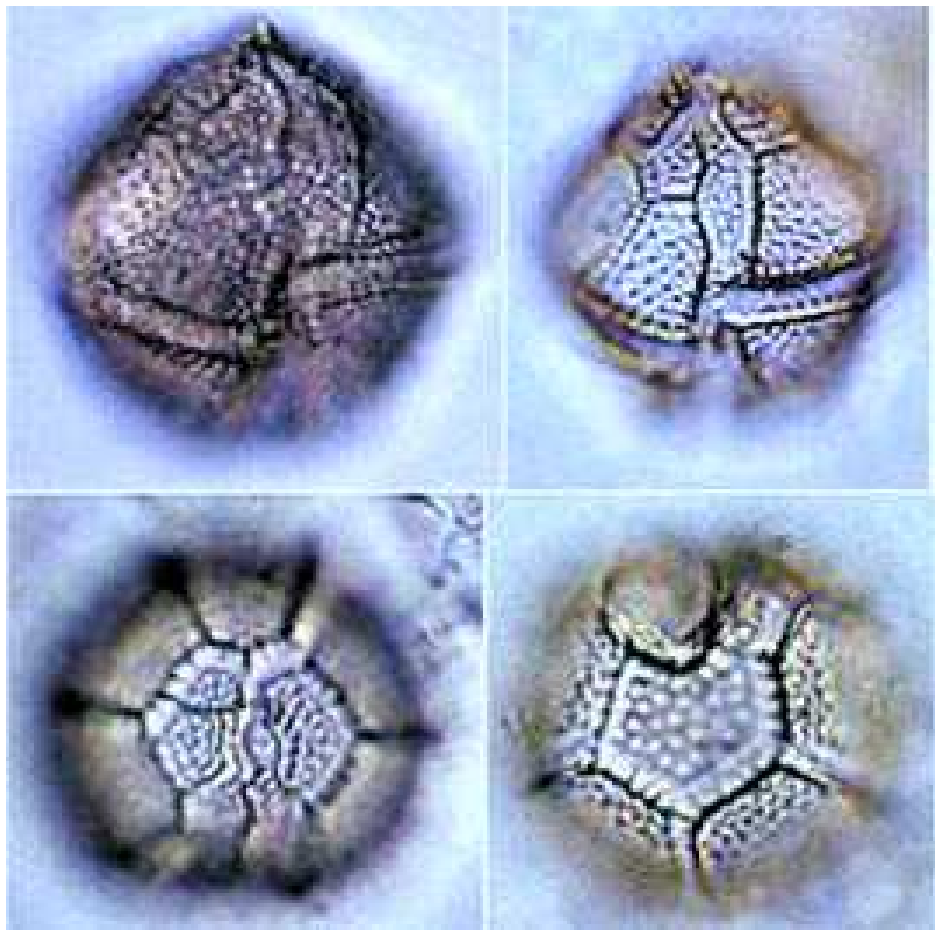

Lingulodinium polyedrum (Dinoflagelados). (Foto: K. Fukuyo, 2000).
Tabla 4.1 - Presencia - Ausencia de Diatomeas y Dinoflagelados para los tres periodos climáticos. 


\begin{tabular}{|c|c|c|c|c|c|c|c|}
\hline DIATOMEAS & NORM & NIÑO & NIÑA & DINOFLAGELDOS & NORM & NIÑO & NIÑA \\
\hline Achanthes longipes & $x$ & $x$ & $x$ & Alexandrium catenella & $x$ & & \\
\hline Actinoptychus undulatus & $x$ & & & Alexandrium tropicale & $x$ & $x$ & $x$ \\
\hline Actinoptychus splendens & $x$ & $x$ & $x$ & Amphidinium curcubita & & & $x$ \\
\hline Actinoptychus mediterraneum & & $x$ & & Amphisolenia bidentata & $x$ & $x$ & $x$ \\
\hline Amphora arenicola & $x$ & $x$ & $x$ & Blepharocysta splendor-maris & $x$ & $x$ & $x$ \\
\hline Amphora graefii & $x$ & $x$ & $x$ & Ceratium breve var breve & $x$ & $x$ & \\
\hline Amphora wisei & $x$ & & & Ceratium candelabrum & $x$ & $x$ & \\
\hline Asterionellopsis glacialis & $x$ & $x$ & $x$ & Ceratium concilians & & $x$ & \\
\hline Asterionellopsis kariana & $x$ & $x$ & $x$ & Ceratium contortum & $x$ & $x$ & $x$ \\
\hline Asteromphalus arachne & $x$ & & & Ceratium extensum & $x$ & $x$ & $x$ \\
\hline Asteromphalus bookeri & $x$ & $x$ & $x$ & Ceratium furca & $x$ & $x$ & $x$ \\
\hline Asteromphalus claveanus & & $x$ & & Ceratium furca var furca & & $x$ & \\
\hline Asteromphalus elegans & $x$ & $x$ & $x$ & Ceratium fusus & $x$ & $x$ & \\
\hline Asteromphalus flabellatus & $x$ & & $x$ & Ceratium fusus var seta & $x$ & $x$ & $x$ \\
\hline Asteromphalus heptactis & $x$ & $x$ & $x$ & Ceratium fusus var fusus & & $x$ & \\
\hline Asteromphalus hyalinus & & & $x$ & Ceratium karsteni & & $x$ & \\
\hline Azpeitia nodulifera & $x$ & & $x$ & Ceratium kofoidii & $x$ & $x$ & $x$ \\
\hline Bacillaria paxillifera & $x$ & $x$ & $x$ & Ceratium lineatum & $x$ & $x$ & \\
\hline Bacteriastrum delicatum & $x$ & & $x$ & Ceratium macroceros var macroseros & $x$ & $x$ & $x$ \\
\hline Bacteriastrum elongatum & $x$ & $x$ & $x$ & Ceratium macroceros var gallicum & $x$ & $x$ & $x$ \\
\hline Bacteriastrum furcatum & $x$ & $x$ & $x$ & Ceratium mássilense & $x$ & $x$ & $x$ \\
\hline Bacteriastrum hyalinum & $x$ & $x$ & $x$ & Ceratium mássilense var armatum & $x$ & $x$ & $x$ \\
\hline Cerataulina bicornis & $x$ & & $x$ & Ceratium mássilense var mássilense & $x$ & $x$ & $x$ \\
\hline Cerataulina pelagica & $x$ & & $x$ & Ceratium paradoxides & & $x$ & \\
\hline Chaetoceros aequatorialis & $x$ & $x$ & $x$ & Ceratium pentagonum & $x$ & $x$ & $x$ \\
\hline Chaetoceros affins & $x$ & $x$ & $x$ & Ceratium pentagonum var pentagonum & $x$ & $x$ & $x$ \\
\hline Chaetoceros anastomosans & & & $x$ & Ceratium pentagonum var tenerum & & $x$ & \\
\hline Chaetoceros atlanticus & $x$ & & $x$ & Ceratium pulchellum & & $x$ & \\
\hline Chaetoceros atlanticus var neapolitana & & $x$ & & Ceratium teres & $x$ & $x$ & \\
\hline Chaetoceros brevis & $x$ & & & Ceratium trichoceros & $x$ & $x$ & $x$ \\
\hline Chaetoceros cinctus & $x$ & $x$ & $x$ & Ceratium tripos & $x$ & $x$ & \\
\hline Chaetoceros coarctatus & $x$ & $x$ & $x$ & Ceratium tripos var porrectum & & $x$ & \\
\hline Chaetoceros compressus & $x$ & & $x$ & Ceratium tripos var breve & $x$ & $x$ & \\
\hline Chaetoceros costatus & $x$ & $x$ & $x$ & Ceratium tripos var brevissonii & $x$ & $x$ & $x$ \\
\hline Chaetoceros curvisetus & $x$ & $x$ & $x$ & Ceratium tripos var tripos & $x$ & $x$ & \\
\hline Chaetoceros decipiens & $x$ & & $x$ & Ceratium vultur & $x$ & $x$ & \\
\hline Chaetoceros debilis & $x$ & & & Ceratium vultur var japonicum & & $x$ & \\
\hline Chaetoceros diadema & $x$ & & & Ceratocorys armata & $x$ & $x$ & $x$ \\
\hline Chaetoceros dichaetas & $x$ & $x$ & $x$ & Ceratocorys horrida & $x$ & $x$ & $x$ \\
\hline Chaetoceros diversus & $x$ & & $x$ & Cladopyxis brachiolata & $x$ & $x$ & \\
\hline
\end{tabular}




\begin{tabular}{|c|c|c|c|c|c|c|c|}
\hline DIATOMEAS & NORM & NIÑO & NIÑA & DINOFLAGELDOS & NORM & NIÑO & NIÑA \\
\hline Chaetoceros didymus var anglica & $x$ & $x$ & $x$ & Corythodinium constrictum & $x$ & $x$ & $x$ \\
\hline Chaetoceros didymus & $x$ & $x$ & $x$ & Corythodinium reticulatum & $x$ & $x$ & \\
\hline Chaetoceros eibenii & $x$ & $x$ & $x$ & Corythodinium tesselatum & $X$ & $x$ & \\
\hline Chaetoceros laciniosus & $x$ & & $x$ & Dinophysis acuminata & $x$ & $x$ & $x$ \\
\hline Chaetoceros laevis & $x$ & $x$ & $x$ & Dinophysis argus & & $x$ & \\
\hline Chaetoceros lorenzianus & $x$ & $x$ & $x$ & Dinophysis brevisulcus & $x$ & $x$ & \\
\hline Chaetoceros messanensis & $x$ & & $x$ & Dinophysis caudata & $x$ & $x$ & $x$ \\
\hline Chaetoceros pelagicus & $x$ & & & Dinophysis doryphora & $x$ & & \\
\hline Chaetoceros peruvians & $x$ & $x$ & $x$ & Dinophysis exigua & $x$ & $x$ & \\
\hline Chaetoceros radicans & $x$ & $x$ & $x$ & Dinophysis fortii & & $x$ & \\
\hline Chaetoceros rostratus & $x$ & & & Dinophysis hastata & & $x$ & \\
\hline Chaetoceros socialis & $x$ & $x$ & $x$ & Dinophysis laevis & $x$ & & \\
\hline Chaetoceros tetrastichon & $x$ & $x$ & $x$ & Dinophysis nias & & $x$ & \\
\hline Climacodium biconcavum & $x$ & $x$ & $x$ & Dinophysis ovum & $x$ & & \\
\hline Climacodium frauenfeldianum & $x$ & $x$ & $x$ & Dinophysis parvula & $x$ & & \\
\hline Climacosphenia moniligera & $x$ & & & Dinophysis similis & & $x$ & \\
\hline Cocconeis scutellum & $x$ & $x$ & & Diplopelta symmetrica & $x$ & $x$ & $x$ \\
\hline Campylodiscus undulatus & & & $x$ & Diplopelta parva & $x$ & $x$ & $x$ \\
\hline Corethron criophilum & $x$ & $x$ & $x$ & Gambierdiscus toxicus & $x$ & $x$ & $x$ \\
\hline Coscinodiscus argus & $x$ & & & Gymnodinium agiliforme & $x$ & $x$ & $x$ \\
\hline Coscinodiscus asteromphalus & $x$ & & & Gymnodinium baccatum & & $x$ & \\
\hline Coscinodiscus concinnus & $x$ & $x$ & $x$ & Gymnodinium breve & $x$ & $x$ & \\
\hline Coscinodiscus eccentricus & $x$ & $x$ & $x$ & Gymnodinium catenatum & $x$ & $x$ & \\
\hline Coscinodiscus gigas & $x$ & & & Gymnodinium fragilissima & & $x$ & \\
\hline Coscinodiscus granii & $x$ & $x$ & $x$ & Gymnodinium sanguineum & $x$ & $x$ & $x$ \\
\hline Coscinodiscus lineatus & $x$ & $x$ & $x$ & Gymnodinium stuarile & $x$ & $x$ & $x$ \\
\hline Coscinodiscus marginatus & $x$ & $x$ & $x$ & Goniodoma polyedricum & $x$ & $x$ & \\
\hline Coscinodiscus nitidus & $x$ & $x$ & $x$ & Goniodoma sphaericum & & & $x$ \\
\hline Coscinodiscus radiatus & $x$ & $x$ & $x$ & Gonyaulax fragilis & $x$ & $x$ & $x$ \\
\hline Coscinodiscus rothii & $x$ & & & Gonyaulax fusiformis & $x$ & & \\
\hline Coscinodiscus stellaris & $x$ & & & Gonyaulax jolliffei & & $x$ & \\
\hline Cyclotella litoralis & $x$ & & & Gonyaulax nigricans & $x$ & $x$ & \\
\hline Cyclotella meneghiniana & $x$ & $x$ & $x$ & Gonyaulax pacifica & $x$ & $x$ & \\
\hline Cyclotella stylorum & $x$ & $x$ & $x$ & Gonyaulax polyedricum & & $x$ & \\
\hline Cyclotella striata & $x$ & $x$ & $x$ & Gonyaulax polygramma & $x$ & $x$ & $x$ \\
\hline Cylindrotheca closterium & $x$ & $x$ & $x$ & Gonyaulax sceptum & & & $x$ \\
\hline Cymbella parva & $x$ & $x$ & $x$ & Gonyaulax scrippsae & $x$ & & $x$ \\
\hline Dactyliosolen antarcticus & $x$ & $x$ & $x$ & Gonyaulax sphaeroidea & $x$ & $x$ & $x$ \\
\hline Dactyliosolem fragilissimus & $x$ & $x$ & $x$ & Gonyaulax spinifera & $x$ & $x$ & $x$ \\
\hline Detonula confervacea & $x$ & & $x$ & Gonyaulax turbynei & $x$ & $x$ & $x$ \\
\hline
\end{tabular}




\begin{tabular}{|c|c|c|c|c|c|c|c|}
\hline DIATOMEAS & NORM & NIÑO & NIÑA & DINOFLAGELDOS & NORM & NIÑO & NIÑA \\
\hline Diploneis bombus & $x$ & $x$ & $x$ & Heterocapsa niei & $x$ & $x$ & $x$ \\
\hline Ditylum brightwellii & $x$ & $x$ & $x$ & Histioneis oxypteris & $x$ & $x$ & $x$ \\
\hline Epithemia musculus & $x$ & & & Kofoidinium velleloides & $x$ & $x$ & $x$ \\
\hline Eucampia cornuta & $x$ & $x$ & $x$ & Lingulodinium polyedrum & & & $x$ \\
\hline Eucampia zodiacus & $x$ & $x$ & $x$ & Ornithocercus magnificus & $x$ & $x$ & $x$ \\
\hline Eunotogramma marinum & $x$ & & & Ornithocercus quadratus & $x$ & $x$ & \\
\hline Fragiliaropsis doliolus & $x$ & $x$ & $x$ & Ornithocercus steinii & $x$ & & $x$ \\
\hline Fragiliaropsis rombica & & & $x$ & Oxytoxum longiceps & $x$ & $x$ & $x$ \\
\hline Gossleriella tropica & $x$ & & & Oxytoxum mediterraneum & $x$ & $x$ & $x$ \\
\hline Grammatophora marina & $x$ & & & Oxytoxum minimun & $x$ & & $x$ \\
\hline Grammatophora oceanica & $x$ & & & Oxytoxum ovum & $x$ & $x$ & $x$ \\
\hline Guinardia delicatula & $x$ & $x$ & $x$ & Oxytoxum scolopax & $x$ & $x$ & $x$ \\
\hline Guinardia flaccida & $x$ & & $x$ & Oxytoxum sphaeroidea & $x$ & $x$ & $x$ \\
\hline Guinardia striata & $x$ & $x$ & $x$ & Oxytoxum turbo & $x$ & $x$ & $x$ \\
\hline Gyrosigma balticum & & $x$ & & Paleophalacroma unicinctum & $x$ & $x$ & $x$ \\
\hline Gyrosigma fasciolata & & $x$ & & Paleophalacroma verrucosum & $x$ & & \\
\hline Gyrosigma spencerii & $x$ & & & Peridinium punctulatum & & & $x$ \\
\hline Haslea wawrikae & $x$ & $x$ & & Phalacroma argus & $x$ & $x$ & $x$ \\
\hline Helicotheca tamensis & $x$ & $x$ & $x$ & Phalacroma cuneus & & $x$ & \\
\hline Hemiaulus hauckii & $x$ & $x$ & $x$ & Phalacroma doryphorum & & & $x$ \\
\hline Hemiaulus membranaceus & $x$ & $x$ & $x$ & Phalacroma favus & & $x$ & \\
\hline Hemiaulus sinensis & $x$ & $x$ & $x$ & Phalacroma rapa & $x$ & $x$ & $x$ \\
\hline Hemidiscus cuneiforme & $x$ & & & Phalacroma rotundatum & & & $x$ \\
\hline Hemidiscus ovalis & $x$ & $x$ & $x$ & Plectodinium nucleovelatum & $x$ & $x$ & $x$ \\
\hline Lauderia annulata & $x$ & $x$ & $x$ & Podolampas bipes & $x$ & $x$ & \\
\hline Leptocylindrus danicus & $x$ & $x$ & $x$ & Podolampas elegans & & $x$ & \\
\hline Leptocylindrus mediterraneus & $x$ & $x$ & $x$ & Podolampas palmipes & $x$ & $x$ & $x$ \\
\hline Leptocylindrus minimus & $x$ & & $x$ & Podolampas spinifer & $x$ & $x$ & $x$ \\
\hline Licmophora abbreviata & $x$ & & & Polykrikos kofoidii & & $x$ & \\
\hline Lioloma pacificum & $x$ & $x$ & $x$ & Polykrikos schwartzii & & & $x$ \\
\hline Lithodesmium undulatum & $x$ & $x$ & $x$ & Preperidinium meunieri & $x$ & $x$ & $x$ \\
\hline Manguinea rigida & $x$ & & & Prorocemtrum micans & $x$ & $x$ & $x$ \\
\hline Melosira fausta & & $x$ & & Prorocentrum brochii & $x$ & & \\
\hline Melosira jurgensii & $x$ & & $x$ & Prorocentrum compressum & $x$ & $x$ & $x$ \\
\hline Melosira mayor & $x$ & $x$ & $x$ & Prorocentrum dentatum & $x$ & $x$ & $x$ \\
\hline Melosira nummuloides & $x$ & $x$ & $x$ & Prorocentrum emarginatum & & $x$ & \\
\hline Meuniera membranacea & $x$ & $x$ & $x$ & Prorocentrum euarcuatum & $x$ & $x$ & $x$ \\
\hline Navicula cancellata & $x$ & & & Prorocentrum gracile & $x$ & $x$ & $x$ \\
\hline Navicula directa & $x$ & $x$ & $x$ & Prorocentrum granii & & $x$ & \\
\hline Navicula lyra & $x$ & & & Prorocentrum lima & $x$ & $x$ & $x$ \\
\hline
\end{tabular}




\begin{tabular}{|c|c|c|c|c|c|c|c|}
\hline DIATOMEAS & NORM & NIÑO & NIÑA & DINOFLAGELDOS & NORM & $\mid$ NIÑO & NIÑA \\
\hline Navicula transitans var deresa & $x$ & & $x$ & Prorocentrum mexicanum & & $x$ & \\
\hline Nitzschia angularis & $x$ & $x$ & $x$ & Prorocentrum minimum & $x$ & $x$ & $x$ \\
\hline Nitzschia bicapitata & $x$ & $x$ & $x$ & Prorocentrum rostratum & $x$ & $x$ & $x$ \\
\hline Nitzschia brebissonii & $x$ & $x$ & $x$ & Prorocentrum scutellum & & $x$ & \\
\hline Nitzschia longissima & $x$ & $x$ & $x$ & Protoperidinium abei & $x$ & $x$ & \\
\hline Nitzschia marina & $x$ & & & Protoperidinium brochi & $x$ & $x$ & $x$ \\
\hline Nitzschia paradoxa & $x$ & & & Protoperidinium cerasus & $x$ & & \\
\hline Nitzschia plana & $x$ & & & Protoperidinium claudicans & $x$ & $x$ & $x$ \\
\hline Nitzschia recta & $x$ & $x$ & $x$ & Protoperidinium conicum & $x$ & $x$ & $x$ \\
\hline Nitzschia sicula & $x$ & & $x$ & Protoperidinium crassipes & & $x$ & \\
\hline Nitzschia sigma & $x$ & & & Protoperidinium cristatum & $x$ & $x$ & $x$ \\
\hline Odontella alternans & $x$ & $x$ & $x$ & Protoperidinium depressum & $x$ & $x$ & $x$ \\
\hline Odontella aurita & $x$ & $x$ & $x$ & Protoperidinium divergens & $x$ & $x$ & $x$ \\
\hline Odontella dubia & $x$ & $x$ & $x$ & Protoperidinium elegans & $x$ & $x$ & $x$ \\
\hline Odontella longicruris & $x$ & $x$ & $x$ & Protoperidinium gibbosum & & $x$ & \\
\hline Odontella longissima & & $x$ & & Protoperidinium grande & $x$ & $x$ & $x$ \\
\hline Odontella mobiliensis & $x$ & $x$ & $x$ & Protoperidinium quarnerense & & $x$ & \\
\hline Odontella pulchella & $x$ & $x$ & $x$ & Protoperidinium joubini & $x$ & $x$ & $x$ \\
\hline Odontella regia & $x$ & $x$ & $x$ & Protoperidinium kofoidii & $x$ & & \\
\hline Odontella sinensis & $x$ & $x$ & $x$ & Protoperidinium leonis & & & $x$ \\
\hline Opephora pacifica & $x$ & & $x$ & Protoperidinium longipes & $x$ & $x$ & $x$ \\
\hline Palmeria hardmaniana & $x$ & $x$ & & Protoperidinium obtusum & $x$ & & $x$ \\
\hline Paralia sulcata & $x$ & $x$ & $x$ & Protoperidinium ovum & $x$ & $x$ & $x$ \\
\hline Pinnularia breviscostata & & & $x$ & Protoperidinium pellucidum & $x$ & $x$ & $x$ \\
\hline Pinnularia stauroptera & $x$ & $x$ & $x$ & Protoperidinium pentagonum & $x$ & $x$ & $x$ \\
\hline Pixidicula cruciata & $x$ & $x$ & $x$ & Protoperidinium sphaericum & $x$ & $x$ & $x$ \\
\hline Pixidicula striata & & & $x$ & Protoperidinium subsphaeroidea & $x$ & $x$ & $x$ \\
\hline Planktoniella blanda & $x$ & & & Protoperidinium thorianum & $x$ & $x$ & $x$ \\
\hline Planktoniella sol & $x$ & $x$ & $x$ & Ptychodiscus inflatus & $x$ & & \\
\hline Pleurosigma angulatum & $x$ & $x$ & $x$ & Pyrocystis banulus & $x$ & & $x$ \\
\hline Pleurosigma directum & $x$ & & $x$ & Pyrocystis fusiformis & $x$ & & $x$ \\
\hline Pleurosigma heros & & $x$ & & Pyrocystis lunula & $x$ & $x$ & $x$ \\
\hline Pleurosigma nicobaricum & $x$ & $x$ & $x$ & Pyrocystis noctiluca & $x$ & & $x$ \\
\hline Pleurosigma normanii & $x$ & $x$ & $x$ & Pyrophacus steinii & $x$ & & \\
\hline Proboscia alata & $x$ & $x$ & $x$ & Scrippsiella trochoidea & $x$ & $x$ & $x$ \\
\hline Proboscia alata var curvirostris & $x$ & $x$ & $x$ & Spiraulax kofoidii & & $x$ & \\
\hline Pseudo-nistzchia pungens & $x$ & & $x$ & & & & \\
\hline Pseudo-nitzschia delicatissima & $x$ & $x$ & $x$ & & & & \\
\hline Pseudo-nitzschia fraudulenta & $x$ & & $x$ & & & & \\
\hline Pseudo-nitzschia lineola & $x$ & $x$ & $x$ & & & & \\
\hline
\end{tabular}




\begin{tabular}{|c|c|c|c|c|c|c|c|}
\hline DIATOMEAS & NORM & NIÑO & NIÑA & DINOFLAGELDOS & NORM & NIÑO & NIÑA \\
\hline Pseudo-nitzschia pacifica & $x$ & $x$ & $x$ & & & & \\
\hline Pseudo-nitzschia pseudodelicatissima & $x$ & $x$ & $x$ & & & & \\
\hline Pseudo-nitzschia seriata & $x$ & $x$ & $x$ & & & & \\
\hline Pseudosolenia calcar avis & $x$ & $x$ & $x$ & & & & \\
\hline Rhizosolenia acuminata & $x$ & $x$ & $x$ & & & & \\
\hline Rhizosolenia bergonii & $x$ & $x$ & $x$ & & & & \\
\hline Rhizosolenia castracanei & $x$ & $x$ & $x$ & & & & \\
\hline Rhizosolenia hebetata & $x$ & $x$ & $x$ & & & & \\
\hline Rhizosolenia hyalina & $x$ & $x$ & $x$ & & & & \\
\hline Rhizosolenia imbricata & $x$ & $x$ & $x$ & & & & \\
\hline Rhizosolenia pungens & $x$ & $x$ & $x$ & & & & \\
\hline Rhizosolenia robusta & $x$ & $x$ & $x$ & & & & \\
\hline Rhizosolenia setigera & $x$ & $x$ & $x$ & & & & \\
\hline Rhizosolenia striata & $x$ & $x$ & $x$ & & & & \\
\hline Rhizosolenia styliformis & $x$ & & $x$ & & & & \\
\hline Roperia teselata & $x$ & & & & & & \\
\hline Skeletonema constatum & $x$ & $x$ & $x$ & & & & \\
\hline Stephanopyxis palmeriana & $x$ & $x$ & $x$ & & & & \\
\hline Stephanopyxis turris & $x$ & $x$ & $x$ & & & & \\
\hline Striatella unipunctata & $x$ & & & & & & \\
\hline Surirella recendens & $x$ & $x$ & $x$ & & & & \\
\hline Surirella fastuosa & $x$ & $x$ & $x$ & & & & \\
\hline Thalassionema bacillare & $x$ & & & & & & \\
\hline Thalassionema delicatula & $x$ & & & & & & \\
\hline Thalassionema fraunfeldii & $x$ & $x$ & $x$ & & & & \\
\hline Thalassionema nitzschioides & $x$ & $x$ & $x$ & & & & \\
\hline Thalassiosira allenii & $x$ & & & & & & \\
\hline Thalassiosira anguste - lineata & $x$ & $x$ & $x$ & & & & \\
\hline Thalassiosira punctigera & $x$ & & & & & & \\
\hline Thalassiosira subtilis & $x$ & $x$ & $x$ & & & & \\
\hline Thalassiothrix heteromorpha & $x$ & $x$ & $x$ & & & & \\
\hline Thalassiothrix mediterranea var pacifica & $x$ & & & & & & \\
\hline Triceratum favus & $x$ & $x$ & $x$ & & & & \\
\hline Trichodesmiun thiebauti & $x$ & & & & & & \\
\hline
\end{tabular}

Especies observadas únicamente durante El Niño

Especies observadas únicamente durante La Niña 


\subsection{ANÁLISIS GENERAL DE LAS CONDICIONES OCEANOGRÁFICAS DE LA CUENCA PACIFICA COLOMBIANA}

Todavía existen interrogantes acerca de cuáles son las condiciones oceanográficas normales de la CPC debido a la corta serie de datos de que se dispone. Sin embargo, como se señala con antelación en este capítulo, se evidencian divergencias al comparar tres situaciones oceanográficas y biológicas de la cuenca, según muestreos y análisis realizados para el mes de mayo de años que presentaron condiciones diferentes.

Al comparar lo anterior con lo presentado a nivel global, donde se conocía sobre la presencia de fenómenos anómalos detectados durante el desarrollo de cruceros oceanográficos en la CPC, se buscaron relaciones entre las condiciones observadas en la cuenca y el ciclo Enos (El Niño, Oscilación del Sur). En esta pesquisa se hallaron además de las situaciones que se han denominado condiciones normales para la cuenca otras que podrían considerarse reacciones ante eventos como son los fenómenos de El Niño y La Niña, los cuales modifican las características físicas, químicas y biológicas del Pacífico colombiano.

Para contar con parámetros comparativos entre las condiciones observadas en la CPC durante los cruceros oceanográficos de mayo de 1998, 1999 y 2000 se utilizó la anomalía de temperatura superficial, calculada con respecto al promedio de 1970 a 1996 (Fig. 4.45). Así, para mayo de 1998 se encontraron valores positivos de hasta $3.5^{\circ} \mathrm{C}$, lo cual fue considerado como indicador de evento Niño.

En complemento a lo anterior fueron utilizadas tanto la oceanografía química como la biológica a manera de herramientas para confirmar los resultados de los tres cruceros; para tal efecto se usó información sobre nutrientes, oxígeno disuelto, clorofilas y organismos fitoplanctónicos. Estas herramientas fueron importantes para determinar las diferencias entre los años Niña y normales.

Al comparar la temperatura de mayo, obtenida del promedio histórico, contra la de la denominada condición normal presentada en mayo de 2000 se observaron similitudes en cuanto a la distribución espacial horizontal; las mayores temperaturas se encontraron en el borde costero y las menores en el sector oceánico. También se observó que los mayores valores se registran en la región norte con un descenso hacia el Sur. La anomalía calculada presenta valores cercanos a cero (Fig. 4.45), indicando una leve diferencia entre los promedios y la condición normal.

También se hallaron similitudes entre los valores promediados y la condición encontrada en mayo del 2000 en
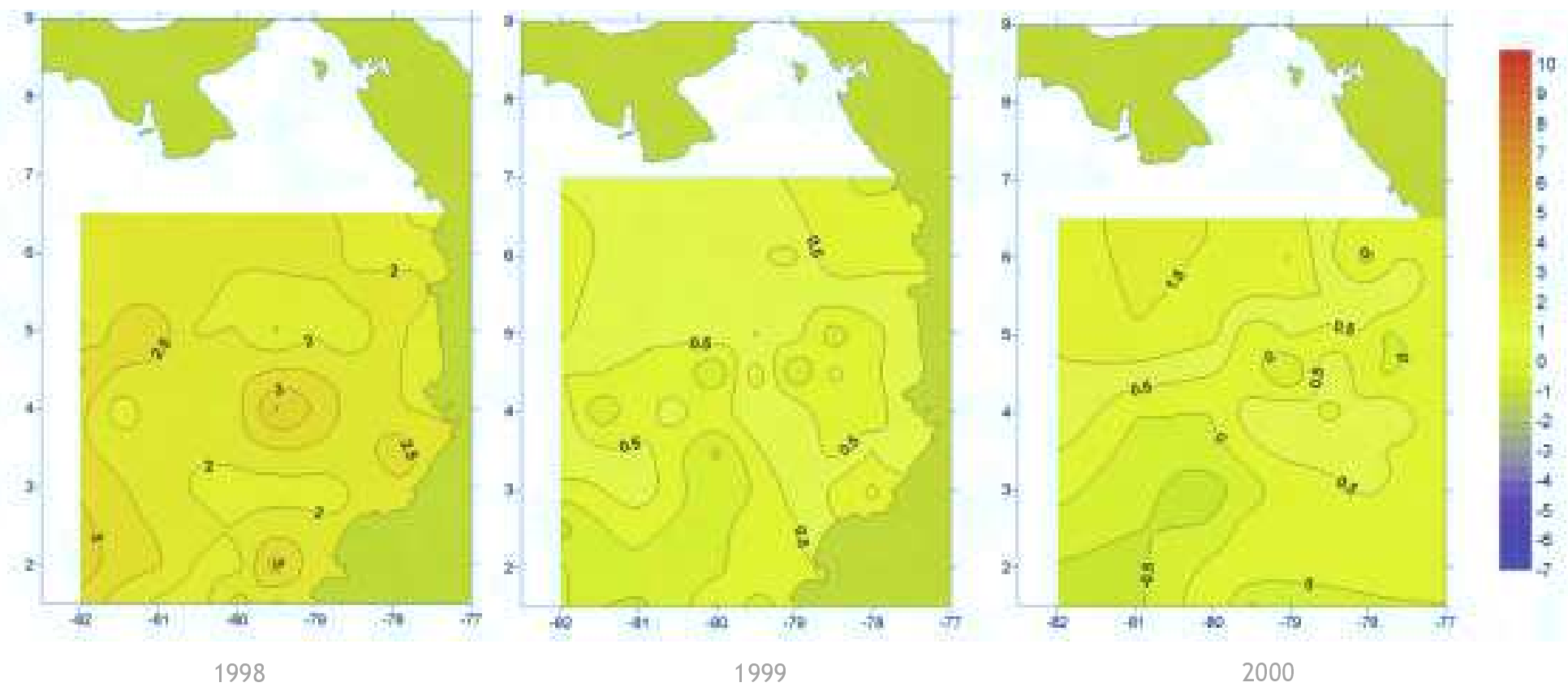

Figura 4.45 Anomalía de temperatura superficial (TSM) para 1998, 1999 y 2000. 
cuanto a la disminución de temperatura con respeto a la profundidad, donde se distingue una capa homogénea muy delgada en superficie (primeros $10 \mathrm{~m}$ ) y, por debajo, la termoclina estacional que varía en el rango de los 27 a los $18^{\circ} \mathrm{C}$. Después de esta capa la temperatura disminuye levemente a medida que aumenta la profundidad. Fueron observadas algunas diferencias para las condiciones normales (Fig. 4.45), debido principalmente a que los promedios tienden a suavizar los datos.

La salinidad, comparada de la misma manera, muestra una igualdad (Fig. 4.46) en cuanto a la presencia de valores muy bajos en la costa y altos a medida que se acerca al mar abierto. También es similar la presencia de una zona intermedia que mezcla salinidades altas y bajas, en la región central de la CPC. Las diferencias se observan en cuanto al grosor de esta franja y la extensión que ésta abarca, ya que para condiciones normales la zona intermedia llega hasta los $80^{\circ} \mathrm{W}$ y en el promedio hasta los $79^{\circ} \mathrm{W}$. Además, resulta diferente la distribución vertical de salinidad, ya que después de la haloclina se dan capas homogéneas horizontales y regiones con una distribución muy variada en los promedios para el mes estudiado (Cap. II, Mayo; 1970-1996).

Al comparar el promedio de mayo con la condición Niño se observa una distribución similar en cuanto a las capas, siendo la TSM mucho mayor $\left(3^{\circ} \mathrm{C}\right)$. Esto hace que las isotermas estén más profundas o en algunos casos se ubiquen más cercanas unas de otras. Por debajo de la termoclina estacional ambos perfiles son iguales. Estas altas temperaturas podrían evidenciar la presencia de un año cálido anómalo en la CPC, el cual fue determinado como año Niño a nivel general para el Pacífico Ecuatorial. La salinidad presenta valores similares (Fig. 4.46) en la primera capa (0-100 m), pero por debajo de ésta es muy distinta la distribución con el aumento de la profundidad.

Mayo promedio fue similar al mayo de la condición Niña 1999, con respecto a la variación de TSM (Fig. 4.45), siendo mayor en la costa y menor hacia el mar abierto, y mayor en la Zona Norte que en la Sur de la CPC. El límite inferior de la termoclina estacional $\left(18^{\circ} \mathrm{C}\right)$ se ubicó alrededor de los $50 \mathrm{~m}$, aunque hubo diferencias en cuanto a la profundidad de la isoterma de $15^{\circ} \mathrm{C}$, la cual fue más profunda para mayo 1999 que durante mayo promedio excepto en el transepto $4^{\circ} \mathrm{N}$. La isoterma $10^{\circ} \mathrm{C}$ se encontró alrededor de los $400 \mathrm{~m}$ de profundidad, en ambos casos. La salinidad fue similar para el promedio y mayo de 1999 (Fig. 4.46); los mayores valores se observaron en la sección oceánica y disminuyeron hacia la región costera, encontrando una haloclina en los primeros 50 m y máximos entre 80 y $150 \mathrm{~m}$. Por debajo de la haloclina se observa este máximo de salinidad, posteriormente los valores disminuyen muy poco con el incremento de la profundidad.

En general, para la CPC las variaciones de salinidad y temperatura son muy marcadas entre la zona costera y la región oceánica, y un poco menos entre las zonas Norte y Sur; identificándose salinidades altas en la región oceánica y bajas en la región costera, además de valores de temperatura mayores en la Zona Norte con respecto a los de la Zona Sur. Esto puede ser consecuencia de la influencia de aguas cálidas de la contracorriente Ecuatorial, CCE, a las corrientes de Panamá y Costera de Costa Rica, y por las corrientes frías de Perú-Colombia.

Durante la condición Niño (mayo 1998) el régimen de corrientes muestra una posible intensificación de la CCE y de las corrientes de Panamá y Costa Rica. Esto puede afectar las condiciones térmicas en la CPC, produciendo para este período un aumento en la temperatura por intrusión de aguas provenientes del Pacífico Ecuatorial.

Durante la condición Niña (mayo 1997) las aguas empiezan a enfriarse, posiblemente debido a que la CCE se debilita y las corrientes predominantes comienzan de nuevo a ejercer su acción típica para este mes. Posteriormente, las condiciones se regulan más aún presentándose en mayo de 2000 características normales para la cuenca, donde se evidenció una marcada influencia de la corriente fría del Perú al sur de la CPC hasta los $3^{\circ} \mathrm{N}$ y también al norte de la cuenca por el sistema de circulación de la ensenada de Panamá.

La influencia que ejercen estas corrientes sobre la CPC determina el patrón de distribución de parámetros físicos, químicos y biológicos en el área, tanto a nivel espacial como temporal. Es así como durante la condición normal se observa, claramente, la presencia de corrientes que transportan aguas cálidas al norte y frías al sur, las cuales están relacionadas con organismos propios de estos tipos de aguas. Las 

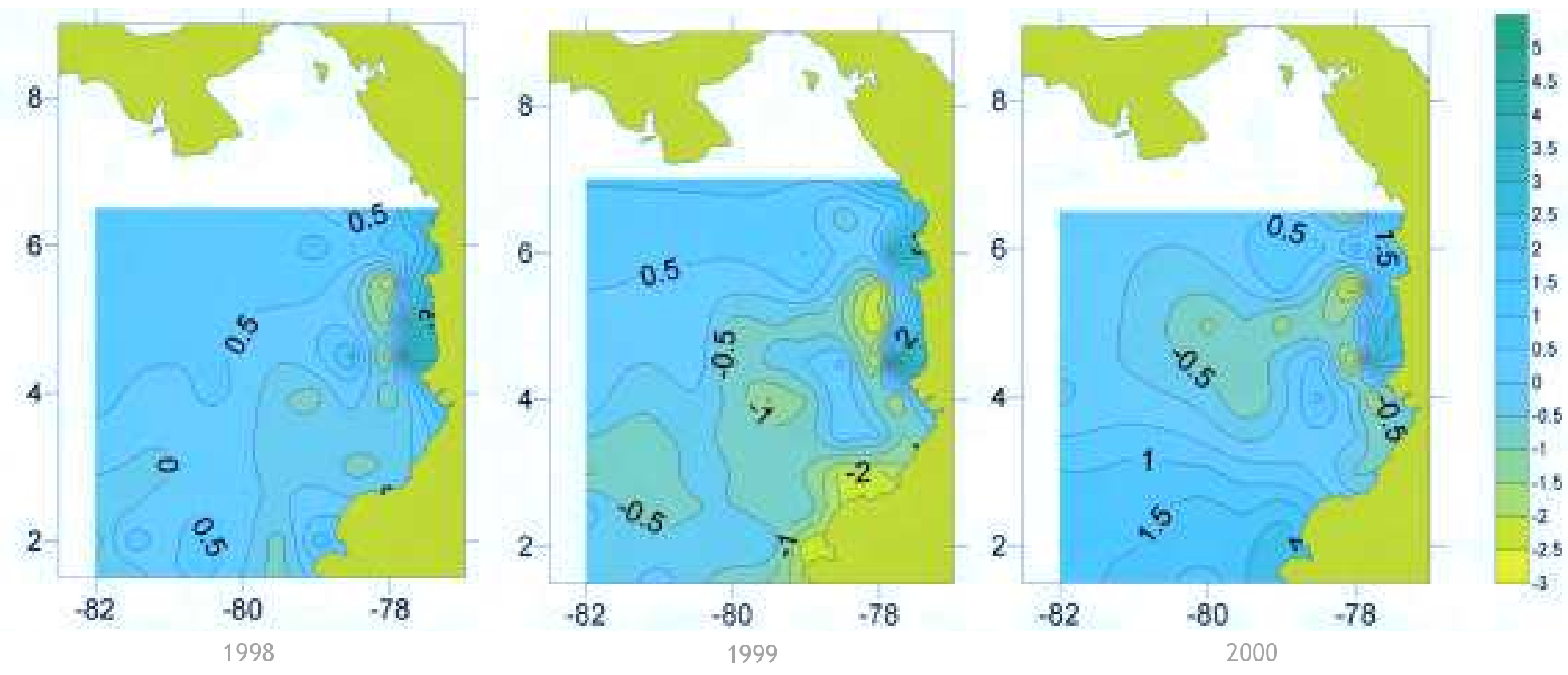

Figura 4.46 - Anomalía de salinidad superficial SSM para 1998, 1999 у 2000.

mayoría por especies de hábitats cálidos tropicales, entre los cuales se destaca el grupo de los dinoflagelados. Por lo que durante esta condición es posible evidenciar la presencia de esta clase de microalgas hacia el Noroeste de la cuenca, representadas principalmente por el género Ceratium; además del arribo al área de las diatomeas Leptocylindrus danicus y Licmophora abbreviata, de hábitos cosmopolitas (Carmelo, 1995). Durante el crucero de mayo de 1998 se observó un aumento de la temperatura al Norte de la CPC, junto con el incremento de las especies mencionadas y la aparición de otras nuevas como el dinoflagelado Prorocentrum mexicanum, de hábitats neríticos y estuarinos (Carmelo, 1995), registrado por primera vez en la zona.

Por otra parte, hacia el Sur, durante la condición normal, se observa claramente la intrusión de aguas frías, ricas en nutrientes desde el sector Suroeste hacia la costa; evidenciando anomalías de temperatura negativas, relativamente altas, asociadas con el desplazamiento de la corriente del Perú (Tchantsev y Cabrera, 1998). Estas condiciones son aptas para el desarrollo de especies fitoplanctónicas en especial del grupo de las diatomeas, registrándose un aumento notorio en estas poblaciones. Según Rojas de Mendiola, et al. (1985), las aguas de esta corriente se encuentran pobladas, principalmente, por diatomeas pequeñas de rápido crecimiento y que en su mayoría viven formando cadenas como es el caso de Thalassionema nitzschiodes, Asterionella japonica, Thalassiosira anguste-
Para la condición normal, este último género, junto con el de las Thalassiosiras fueron los más abundantes hacia la Zona Sur, en la capa superficial y a $50 \mathrm{~m}$. En las condiciones Niña estas microalgas fueron muy escasas debido a que las condiciones fisicoquímicas en la cuenca durante este período no son aptas para su desarrollo, lo que a la vez permite el predominio de otras especies de diatomeas destacándose en este caso Dactyliosolen fragissimus y Eucampia cornuta. Para la condición Niño, gracias al calentamiento de las aguas fue posible detectar una drástica disminución del grupo de las diatomeas y el ingreso de especies propias de aguas cálidas y de tipo oceánico. Según Ochoa, et al. (1985), una de las características de los eventos cálidos es la consecuente disminución de las poblaciones de diatomeas e incremento de dinoflagelados en las áreas de influencia.

Estas variaciones en la abundancia y composición especiológica han permitido detectar organismos que actúan como indicadores de eventos ENOS en pleno desarrollo. Es así como la condición Niño coincide con el aumento y aparición de especies del grupo de los dinoflagelados, en especial del género Ceratium, observándose el arribo al área de especies como Ceratium furca var furca, C. fusus var fusus, C. tipos var porrectum, C. vultur var japonicum, entre otras, que hasta el momento sólo han hecho su aparición durante este período (Tabla 4.1), y el aumento de especies como Amphysolenia bidentata, Ceratium fusus var seta, C. tripos, C. massilliense var massillience, $C$. breve var breve y $C$. 
trichoceros. Estas mismas especies han sido reportadas como indicadoras para el Pacífico colombiano por Costain y Delgado (1985); Castillo, et al. (1988); Vizcaíno y Castillo (1992), y Garcés y Medina $(1994,1996)$. Hasta el momento unas 30 especies de dinoflagelados han sido observadas únicamente durante el evento cálido (Tabla 4.1).

Para El Niño este tipo de especies presentaron además una amplia distribución en la cuenca acercándose hacia la costa, en donde la dominancia de diatomeas se ve restringida a la franja costera a diferencia de lo observado para las condiciones Niña y normal. Este mismo comportamiento de distribución anómalo se registró frente a las costas del norte de Chile, Perú y Ecuador, donde también se detectaron menores concentraciones de fitoplancton y una drástica disminución de las diatomeas, restringidas a un área muy costera, y a la vez una amplia distribución y abundancia de dinoflagelados oceánicos de aguas cálidas en el plancton nerítico (CPPS, 1983 y Avaria, 1984).

Otro aspecto importante a considerar es que las especies que se ven limitadas debido a la presencia de factores adversos en su medio, pueden encontrar en otras áreas un ambiente afín para su desarrollo, tal es el caso de Pyrophacus steinii la cual durante los efectos causados por El Niño desaparece de las aguas de la CPC, aumentando su abundancia y ampliando su distribución en las costas de Perú y Chile, en donde encuentra para ésta condición los requerimientos que necesita.

No sólo para El Niño es posible hablar de organismos que actúan como indicadores, ya que durante La Niña hay predominio del grupo de las diatomeas y se registra la presencia de especies con aparición única, como es el caso de Asteromphalus hyalinus, Chaetoceros anastomosus, Compilodiscus undulatus, Cymbella parvula, Guinardia delicatissima, Nitzschia lineata, Pinnularia brevicostata y Pixidicula striata, las cuales podrían ser consideradas como indicadores de las condiciones Niña.

Para este mismo período a $150 \mathrm{~m}$ de profundidad se observaron abundancias muy elevadas (5900 cel/l) de la diatomea Fragiliaropsis rombica, que según Carmelo (1995) corresponde a un organismo de aguas frías del Pacífico Sur; mientras que para la condición normal la cantidad de organismos a esta profundidad no superó las $300 \mathrm{cel} / \mathrm{l}$, dominando las microalgas Planctoniella sol y Thalassiosira anguste-lineata, descritas por Carmelo (1995) como especies cosmopolitas.

En los años considerados como condición normal y, ante todo, durante la condición Niña se observa un aumento de la productividad en el área, con predominio de especies como Skeletonema costatum, Dactyiliossolem fragilissimus, Rhizosolenia imbricata, Bacteriastrum furcatum y varias especies de Chaetoceros, las que a su vez han sido descritas por varios autores como altamente productivas. Tanto para el primer período de 1999 como para el 2000 se registraron florecimientos de la especie $S$. costatum con densidades que superaron las 75000 cel/l. De acuerdo con Carmelo (1995), estas condiciones de alta productividad presuponen un incremento de los productores secundarios y por ende de los niveles tróficos superiores.

La distribución espacial de los organismos fitoplanctónicos en el área, además de verse influenciada por las corrientes, la salinidad y la temperatura, está directamente ligada con la disposición de nutrientes. Carlsson (1993), comenta que al actuar las sustancias nutritivas como limitantes, se condiciona la distribución de los organismos hacia las zonas en donde haya una alta concentración de las mismas, lo cual reduce su disponibilidad a las áreas de afloramiento o aquellas cercanas a descargas fluviales o terrestres. Es así como los máximos valores de abundancia sobre la cuenca, independientemente de la época climática, se detectaron hacia la región costera, en especial frente a la bahía de Tumaco e isla Gorgona y en la región oceánica que circunda la isla de Malpelo; presentándose una alta diversidad de especies y caracterizándose por la dominancia de diatomeas, lo que además se correlaciona con los más altos registros de clorofila "a". De acuerdo con Parson et al. (1984), se conoce un proceso denominado 'efecto de masa en islas' donde se presenta una alta producción biológica cerca de islas o zonas ricas en nutrientes por turbulencias locales o surgencias.

De igual manera, para estas mismas zonas se detectaron las mayores concentraciones de oxígeno disuelto debido a procesos de turbulencia y a la producción fotosintética. La concentración de oxígeno también presenta variaciones con la profundidad, obteniéndose los registros más elevados a nivel superficial. Según Meadows y Campbel (1981) la 
concentración de oxígeno es alta cerca de la superficie debido a la fotosíntesis y va disminuyendo por debajo de la zona fotosintética. Aunque de acuerdo con Beer (1996) otro factor que afecta la solubilidad del oxígeno en el agua es la temperatura, presentándose una relación directa entre estas dos variables; lo que explica porque durante El Niño fue posible hallar los más altos registros de oxígeno disuelto desde la superficie hasta los $50 \mathrm{~m}$ en relación con altas temperaturas, mientras que durante La Niña se presentaron las concentraciones más bajas. Normalmente, con el aumento de la profundidad y la disminución de la luz se observan variaciones tanto en la composición como en la abundancia de organismos fitoplanctónicos, disminuyendo la cantidad de organismos, principalmente en los primeros $75 \mathrm{~m}$ hasta alcanzar abundancias muy bajas con valores cercanos a cero a $150 \mathrm{~m}$. De igual forma, la concentración de clorofila "a" diminuye con la profundidad. Durante la condición Niña el grupo predominante en la columna de agua son las diatomeas, hallándose los registros más altos de estas microalgas entre 0 y 50 metros, profundidad en la cual las abundancias son mucho más elevadas en comparación con lo observado durante la condición normal y Niño. Esto se correlaciona, directamente, con la concentración de clorofila "a", la cual en La Niña 1999 presentó los valores más altos en los primeros $50 \mathrm{~m}$, con concentraciones promedio de $2.8 \mathrm{mg} / \mathrm{m}^{3}$ a esta profundidad; mientras que durante la condición normal 2000 el valor promedio fue de $0.75 \mathrm{mg} / \mathrm{m}^{3}$, y en El Niño 1998 tan sólo alcanzó los $0.47 \mathrm{mg} / \mathrm{m}^{3}$.

Por otro lado, se observó una tendencia al aumento de los nutrientes con la profundidad, lo cual se registra como un comportamiento normal, detectándose en algunas ocasiones valores cercanos a cero en superficie. Jordán (1991) dice al respecto que es posible encontrar bajas concentraciones de nutrientes a nivel superficial debido al consumo de estas sales por parte de las microalgas, incorporándolas a la red trófica. En la condición Niña y normal se observó una mayor disponibilidad de las sales nutritivas en la columna de agua entre la superficie y los $50 \mathrm{~m}$, lo que resultó benéfico para el desarrollo de las microalgas en el área; mientras que durante El Niño en esta misma capa se presentó una disminución de nutrientes, afectando de forma notoria la abundancia de fitoplancton. Meadows y Campbel (1981) exponen que la escasez de elementos como el nitrógeno, el fósforo y el silicio puede limitar el desarrollo de numerosos organismos en el océano.

El bajo registro de nutrientes obtenido durante las condiciones Niño, sobre todo en los primeros $50 \mathrm{~m}$ de profundidad, se debe al ingreso de aguas cálidas pobres en estos elementos, lo que a su vez afecta la productividad en el área, coincidiendo este período con los registros más bajos de clorofila "a". Las aguas con estas características son aprovechadas por los dinoflagelados, los cuales son más estables y tienden a sacar el máximo provecho de los ambientes caracterizados por la escasez de elementos nutritivos. Es así como durante El Niño este grupo aumenta en abundancia y distribución a pesar de las condiciones adversas.

En general, para las tres condiciones observadas se evidencia que nutrientes como el nitrato y el fosfato presentan valores muy bajos hacia la costa y en toda la superficie, lo que se debe principalmente a que su relación con la distribución de las abundancias fitoplanctónicas es inversa; por tal motivo, donde se encuentren las mayores abundancias se registran los valores mínimos para estas sales. Meadows y Campbel (1981) comentan al respecto que los niveles de nitrato y fosfato son muy bajos y variables, y aumentan con la profundidad, alcanzando un máximo entre los 500 y los $1500 \mathrm{~m}$. El bajo nivel de estos iones en la superficie se debe al crecimiento del fitoplancton y el máximo alcanzado a profundidades intermedias es causado, probablemente, por la excreción animal. La proporción de nitrato y fosfato es bastante constante (aproximadamente 7:1 en peso), lo que sugiere que ambos iones son absorbidos y desprendidos por los organismos vivos en las mismas proporciones. Cabe anotar que el nitrato es la principal sal nitrogenada que aporta a la relación nitrógeno/fósforo (N/ P), lo cual determina en ciertos casos la productividad de una zona. Normalmente, cuando esta relación es mayor para el nitrógeno se presentan incrementos poblacionales (Margalef, 1982).

Durante la condición Niña la concentración de silicatos fue menor entre los 100 y $150 \mathrm{~m}$, a diferencia de las otras condiciones estudiadas, lo que posiblemente se debió al consumo de esta sal por parte de las diatomeas durante los primeros metros de profundidad. Cabe recordar que el sílice 
es componente fundamental del frústulo de las diatomeas, con lo cual en condiciones de blooms algales pueden detectarse en forma inicial concentraciones elevadas de este elemento y sus sales; sin embargo, al incrementarse las poblaciones tienden a ser menores las concentraciones.

Para esta misma condición se detectaron los registros más bajos de amonio en la columna de agua, a diferencia de lo observado durante las condiciones Niño y normal, lo que posiblemente guarda relación con la temperatura, pues cuando esta se incrementa la descomposición orgánica es mayor, aumentando la concentración de amonio debido la actividad bacteriana. Carlsson (1993) comenta que al descomponerse la materia orgánica se liberan inicialmente al medio iones amonio, los cuales posteriormente se oxidan pasando a nitrito y, finalmente, a nitrato. Por otro lado, Meadows y Campbel (1981) exponen que cerca de los sedimentos del fondo se produce una alta liberación de amonio a causa de la actividad microbiana, lo que explica el hecho de que las mayores concentraciones de esta sal fueran registradas a $150 \mathrm{~m}$, en especial para las condiciones Niño y normal. 


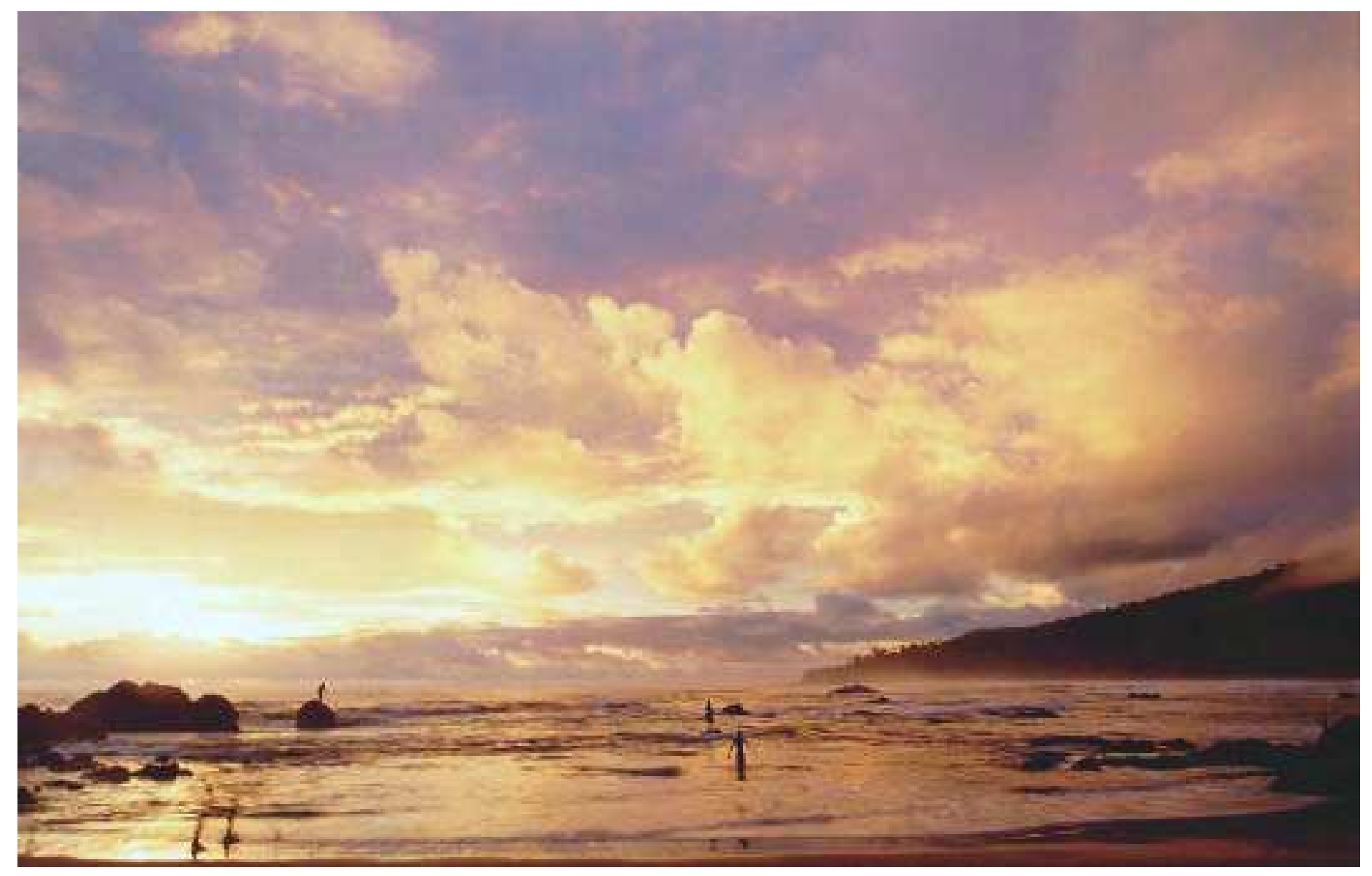

Al norte de Cabo Corrientes, la Serranía de Baudó configura una costa de acantilados. 


\section{CAPÍTULO V - Plan Científico del Grupo de Investigación en Oceanografía para el Período 2001 - 2010}

El Centro Control Contaminación del Pacífico en aras de mejorar continuamente su gestión investigativa ha definido un Plan Estratégico de Desarrollo para el período 2001 al 2010, que consta de seis objetivos estratégicos bien definidos. Siendo uno de los más relevantes la consolidación de un grupo de investigación en el área de Oceanografía y más concretamente en el estudio del fenómeno de El Niño.

Las metas y acciones a adelantar por parte del grupo mencionado se elaboraron con la participación del Jefe del Departamento de Oceanografía de la Universidad Autónoma de Baja California, de una doctorante del Instituto Hidrometeorológico del Estado Ruso, de un profesor del Programa de Posgrado en Meteorología de la Universidad Nacional de Colombia y de los investigadores del CCCP asignados a este grupo, los cuales cuentan con formación en el área de Oceanografía y Biología Marina. Con ellos se realizaron varias sesiones de trabajo que permitieron establecer el quehacer futuro y, además, definir los indicadores que permitan evaluar el desempeño del grupo de investigación en Oceanografía con el fin de identificar posibles desviaciones en la implementación del Plan y tomar las acciones correctivas del caso.

Las acciones a considerar permitirán enfocarse en los elementos teóricos, científicos y metodológicos sobre la investigación oceanográfica generada por el CCCP además de promover y fortalecer el intercambio Técnico y Científico con instituciones nacionales e internacionales y su proyección en la conformación de un grupo de investigación consolidado, cuya base estratégica será la de Profundizar en el conocimiento Oceanográfico de la Cuenca Pacífica Colombiana, orientado a la determinación de sus respuestas ante la variabilidad climática de eventos globales como el fenómeno El Niño.

Debe resaltarse que para la elaboración del Plan se tomaron en consideración los planteamientos del Programa Integral y Multidisciplinario para el Estudio sobre el Fenómeno de El Niño ERFÉN, realizado en el seno del Comité Técnico Nacional del ERFÉN de la Comisión Colombiana del Océano, con la participación del CCCP como miembro activo del mismo, al interior de la cual tiene asignada la responsabilidad del componente Oceanográfico.
El Plan como tal se enfocó hacia tres áreas, una relacionada con el grupo de investigadores; otra con la infraestructura, y la última a definir los temas de estudio de los próximos años. En resumen el Plan cuenta con tres estrategias básicas, cinco metas y 18 acciones, las cuales se presentan en forma esquemática a continuación.

\section{Plan Estratégico del Programa Oceanografía CCCP}

\section{Objetivo Estratégico:}

Profundizar en el conocimiento oceanográfico de la Cuenca Pacífica Colombiana, orientado a la determinación de sus respuestas ante la variabilidad climática que se presenta a nivel global.

\section{Estrategias:}

Estrategia No. 1: Fortalecer el Grupo de Investigación responsable del Programa de Oceanografía.

Estrategia No. 2: Complementar la infraestructura actual del CCCP en el área de Oceanografía física.

Estrategia No. 3: Generar conocimiento científico sobre las características oceanográficas y meteorológicas de la Cuenca Pacífica Colombiana.

(Ver las Tablas en las paginas siguientes) 


\begin{tabular}{|c|c|c|c|c|}
\hline Meta & Acción & Indicador & Resultado esperado & Responsable \\
\hline $\begin{array}{l}\text { Consolidación de un grupo de } \\
\text { investigación altamente calificado } \\
\text { para desarrollar investigación } \\
\text { oceanográfica. }\end{array}$ & $\begin{array}{l}\text { Establecer apoyo técnico y } \\
\text { científico a través de convenios } \\
\text { con la Universidad de Baja } \\
\text { California, el CICESE y el Instituto } \\
\text { Hirdometeorológico de Rusia. } \\
\text { Elevar el nivel académico del } \\
\text { personal de investigadores a través } \\
\text { de doctorados, maestrías y pasan- } \\
\text { tías. } \\
\text { Fomentar la participación de } \\
\text { estudiantes de tesis y yasantes de } \\
\text { nivel posgrado (PhD, MSC) dentro } \\
\text { de los temas de investigación } \\
\text { adelantados en el programa. }\end{array}$ & $\begin{array}{l}\text { Grupo de investigación confor- } \\
\text { mado por lo menos por un (1) PhD, } \\
\text { dos (2) Sc y un (1) profesional } \\
\text { especializado. } \\
\text { Realización de un PhD en } \\
\text { Oceanografía Física (Universidad } \\
\text { de Concepción - Chile). } \\
\text { Realización de una (1) maestría en } \\
\text { Oceanografía Física y una (1) en } \\
\text { Oceanografía Química. } \\
\text { Realización de por lo menos una } \\
\text { (1) pasantía por año para el } \\
\text { personal técnico del programa de } \\
\text { investigación. } \\
\text { Participación de un (1) candidato a } \\
\text { PhD y uno (1) a MSc en el pro- } \\
\text { grama por cada dos años. } \\
\text { Número de intercambios o } \\
\text { pasantías por año. }\end{array}$ & $\begin{array}{l}\text { Grupo de Investigación consolidado } \\
\text { y calificadod de acuerdo con los más } \\
\text { altos estándares de calidad a nivel } \\
\text { nacional e internacional. } \\
\text { Alto nivel de formación del Grupo } \\
\text { de Investigación y compromiso de } \\
\text { dedicación a las labores } \\
\text { investigativas. } \\
\text { Artículos científicos indexados en } \\
\text { revistas científicas nacionales e } \\
\text { internacionales. } \\
\text { Tesis de doctorado y trabajos de } \\
\text { maestría aprobados. } \\
\text { Intercambio de pasantías y cursos } \\
\text { cortos para estudiantes de } \\
\text { postgrado e investigadores ads- } \\
\text { critos a universidades o centros de } \\
\text { investigación nacionales e inter- } \\
\text { nacionales. }\end{array}$ & DCCCPJefe Programa Oceanografía \\
\hline
\end{tabular}




\begin{tabular}{|c|c|c|c|c|}
\hline Meta & Acción & Indicador & Resultado esperado & Responsable \\
\hline $\begin{array}{l}\text { Efectuar una valoración de la } \\
\text { infraestructura actual del } \\
\text { programa de oceanografía, con el } \\
\text { fin de determinar y solucionar las } \\
\text { necesidades que en infraestruc- } \\
\text { tura y obtención de recursos } \\
\text { necesita el programa para su } \\
\text { desarrollo }\end{array}$ & $\begin{array}{l}\text { Mejorar la infraestructura de } \\
\text { investigación con que cuenta el } \\
\text { programa (equipos, sistemas y } \\
\text { material bibliográfico). } \\
\text { Crear vínculos con organizaciones } \\
\text { nacionales e internacionales, que } \\
\text { faciliten la obtención de recursos } \\
\text { para investigación. } \\
\text { Proponer un plan de monitoreo } \\
\text { con boyas oceanográficas que } \\
\text { permitan obtener información en } \\
\text { tiempo real en puntos estratégicos } \\
\text { de la CPC. } \\
\text { Diseñar una red de estaciones } \\
\text { meteorológicas con transmisión de } \\
\text { datos en tiempo en real. }\end{array}$ & $\begin{array}{l}\text { Adquisición de nuevos equipos } \\
\text { oceanográficos y meteorológicos: } \\
\text { dos (2) salinómetros } \\
\text { conductímetros, tres (3) } \\
\text { termómetros de reversión, dos (2) } \\
\text { sistemas Winkler para oxígeno } \\
\text { disuelto, dos (2) sistemas para } \\
\text { clorofilas. } \\
\text { Cantidad de recursos para } \\
\text { investigación gestionados nacional } \\
\text { e internacionalmente. } \\
\text { Adquisición de nuevo material } \\
\text { bibliográfico actualizado. } \\
\text { Adquisición y/o mejoramiento del } \\
\text { hardware y software del Programa } \\
\text { de Oceanografía. } \\
\text { Adquisición de boyas } \\
\text { oceanográficas y estaciones } \\
\text { meteorológicas. }\end{array}$ & $\begin{array}{l}\text { Contar con una infraestructura } \\
\text { sólida que permita desarrollar la } \\
\text { investigación oceanográfica } \\
\text { requerida. } \\
\text { Acceso y conectividad a } \\
\text { información científica nacional e } \\
\text { internacional. } \\
\text { Obtener información } \\
\text { oceanográfica, meteorológica y } \\
\text { biológica de la CPC por medio de la } \\
\text { transmisión de datos en tiempo } \\
\text { real. } \\
\begin{array}{l}\text { Adquisición de equipos científicos y } \\
\text { mantenimiento o reparación de los } \\
\text { equipos existentes. }\end{array}\end{array}$ & Jefe Programa Oceanografía \\
\hline
\end{tabular}




\begin{tabular}{|c|c|c|c|c|}
\hline Meta & Acción & Indicador & Resultado esperado & Responsable \\
\hline $\begin{array}{l}\text { Estudiar el efecto del forzamiento } \\
\text { atmosférico y remoto sobre la } \\
\text { variabilidad intranual e interanual } \\
\text { de la circulación de la CPC. }\end{array}$ & $\begin{array}{l}\text { Analizar la información existente y } \\
\text { conseguir información actualizada } \\
\text { sobre los temas de interés para las } \\
\text { investigaciones que adelanta el } \\
\text { CCCP. } \\
\text { Analizar la variabilidad climática, } \\
\text { espacial y temporal por medio de } \\
\text { metodologías fisicoestadísticas. } \\
\text { Estudiar la interacción entre aguas } \\
\text { costeras y oceánicas. } \\
\text { Estudiar la circulación de las } \\
\text { corrientes oceánicas que afectan } \\
\text { la CPC. } \\
\text { Correlacionar los índices } \\
\text { meteomarinos con la ocurrencia } \\
\text { de eventos extremos en la CPC. } \\
\text { Adaptar modelos de diagnóstico y } \\
\text { pronóstico meteomarinos } \\
\text { existentes a nivel mundial. }\end{array}$ & $\begin{array}{l}\text { Base de datos reanálisis NCEP- } \\
\text { NCAR (National Center for } \\
\text { Enviromental Prediction - National } \\
\text { Center for Atmosferic Researce } \\
\text { Colorado). } \\
\text { Línea de base (parámetros } \\
\text { identificadodos que determinan la } \\
\text { variabilidad climática). } \\
\text { Correlación canónica- SSA } \\
\text { (Spectral Singular Análisys) - FEOs } \\
\text { (Funciones ortogonales empiricas) } \\
\text { - Análisis de series de tiempo y } \\
\text { Análisis Objetivo. Cambios en la } \\
\text { circulación costera. } \\
\text { Cambios de los índices } \\
\text { termohalinos de las aguas costeras } \\
\text { de la CPC. } \\
\text { Incrementos y disminuciones en la } \\
\text { temperatura del aire y tasa de } \\
\text { evaporación debido a los cambios } \\
\text { en procesos de interacción } \\
\text { océano- atmósfera. }\end{array}$ & $\begin{array}{l}\text { Conocer los principales rasgos de la } \\
\text { circulación costera y el efecto de } \\
\text { los forzamientos locales y remotos } \\
\text { en su variabilidad espacial y } \\
\text { temporal. } \\
\text { Presentación de modelos } \\
\text { conceptuales que expliquen los } \\
\text { principales rasgos observados. } \\
\text { Detección temprana de ondas } \\
\text { Kelvin Ecuatoriales Costeras, Ondas } \\
\text { Madee and Julian, surgencias y } \\
\text { frentes termohalinos. } \\
\text { Establecer el panorama } \\
\text { oceanográfico y meteorológico de } \\
\text { la CPC. }\end{array}$ & Grupo de Investigación \\
\hline
\end{tabular}




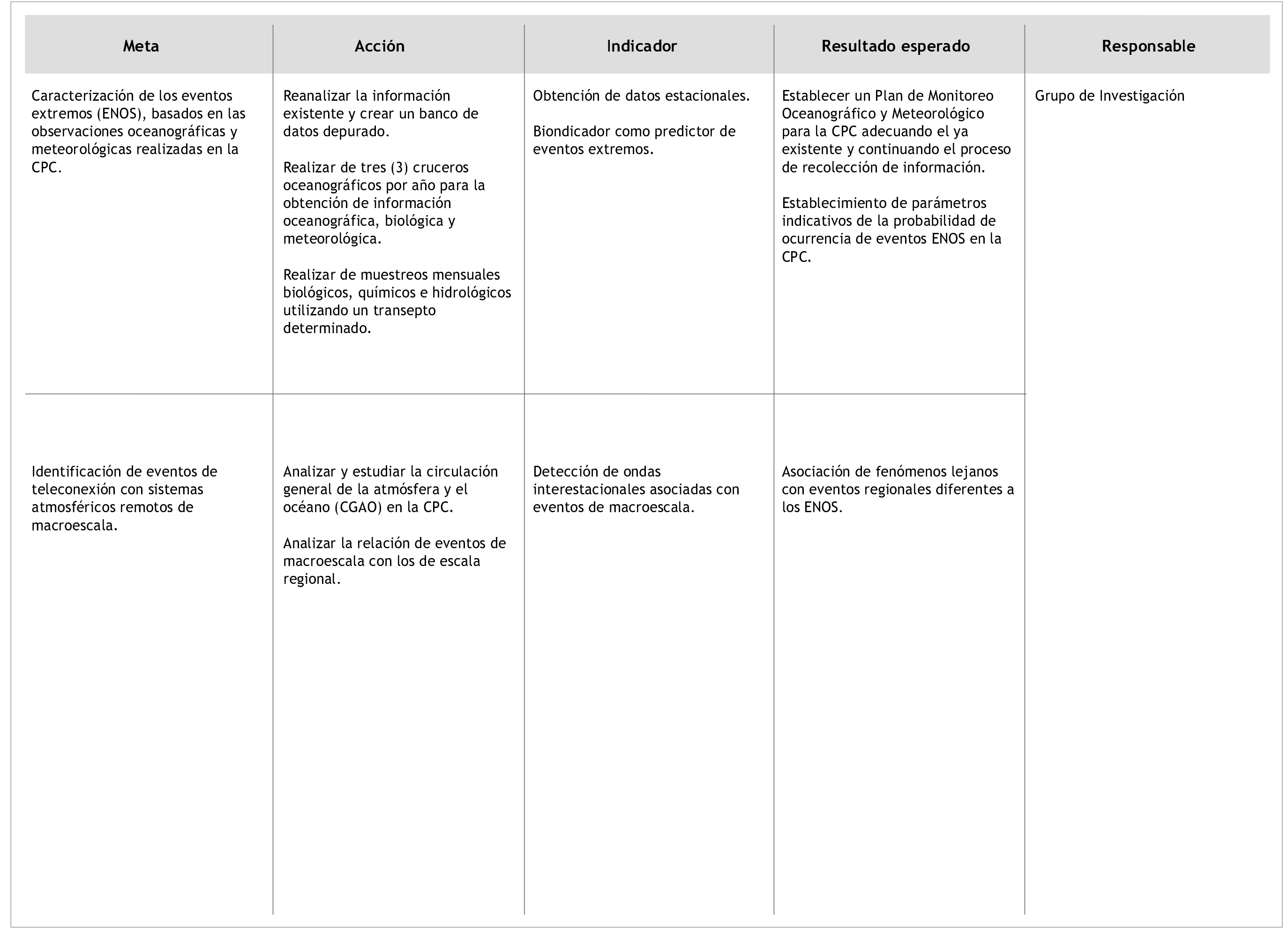




\section{BIBLIOGRAFÍA}

Abuziarov, Z. K. 1988. Pronósticos Marinos. Hidrometeoizdat, Leningrado.

Antonietti, E., P. Villanueva, E. Delgado y F. Chang. 1993. Organismos indicadores: Dinofagelados indicadores del Niño 1991-92. Boletín ERFEN. Comisión Permanente del Pacífico Sur. Chile. (1): 20-22 p.

Avaria, S. 1984. Cambios en la composición y biomasa del fitoplancton marino del norte de Chile durante el fenómeno El Niño, 1982-1983. Rev. Com. Perm. Pacífico Sur. (15): 303-309.

Balech, E. 1988. Los dinoflagelados del Atlántico Sudoccidental Publicaciones Especiales Institución Española de Oceanografía. España, 310 p.

Barrios, L. M. y M. López-Victoria (eds). 2001. Gorgona marina: Contribución al conocimiento de una isla única. Invemar, Serie publicaciones especiales No. 7, Santa Marta. Colombia. $160 \mathrm{p}$.

Beer, T. 1996. Environmental oceanography. 2nd. Edition. CRC Press. Florida, USA. 367 p.

Boyer, T. y S. Levitus. 1994. Quality Control and Processing of Historical Oceanographic Temperature, Salinity and Oxygen Data. NOAA Technical Report NESDIS 81. Washington, D.C.

Bubnov, V. A. 1990. Circulación de las Aguas de la Zona Ecuatorial del Océano Mundial. Hidrometeoizdat. Leningrado. 210 p.

Carlsson, T. 1993. Nitrogen bound to humic matter of terrestrial origin - A nitrogen pool coastal phytoplankton. Mar. Ecol. Prog. Ser. Vol 97: 105-116.

Carmelo, T. 1995. Identifying marine diatoms and dinoflagellates. Academic Press, Inc. San Diego, USA, 598 p.

Castillo, F. A., C. Montagut y C. Manuel. 1988. Avances en el estudio del fitoplancton marino (Dinoflagelados) como parte del componente ERFEN. Bol. Cient. $\mathrm{CIOH}$, Cartagena. 338-349 pp.

Climate Diagnostics Bulletin - Delayed mode analyses, ocean/atmosphere. National meteorological Center, Washington, 19881995.

Climate Diagnostics Bulletin - Near Real - Time analyses, ocean/atmosphere. National meteorological Center, Washington, 19901998.
Costain, L. F. \& L. F. Delgado. 1985. Dinoflagelados del Pacífico colombiano como indicadores del fenómeno El Niño, Crucero P. VIII ERFEN V. Nov-dic. 1982. Tesis de grado, Univ. Jorge Tadeo Lozano, Bogotá, $44 \mathrm{p}$.

CPPS. 1983. Tercera reunión del Comité Científico del ERFEN. Comisión Permanente del Pacífico Sur. Cali, $36 \mathrm{p}$.

Doronin, Y. P. 1980. Dinámica del Océano. Hidrometeoizdat, Leningrado. 304 p.

Doronin, Y. P. 1986.Oceanología Regional. Hidrometeoizdat, Leningrado.

Egorov, N. I. 1966. Oceanografía Física. Hidrometeoizdat. Leningrado. 406-435 pp.

Eslava, J. 1994. Climatología del Pacífico Colombiano. Academia Colombiana de Ciencias Geofísicas. Colección Eratóstenes No. 1. Bogotá DC. Colombia.

Forsbergh, E. D. 1969. Estudio sobre la climatología, oceanografía y pesquería del Panamá Bight. Bol. Inter-amer. Trop. Tuna Comm. 14(2): 260-285.

Gansser, A. 1950. Geological and petrological notes on Gorgona Island in relation to north-western South America. Schweiz. Min. Petrogr. 30: 219-237.

Garcés, L. y L. Medina. 1994. Indicadores Biológicos, ERFEN costero 1994. Centro Control Contaminación del Pacífico. Inf. Técnico. Tumaco, $64 \mathrm{p}$

Garcés, L. y L. Medina. 1996. Evaluación de las especies reportadas como indicadores biológicos para el fenómeno El Niño, en el Pacífico colombiano. Tesis de grado. Facultad de Biología Marina. Univ. Jorge Tadeo Lozano, Bogotá.

Graefe, K., W. Frisch y M. Meschede. 1997. Exhumation of the Cordillera de Talamanca, SE Costa Rica. Geol. Soc. Am. Abstr. Progr., 29:A 442.

Gutscher, M.A., J. Malavielle, S. Lallemand y J. Y. Collot. 1999. Tectonic segmentation of the North Andean margin; impact of the Carnegie Ridge collision. Earth Planet. Sci. Lett. 168: 255-270.

Hasle, G. y E. Syvertsen. 1996. Marine Diatoms. In: Identifying Marine Diatoms and Dinoflagellates. Academic Press, Inc. USA

Hey, R. 1977. Tectonic evolution of the Cocos-Nazca spreading center. Geol. Soc. Am. Bull., 88:1404-1420.

Icochea Salas, I. y E. Rojas Gonzáles. La Corriente Cromwell y sus variaciones en los $0^{\circ} \mathrm{N} 110^{\circ} \mathrm{W}$, Instituto del 
Mar del Perú (www.imarpe.gob.pe/informes/info merluza). IDEAM - UNIVERSIDAD NACIONAL. 1997. Morfodinámica, Población y Amenazas Naturales en la Costa Pacífica Colombiana. Santafé de Bogotá. Colombia.

Jordán, R. 1993. Nota sobre los indicadores biológicos de El Niño y el programa Regional del Fenómeno del Niño (EREN). Boletín ERFEN. Comisión Permanente del Pacífico Sur. (2): 44-47.

Jordán, T. 1991. Nutrients and chlorophyll at the interface of a watershed and an estuary. Limnol. Oceanogr. 36(2):251-267.

Kagan, B. A. 1992. Interacción Océano Atmósfera. Hidrometeoizdat. San Petersburgo. 125-140 pp.

Kraus, E. B. y J. A. Businger. 1994. Atmosphere Ocean Interaction. Oxford Monographs On Geology And Geophysics. Oxford University Press. New York. No.27.

Levitus, S. 1982. Climatological Atlas of the World Ocean. NOAA Profesional Paper 13, U.S. Departament of Commerse, Rockville, Md.

Lonsdale, P. y K. D. Klitgord. 1978. Structure and tectonic history of the eastern Panama Basin. Geol. Soc. Am. Bull. 89: 981-999.

Málikov, I. y G. Camacho. 1998. Método de Aproximación para Determinar Cambios Entreanuales Aplicado a Parámetros de Temperatura y Salinidad del Pacífico Colombiano. Boletín Científico CCCP. Centro Control Contaminación del Pacífico. San Andrés de Tumaco. (7): 3041.

Málikov, I. 1998. Determinación de los cambios entre anuales del campo de presión atmosférica en el Pacífico colombiano. Informe Técnico. Centro Control Contaminación del Pacífico, CCCP. Tumaco.

Malinin, V. N. 1998. Oceanología General. Parte I. Procesos Físicos. Russian State Hydrometeorological University - RSHMU. San Petersburgo. 342 p.

Margalef, R. 1982. Ecología. Ediciones Omega. Barcelona, $951 \mathrm{p}$.

Meadows, P. S. y J. I. Campbel. 1981. Introducción a la ciencia del mar. Ed. ACRIBIA, Zaragoza, España, 189 p.

Meschede, M., U. Barckhausen y H. U. Worm. 1998. Extinct spreading on the Cocos Ridge. Terra Nova, 10:211216.

Moiseev, P. A. 1989. Recursos biológicos del océano mundial. Agropromizdat, Moscú, 367 p.

National Oceanic and Atmospheric Administration. 1996. Global Gridded Upper Air Statistics, 1980-1995. National Climatic Data Center, Asheville. North Carolina.

Neolov, I. y N. Villegas. 2002. Modelling of the seasonal variability of the circulation of Colombian Pacific waters. Conclusions of the Scientific Council on investigations of 30-31 January 2002. St. Petersburg, Russia. 123-125 pp.

Ochoa. N, B. Rojas de Mendiola y O. Gómez. 1985. Identificación del Fenómeno 'El Niño' a través de los organismos fitoplanctónicos. Boletín 'El Niño' Su impacto en la fauna marina. IMARPE. 23-31 pp.

Palacios Moreno, M. A. 1999. Boletín informativo DIMAR. Bogotá, Colombia.

Parsons, T. R. et al. 1984. Biological oceanographic processes. Pergamon Press. $3^{\circ}$ Edition. England. 330 p.

Pickard, G. L. 1975. Descriptive Physical Oceanography: An Introduction. Butterworth-Heinemann Ed. Nueva York.

Pontificia Universidad Católica de Chile. 1999. Departamento de Oceanografía. www.puc.cl/sw.educ/ goe mar/

Prahl, H von, J. R. Cantera y R. Contreras. 1990. Manglares y hombres del Pacífico colombiano. Fonde FEN Colciencias. Bogotá, D.E. Colombia, 193 p.

Rojas de Mendiola, B., O. Gómez y B. Ochoa. 1985. Identificación del Fenómeno 'El Niño' a través de los Organismos Fitoplanctónicos. 'El Niño' Su impacto en la Fauna marina. Boletín Instituto del Mar del Perú. Callao, Perú. 23$31 \mathrm{pp}$.

Sarkicyan, A. S. y L. Demina. 1986. Métodos y resultados de cálculos de circulación de las aguas del Océano Mundial. San Petersburgo. Hidrometeoizdat, 100152 pp.

Sarkicyan, A. S. 1991. Modelación de la Dinámica del Océano. San Petersburgo. Hidrometeoizdat. 296 p.

Scientific American. 1976. Deriva Continental y Tectónica de Placas. H. Blume Eds. España. 271 p.

Semionov, B. V. 1981. Cálculos de los Movimientos Verticales con Modelos Numéricos de Circulación de las Aguas Oceánicas. Oceanología Tomo XXI. San Petersburgo. Hidrometeoizdat, 433440 pp.

Steidinger, K. y K. Tangen. 1996. Dinoflagellates En: Identi- 
fying marine diatoms and dinoflagellates. Academic Press. USA.

Stevenson M. R., G. O. Guillén y J. Santorode Ycaza.

1970. Marine atlas of the Pacific coastal waters of South America Berkeley, Univ. Calif. Press.23p

Tchantsev, V. y E. Cabrera. 1998. Algunos aspectos de investigación de la formación del régimen oceanográfico en el Pacífico colombiano. Boletín Científico CCCP. San Andrés de Tumaco. (7): 7-19.

Teramoto, T. 1993. Deep Ocean Circulation: Physical and Chemical Aspects. Elsevier.

Tomczak, M. y J. S. Godfrey. 1994. Regional Oceanography: an Introduction. Pergamon, New York, 422 p.

Trojer, H. 1958. Meteorología y climatología de la vertiente del Pacífico colombiano. Rey. Acad. Colom. Ci. Ex. Fis. Nat., 10(40): 199-2 19.

Villegas, N. 1997a. Estudio del Movimiento de las Aguas en la Región Este de la Cuenca del Pacífico Colombiano. Boletín Científico CCCP 6. San Andrés de Tumaco. Centro Control Contaminación del Pacífico. 7180 pp.

Villegas, N. 1997b. Movimiento Vertical de las Aguas en el Pacífico Colombiano Durante Junio y Octubre de 1996. Boletín Científico CCCP 6. San Andrés de Tumaco. Centro Control Contaminación del Pacífico. 8193 pp.

Vizcaíno, Z. 1993. Fitoplancton del Pacífico colombiano como indicador del Fenómeno El Niño. Tesis de grado. Facultad de Biología. Cali.

Vizcaíno, Z. y F. Castillo. 1992. Estudio del fitoplancton marino en el Pacífico colombiano como indicador biológico durante septiembre-octubre/91. Informe técnico. COIH. Cartagena, 41 p.

Wilches-Chaux, G. y A. Velásquez. 1993. La costa brava: catástrofes naturales, vulnerabilidad y desastres en la costa del Pacífico:488-495. En: P. de Leyva (Ed.). Status of coral reefs of the world. Australian Ins. Mar. Sci., Townsville.

Wooster, W. 1959. Oceanographic observations in the Panama Bight. Askoy Expedition, 1941. Amer. Mus. Nat. Hist. Bull. 118(3):115-151

Wyrtki, K. 1963. Surface currents of the eastern tropical Pacific Ocean. Inter-Amer. Trop. Tuna Comm. Bull. 9(5):269-304.

Wyrtki, K. 1965. Oceanographic observations in the Panamá Bight. "Askoy Expedition, 1941. Amer. Mus. Nat. Hist., Bull. 118(3)::13-152. 
Compilación Oceanográfica de la Cuenca Pacífica Colombiana 


\section{Agradecimientos}

El editor y los autores agradecen especialmente a los profesores Affonso da Silveira Mascarenhas Jr. y Emel Enrique Vega Rodrígez por la revisión de los manuscritos y sus acertados comentarios.

Al doctor Y. Fukuyo por ceder amablemente, las fotografías de dinoflagelados.

A los ingenieros Carolina Jerez Romero, Yuley Cardona y Santiago Grisales Soto por su apoyo en el procesamiento de la información digital. 
Compilación Oceanográfica de la Cuenca

Pacifica Colombiana

Esta obra monumental es fruto de dieciocho años de
experiencia del Centro Control Contaminación del Pacífico,

Bajo la orientación de la Dirección Cencral Martina, Bajo la orientación de la Dirección General Marítima,
DIMAR, esta obra marca un hito en la historia de la oceanografía colombiana y constituye una referencia obligada para a la comunidad científica nacional e interna-
cional. cional.
Los grandes temas de la oceanografía del Pacífico Tropical; el fenómeno de El Niño, las surgencias, el desplazamiento de la Zona Intertropical de Convergencia de los vientos Alisios, la distribución vertical y horizontal de
nutrientes... se examinan, en esta obra, a la luz de los nutrientes... se examinan, en esta obra, a la luz de los
datos de casi tres décadas de cruceros oceanográficos y el análisis de reputados hombres de mar de Colombia y el Mundo. $\quad$ El Editor

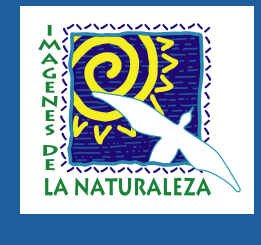

